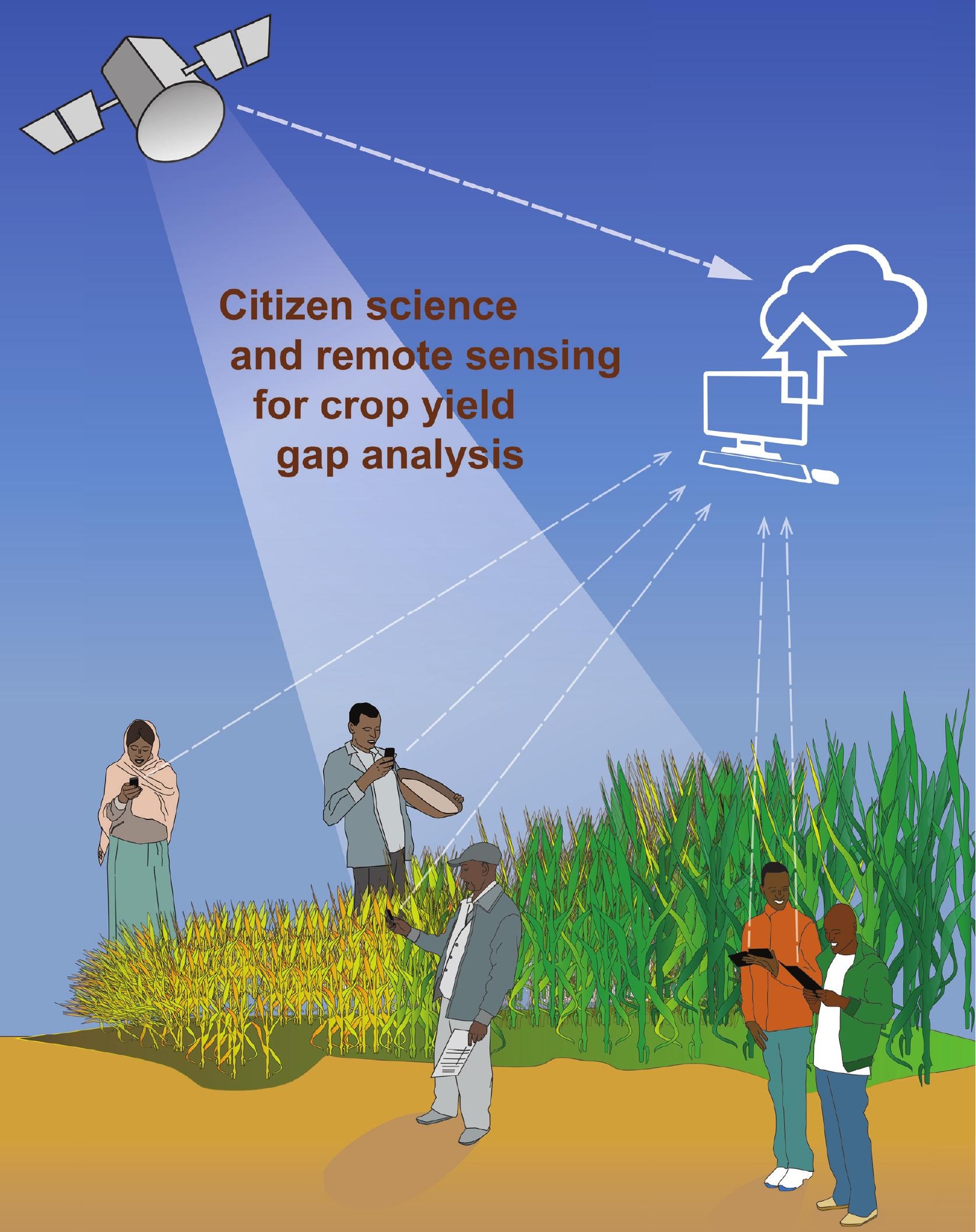


Citizen science and remote sensing for crop yield gap analysis 


\section{Thesis committee}

\section{Promotor}

Prof. Dr M. Herold

Professor of Geo-information Science and Remote Sensing

Wageningen University \& Research

\section{Co-promotors}

Dr L. Kooistra

Associate professor, Laboratory of Geo-information Science and Remote Sensing Wageningen University \& Research

Dr P. Reidsma

Assistant professor, Plant Production Systems Group

Wageningen University \& Research

\section{Other members}

Prof. Dr C. Leeuwis, Wageningen University \& Research

Dr C.A.J.M. de Bie, University of Twente, Enschede

Dr K. Tesfaye Fantaye, International Maize and Wheat Improvement Center (CIMMYT), Addis Ababa, Ethiopia

Prof. Dr F. Ludwig, Wageningen University \& Research

This research was conducted under the auspices of the C.T. de Wit Graduate School of Production Ecology \& Resource Conservation (PE\&RC) 


\title{
Citizen science and remote sensing for crop yield gap analysis
}

\author{
Eskender Andualem Beza
}

Thesis

submitted in fulfilment of the requirements for the degree of doctor at Wageningen University

by the authority of the Rector Magnificus, Prof. Dr A.P.J. Mol, in the presence of the

Thesis Committee appointed by the Academic Board to be defended in public on Tuesday 29 August 2017 at 4 p.m. in the Aula. 
Eskender Andualem Beza

Citizen science and remote sensing for crop yield gap analysis, 204 pages.

$\mathrm{PhD}$ thesis, Wageningen University, Wageningen, the Netherlands (2017) With references, with summary in English and Dutch

ISBN: 978-94-6343-641-0

DOI: $10.18174 / 420049$ 


\section{Table of Contents}

$\begin{array}{lll}\text { Chapter } 1 & \text { Introduction } & 1\end{array}$

$\begin{array}{lll}\text { Chapter } 2 & \text { Review of yield gap explaining factors and } & 13\end{array}$ opportunities for alternative data collection approaches

Chapter 3 What are the prospects for citizen science in agriculture? Evidence from three continents on motivation and mobile telephone use of resourcepoor farmers

Chapter 4 Exploring farmers' intentions to adopt mobile Short Message Service (SMS) for citizen science in agriculture

Chapter 5 Remote sensing and crowdsourcing for estimating and explaining yields: sesame in Ethiopia

Chapter 6 Synthesis

References

Summary (English)

Summary (Dutch)

Acknowledgments

List of publications

About the author 

Chapter

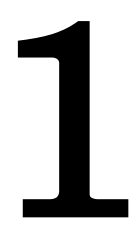

Introduction 


\subsection{Background}

The world population is expected to peak around 9 billion by the middle of this century (Bruinsma 2009) and the question how to feed this large number of people will be one of the greatest challenges facing humanity in the coming decades (van Ittersum et al. 2016; Godfray et al. 2010). Options to bridge the gap between projected food demand and current level of supply include: 1) expansion of land under cultivation, 2) intensification on currently available farmlands by growing two or three crops per year, 3) reducing the yield gap in farmers' fields, 4) raising the yield ceiling by introducing higher yielding varieties, and 5) reducing postharvest losses and food waste (Keating et al. 2014; Godfray et al. 2010; Koning and van Ittersum 2009). Ramankutty et al. (2008) showed that roughly half of the land that is suitable for agriculture on the planet is already under cultivation today. They also showed that much of the remaining cultivable land covers the tropical rain forests of South America and Africa; biomes that have high economic, social and ecological values. Therefore, the option of expansion of land under cultivation has associated costs such as deforestation, biodiversity loss and, soil degradation. The other alternative and promising strategy to increase agricultural production is to intensify production. While yield ceilings (potential yields) (Hall and Richards 2013) and cropping intensity may be further increased, the largest role is foreseen for reducing the gap between yields currently achieved on farmers' fields and those that can be achieved by using the best adapted crop varieties with the best current crop and land management practices for a given environment (Keating et al. 2014; van Ittersum et al. 2013). In order to estimate the magnitude of the yield gap, two quantities are required: the benchmarking yield and the actual yield.

For the benchmark yield two situations can be distinguished: yield potential or potential yield (Yp) for irrigated crops or water-limited yield potential (Yw) for rainfed crops. Yp is the maximum theoretical yield achieved by a specific crop genotype in a well-defined biophysical environment, with both abiotic (water and nutrients) and biotic factors (pests, diseases and weeds) effectively controlled (van Ittersum and Rabbinge 1997). Yp is determined by solar radiation, temperature, atmospheric $\mathrm{CO}_{2}$ and crop characteristics that govern the length of the growing period (cultivar or hybrid maturity) and light interception by the crop canopy (i.e., canopy structure) (van Ittersum et al. 2013). For rainfed crops, water-limited yield potential, also known as waterlimited (potential) yield, is the most relevant benchmarking yield (van Ittersum et al. 2013). The definition of $Y_{w}$ is similar to $Y p$, but in the case of $Y_{w}$, crop growth is also limited by water supply. The actual yield (Ya) is defined as the yield currently realised in farmers' fields. To capture variation in space and time for a specific location, van Ittersum et al. (2013) defined actual yield as 
the spatial and temporal average yield achieved by farmers in the region for the most widely used management practices (sowing date, cultivar maturity, and plant density, nutrient management and crop protection). The yield gap $(\mathrm{Yg})$ is then defined as the difference between $\mathrm{Yp}$ (for irrigated crops), or $\mathrm{Yw}_{\mathrm{w}}$ (for rainfed crops) and the actual yield (Ya). Figure 1.1 illustrates the schematic representation of the yield gap concept.

Yield gap analysis is critical for four main reasons (van Ittersum et al. 2013). First, yield gap analysis provides the foundation to identify the main crop, soil and management factors limiting current farm yields and improved practices to close the yield gap (Lobell et al. 2009). Second, to enable effective prioritization of research, development and interventions (van Oort et al. 2017). The third reason is to evaluate the impact of climate change and other future scenarios that influence land and natural resource use (Reidsma et al. 2010). And fourth, results from yield gap analysis are important inputs to economic models that assess food security and land use at different spatial scales.

In yield gap analysis, two major steps can be identified. The first step is to quantify the magnitude and distribution of the yield gap. The second step is to identify the main factors that cause the yield gap (Lobell 2013). A prominent example of the first step is the Global Yield Gap Atlas (GYGA), a project designed to quantify the size and distribution of the yield gap for the major crops across the globe (www.yieldgap.org) (Hochman et al. 2016). In the GYGA project, a "bottom-up" approach for yield gap analysis has been proposed that can be applied globally, but has a strong local agronomic relevance and exploits local knowledge and data (van Ittersum et al. 2013). The GYGA "bottom-up" approach recommends (1) the use of well-calibrated crop growth simulation models applied to relatively homogenous climate zones, (2) the use of measured daily weather data, (3) the simulations to estimate Yp or Yw to be done for the dominant soil types and cropping systems, taking into consideration the current spatial crop distribution, (4) the use of site-specific agronomic and actual yield information, (5) empirical verification at the local level of estimated yield gaps with on-farm data and experiments and (6) the use of an explicit methodology for up-scaling (www.yieldgap.org) (Boogaard et al. 2013). At the time of writing, the yield gaps of 9 field crops in 47 countries (one up to five crops per country) have been estimated using the aforementioned protocols and work is underway in another five countries (www.yieldgap.org; last accessed March 10, 2017). 


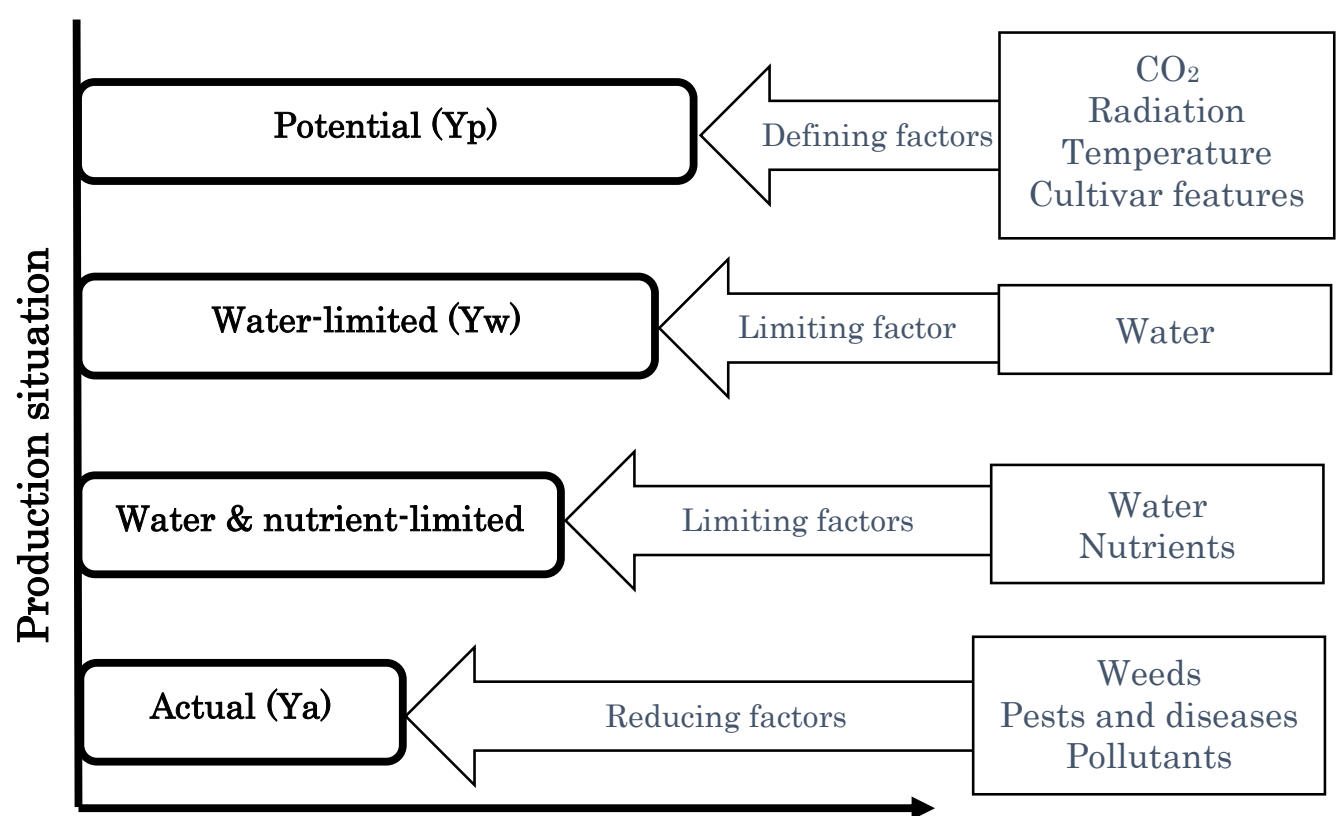

\section{Production level ( $\mathrm{Mg} / \mathrm{ha})$}

Figure 1.1 Different production levels as determined by growth defining, limiting and reducing factors (van Ittersum et al. 2013).

Several studies have examined the yield gap at the regional or global scale using aggregated data for actual crop yield and explaining factors (Mueller et al. 2012; Foley et al. 2011; Neumann et al. 2010; Licker et al. 2010). These types of "top-down" studies are useful in quantifying the scope for yield improvement in a broad sense and comparing different regions using harmonised data (van Ittersum et al. 2013). Moreover, such global studies are useful to understand the spatial variability of yield gaps at a larger scale, along with trends across regions (Mueller et al. 2012; Neumann et al. 2010). However, there are a number of issues associated with such "top-down" yield gap studies (van Ittersum et al. 2013). For example, these studies mostly use global datasets on agricultural management (e.g., Waha et al. 2012) and actual yields (Monfreda et al. 2008) which are generally too coarse for local relevance (van Ittersum et al. 2013). Estimates of Yp, Yw and Yg based on these global datasets may not represent current management of a cropping system (e.g., crop rotation, planting date, cultivar maturity) in a specific location, which limits the agronomic relevance of the yield gap analysis. Therefore, for yield gap analysis to have a strong local agronomic relevance and to improve understanding of the main factors causing the yield gap, more local studies are needed to bring 
the role of farm and farmer characteristics into the picture, as well as more local biophysical and socio-economic conditions (Silva et al. 2017). A major challenge for this type of analysis is the high data standards required which typically refer to (a) large sample size, (b) fine resolution and (c) great level of detail. Clearly, obtaining information about biophysical characteristics and crop and farm management for individual agricultural activities within a farm, as well as farm and farmer's characteristics and socio-economic conditions for a large number of farms is costly and time-consuming.

Nowadays, the proliferation of different types of mobile phones (e.g., smartphones) equipped with sensors (e.g., GPS, camera) makes it possible to implement effective and low-cost "bottom-up" data collection approaches such as citizen science (Ferster and Coops 2013). Using these innovative methodologies facilitate the collection of relatively large amounts of information directly from local communities (Van Etten et al. 2016; Herrick et al. 2013). Moreover, other data collection methods such as remote sensing can provide data (e.g., on actual crop yield) for yield gap analysis (Lobell 2013).

\subsection{Innovative data collection methods for yield gap analysis}

\subsubsection{Citizen science and crowdsourcing}

Citizen science is the involvement of non-professional scientist volunteers to participate in scientific activities like data collection, analysis and dissemination for a scientific project (Silvertown 2009; Cohn 2008). Citizen scientists - volunteers who collect and/or process data as part of a scientific enquiry (Silvertown 2009) - have been participating among others in projects about seed variety selection (Van Etten et al. 2016), invasive species (CarballoCárdenas and Tobi 2016), water quality monitoring (Scott and Frost 2017) and stream water levels monitoring (Fienen and Lowry 2012). Recent citizen science approaches accomplish large tasks by distributing small tasks to many volunteers, and combine the results (Van Etten et al. 2016). This distributed way of working is termed as 'crowdsourcing' and was first coined by Howe (2006). According to the definition of USAID (2013), 'crowdsourcing is when information is sourced from a group of people (e.g. farmers) in response to an open call, a request for specific information (e.g. management information), or for an exchange, organized by a central organizer/organizing body'. In the context of this thesis, the crowd/citizen scientists mainly refer to the smallholder farmers in developing countries.

According to Silvertown (2009), there are three main factors behind the great explosion of activities using the citizen science approach. The main factor is the ubiquitous availability of technological tools (e.g., Personal Digital Assistance (PDA), mobile phones, smartphones) for disseminating information about 
projects and collecting data from the public. A second factor for the rapid growth of citizen science is the increasing realisation by the scientific community that the public represents a free source of skills, computational power, labour and even finance (Cohn 2008) through an approach called crowdfunding (Vachelard et al. 2016). The third reason is that research funders are imposing upon every grantholder to undertake project-related scientific outreach.

The emergence of the internet and the world wide web has enabled a new era of citizen science, which has been termed 'citizen cyberscience' by Grey (2009) and also called 'technology-mediated (or 'online') citizen science' (Nov et al. 2014). Within citizen cyberscience, three subcategories are identified, namely: volunteered computing, volunteered thinking and participatory sensing (Haklay 2013). These categories of citizen science projects can be characterised by the different level of task granularity: "the smallest possible individual investment necessary to participate in a project" (Nov et al. 2014).

In volunteered computing type of projects, a large computational task is divided into 'micro tasks' that are then distributed over the internet and the unused processing capacity of personal computers are used to analyse the tasks and once completed, tasks are send automatically back to a central server (Nov et al. 2014; Haklay 2013). Participation in this type of projects requires very little effort from the participants (Haklay 2013). Mostly, it requires the download and installation of a software application, after which contribution is largely passive, and therefore the task granularity is relatively low (Nov et al. 2014). Prominent volunteered computing projects include SETI@home (setiathome.berkeley.edu/) and Folding@home (folding.stanford.edu/).

In volunteered thinking, also called distributed analysis projects, the volunteers are engaged at a more active and cognitive level (Grey 2009). Well known examples in volunteered thinking category include projects like Stardust@home (stardustathome.ssl.berkeley.edu) in which volunteers analyse images of interstellar dust particles (Westphal et al. 2006), and Galaxy Zoo (www.galaxyzoo.org/), a project in which volunteers classify galaxies (Raddick et al. 2010). Participation in this type of projects often require some taskspecific training, and ongoing cognitive effort in analysing the images, and therefore the task granularity is relatively high (Nov et al. 2014). The last category of citizen cyberscience, participatory sensing is the most recent type of citizen science activity (Haklay 2013). In this type of citizen science, the capabilities of the mobile phones (e.g., camera, GPS) are used to sense the surrounding environment of participating citizens (Ferster and Coops 2013; Newman et al. 2012). 
According to Nov et al. (2014), digital citizen science is grounded on two pillars: 1) a motivational pillar, and 2) a technological pillar. The motivational pillar involves attracting and retaining people who are willing to contribute their time, skills, effort and knowledge for a scientific cause. The technological pillar involves the development of systems to collect, store, analyse, visualise and disseminate large volume of data from geographically distributed citizen science participants. These two pillars are described in detail below.

\subsubsection{Motivation}

One of the important steps in citizen science is to understand what motivates people to get involved in order to attract and retain a large number of citizen science volunteers (Land-Zandstra et al. 2016a; Nov et al. 2014). Ryan and Deci (2000a) describe motivation as a continuum ranging from "amotivation or unwillingness, to active personal commitment", and define that: "to be motivated means to be moved to do something. A person who feels no impetus or inspiration to act is thus characterized as unmotivated, whereas someone who is energized or activated toward an end is considered motivated." Ryan and Deci (2000a) further distinguished two basic types of motivations: intrinsic and extrinsic motivations. Intrinsic motivation refers to "doing something because it is inherently interesting or enjoyable", and extrinsic motivation, refers to "doing something because it leads to a separable outcome".

Previous citizen science studies have identified different categories of motivations (Land-Zandstra et al. 2016a; Curtis 2015; Raddick et al. 2010). Some participants get involved because they would like to contribute to scientific research (Land-Zandstra et al. 2016a). Others are motivated to participate because they would like to use the opportunity to network with other citizen science community members with similar interests, either in person or online (Nov et al. 2014; Dickinson et al. 2012). Another reason to participate is because volunteers find the citizen science activities enjoyable and fun (Curtis 2015; Nov et al. 2011b; Raddick et al. 2010). The motivation of people to participate in citizen science is not static, it might differ during the citizen science process. For example, the study of Rotman et al. (2012) showed that participants have different types of motivation at the different stages of the citizen science process. This implies that responding to the different motivational factors at different times of participation will help the participants to keep engaged in the citizen science process. For example, provision of relevant and timely agronomic advice to the farmers at the different stages of crop growth (Aker 2011) might help to keep farmers engaged in the citizen science process. As citizen science methodologies for the agricultural sciences have only recently emerged (Van Etten et al. 2016; van Etten 2011), it is questionable to what extent insights from motivational studies with participants in citizen science projects from other disciplines may 
be generalized. Therefore, it is important to study the motivations of farmers to participate in agriculture oriented citizen science projects.

\subsubsection{Technology}

Next to motivation, the other important factor for the success of digital citizen science is the technological pillar, which deals with developing a system to collect, manage, analyse, and disseminate information (Nov et al. 2014, 2011b). New emerging and affordable technologies, such as mobile phones (smartphones and tablets), mobile apps (shore for applications), sensor networks, and also the growing ubiquity of social media and new communication platforms, show great promise for advancing citizen science (Newman et al. 2012; Silvertown 2009). Mobile apps are software programs developed for use on portable devices such as smartphones and other mobile, web-enabled equipment (Herrick et al. 2017). Sensor networks consist of spatially distributed, autonomous or semi-autonomous sensors that monitor physical or environmental conditions (Newman et al. 2012), such as air temperature and humidity (e.g., iButtons; Mittra et al. 2015) and soil nutrient and moisture content (Viscarra Rossel and Bouma 2016). The recent proliferation of web 2.0 channels (e.g., Twitter, Facebook and picture sharing sites such as Flicker) have opened up opportunities to engage with citizen scientists for scientific purposes (Pratihast et al. 2016; Muller et al. 2015). For example, the study of Pratihast et al. (2016) used social media Facebook as a platform to engage local forest rangers for community-based forest monitoring.

Depending on the purpose and type of the community, different kinds of technologies (e.g., smartphones/tablets or basic phones) can be used by citizen science volunteers. Using the appropriate technology helps to avoid bias, i.e. not only educated community members but everyone in the community interested to participate can provide data. This allows to address some of the issues (e.g., skill and usage) discussed under the notion of digital divide (van Dijk 2006). Moreover, to assure data quality, the type of technology used should be clear to everyone participating in citizen science.

In developing countries, where there is a large yield gap for most of the crops (Tittonell and Giller 2013; Laborte et al. 2012; Neumann et al. 2010), the proliferation of mobile phone technology offers a unique opportunity to collect relevant factors for yield gap analysis (e.g., Herrick et al. 2013). As shown in Figure 1.2, in developing countries there were around 23 mobile-cellular telephone subscriptions per 100 people in 2005 and this number has raised to 94 mobile-cellular telephone subscriptions per 100 people in 2016. Currently, the use of mobile phones is mostly focused on delivering market information to farmers (e.g., using Esoko platform; www.esoko.com) so that farmers can make informed decisions on when and where to sell their products (Muto and Yamano 
2009). Provision of information, such as management advice and weather forecasts is another area of development where the use of mobile phones play a major role (Aker 2011). The experiences and lessons learnt from aforementioned initiatives can be used to collect agricultural information (e.g., using mobile SMS) (Paustian 2013), including the relevant factors for yield gap analysis. In addition to data collection and management, innovative use of existing technology may help citizen science project managers to identify participants and expedite team formation, and assist professional scientists and program coordinators with locating required resources, and disseminate project results to the public (Newman et al. 2012).

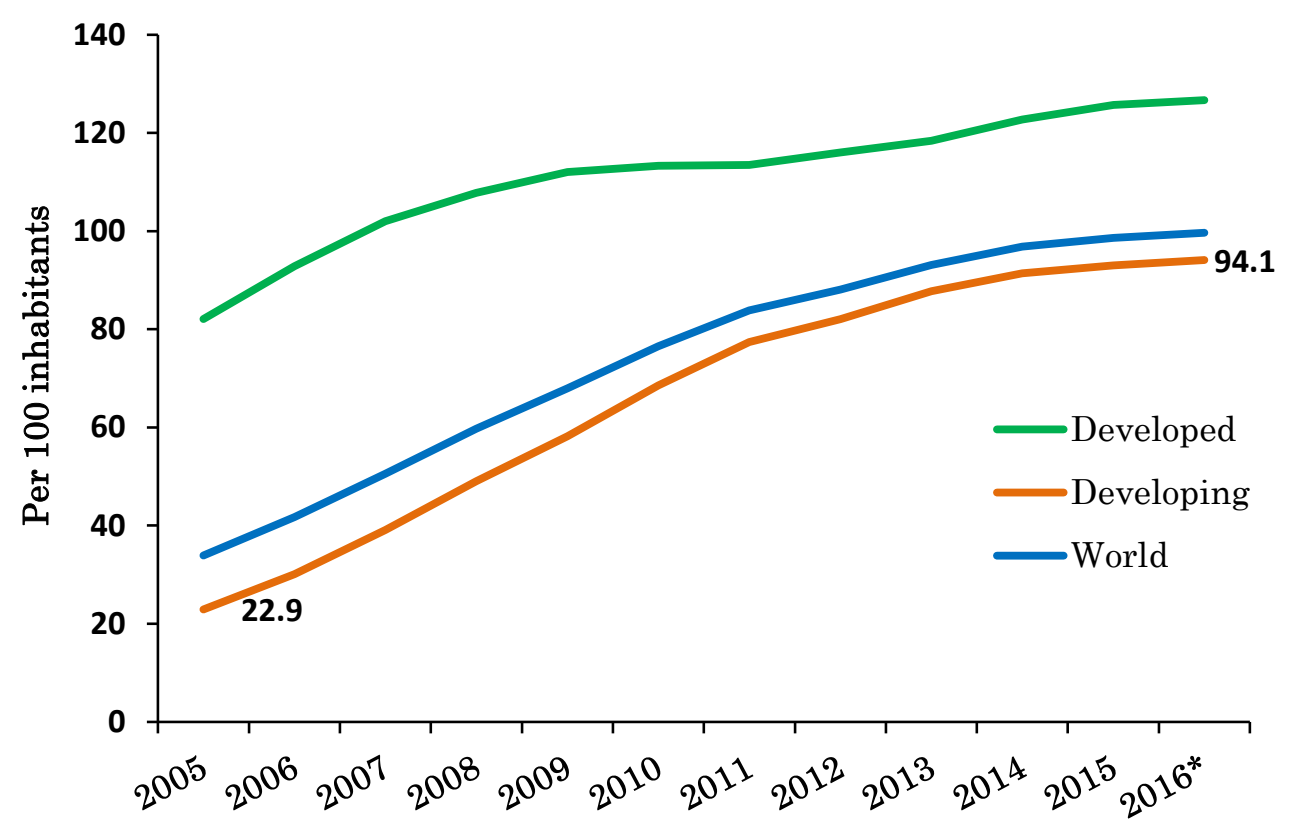

Figure 1.2 Global mobile-cellular telephone subscriptions per 100 inhabitants Source: ITU World Telecommunication/ICT Indicators Database [I.T.U. 2016]. Note: * estimate.

\subsubsection{Remote sensing}

Another innovative data collection approach for yield gap analysis is remote sensing. Remote Sensing (RS) is the science of obtaining information about objects or areas through the analysis of data obtained by a device (e.g., sensor) that is distant from the object of interest (Lillesand et al. 2014). Satellite remote sensing has been used for agricultural applications for over three decades (Tucker et al. 1981; Knipling 1970). In particular, remotely sensed vegetation indices (VIs), for example the Normalized Difference Vegetation 
Index (NDVI), have been widely utilized for different purposes such as agricultural mapping and monitoring (Funk and Budde 2009), crop yield estimation and forecasting (Bolton and Friedl 2013; Mkhabela et al. 2011) and crop disease prediction (Wakie et al. 2016).

Crop yield information is one of the important parameters for yield gap analysis (Grassini et al. 2015). The most common traditional methods (e.g., farm surveys and crop cuts) to collect crop yield information are expensive, time-consuming, labour-intensive, and often difficult (Fermont and Benson 2011). Remote sensing is an alternative to complement/substitute the traditional methods to collect crop yield information. Remote sensing has been successfully used for yield estimation and monitoring over the last few decades due to its ability to acquire spatiotemporal data over a large region (Son et al. 2014; Schulthess et al. 2013). Generally, three main approaches are used to estimate crop yields using remote sensing data (Lobell 2013). The first approach is based on an empirical relationship that relates ground-based yield measures to vegetation indices (VIs) derived from remotely sensed surface reflectance (Schulthess et al. 2013; Mkhabela et al. 2011). The second approach to estimate crop yields is by incorporating VIs or biophysical variables (e.g., LAI) derived from remote sensing data into crop growth simulation models (Rembold et al. 2013; Dente et al. 2008; Doraiswamy et al. 2005). The simulated yield by the model then provides an estimate of crop yield. The last approach is by using the relationship between the fraction of photosynthetically active radiation (fPAR) and crop yield (Monteith and Moss 1977).

\subsection{Problem description}

Yield gap analysis at the farm and farming system level provides the foundation for identifying the most important crop, soil and management factors limiting current farm yields (e.g., Affholder et al. 2013). However, limited data availability at the individual farm level for a large number of fields within a farm often limits the use of more detailed modelling approaches and detailed assessments of cause-effect relationships related to agricultural production (Reidsma et al. 2009).

Nowadays, the proliferation of computing devices like different types of mobile phones equipped with sensors (e.g. GPS), and other similar technologies makes it possible to implement effective and low-cost "bottom-up" data collection using the citizen science approach (Ferster and Coops 2013). However, citizen science methodologies for the agricultural sciences have only recently emerged and therefore, seem to be underdeveloped (Van Etten et al. 2016). Specific requirements for this development in developing countries and smallholder farming communities, such as motivation and technology adoption, are yet not 
well studied. Therefore, to receive accurate and timely information using the citizen science approach, the motivations of the farmers to participate in citizen science need to be understood. Moreover, as the most pervasive ICT tool in the developing world, mobile phone technology presents an unprecedented opportunity to address the data gap researchers (agronomists) face to perform detailed yield gap analysis at the farm and farming system level. However, this potential will only be achieved when the factors that determine the farmers to adopt mobile phone as a data collection tool are studied. Therefore, the factors that determine farmers to adopt mobile phone technology for agricultural data collection need to be investigated.

Vegetation indices (VIs) derived from multi-temporal remote sensing has been successfully used to estimate crop yield. However, the relationship between VIs derived from multi-temporal remote sensing and crop yield vary over the growing season (Mkhabela et al. 2011; Wall et al. 2008). Thus, using a fixed calendar date to estimate remote sensing-based yield prediction models is not optimal (Bolton and Friedl 2013). However, synergetic use of data streams (i.e., combining remote sensing and crowdsourcing) may offer opportunities to improve the accuracy of remote sensing based crop yield estimation.

\subsection{Objectives and research questions}

The main objective of the $\mathrm{PhD}$ research is to investigate the applicability of innovative data collection approaches such as crowdsourcing and remote sensing to support the assessment and monitoring of crop yield gaps. The focus is largely on developing countries. The $\mathrm{PhD}$ thesis addresses the following research questions:

1. What are the main factors causing the yield gaps at the global, regional and crop level?

2. How could data for yield gap explaining factors be collected with innovative "bottom-up" approaches?

3. What are motivations of farmers to participate in agricultural citizen science?

4. What determines smallholder farmers to use technologies (e.g., mobile SMS) for agricultural data collection?

5. How can synergy of crowdsourced data and remote sensing improve the estimation and explanation of yield variability?

\subsection{Thesis outline}

This thesis comprises of six chapters among which chapter 2 until chapter 5 form the core of the thesis (Figure 1.3). Chapter 2 addresses research question 
1 and 2 and provides an overview of the factors considered and explaining the yield gap at the global, regional and crop level, based on a review of 50 agronomic studies. Moreover, to address research question 2, the potential of innovative data collection approaches to collect the relevant factors for yield gap analysis are extensively discussed and presented in chapter 2. Chapter 3 explores research question 3 and provides the motivations of farmers to participate in citizen science. A questionnaire based methodology was applied in three communities of farmers, in countries from different continents (Ethiopia, India and Honduras), participating as citizen scientists. Chapter 4 addresses research question 4 and provides the determining factors for farmers to adopt mobile SMS technology for agricultural data collection. Chapter 5 demonstrates the results of synergetic use of remote sensing and crowdsourcing for estimating and explaining crop yields at the field level. In Chapter 6 the main results from the previous chapters are summarised and the necessary additional steps that need to be considered to utilize the full potential of innovative data collection approaches for agricultural citizen science are discussed.

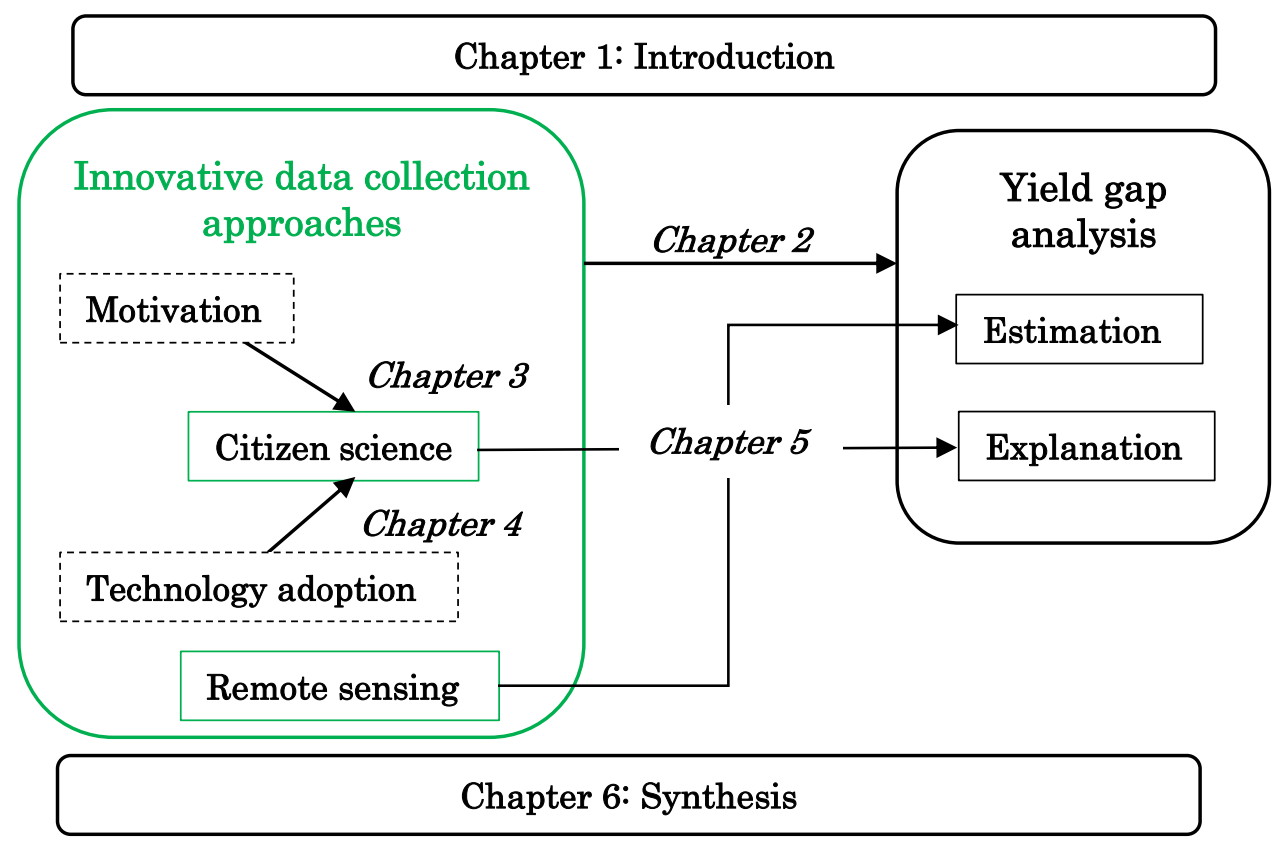

Figure 1.3 Overview of the chapters of the thesis. 


\title{
Chapter
}

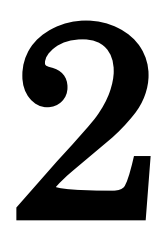

\section{Review of yield gap explaining factors and opportunities for alternative data collection approaches}

\author{
Eskender Beza, João Vasco Silva, Lammert Kooistra, Pytrik Reidsma
}

Published in European Journal of Agronomy, Volume 82, Part B, January 2017, Pages 206-222 


\begin{abstract}
Yield gap analysis is gaining increased scientific attention, as estimating and explaining yield gaps shows the potential for sustainable intensification of agricultural systems. Explaining yield gaps requires detailed information about the biophysical environment, crop management as well as farm(er) characteristics and socio-economic conditions in which farmers operate. However, these types of data are not always available, mostly because they are costly to collect. The main objective of this research is to assess data availability and data collection approaches for yield gap analysis, and to summarize the yield gap explaining factors identified by previous studies. For this purpose, a review of yield gap studies (50 agronomic-based peer-reviewed articles) was performed to identify the most commonly considered and explaining factors of the yield gap. Besides a global comparison, differences between regions, crops and methods were analysed as well.
\end{abstract}

The results show that management and edaphic factors are more often considered to explain the yield gap compared to farm(er) characteristics and socio-economic factors. However, when considered, both farm(er) characteristics and socio-economic factors often explain the yield gap. Fertilization and soil fertility factors are the most often considered management and edaphic factors. In the fertilization group, factors related to quantity (e.g. $\mathrm{N}$ fertilizer quantity) are more often considered compared to factors related to timing (e.g. $\mathrm{N}$ fertilizer timing). However, when considered, timing explained the yield gap more often.

Explaining factors vary among regions and crops. For example, while soil fertility is considered relatively much both in Africa and Asia, it is often explaining in Africa, but not in Asia. Agronomic methods like crop growth simulation models are often used for yield gap analysis, but are limited in the type and number of factors that can be included. Qualitative methods based on expert knowledge can include the largest range of factors.

Although the data included in yield gap analysis also depends on the objective, knowledge of explaining factors, and methods applied, data availability is a major limiting factor. Bottom-up data collection approaches (e.g. crowdsourcing) involving agricultural communities can provide alternatives to overcome this limitation and improve yield gap analysis.

Keywords: Yield variability, potential yield, actual yield, benchmarking, crowdsourcing, data collection 


\subsection{Introduction}

Sustainable intensification of agricultural systems, including the closure of existing yield gaps on currently available agricultural land, has been pointed as a possible pathway to meet the future food demand (Cassman 1999). The concept of 'yield gap' is based on production ecological principles and can be estimated as the difference between a benchmark (e.g. climatic potential or water-limited yield) and the actual yield (van Ittersum and Rabbinge 1997). This concept is particularly important because it indicates the biophysical potential available to improve agricultural production in a specific location (van Ittersum et al. 2013).

Yield gap analysis provides the foundation for identifying the most important crop, soil and management factors limiting current farm yields (van Ittersum et al. 2013; Lobell et al. 2009; Tittonell et al. 2008; Lobell et al. 2005). Information on the magnitude of the yield gap, and associated explaining factors, is important for efficiently targeting efforts to increase crop production in a particular farming system (Affholder et al. 2013). For example, a yield gap analysis for cassava in Cambodia revealed that soil nutrients, short crop duration and weed infestation explained much of the yield gap in the area and these factors had to be improved to increase cassava yield (Sopheap et al. 2012). A number of yield gap analysis studies have been conducted for different crops in different agro-ecological conditions (van Ittersum and Cassman 2013) and the results of these studies showed that the magnitude and factors that cause the yield gap vary among locations (e.g., Affholder et al. 2013).

Many studies have examined yield gaps at the scale of the region or agroclimatic zone, using aggregated data on crop yields and explaining factors (e.g., Mueller et al. 2012; Neumann et al. 2010). These type of studies are useful to compare different regions in relative terms using harmonized data (van Ittersum et al. 2013). How ever, in order to further understand yield gaps, more local studies are needed to bring the role of farm and farmer characteristics into the picture, as well as more local biophysical and socio-economic conditions (Silva et al. 2017).

The interactions between different activities at farm level, together with resource constraints faced by individual farmers, likely explain why inputs are not optimally allocated across the farm and hence why yield gaps persist (e.g., Tittonell et al. 2008). Therefore, yield gap analysis at farm and farming system level can contribute to better understand whether or not yield gaps can be closed and if so, under which production, economic and environmental conditions (Giller et al. 2006). A major drawback of this type of analysis is the high data standards required which typically refer to a) large sample size, 
b) fine resolution and c) great level of detail. Clearly, obtaining information about biophysical characteristics and crop and farm management for individual agricultural activities within a farm, as well as farm and farmer's characteristics and socio-economic conditions for a large number of farms is costly and time-consuming. Nowadays, the proliferation of computing devices like different types of mobile phones equipped with sensors (e.g. GPS), and other similar technologies makes it possible to implement effective and lowcost "bottom-up" data collection approaches such as crowdsourcing (Ferster and Coops 2013). These innovative methodologies facilitate the collection of relatively large amounts of information directly from local communities (Herrick et al. 2013; Pratihast et al. 2013a).

The main objective of this research was to review the yield gap explaining factors identified by previous studies, in order to assess data availability and suggest improved data collection approaches for yield gap analysis. To address this specific objective, the following steps were undertaken: (1) to provide an overview of factors considered and explaining yield gaps; (2) to identify most commonly considered and often explaining factors of the yield gap at the global, regional and crop levels; (3) to investigate if there are regional similarities or differences in the factors which are commonly considered and explaining yield gaps; (4) to identify the most common data sources for the different factors considered for yield gap analysis; (5) to evaluate to which extent innovative data acquisition methods (e.g. crowdsourcing) are relevant for improving data availability.

\subsection{Methodology}

\subsubsection{Literature search and study selection}

A detailed literature search was carried out as starting point for this review. The selection of papers was made through specific searches for peer-reviewed articles on yield gap analysis in agronomic journals with key words "yield gap", "potential yield", "yield variability", "water-limited yield" and "yield gap variability". The initial focus was on a special issue released by Field Crops Research on yield gap analysis (van Ittersum and Cassman 2013). In addition, whenever peer-reviewed articles related to yield gap analysis were found in the reference list of an already reviewed article, they were analysed and included for our study. However, priority was given to articles which explained yield gaps and/or yield variability rather than only estimating the yield gap. The review was not completely systematic, as using a keywords-based approach resulted in a large amount of papers that were not directly relevant for this review, as they did not explain yield gaps. Although some relevant papers may be missing due to this, the selected papers provide a good basis to reach our objectives. 


\subsubsection{Review of studies and construction of database}

A database was created using MS-Excel 2010 in order to store the information from the selected articles. The database consists of five different tables, namely: "yield gap", "determining factors", "considered factors", "explaining factors" and "validation table". Each of the tables was organised in such a way that information about the five main categories climate, edaphic, management, farm characteristics and socio-economic factors were stored separately. All of the tables were linked with unique identifiers (IDs) to facilitate information retrieval.

Specific information about the study locations including the continent, country, administrative region and site names and their respective coordinates were compiled in the "yield gap" table. When the coordinates of the study locations were not provided, the names of the study locations were used as a geographic reference and Google Maps was used to obtain the approximate coordinates of the study locations. In addition, information about the level at which the yield gap was estimated and explained (e.g. farm, field, regional or global level), resolution of data collection and the types of crops grown were also compiled. In this table, we also included the years in which the yield gap analysis was performed, the data sources used to estimate both actual and benchmarking yields as well as the methods used to estimate the benchmarking yield (e.g. name of crop model) and the term(s) used to indicate the benchmarking yield (e.g. potential yield, attainable yield, water-limited yield or economic yield). For studies that explained the yield gap, the explanatory methods used to explain the yield gap/yield variability (e.g. boundary-line, linear regression) were included in the database as well. Finally, the purpose of the different methods (for e.g. to explain yield gap or yield variability) used within each paper were recorded.

For each of the methods used in a specific paper, the dependent variable (Y) and the independent variables (X) were identified and included in the database. The independent variables were included in the "considered factors" table of the database. Out of these "considered factors", the ones which explained part of the yield gap and/or yield variability according to the criteria set by the specific paper were included in the "explaining factors" table.

In order to determine the number of records (entries) per study, the following criteria were used: number of crops considered, number of locations, years in which the yield gap analysis was performed, and methods used to estimate the benchmarking yield and to explain the yield gap. One record is a unique combination of location $\mathrm{x}$ crop $\mathrm{x}$ year $\mathrm{x}$ benchmark yield estimation method $\mathrm{x}$ yield gap explanatory method. A total of 270 records with unique identifiers (IDs) were included into the database. For studies which explicitly provided the 
actual yield ( $\mathrm{Ya}$ ) and the benchmarking yield ( $\mathrm{Yp}$ or $\mathrm{Yw}$ ), the magnitude of the yield gap (\%) was calculated as the difference between the benchmark yield and the actual yield divided by benchmark yield times 100\%. For studies which didn't provide the values explicitly, we didn't calculate the percentage of the yield gap and it was left blank in the database.

In order to categorize the data and methods used, and ensuring consistency, a "validation table" was included in the database. This table provides an overview of all different variables considered, including their units. This table also provided the basis for grouping variables and methods.

\subsubsection{Identification of factors}

\subsubsection{Determining factors}

Determining factors are all the input factors that were used to estimate the benchmark yield. As the focus of this analysis is on investigating factors explaining the yield gap or yield variability, and because required determining factors mainly depend on the method used, these factors are not further analysed in this chapter. In general, the least data are needed when using the highest farmers' yields, as only yield data are needed. When using frontier analysis methods, it is important that the yield data are available for a large number of farmers. When using crop growth models, data on climatic conditions and cultivars are required in order to simulate potential or waterlimited yields (Lobell et al. 2009). Most data are needed when using experimental data/fields, as detailed information is required about the optimal management used to obtain the highest possible yields.

\subsubsection{Considered and explaining factors}

Considered factors are all the input factors that were used as explanatory factors in the analysis of the yield gap or yield variability. Explaining factors are the factors which, out of the considered factors, explained part of the yield gap or yield variability. For example, if correlation or regression analysis was used to explain the yield gap then all the input factors included as independent variables were classified as considered factors. Out of the considered factors those which had a statistical significant relationship with the yield gap were classified as explaining factors. If a method that was used to compare differences between groups (e.g. ANOVA) was used and if there were statistical significant differences between the treatments and the control plot, then all the factors in the treatments were included into the database under explaining factors. In this case, all factors behind the treatments and control plot were defined as considered factors. If interviews were used to explain the yield gap, all the factors asked for were included as "considered factors", and all the factors that were judged to be explaining by the authors were included as 
"explaining factors". The selection of the explaining factors for our database was based on results from the reviewed papers, i.e. additional information cited from other papers was not included in the database. Authors of the papers were asked to check the "explaining factors", and around $50 \%$ responded to this.

\subsubsection{Grouping of factors}

Prior to the review, factors in the five main categories were grouped into different sub-groups. The climatic factors were grouped into six sub-groups, namely: radiation, temperature, precipitation, evapotranspiration, wind speed and others. The edaphic factors were grouped into four groups, namely: soil type, soil fertility, soil water and slope. The crop and farm management factors were grouped into eight sub-groups, namely: land preparation, planting, fertilization, irrigation, weeding, crop protection, crop characteristics and others. The farm characteristics were grouped into five sub-groups, namely: income, labour, training, size and intensity, and the socio-economic factors were grouped into three sub-groups, namely: institutional, technical and population. An overview with all the individual factors belonging to each of the aforementioned sub-groups is provided in Appendix 1.

\subsubsection{Analysis of factors explaining yield gaps}

An analysis was conducted based on the "considered factors" and "explaining factors" tables to quantify the percentage of considered and explaining factors within particular subsets of the database. The percentage of considered factors within a group (e.g. fertilization) was computed as the fraction between the total number of records in the "considered factors" table which contained at least one factor from the group of interest and the total number of unique records in the database $(n=270)$. The percentage of explaining factors within a specific group was calculated as the quotient between the total number of records in the "explaining factors" table which contained at least one factor from the group of interest and the total number of records in the "considered factors" table which contained at least one factor from the same group.

To calculate the considered percentage of the individual factors within the specific groups (e.g. considered \% of $\mathrm{N}$ fertilization quantity), first we counted the total number of records which included the individual factor in the "considered factors" table. We then divided the counted number of records by the total number of records in the database (i.e. 270 records) and multiplied by $100 \%$. To calculate the explaining percentage of the individual factors within the specific groups (e.g. explaining \% of $\mathrm{N}$ fertilization quantity), first we counted the total number of records which included the individual factor in the "explaining factors" table. We then divided this number of "explaining factors" by the counted number of "considered factors" and multiplied by $100 \%$. Besides 
the global analysis, both continent and crop specific percentages of considered and explaining yield gap factors were analysed. The same procedures were used, but studies were filtered by continent and/or crop.

To calculate the percentage of factors from a specific data source (e.g. farm survey), first we counted total number of factors in a specific category (e.g. edaphic), and second we counted total number of factors in a specific category which were collected from a specific data source. We then divided the total number of factors collected from a specific data source by the total number of factors in a specific category and multiplied by $100 \%$. The considered and explaining percentage for climatic factors were not analysed in this study because they were used mostly as determining factors.

\subsection{Results}

\subsubsection{Crops, continents and yield gaps}

A total of 14 different crops were identified and the majority of the studies focused on rice (34\%), maize (28\%) and wheat (26\%). The majority of the studies (64\%) included in the database were from Africa and Asia (Figure 2.1 and Appendix 2). Studies from Africa are mostly concentrated in the east, west and southern parts and studies from Asia were mainly in the southern and southeastern regions. Studies from other continents (Europe, America and Oceania) were also included but are few in number (38\%) compared to the number of studies from Africa and Asia. The reason for the large number of studies in Africa and Asia might be because of the existence of large yield gaps in these continents (Tittonell and Giller 2013; Laborte et al. 2012; Neumann et al. 2010). Also the increasing human population in Asia and the associated future food demand to feed this population stimulates scientists to identify factors explaining the yield gap (Laborte et al. 2012).

Overall, yield gaps for different crops in different continents range from 3-91\% (Appendix 2). Even for one crop in one country, estimated yield gaps can be large. For example yield gaps range from $14-80 \%$ for rice in an irrigation scheme in Mauritania (Haefele et al. 2001). Although yield gaps are on average smaller in Europe compared to Africa, this is not necessarily the case for rice, as the yield gaps found in La Camargue, France (37-57\%) (Delmotte et al. 2011) are similar to yield gaps in an irrigation scheme in West Africa (27-49\%) (Wopereis et al. 1999). This brings us to the important notion that although it is relevant to compare yield gaps, yield gaps may differ not only depending on the crop and location, but also depending on the level of yield gap estimation, the resolution at which data are collected, the benchmark yield, and data and model quality to estimate benchmark and actual yields. 


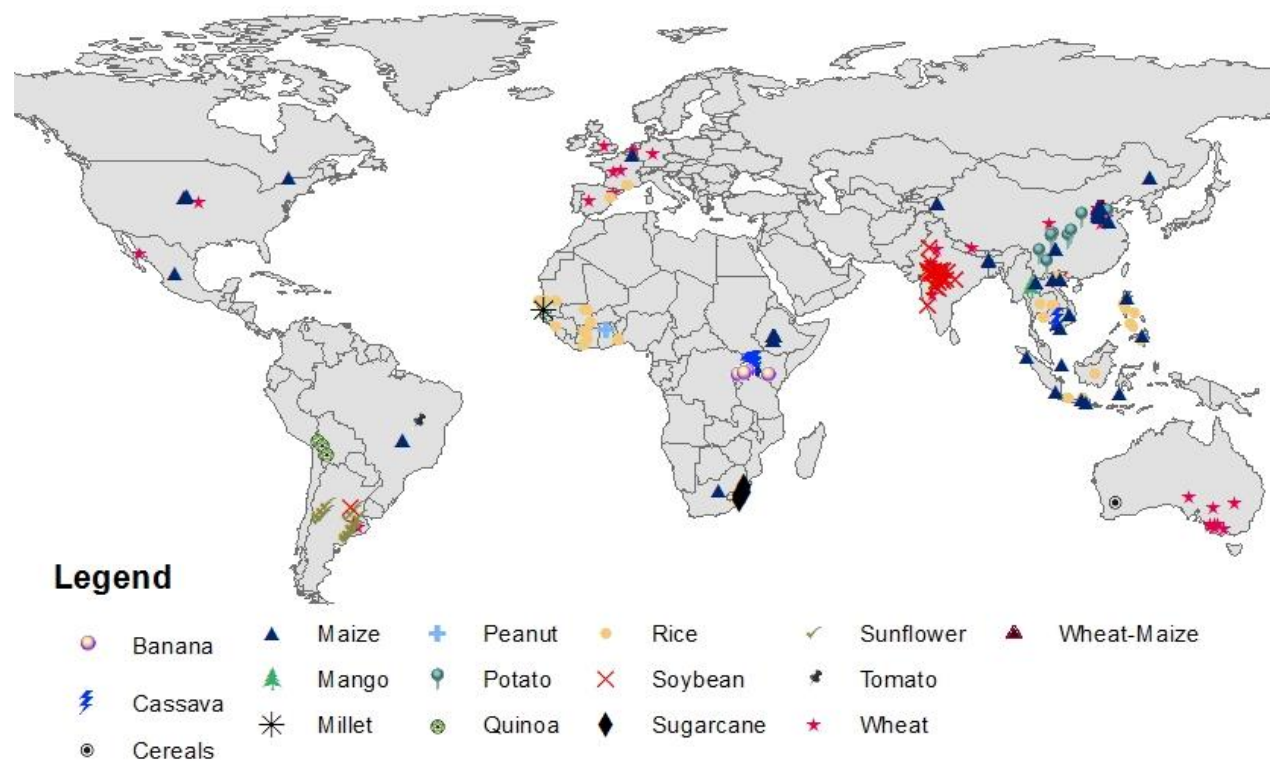

Figure 2.1: A map showing location of the studies and the type of crops included in the review. Although not presented in the map, the global studies of Neumann et al. (2010) and Licker et al. (2010) were also included in the database.

\subsubsection{Between group comparison of considered and explaining factors}

Management factors can often explain the yield gap (Figure 2.2a; see Appendix 1 for details on variables included in the groups). Fertilization was the group most often considered; it was considered by $45 \%$ of the records. In $94 \%$ of the records where a factor related to fertilization was included in the analysis, this factor could also explain the yield gap. Irrigation had a similar explaining power but it was only considered in $15 \%$ of the records. Factors related to land preparation and crop characteristics explained the yield gap in $88 \%$ and $86 \%$ of the records respectively but only $10 \%$ of the records considered land preparation factors and $16 \%$ of the records considered crop characteristics factors. Planting, crop protection and weeding also explained the yield gap in more than $60 \%$ of the cases. Only one study included at least one factor from each of the management groups (Tanaka et al. 2013). In section 2.3.3 the result of detailed analysis of specific management factors are presented.

Like management factors, edaphic factors also explain the yield gap (Figure $2.2 \mathrm{~b})$. For $69 \%$ of the records where a factor related to slope was considered in 
the analysis, this factor could also explain the yield gap. Factors related to soil fertility were considered by a relatively large number of records $(25 \%)$ compared to the other groups of factors and it explained the yield gap in $69 \%$ of these records. Soil type explained the yield gap in around $58 \%$ of the cases while soil water explained the yield gap in $38 \%$ of the cases. Compared to management factors, edaphic factors were in general less often considered to explain the yield gap and when considered, the power of the factors to explain yield gap was less than that of management factors (Figure 2.2a \& b). For example, both soil fertility and fertilization were considered by a relatively large number of records, $25 \%$ and $45 \%$ of the cases respectively. However, factors in the fertilization group explained the yield gap more often than factors in the soil fertility group.

In general, few studies considered farm characteristics when explaining the yield gap, compared to management and edaphic factors. However, from Figure $2.2 \mathrm{c}$ we see that in $93 \%$ of the records where a factor related to intensity (e.g. resource use intensity) or labour (e.g. cost of labour) was considered in the analysis, this factor could also explain the yield gap. Although none of the factors in this category were considered often, size was relatively most often considered. Factors in the size category explained the yield gap in $70 \%$ of the records when a factor related to size (e.g. farm area) was considered in the analysis. The maximum number of farm characteristics factors considered were five (Fermont et al. 2009; Haefele et al. 2001) and there were 16 studies out of 50 which considered farm characteristics to explain the yield gap.

Like the farm characteristics factors, socio-economic factors were not often considered to explain the yield gap. Compared to other types of factors, the maximum number of socio-economic factors considered by a specific study was also smaller. For example, compared to the management factors where a maximum of 29 factors was considered by one study (Delmotte et al. 2011), for socio-economic factors a maximum of three was considered (Neumann et al. 2010). However, when socio-economic factors were considered, they were often explaining, especially factors related to population (e.g. rural population density) and institutions (e.g. access to fertilizers and credits), but also technical factors (e.g. technical assistance) were explaining in more than $50 \%$ of the cases (Figure 2.2d). 
a)

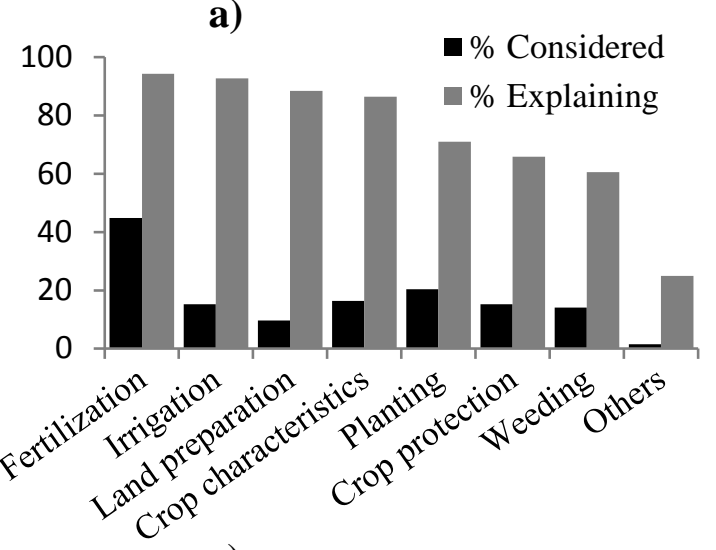

c)

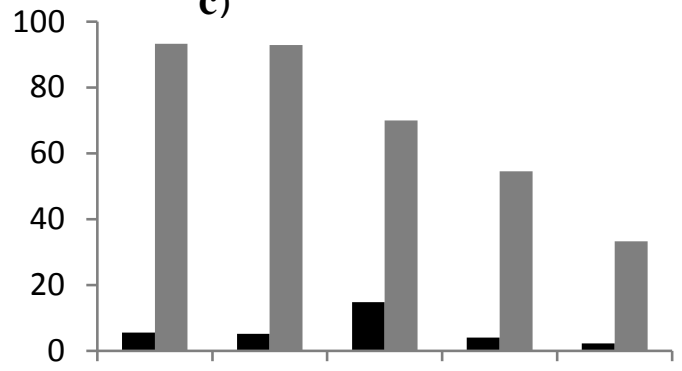

Intensity labour size uncome rraining b)

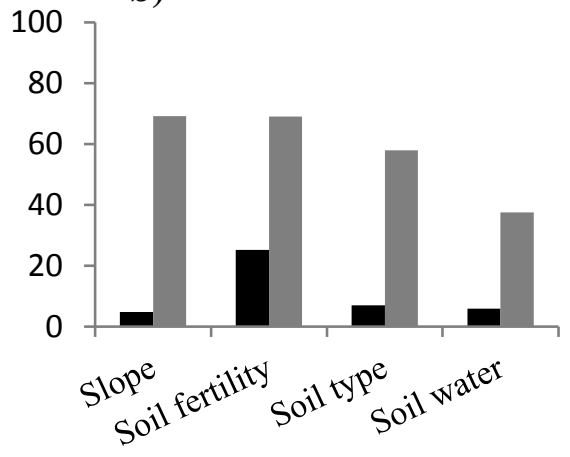

d)

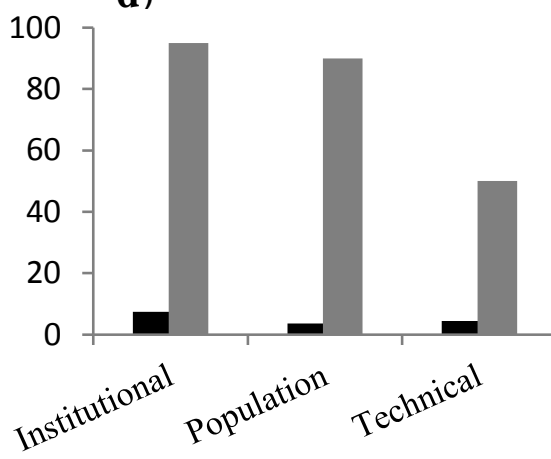

Figure 2.2: Percentage of considered and explaining factors for management (a), edaphic (b), farm characteristics (c) and socio-economic (d) sequence based on explaining percentage.

\subsubsection{Within group comparison of considered and explaining factors}

As data availability may be a relevant issue to include or exclude factors, we analysed 179 unique management factors which were included in the studies reviewed. The average number of factors considered for management per record was three, the minimum was zero (Kassie et al. 2014; Neumann et al. 2010; Licker et al. 2010; Bhatia et al. 2008) and the maximum was 29 (Delmotte et al. 2011). For the most considered and explaining groups, we analysed the factors in detail (Figure 2.3). The explaining power of the quantity of fertilizer is relatively smaller compared to the timing of fertilizer application (Pfertilization timing, Kfertilization timing and Nfertilization timing), but data related to quantity are more considered than timing (Figure 2.3a). Fertilizer costs are also not often considered, but explained the yield gap in $80 \%$ of the 
cases. This might be because data related to quantity are more abundant than timing and cost.

As for fertilization, also in other management groups, including irrigation and weeding, timing of operation was less often considered than amounts used, but more often explaining (see Appendix 1). Also in the planting group, sowing date was more often explaining than sowing density, but it was also more considered.

In the soil fertility group of the edaphic category (Figure 2.3b), exchangeable cations and electric conductivity are not often considered, but when considered, they often explained the yield gap. Total $\mathrm{N}$, organic matter, $\mathrm{pH}$ and $\mathrm{P}$-Olsen are relatively considered by more records, but have smaller explaining power compared to exchangeable cations and electric conductivity.

Detailed analysis on the labour group of the farm characteristics category showed that opportunity cost of labour, availability of machines and mechanization are the three most often explaining factors despite their low frequency consideration to explain yield gaps (Figure 2.3c). Besides, labour efficiency and labour availability explained the yield gap in $80 \%$ and $67 \%$ of the cases respectively. Looking into the institutional group of the socio-economic category, access to fertilizer, credit and markets $(\mathrm{km})$ are the three institutional factors which explain the yield gap the most. Moreover, market access (hrs), market influence and subsides explain the yield gap in more than $75 \%$ of the cases when considered (Figure 2.3d).

\subsubsection{Spatial differences in considered and explaining factors}

\subsubsection{Africa}

It is evident that more management factors were considered in Africa compared to Asia (Figure 2.4a \& b). In Africa, factors in the fertilization category were both often considered (57\%) and often explaining (96\%). Factors in the weeding, planting, crop characteristics and crop protection were often considered but less often explaining, compared to factors in the land preparation category. Factors in the land preparation and irrigation categories were less often considered, but when a factor from these categories was considered, it explained the yield gap in $89 \%$ and $67 \%$ of the cases respectively. With regard to the edaphic category, soil fertility factors often explained the yield gap in Africa compared to factors in the slope, soil water and soil type groups (Figure 2.4c). 


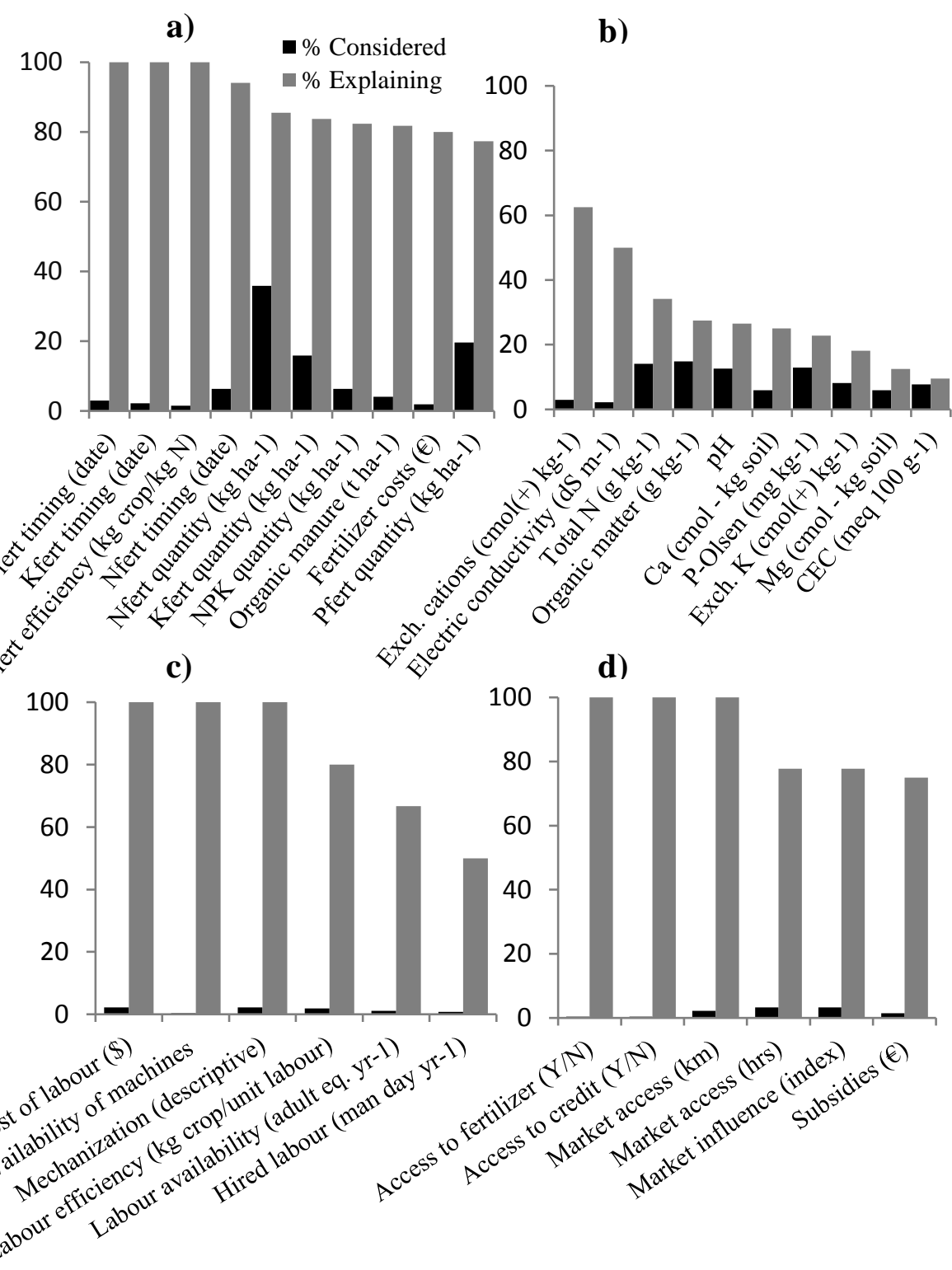

Figure 2.3: The top ten most considered factors in the fertilization (a), soil fertility (b), labour (c) and institution (d) groups sequenced based on explaining percentage. 
In general more management factors were considered in Africa (Figure 2.4a) compared to global studies (Figure 2.2a). Among the management factors, fertilization factors were often considered and often explaining, both in Africa and globally. Slope is the most often explaining edaphic factor in the global analysis (Figure 2.2b), while it less often explained the yield gap in Africa (Figure 2.4c). Soil fertility was often considered and often explaining both in Africa and globally. Among others, size was the most often considered farm characteristic, both in Africa and globally, but less often considered factors, labour and intensity, explain the yield gap more often both in Africa and in global studies (Figure 2.4e \& Figure 2.2c). Institutional and population factors also often explained the yield gap both globally (Figure 2.2d) and in Africa (Figure 2.4g).

\subsubsection{Asia}

Similar to studies in Africa, yield gap analysis in Asia focused mainly on the influence of soil fertility and fertilization (Figure $2.4 \mathrm{~b} \& \mathrm{~d}$ ). However, while soil fertility was explaining in $70 \%$ of the cases in Africa, in Asia it explained yields in only $43 \%$ of the cases. Fertilization did have a high explaining power $(100 \%)$, but this was also the case for land preparation, crop characteristics, crop protection, weeding and irrigation, which were not often considered. Even though less management factors were considered in Asia compared to Africa, when considered, they often explain the yield gap. Soil water and slope appeared to be more important, although they were only considered in few cases. Factors in the labour, intensity and size groups explain the yield gap more often in Asia compared to Africa. However, it was found that both farm characteristics and socio-economic factors were considered by few studies to explain yield gap in Asia compared to Africa. In general, many factors were often considered in Africa, while in Asia less number of factors were considered for yield gap analysis. This might be because in Africa there are more complex interactions and therefore, the problems for the existence of the yield gap are less well known compared to Asia, where they have better ideas of the problems. 


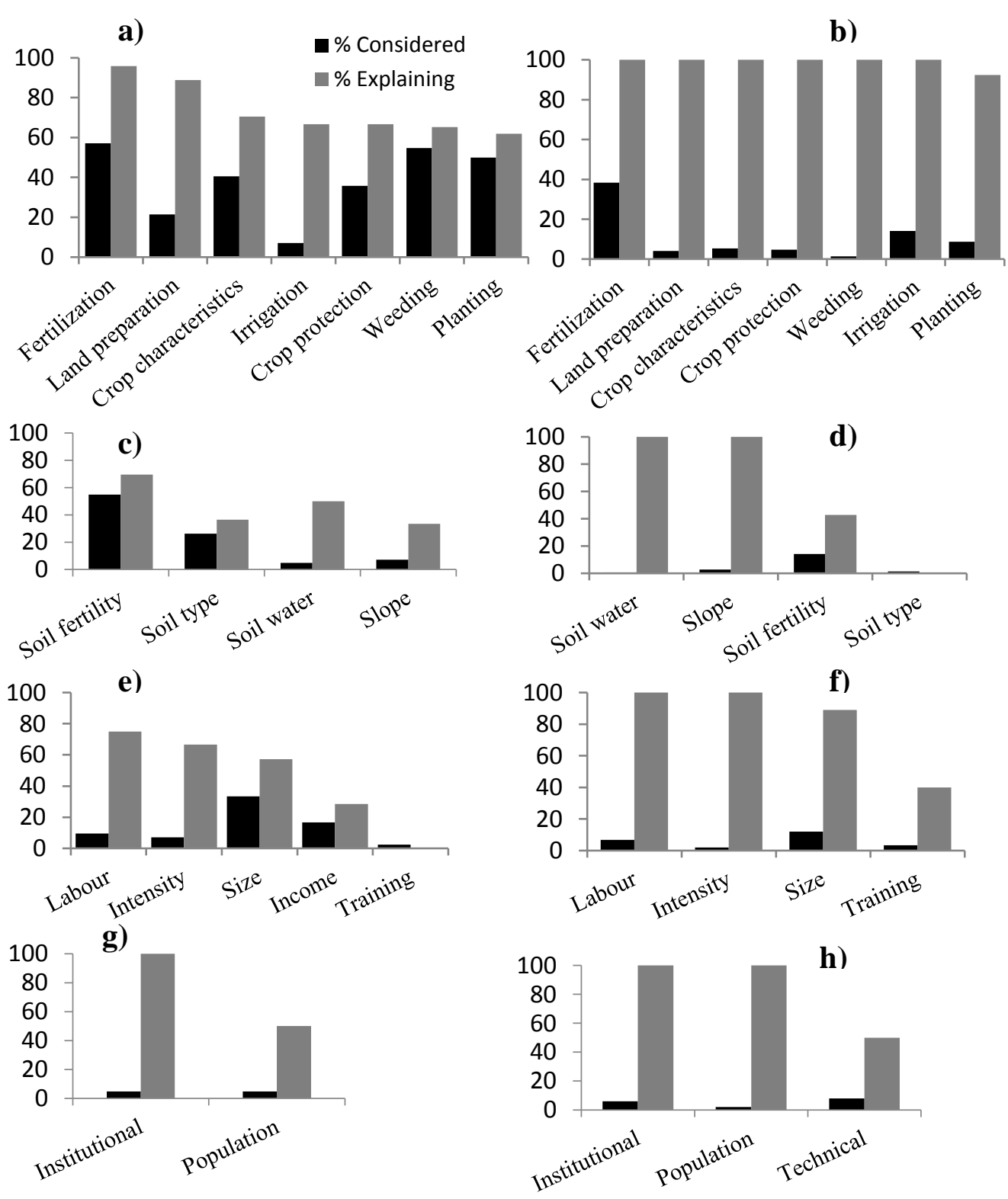

Figure 2.4: Percentage of considered and explaining factors in Africa (left column) and Asia (right column). The first row shows management factors in Africa (a) \& Asia (b), second row edaphic factors in Africa (c) \& Asia (d), third row farm characteristics in Africa (e) \& Asia (f) and fourth row, socio-economic factors in Africa (g) \& Asia (h). 


\subsubsection{Crop specific considered and explaining factors}

\subsubsection{Rice}

In the analysis, rice was considered in seven studies in Africa, seven in Asia, and two in Europe (Appendix 2). Fertilization, land preparation and crop protection categories often explain the rice yield gap in Africa while crop characteristics and planting more often explain the rice yield gap in Europe (Figure 2.5). Factors from the land preparation group were less often considered but often explained the yield gap in Africa, whereas they never explained the yield gap in Europe, even though they were more often considered. In general, management factors were more often considered and often explain (except for land preparation) the rice yield gap in Europe compared to Africa, whereas they were not considered (except fertilization) for rice yield gap analysis in Asia (at least not in the studies included, as based on our criteria, we did not capture research dealing with, for example, site-specific nutrient management (Dobermann et al. 2002) and irrigation water management (Bouman and Tuong 2001)).

Compared to the overall analysis in Africa (Figure 2.4), crop protection, soil type, slope and soil fertility factors were more important to explain the rice yield gap in Africa, while crop characteristics and soil water factors had less importance (Figure 2.5). Farm characteristics factors were in general less important to explain the rice yield gap in Africa compared to their large contribution to explain yield gaps for the overall analysis conducted in Africa.

In the overall analysis, soil fertility was of little importance to explain the yield gap in Asia (Figure 2.4d) but it was important to explain rice yield gap in Asia (Figure 2.5). Soil fertility was also most often considered and often explained the rice yield gap in Europe, while soil type explained the rice yield gap more often in Africa. Moreover, soil water often explained yield gaps in Asia but not rice yield gaps in Asia. Technical factors from the farm characteristics category less often explained the rice yield gap in Asia compared to overall analysis in Asia. Both farm characteristics and socio-economic factors were not considered to explain rice yield gaps in Europe.

\subsubsection{Maize}

In the analysis, four studies from Africa, six studies from Asia, three studies from North America, one study from Europe, one study from South America and two global studies on maize were included (Appendix 2); the first three continents were further analysed.

In Africa, factors in the fertilization, crop characteristics and planting groups explained the maize yield gap in all the cases when factors from these groups 
were considered (Figure 2.6). Crop protection factors were less important to explain the yield gaps of maize compared to rice (Figure 2.5). Land preparation factors explained the yield gaps in $89 \%$ of the studies performed in Africa (Figure 2.4a), but they were not considered in studies on maize (Figure 2.6). While crop characteristics factors did not explain much of the rice yield gap in Africa, they did explain the maize yield gap more often. Soil fertility is the most considered and often explaining edaphic group for maize yield gap (Figure 2.6) whereas soil type often explained the rice yield gap (Figure 2.5). Size and intensity also explained the yield gap in more than $60 \%$ of the cases, but labour factors which often explained rice yield gaps in Africa were not considered for maize studies in Africa. Intensity factors explained maize yield gaps in Africa in $67 \%$ of the cases, while this group of factors were not considered for rice studies. Socio-economic factors were less often considered; however, institutional and population groups explained the maize yield gap in all the cases when factors from these groups were considered.

For maize yield gap analysis in Asia, factors from farm characteristics and socio-economic categories were not considered; only management and edaphic factors were considered (Figure 2.6). Even from the management categories, only fertilization, crop characteristics and irrigation groups were considered. Fertilization and irrigation factors were most often considered and often explain the maize yield gap in Asia. However, less often considered factors in the crop characteristics group also explain the yield gap in all the cases when factors from this group were considered. Soil fertility factors were the only edaphic factors considered for maize yield gap analysis in Asia.

In North America, fertilization, weeding and planting groups were most often considered to explain the maize yield gap (Figure 2.6). Except from the planting and crop protection groups, management factors explained the yield gap in all the cases when factors from these groups were considered. Crop protection factors were considered but did not explain maize yield gaps in North America. Slope was the only edaphic factor considered and often explained maize yield gap in North America. Farm characteristics factors from the intensity group and socio-economic factors from the institutional and population groups also explain the yield gap in all the cases when considered. 


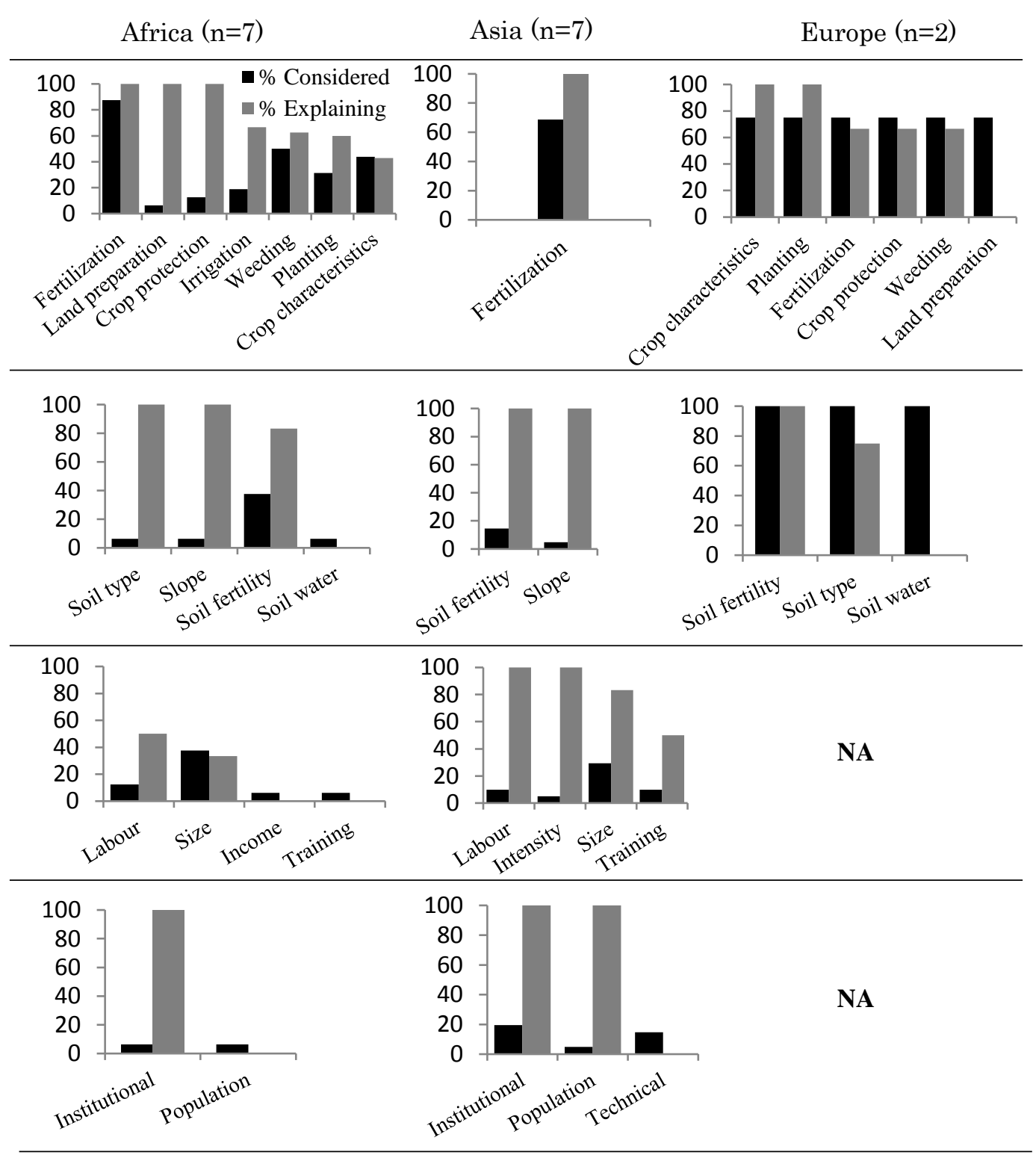

Figure 2.5: Percentage of considered and explaining factors for rice yield gaps in Africa ( $1^{\text {st }}$ column), Asia ( $2^{\text {nd }}$ column) and Europe ( $3^{\text {rd }}$ column). The first row of the table shows management factors, second row edaphic factors, third row farm characteristics and fourth row, socio-economic factors. Empty cells (NA) in the table indicate that in Europe farm characteristics and socio-economic factors were not considered by rice studies included in this analysis. 


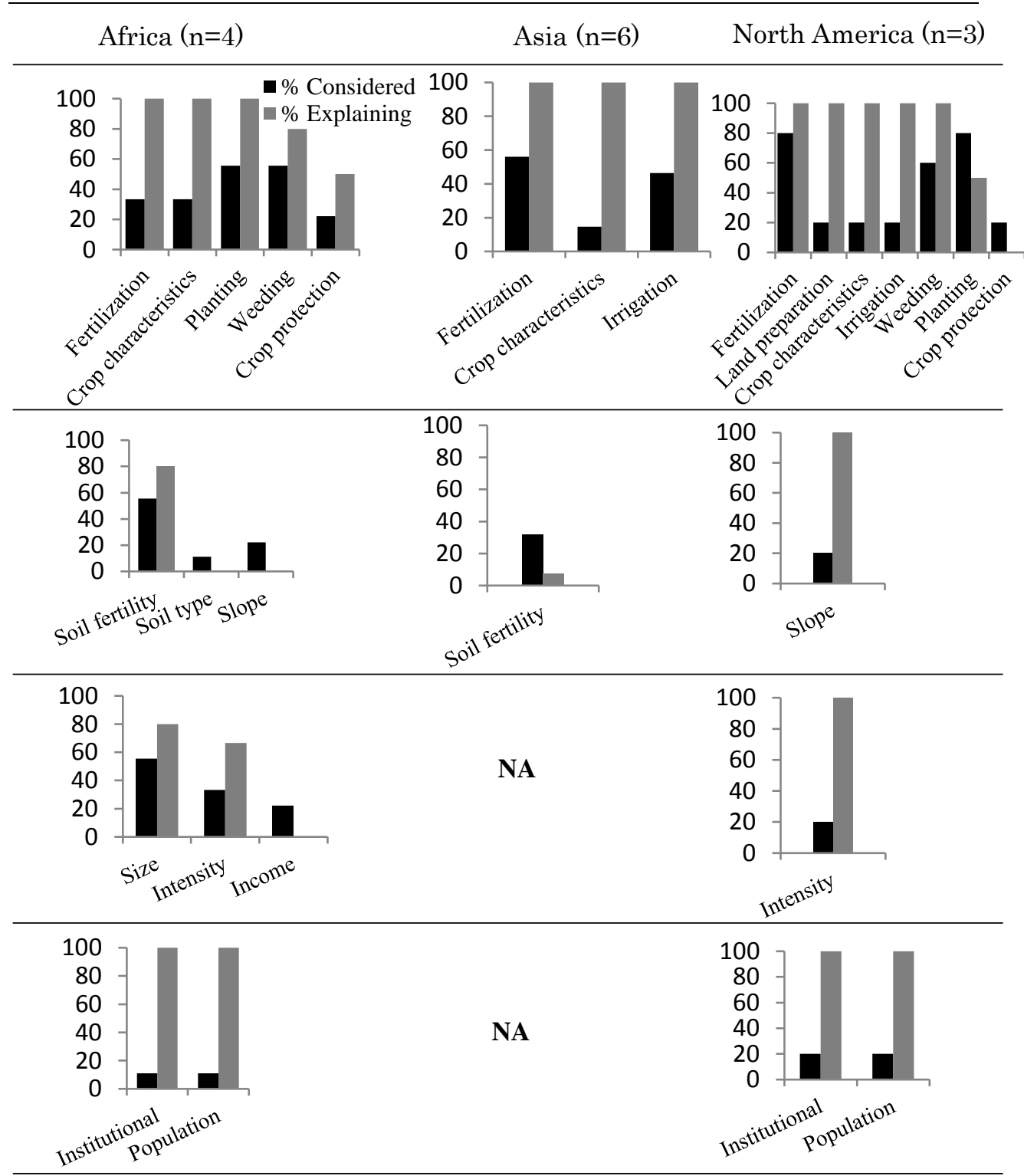

Figure 2.6: Percentage of considered and explaining factors for maize yield gaps in Africa ( $1^{\text {st }}$ column), Asia ( $2^{\text {nd }}$ column) and North America ( $3^{\text {rd }}$ column). The first row of the table shows management factors, second row edaphic factors, third row farm characteristics and fourth row, socio-economic factors. Empty cells (NA) in the table indicate that, in Asia farm characteristics and socioeconomic factors were not considered by maize studies included in this analysis. 


\subsubsection{Wheat}

Regarding wheat, four studies from Asia, three from Europe, two from Australia, two from North America and one from South America were included in the analysis (Appendix 2). For Asia (Figure 2.7), factors in the planting group were more often considered compared to other groups; however, factors in the fertilization, land preparation, irrigation and crop protection groups explain the wheat yield gap as often as the factors in the planting group. Crop characteristics and weeding factors were not considered for explaining the wheat yield gap in Asia. In general, more management factors were considered for wheat yield gap analysis compared to the overall (Figure 2.4a) and specifically compared to maize yield gap analysis in Asia (Figure 2.6). Slope was the only edaphic factor considered and often explained the wheat yield gap in Asia. Labour and size were most often considered farm characteristics factors to explain the wheat yield gap. However, less often considered factors from the intensity group also often explained the yield gap. More labour factors were considered by wheat studies in Asia than for other crops. From the socioeconomic category, factors in the technical group were more often considered and explained the wheat yield gap in Asia than for the average (Figure 2.4h). In addition, less often considered factors from institutional and population groups also explained the wheat yield gap in all the cases when considered.

Studies in Europe considered only management factors for wheat yield gap analysis (Figure 2.7). However, management factors from land preparation, weeding and irrigation groups were not considered for wheat yield gap analysis in Europe. Fertilization and crop characteristics factors were more often considered management factors but less often considered factors from crop protection and planting groups explained the yield gap more often compared to crop characteristics factors.

For North America, land preparation is the least considered management group to explain the wheat yield gap; however, it explained the yield gap more often compared to other management factors (Figure 2.7). Irrigation is the most considered management group and explained the yield gap in $86 \%$ of the cases. Fertilization, planting and crop protection factors were less important to explain wheat yield gap in North America compared to land preparation and irrigation. Fertilization, planting and crop protection were equally considered ( $71 \%$ of the cases) and both fertilization and planting explained the yield gap in $60 \%$ of the cases, while crop protection in only $20 \%$ of the cases. In addition, farm characteristics factors from the intensity group and socio-economic factors in the institutional and population groups were less often considered but when considered, they explained the yield gap in all the cases. For South America, fertilization factors and soil fertility factors explain the yield gap more often compared to other groups (data not shown). 
For Australia, fertilization, land preparation, crop protection and planting groups were considered in $50 \%$ of the cases and factors from these groups explained the wheat yield gap in all the cases (Figure 2.7). Irrigation, crop characteristics and weeding factors were not considered for wheat yield gap analysis in Australia. From the edaphic category, soil fertility and soil water factors also explained the wheat yield gap in all the cases. Soil type and slope groups from edaphic categories were not considered. In addition, farm characteristics and socio-economic factors were also not considered for wheat yield gap analysis in Australia. 


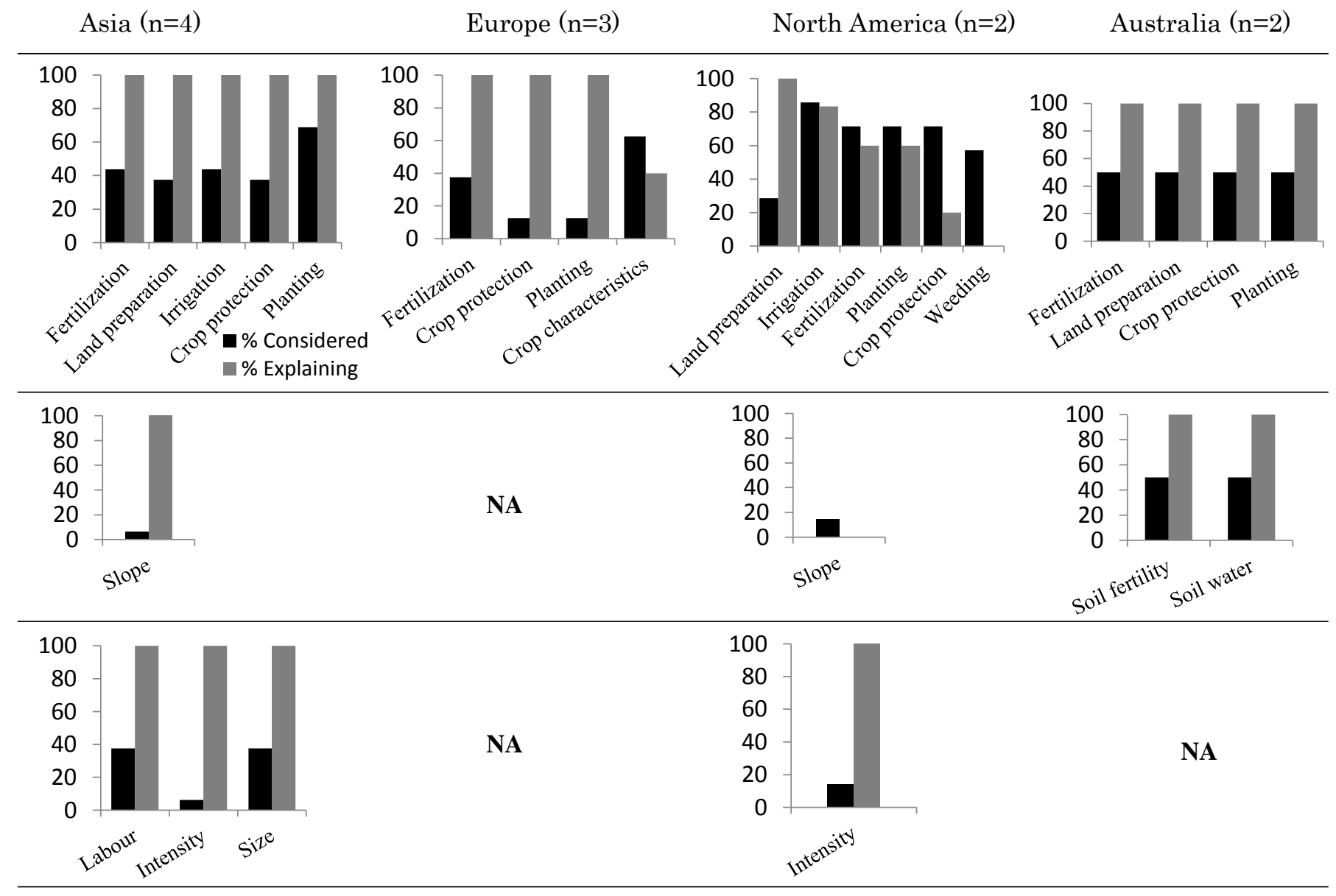




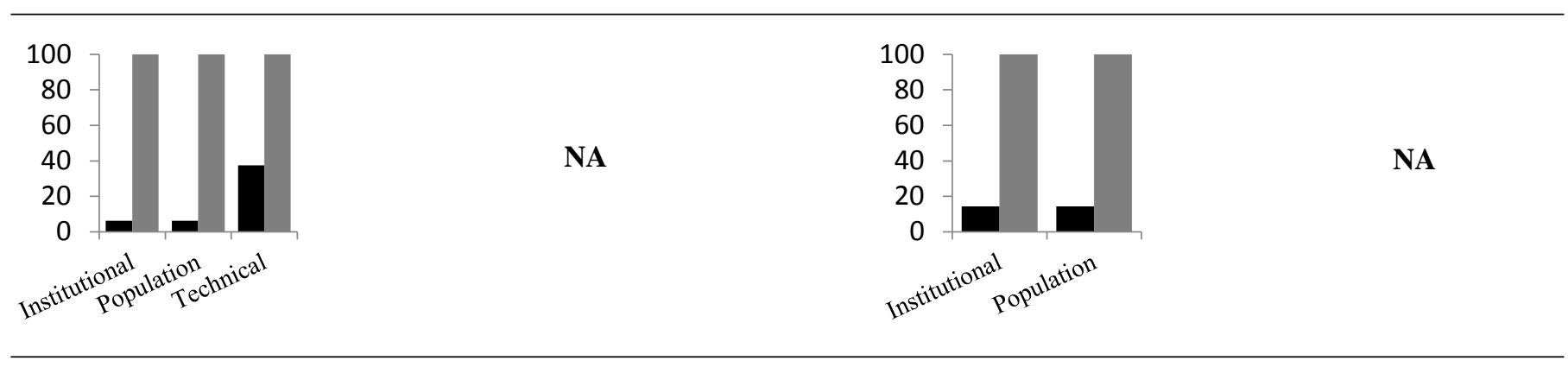

Figure 2.7: Percentage of considered and explaining factors for wheat crop in Asia ( $1^{\text {st }}$ column), Europe ( $2^{\text {nd }}$ column), North America ( $3^{\text {rd }}$ column) and Australia (4th column). The first row of the table shows management factors. Second row edaphic factors, third row farm characteristics and fourth row, socio-economic factors. Empty cells (NA) in the table indicate that edaphic factors in Europe and farm characteristics factors in Europe and Australia and socioeconomic factors in Europe and Australia were not considered by maize studies included in this analysis. 


\subsection{Discussion and opportunities for innovative data collection approaches}

\subsubsection{Methodological approach}

The main objective of this research was to review the yield gap explaining factors identified by previous studies, in order to assess data availability and suggest improved data collection approaches for yield gap analysis. A review was performed based on peer-reviewed journal articles, using the keywords "yield gap", "potential yield", "yield variability", "water-limited yield" and "yield gap variability". We acknowledge however that this terminology is used by a specific group of researchers, and that many studies may be available on similar work, but which are not included in this analysis. For example, economists use production functions and frontier analysis to explain yields (e.g., Monchuk et al. 2010; Helfand and Levine 2004; Giannakas et al. 2001; Ali 1995) and few of such studies came back in this analysis. Such type of studies focus more on farm(er) characteristics and socio-economic factors, and therefore including those would have increased the percentage of considered factors on these categories.

In addition, our analyses rely on data from a variety of yield gap studies at different scales. At each scale, different factors are more or less important. Also benchmark yields are different among different type of studies. While for example soil type may be important to explain the gap between actual and potential yield, soil type is considered when estimating the water-limited yield, and therefore its relevance is smaller when explaining the gap between actual and water-limited yield. During the review we also learnt that there is no consistent procedure followed to report the importance of explaining factors. Hence, we had to only compile factors explaining part of the yield gap based on the criteria (e.g. significance) used by the individual papers. However, a more consistent procedure is required for reporting the importance of explaining factors in future yield gap analysis studies.

Nevertheless, despite these limitations, this review gives a good overview of considered and explaining factors in yield gap studies across the globe, and therefore it provides a good impression of gaps in required data, and a basis for improved data collection.

\subsubsection{Important factors for yield gap analysis}

The global analysis shows that factors from the management category are most often considered to explain the yield gap or yield variability compared to the other main categories (edaphic, farm characteristics and socio-economic). Among the management groups, the fertilization group is most often 
considered and often explains the yield gap. However, less often considered factors from the irrigation, land preparation and crop characteristics groups also explain the yield gap in more than $80 \%$ of the cases, when considered. The importance of fertilization and irrigation factors for explaining the existing yield gaps at the global level is also indicated by Mueller et al. (2012). Planting, crop protection and weeding are the other groups which explain the yield gap in more than $60 \%$ of the cases when considered. Overall, this highlights the importance of crop management for existing yield gaps.

In general, both the global and detailed analysis show that edaphic factors explain a relatively lower percentage compared to management, farm characteristics and socio-economic factors (Figure $2.2 \mathrm{~b}$ and $2.3 \mathrm{~b}$ ). This could be explained by the improved access to technology and resources to solve soil limitations. Farm characteristics and socio-economic factors appear to be of high relevance to explain yield gaps, but these were only considered in a few studies. For example, when considered, institutional factors (e.g. access to fertilizers, credit and market) and labour related factors (e.g. opportunity cost of labour, access to machineries and mechanisation) are relevant socioeconomic and farm characteristics factors to explain the yield gap (Figure 2.3). The majority of the studies included in this review are agronomic studies and this certainly explains the lower number of factors considered from these two categories.

Our detailed analysis shows that timing of fertilization, irrigation and weeding is less often considered compared to quantities applied. However, when considered, the timing factors explain the yield gap more often than the quantity factors. The study of Lobell et al. (2005) noted that timing of irrigation was more important than number of irrigations, suggesting that the efficient use of water is more important than total amount of water applied for yields in Yaqui valley region, Mexico. The issue on timing is very important because it strengthens the notion that for example water or nutrients should be available to the crop in both the right amount and the right moment of time (i.e. in some stages the demand for $\mathrm{N}$ is higher than others). Further, it is related to labour and cash availability at farm level (Chadwick et al. 2015). The timing of operations (e.g. weeding) is strongly related to labour dynamics at farm level (Gianessi 2013). Family labour depends on household composition and off-farm activities, while hired labour refers to cash availability and market conditions.

We must also conclude however that the relevance of factors depends on the location and crop, and that generalizations should not be made. For example soil fertility is relevant to explain yield gaps in Africa whereas soil water is more relevant for yield gaps in Asia. The importance of soil fertility factors to explain part of the yield gap in Africa is explicitly indicated by several studies 
(e.g., Affholder et al. 2013; Okumu et al. 2011; Wairegi et al. 2010; Fermont et al. 2009). Fertilization, land preparation and crop protection are the factors that often explain the rice yield gap in Africa while crop characteristics and planting are important factors for the rice yield gap in Europe. The latter can be explained by the availability of agricultural inputs (e.g. fertilizers) and farm machineries in Europe and lack of these resources in many African countries. In addition, explaining factors can be considered in many different ways (e.g. $\mathrm{kg} \mathrm{N} / \mathrm{ha}$, fertilization $(\mathrm{Y} / \mathrm{N})$ ), and an overview of these is given in Appendix 1. The data collection procedure is therefore highly important when performing yield gap analysis, as a focus on few factors may bias the results.

\subsubsection{Selection of factors for explaining yield gap}

While we have shown that many factors can explain the yield gap, and ideally these should all be considered in a study, in practice the selection of factors is limited. The selection of factors may be influenced by 1) objectives of the study, 2 ) knowledge on possible explaining factors, 3 ) the method used to explain yield gaps and 4) data availability. Below we will first discuss the first three reasons, and then go in further detail on data availability, and possibilities to improve this.

\subsubsection{Objective, previous knowledge and methods used}

First of all, the objective of a study may limit the selection of factors. For example if the objective of a study is to assess the effect of soil quality problems or iron toxicity on yield, then authors tend to focus on factors related to soil quality or iron toxicity instead of other types of factors (Audebert and Fofana 2009; Van Asten et al. 2003). In addition, most of the studies analysing yield gaps are of agronomic nature, and therefore focused more on management and edaphic factors compared to farm characteristics and socio-economic factors.

Secondly, knowledge on possible explaining factors may guide the selection of considered factors. Soil fertility is more often explaining in Africa compared to Asia (Figure 2.4). Previous studies on the importance of soil fertility factors in Africa could influence studies in Africa to consider more soil fertility factors compared to other factors. This is also the case in other regions. For example, a study by Anderson et al. (2005) indicated that in Western Australia yields are more constrained by edaphic factors compared to management factors. Following these findings, the focus of the study of Oliver and Robertson (2013) was to relate yield gaps to spatial variation in soil properties that are known to limit yield in a water-limited environment.

Finally, the method used to explain the yield gap also has an influence on the selection of factors. Table A and B in Appendix 3 show an overview of the different methods used to explain yield gaps and factors used by the methods. 
It is notable that some methods like Classification And Regression Tree (CART) analysis and qualitative methods use many and different types of factors to explain the yield gap (e.g., Tittonell et al. 2008), while other methods like CERES-Wheat (a crop model; Abeledo et al. 2008) use only few factors to explain the yield gap.

\subsubsection{Data availability}

Although the data included in yield gap analysis also depends on the objective, previous knowledge of explaining factors, and method used, data availability is a major limiting factor. Selecting few factors based on available data may bias the analysis and the researcher might miss some important yield gap explaining factors because of unavailability of data. To mention few examples, the study of Neumann et al. (2010) indicated that fertilizer application, one of the most important management options to increase actual grain yields, could not be included into their analysis due to lack of appropriate data and hence the yield gap attributed to fertilizer application was not identified in their study. Lu and Fan (2013) also mentioned that due to lack of data, the EPIC model, which was used in their study to assess yield gaps in the North China Plain (NCP), was validated using data from only two experimental stations. The authors indicated validation of the EPIC model with data from two to four other sites would be worthwhile to provide stronger evidence of the utility of the model in yield gap assessment for the NCP region.

Figure 2.8 shows the main data sources for factors used for yield gap analysis in different parts of the world. It is evident that around $47 \%$ of the management factors were from field trials, followed by farm surveys which contributed with $19 \%$ to the management data used for yield gap analysis. Compiled databases and a combination of measurements \& surveys contributed to $12 \%$ and $11 \%$ of the management factors, respectively. Soil sampling was the main data source for edaphic factors', with $55 \%$, followed by national databases, which contributed with $22 \%$ to the edaphic factors for yield gap analysis. Farm surveys and global databases were the main data sources for farm characteristics and socio-economic factors, respectively. The majority of the management data were from field trials, not from real farms. However, data from field trials generally do not represent real farms in the area in terms of soil properties and crop management. Moreover, it is important to understand what are the farm level constraints and technical problems farmers face. One of the reasons not to consider data from real farms for yield gap analysis might be because of the lack of datasets containing field-specific information for a large set of individual farms. Therefore, how can we collect more of these relevant factors for yield gap analysis? The next section provides an overview of alternative data collection approaches that can potentially be used to 
complement traditional data collection methods (e.g. farm survey) to collect some of the relevant factors for farm level yield gap analysis.

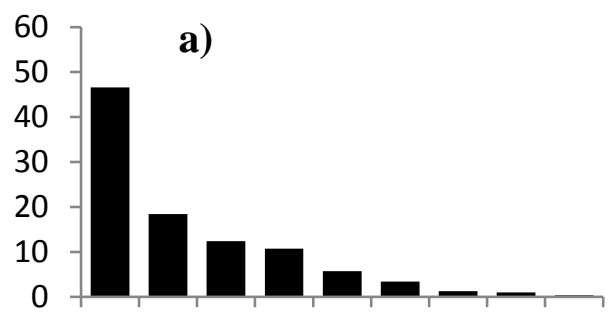

b)
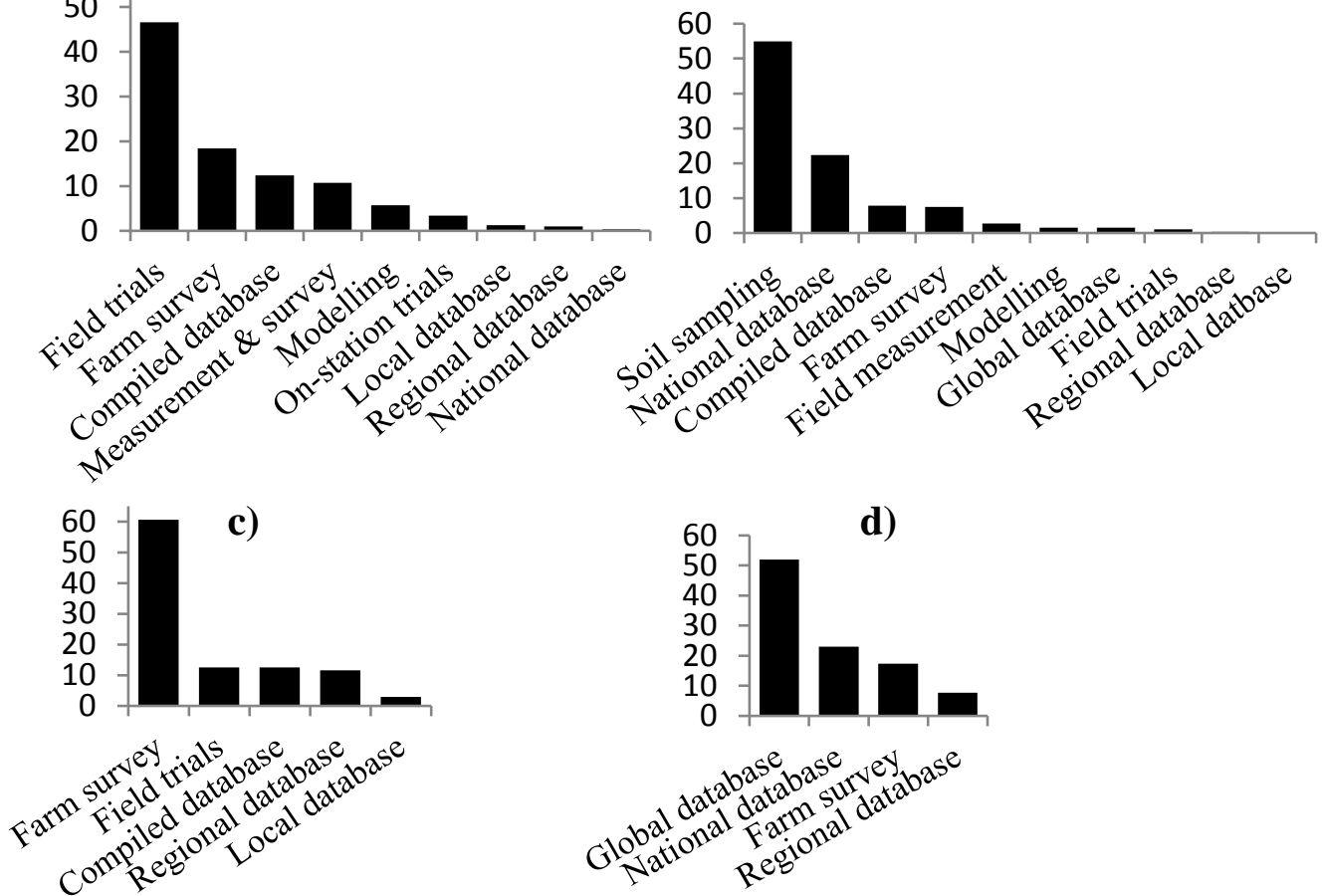

Figure 2.8: An overview of data sources for factors considered for yield gap analysis a) management factors b) edaphic factors c) farm characteristics factors d) socio-economic factors.

\subsubsection{Opportunities for alternative data collection approaches}

Most of the management, farm characteristics and socio-economic factors that explain the yield gap (e.g. timing of fertilization, education level/age of the farmer, access to fertilizers) can only be obtained either by asking farmers using traditional farm survey methods (e.g., Tittonell et al. 2008) or through self-reporting (e.g. Yield Prophet: www.yieldprophet.com.au; Hochman et al. 2012). Other data collection methods, e.g. remote sensing can provide data on factors such as soil organic matter content (Gomez et al. 2008), field size calculated from high spatial resolution satellite images (Schulthess et al. 2013), and crop density (Bai et al. 2011; Thorp et al. 2008). Moreover, sensor networks can also provide factors such as crop canopy (e.g. using upward-pointing digital 
cameras; Ryu et al. 2012) and soil moisture content (e.g. using DACOM sensor). However, remote sensing measurements are still highly uncertain and specifically challenging for the heterogeneous and small size fields that are common for smallholder agriculture in the tropics (Lobell 2013), where there is a large yield gap for most of the crops (www.yieldgap.org). Moreover, the use of remote sensing to collect data for farm level yield gap analysis can be constrained by availability of satellite images at the required spatial and temporal resolution.

Most developed countries have a well-developed and organised infrastructure to collect harmonised agricultural data that are used for different purposes (Paustian 2013), including yield gap analysis. For example, the Farm Accountancy Data Network (FADN) of the European Commission collects farm characteristics (e.g. crop areas, labour force) and socio-economic data (e.g. subsidies) at farm level. As an example, these data were used to asses regional yield gaps in Europe (Reidsma et al. 2009). However, even these wellestablished and organised databases lack some important factors (Paustian 2013) for yield gap analysis (e.g. soil and crop-specific management data) and additionally, these are available only as aggregated averages at farm level that might not fully capture some important field specific factors (e.g. amount of fertilizer applied).

In most developing countries detailed agricultural data are much less harmonised and scarce due to lack of resources to conduct extensive surveys on agricultural practices (Paustian 2013). Data compiled in national level databases (e.g. FAOSTAT) provide a useful first estimate of agricultural activities (Paustian 2013) that can be used in national and global yield gap analysis, but are inadequate for detailed farm level yield gap analysis (Grassini et al. 2015; van Ittersum et al. 2013). One possible way to overcome this critical data gap is by 'letting the farmers tell us themselves' (Paustian 2013). Nowadays, due to the proliferation of computing and mobile devices which are equipped with sensors (e.g. GPS), and other similar technologies, it has become possible to implement bottom-up data collection approaches like crowdsourcing with which relatively large amounts of information can be directly obtained from local communities (Herrick et al. 2013). Currently, applications are mostly focused on delivering market information to farmers so that farmers can make informed decisions on when and where to sell their products (Muto and Yamano 2009). Provision of information, such as management recommendations and weather forecasts is another area of development where the use of mobile phones played a major role (Aker 2011). As also suggested by (Paustian 2013), the experiences and lessons learnt from aforementioned initiatives can be used to collect more of the relevant factors for yield gap analysis. 
Table 2.1 provides an overview of the potential and limitations of three categories of alternative data collection methods to acquire factors relevant for yield gap analysis: 1) crowdsourcing (CS); 2) remote sensing (RS); and 3) sensor networks (SN). While describing the different data collection methods, special attention is given to the potential of the crowdsourcing approach due to its great potential for collecting farm level data (Table 2.1).

With the advent of widespread mobile phone access, crowdsourcing for data collection is an emerging method for data capture (Belden et al. 2013). Crowdsourcing can mainly be used to collect information related to the timing of an activity (e.g. timing of fertilization, weeding, irrigation). Moreover, quantity information like amount of fertilizer applied, number of weeding and irrigation operations performed in a specific field can be collected. Cropping calendar (e.g. sowing date, dates of flowering, maturity and harvest) are other potential management factors that can be collected using crowdsourcing. With the ubiquitous availability of smartphones which are equipped with sensors (e.g. GPS), the geo-location (boundary) of a field can be collected which can be used to calculate field size. The camera feature of the phone can be used to capture some incidents in a field (e.g. incidence of pest, disease or weed) which can later be used by experts to assess the infestation level and also to identify the type of pest, disease and/or weed that caused the damage to the crop. Providing training for selected community members (e.g. focal farmers) to be able to identify pest and/or disease as done by Plant clinics of CABI (www.plantwise.org/plant-clinics/) can help the farmers to get assistance and provide the right information.

Unlike management factors, collecting soil fertility factors using the crowdsourcing approach might not be straight forward. However, asking farmers to assess the fertility level of their soils using their own local indicators can potentially be used to complement soil chemical analysis (Desbiez et al. 2004). In addition, an on-farm soil testing kit which allows farmers to diagnose soil constraints in the field and transmit the information quickly through SMS (e.g. SoilDoc) could potentially be used for acquiring soil fertility factors. For smartphone/tablet users, apps like MySoil app can be used to provide information about $\mathrm{pH}$ and organic-matter content of the soil (Shelley et al. 2013).

The crowdsourcing approach also has huge potential to collect farm characteristics and socio-economic factors. Farm(er) characteristics factors like labour (e.g. labour availability), training (e.g. years in school) and income (e.g. farm income) are factors that can be collected using the crowdsourcing approach. Socio-economic factors like access to fertilizer (Y/N), access to credit $(\mathrm{Y} / \mathrm{N})$, number of technical assistances received and gender of a farmer are few 
example factors which can be collected using crowdsourcing. However, to receive accurate and timely information, understanding the motivations of the community (farmers) to participate in crowdsourcing and incentivising them to provide the requested information is critical (Roy et al. 2012). Moreover, identifying the right technology (platform) for the farmers to use in the crowdsourcing activity is another important step that needs to be considered while designing a crowdsourcing campaign. 
Table 2.1: Alternative data collection methods (crowdsourcing (CS), remote sensing (RS) and sensor networks (SN)) and their potential to collect factors relevant for yield gap analysis.

\begin{tabular}{|c|c|c|c|c|c|}
\hline \multicolumn{2}{|r|}{ Factors } & $\mathrm{CS}$ & $\mathrm{RS}$ & SN & Examples/Reference \\
\hline \multirow{6}{*}{ 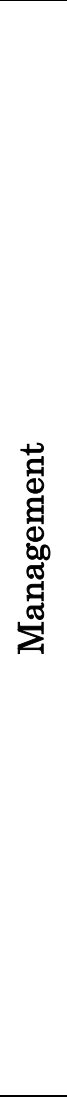 } & Fertilization & $+/-$ & - & - & $\begin{array}{l}\boldsymbol{C S} \text {. Timing of fertilization, quantity of fertilizer(s) applied and } \\
\text { fertilizer costs. }\end{array}$ \\
\hline & Planting & $+/-$ & + & - & $\begin{array}{l}\text { CS. Sowing date, number of plants/m }{ }^{2} \text {, seeding method and } \\
\text { intercropping (Y/N).RS Crop density (Bai et al. 2011; Thorp et al. } \\
\text { 2008), sowing date (Ortiz-Monasterio and Lobell 2007; Lobell et al. } \\
\text { 2003) and intercropping (Jain et al. 2013). }\end{array}$ \\
\hline & $\begin{array}{c}\text { Crop } \\
\text { characteristics }\end{array}$ & + & + & + & $\begin{array}{l}\text { CS } \text { LAI app (Confalonieri et al. 2013), lodging (Y/N), physiological } \\
\text { maturity (using Growing Degree Days app): } \\
\text { https://itunes.apple.com/us/app/growing-degree- } \\
\text { days/id386655475?mt=8\%0D, harvesting time, crop genotype (name } \\
\text { of variety planted), and dates of flowering and maturity. } \\
\boldsymbol{R S} \text {. Canopy cover percentage (Pacheco et al. 2008; DeTar and } \\
\text { Penner 2007), lodging (Zhang et al. 2014). SN. LAI (Ryu et al. 2012). }\end{array}$ \\
\hline & Irrigation & + & + & + & $\begin{array}{l}\boldsymbol{C S} \text {. Timing of irrigation (Smart ICT- Africa project: } \\
\text { http://www.smartict-africa.com/EN/), irrigation infrastructure, } \\
\text { irrigation system, supplementary irrigation (Y/N), water control } \\
\text { (good/bad) and number of irrigations. } \boldsymbol{R S} \text {. Irrigation amount } \\
\text { (Droogers et al. 2010). SN: DACOM sensor (http://en.dacom.nl/). }\end{array}$ \\
\hline & Weeding & $+/-$ & + & + & $\begin{array}{l}\boldsymbol{C S} \text {. Timing of weeding/herbicide application, number of } \\
\text { weeding/herbicide applications, weeding method and weed } \\
\text { management (score). Moreover, using apps to identify weeds and } \\
\text { assess weed pressure (Rahman et al. 2015). } \boldsymbol{R S} \text {. Weed management } \\
\text { (Goel et al. 2003). SN. Weed intensity (Sui et al. 2008). }\end{array}$ \\
\hline & $\begin{array}{c}\text { Crop } \\
\text { protection }\end{array}$ & + & + & $+/-$ & $\begin{array}{l}C \boldsymbol{S}: \text { 1) Digital Early Warning Network (DEWN): } \\
\text { http://www.scidev.net/global/farming/news/cassava-disease- } \\
\text { monitoring-goes-mobile.html, }\end{array}$ \\
\hline
\end{tabular}




\begin{tabular}{|c|c|c|c|c|c|}
\hline & & & & & $\begin{array}{l}\text { 2) PestNet: } \text { http://www.pestnet.org and 3) Plant clinics of CABI: } \\
\text { http://www.cabi.org/projects/plantwise/plant-clinics/. } \\
\text { RS: Disease detection (Cao et al. 2013). }\end{array}$ \\
\hline & $\begin{array}{c}\text { Land } \\
\text { preparation }\end{array}$ & $+/-$ & + & - & $\begin{array}{l}\boldsymbol{C S} \text {. Tillage system, area per crop (\%), land levelling (\#), fallow reside } \\
\text { management and crop residue management. } \\
\boldsymbol{R S} \text {. Crop residue and tillage practices (Zheng et al. 2014). }\end{array}$ \\
\hline \multirow{4}{*}{. } & $\begin{array}{c}\text { Soil } \\
\text { fertility }\end{array}$ & + & + & + & $\begin{array}{l}\text { CS. Farmers diagnose soil constraints in the field using soil testing } \\
\text { kits (SoilDoc) and transmit the information through SMS: } \\
\text { http://agriculture.columbia.edu/projects/agriculture/soildoc/ and } \\
\text { using MySoil app to provide information about pH \& organic-matter } \\
\text { content of the soil (Shelley et al. 2013). } \\
\boldsymbol{R S} \text {. Organic matter content of the soil (Gomez et al. 2008) } \\
\boldsymbol{S N} \text { : SoilCares initiative - Mobile Lab: } \\
\text { http://www.soilcares.com/en/our-ongoing-projects and SoilCares } \\
\text { handheld scanner: http://www.soilcaresscanner.com/ }\end{array}$ \\
\hline & $\begin{array}{c}\text { Soil } \\
\text { water }\end{array}$ & + & + & + & $\begin{array}{l}\text { CS: Soil Water app for smartphones (SWApp): } \\
\text { http://www.grdc.com.au/Research-and-Development/GRDC-Update- } \\
\text { Papers/2015/03/A-new-way-to-estimate-and-monitor-the-water- } \\
\text { content-of-soil. } \boldsymbol{R S} \text {. Soil moisture (Petropoulos et al. 2015). } \\
\boldsymbol{S N} \text {. Soil moisture sensors (Xiao et al. 2013). }\end{array}$ \\
\hline & $\begin{array}{l}\text { Soil } \\
\text { type }\end{array}$ & + & + & - & $\begin{array}{l}\boldsymbol{C S} \text {. Using SoilWeb app to provide the soil type of the current } \\
\text { location of the phone: } \mathrm{http}: / / \text { casoilresource.lawr.ucdavis.edu/soilweb- } \\
\underline{\text { apps. } \boldsymbol{R} \boldsymbol{S} \text {. Soil type identification (Jiji and Nadar 2015). }}\end{array}$ \\
\hline & Slope & + & + & - & $\begin{array}{l}\boldsymbol{C S} \text {. Using LandInfoapp to assess slope: http://landpotential.org/ } \\
\boldsymbol{R S} \text {. Using satellite images for Digital Elevation Model extraction } \\
\text { (Murgante et al. 2012). }\end{array}$ \\
\hline
\end{tabular}




\begin{tabular}{|c|c|c|c|c|c|}
\hline \multicolumn{2}{|r|}{ Factors } & CS & RS & SN & Examples/Reference \\
\hline \multirow{5}{*}{ 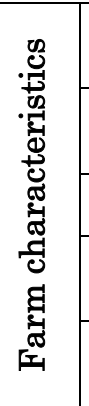 } & Labour & $+/-$ & - & - & $\begin{array}{l}\boldsymbol{C S} \text {. Labour availability, cost of labour, availability of machines and } \\
\text { mechanisation. }\end{array}$ \\
\hline & Income & $+/-$ & - & - & $\begin{array}{l}\text { CS } \text { Crop income, farm income, household income and production } \\
\text { costs. }\end{array}$ \\
\hline & Training & $+/-$ & - & - & $\boldsymbol{C S}$ Y Years in school, farming experience (years) and farmer age. \\
\hline & Size & + & + & - & $\begin{array}{l}\text { CS. Field size (Fritz et al. 2015). } \\
\boldsymbol{R S} \text {. Field size (Yan and Roy 2014). }\end{array}$ \\
\hline & Intensity & $+/-$ & $+/-$ & - & $\begin{array}{l}\boldsymbol{C S} \text {. Resource use intensity (score), irrigated area (\%), irrigated area } \\
\text { per grain type (ha). }\end{array}$ \\
\hline \multirow{3}{*}{ 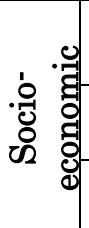 } & Institutional & $+/-$ & - & - & $\begin{array}{l}\text { CS } \text { Access to fertilizer }(\mathrm{Y} / \mathrm{N}) \text {, access to credit }(\mathrm{Y} / \mathrm{N}) \text { and market access } \\
(\mathrm{hrs} \text { or } \mathrm{km}) \text {. }\end{array}$ \\
\hline & Technical & $+/-$ & - & - & CS: Technical assistance (\#) and extension contacts (score). \\
\hline & Population & $+/-$ & - & - & $\boldsymbol{C S}$ : Gender (M/F). \\
\hline \multirow{2}{*}{ 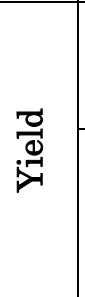 } & $\begin{array}{l}\text { Actual farm } \\
\quad \text { yields }\end{array}$ & + & + & - & $\begin{array}{l}\boldsymbol{C S} \text {. Farmers self-report the amount of yield they harvested: } \\
\text { www.yieldprophet.com.au (Hochman et al. 2012), (Gittleman et al. } \\
\text { 2012). } \boldsymbol{R S} \text { (Lobell et al. 2005). }\end{array}$ \\
\hline & $\begin{array}{l}\text { Benchmarking } \\
\text { yield }\end{array}$ & $+/-$ & + & - & $\begin{array}{l}C \boldsymbol{S} \text {. Asking farmers to provide the maximum yield they have } \\
\text { harvested in a specific field for the last few growing seasons. } \\
\boldsymbol{R S} \text {. to use the maximum yield within the remote sensing estimates } \\
\text { as a proxy for the benchmarking yield (Lobell et al. 2002). }\end{array}$ \\
\hline
\end{tabular}

(+): It is possible and has already been used, (+/-): Potentially possible, (-): It is not possible/ it has not been used. 


\subsection{Conclusion}

In studies explaining yield gaps a large variety of factors are considered. The selection of factors is influenced by 1) objectives of the study, 2) knowledge on possible explaining factors, 3) the method used to explain yield gaps and 4) data availability.

The results of this study show that management factors were most often considered compared to edaphic, farm characteristics and socio-economic factors. Although fertilization related factors seem to be more often considered, when considered, other management factors like land preparation, irrigation and crop characteristics also often explained the yield gap. When considered, both farm characteristics and socio-economic factors also often explain the yield gap; thus future yield gap studies need to collect and consider farm characteristics and socio-economic factors to explain the yield gap as well. Information related to quantity (e.g. $\mathrm{N}$ fertilizer quantity, irrigation amount and no. of weeding operations) is more often collected and used in yield gap analysis than timing (e.g. $\mathrm{N}$ fertilizer timing, irrigation timing and timing of weeding). However, when considered, the timing of management activities often explains the yield gap; hence it is important that data about the timing of operational activities is also collected and taken into account in the analysis.

The relevance of factors to explain the yield gap depends on the location and crop, and generalization should not be made. Explaining factors are region and crop specific, and approaches for data collection should be region and/or crop specific.

Data availability can be increased by using bottom-up data collection approaches like crowdsourcing which might help to collect more of the explanatory factors particularly from the categories of farm characteristics and socio-economic factors. Crowdsourcing based methods (e.g. farmers send timing information via SMS) is also a promising alternative to acquire real-time information about timing of management activities.

Supplementary data associated with this chapter can be found in the online version at: http://dx.doi.org/10.1016/j.eja.2016.06.016

\section{Acknowledgements}

This research was carried out in a $\mathrm{PhD}$ project and it is part of the Wageningen UR strategic programme 'Mapping for sustainable intensification', 2012-2016, funded by the Strategic Funds of Wageningen UR. The authors also would like to thank Marcel Lubbers for developing the Excel macros used for the analysis of the data. 



\section{Chapter}

\section{What are the prospects for citizen science in agriculture? Evidence from three continents on motivation and mobile telephone use of resource-poor farmers}

Eskender Beza, Jonathan Steinke, Jacob van Etten, Pytrik Reidsma, Carlo Fadda, Sarika Mittra, Prem Mathur, Lammert Kooistra 


\section{Abstract}

As the sustainability of agricultural citizen science projects depends on volunteer farmers who contribute their time, energy and skills, understanding their motivation is important to attract and retain participants in citizen science projects. The objectives of this study were to assess 1) farmers' motivations to participate as citizen scientists and 2) farmers' mobile telephone usage. Building on motivational factors identified from previous citizen science studies, a questionnaire based methodology was developed which allowed the analysis of motivational factors and their relation to farmers' characteristics. The questionnaire was applied in three communities of farmers, in countries from different continents, participating as citizen scientists. We used statistical tests to compare motivational factors within and among the three countries. In addition, the relations between motivational factors and farmers characteristics were assessed. Lastly, Principal Component Analysis (PCA) was used to group farmers based on their motivations. Although there was an overlap between the types of motivations, for Indian farmers a collectivistic type of motivation (i.e., contribute to scientific research) was more important than egoistic and altruistic motivations. For Ethiopian and Honduran farmers an egoistic intrinsic type of motivation (i.e., interest in sharing information) was most important. While fun has appeared to be an important egoistic intrinsic factor to participate in other citizen science projects, the smallholder farmers involved in this research valued 'passing free time' the lowest. Two major groups of farmers were distinguished: one motivated by sharing information (egoistic intrinsic), helping (altruism) and contribute to scientific research (collectivistic) and one motivated by egoistic extrinsic factors (expectation, expert interaction and community interaction). Country and education level were the two most important farmers' characteristics that explain around $20 \%$ of the variation in farmers motivations. For educated farmers, contributing to scientific research was a more important motivation to participate as citizen scientists compared to less educated farmers. We conclude that motivations to participate in citizen science are different for smallholders in agriculture compared to other sectors. Citizen science does have high potential, but easy to use mechanisms are needed. Moreover, gamification may increase the egoistic intrinsic motivation of farmers.

Keywords: Citizen science, crowdsourcing, mobile phone, motivations, gamification, smallholder farmers 


\subsection{Introduction}

Public participation has a long and distinguished tradition in agricultural research. Over the last decades, numerous methodologies have been developed to address the participation of farmers as agricultural end-users in trial design, innovation development, different steps of plant breeding, and other fields of research (Neef and Neubert 2011; Bellon 2001; Okali et al. 1994). Important objectives of involving farmers in research include creating synergies between local and formal innovation, and increasing the practical impact of research (Hellin et al. 2008; Sumberg et al. 2003). Participatory methodologies in the agricultural sciences usually involve limited numbers of farmers, often trained by researchers and living in close proximity to the research facility, and scaling is usually difficult due to requirements in training and farmer group organization (Ceccarelli and Grando 2007). Yet, given the strong heterogeneity of socio-economic requirements and environmental conditions in many locations, there is increasing interest in methodologies that facilitate the engagement of larger numbers of farming households and environments.

In the last fifteen years, modern communication tools have enabled the emergence of participatory research methodologies involving very high numbers of contributors via crowdsourcing (Dickinson et al. 2012; Newman et al. 2012). Although the term may include any participatory research, such methodologies are usually referred to as 'citizen science', and have now become widely established and led to many peer-reviewed publications in the ecological and biological disciplines (Follett and Strezov 2015; Cooper et al. 2010; Hand 2010). In citizen science projects, a large number of volunteers individually participate in crucial activities of formal research. These projects have accomplished tasks that traditional research often cannot, due to restricted resources. The accumulated time dedicated to the crowdsourced research task, the number of contributions, and, in many cases, the geographic spread of data entries often exceed the capacities of traditional research. Successful examples include national surveys of bird migration (Sullivan et al. 2014), or citizens classifying the water quality of nearby water bodies (Conrad and Hilchey 2011). Only now, similar research methodologies are under development for the agricultural sciences, offering new opportunities for the scaling and specification to local context of agricultural research.

Although other factors also play a role, recent literature suggests two important preconditions for establishing successful crowdsourced research. Firstly, since the remote network of participants is a key characteristic of crowdsourced research, participants must have access to digital communication infrastructure. And secondly, since participation is voluntary, participants need to be motivated (Nov et al. 2011a). In Self-Determination 
Theory (SDT) two basic types of motivations are distinguished: intrinsic motivation, which refers to "doing something because it is inherently interesting or enjoyable", and extrinsic motivation, which refers to "doing something because it leads to a separable outcome" (Ryan and Deci 2000a). Research about volunteers' motivation to participate in citizen science has suggested a key role of egoistic affective goals, like fun and the experience of participating in a meaningful activity (Singh et al. 2014; Raddick et al. 2010). So, to address affective parts of motivation in designing for large-scale participation, many recent citizen science projects have introduced elements of gamification (Dickinson et al. 2012). Gamification refers to the application of design elements from games to a non-game context, with the end goal of improving the user experience, and, eventually, motivating participation (Deterding 2011). Empirical research demonstrates that gamification can encourage some people to use an application more often (Thom et al. 2012) and to derive greater enjoyment from their use of an application (Fitz-Walter et al. 2011; Flatla et al. 2011).

One simple way to gamify citizen science is to provide extrinsic incentives such as score boards, badges or progressive ranks. But many projects rely on more sophisticated motivational design. For example, the citizen science project eBird provides game-type incentives like personal bird lists, user rankings or rare bird alerts, the introduction of which contributed to a strong increase in participant numbers (Wood et al. 2011). These incentives draw on intrinsic motivation rather than the extrinsic motivation of scoreboards and social rewards. Many successful citizen science projects rely on intrinsic motivation, like participants' interest in learning, developing skills, and social exchange (Land-Zandstra et al. 2016a; Curtis 2015; Rotman et al. 2012). We are specifically interested in the relation between intrinsic and extrinsic motivation in farmer citizen science.

The goal of our research is to contribute to the design and development of citizen science methodologies for the agricultural sciences that can effectively engage high numbers of smallholder farmers in developing countries. According to Nov et al. (2011b), digital citizen science is founded on two facilitating pillars: motivational and technological. Our specific objectives are therefore to assess 1) farmers' motivations to participate as citizen scientists and 2) farmers' mobile telephone usage. Although the mantra "easy, fun and social" (Dickinson et al. 2012) points the way, more context-specific analysis is needed. As citizen science methodologies for the agricultural sciences are just emerging, it is questionable to what extent insights from motivational studies with participants in citizen science projects from other disciplines may be generalized. Given the strong link of the research topic to their families' livelihoods, farmers' motivation may differ substantially from the motivation 
revealed in previous studies, where participants usually engaged as a leisuretime activity. Thus, to be able to design methodologies for large-scale agricultural citizen science, it is crucial to understand what motivates participants.

We draw insights from citizen science projects of crop variety trials which implement 'triadic comparison of technologies' (tricot). In this project, farmers participate by planting three varieties of one crop on their own farms, and reporting simple observations to an implementing body, like an NGO or a research organization (Van Etten et al. 2016; van Etten 2011). Data and information exchange is already facilitated by mobile phone technology, which we see as a simple technological interface that allows observing opportunities and constraints of future digitalized citizen science trials in practice.

In order to derive conclusions that may contribute to design principles for agricultural citizen science, we were interested in what are the roles of different drivers of motivation for the engagement of participants. We therefore assessed the relative importance of egoistic, collectivistic, and altruistic motives. Motivation may not be homogeneous among participants: individual differences in, for example, age, gender, education level or country may influence what motivates participants (and what does not). When different groups of participants can be distinguished by their motivation, citizen science projects may be specifically designed to offer different roles for participants, with different types of participation. Hence, we tested for interactions between motivation and farmers' characteristics. We addressed the following research questions: What motivates farmers to participate in agricultural citizen science? Which different groups of participants can be distinguished with regard to their motivation?

To be able to make statements about potential future use of communication technology in citizen science, it is vital to understand opportunities and constraints related to the use of mobile phone technology by current participants in citizen science, who represent an already-motivated subsample. We studied the habits in usage of mobile phones, as well as the availability and distribution of related resources like literacy and airtime credit among participants in tricot. Here, too, it is interesting to identify discrete groups of participants, since different roles and different types of participation in the citizen science project may also be offered in order to address the variety of technology user profiles. With our research, we want to answer the following questions: In what ways are mobile phones used by participants in citizen science? Which opportunities and constraints does this experience bring along? We then conclude by analysing how these findings may translate into design principles for agricultural citizen science projects. 


\subsection{Material and Methods}

\subsubsection{Seeds for Needs initiative}

Seeds for Needs is a Bioversity International initiative involving more than 20,000 smallholder farmers in 14 countries (Figure 3.1), to explore how agricultural biodiversity can minimize the risks associated with climate variability (www.bioversityinternational.org/seeds-for-needs/). The main idea of the initiative is: if farmers have the opportunity to access better information and different varieties, they are better able to choose what is appropriate for their conditions and cope with unpredictable weather (Van Etten et al. 2016; van Etten 2011). The Seeds for Needs initiative addresses the issue of access to information and seed variety by exposing farmers to more crop varieties and increasing their knowledge about different traits. Since 2011, the initiative has been using a crowdsourcing approach called triadic comparisons of technologies (tricot): each farmer receives three randomly-assigned varieties from a larger pool of varieties, to compare with their own varieties. By carrying out these onfarm mini-trials with a small number of varieties, many farmers can participate voluntarily as citizen scientists. The initiative involves farmers directly in evaluating and selecting varieties, and provides valuable feedback about preferred traits to researchers. Mobile phones are also used by the initiative to communicate with farmers. Weather sensors, known as iButtons, have been setup in farmers' fields to record local temperature and humidity (Mittra et al. 2015). The collected data is compared with feedback from farmers on crop performance. The ClimMob data analysis software has been developed to help identify trends and give farmers feedback based on the collected data (Van Etten et al. 2016). The participation of farmers is voluntary.

\subsubsection{Study areas}

We chose India, Ethiopia and Honduras to explore the motivation of the farmers to participate in crop improvement trials using the crowdsourcing approach as citizen scientists. The main reason why we focused on these three countries is because of their geographical locations (in three continents) and duration of the Seeds for Needs initiative. The initiative has been testing the crowdsourcing for crop improvement trial approach in these three countries at least since 2013.

\subsubsection{India}

The Seeds for Needs initiative started with 10 farmers in 2010. The crowdsourcing approach was first implemented in 2012 and, within three years, included 15,000 rice and wheat growing farmers in 24 districts in four 
states (Mittra et al. 2015). For the current research, data were collected from 300 farmers in 30 villages from Muzaffarpur $\left(26.17^{\circ} \mathrm{N}, 85.42^{\circ} \mathrm{E}\right)$, Samastipur $\left(25.86^{\circ} \mathrm{N}, 85.78^{\circ} \mathrm{E}\right)$ and Vaishali $\left(25.99^{\circ} \mathrm{N}, 85.13^{\circ} \mathrm{E}\right)$ districts in the state of Bihar.
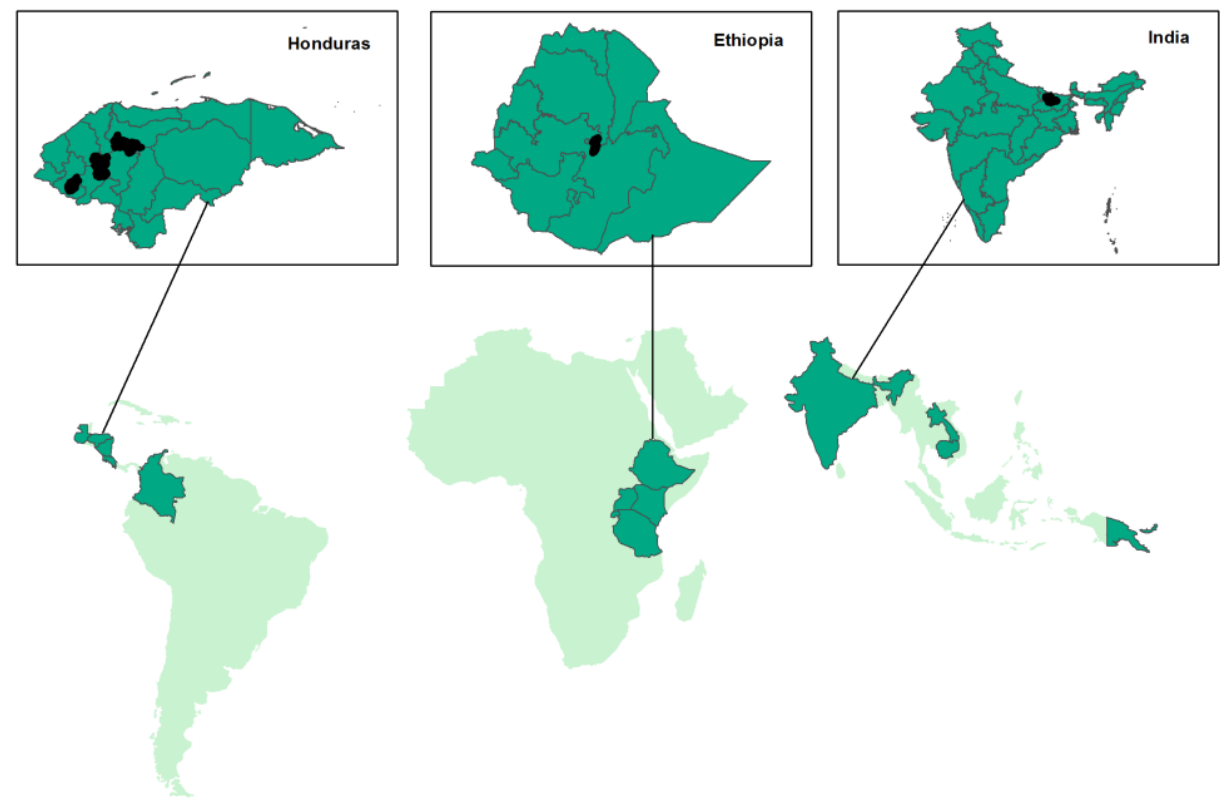

Figure 3.1: Overview of countries where the Seeds for Needs initiative is running (lower map) and locations in Honduras, Ethiopia and India (upper insets) where the surveys were conducted (black polygons inside the three countries).

\subsubsection{Ethiopia}

The Seeds for Needs initiative first started in Ethiopia in 2009. From 25,000 accessions of durum wheat and barley, 500 were short listed using Geographic Information System (GIS) technology and characterization. Out of this short list, farmers and scientists selected 50 to test for local adaptation. The crowdsourcing approach was first tested in two areas involving 200 farmers in 12 villages covering $350 \mathrm{~km}^{2}$ with different climatic conditions. Currently the project is working with more than 1500 farmers. For our current research, data were collected from 94 farmers in 9 Kebele's (smallest administrative unit) from Gimbichu $\left(8.83^{\circ} \mathrm{N}, 39.17^{\circ} \mathrm{E}\right)$ and Lume districts $\left(8.58^{\circ} \mathrm{N}, 39.17^{\circ} \mathrm{E}\right)$ of the Oromia Region. 


\subsubsection{Honduras}

The Bean Research Program at Zamorano, a private agricultural school, has collaborated with two local NGOs in the diffusion and evaluation of 18 traditional and improved varieties of common bean within Seeds for Needs, from 2013 to 2015. Around 200 farming households in four different regions participated in the project. For this research, data were collected from 32 farmers in 9 municipalities from Comayagua $\left(14.46^{\circ} \mathrm{N}, 87.65^{\circ} \mathrm{W}\right)$, Intibucá $\left(14.32^{\circ} \mathrm{N}, 88.15^{\circ} \mathrm{W}\right)$, Lempira $\left(14.58^{\circ} \mathrm{N}, 88.58^{\circ} \mathrm{W}\right)$, Santa Barbará $\left(14.91^{\circ} \mathrm{N}\right.$, $\left.88.23^{\circ} \mathrm{W}\right)$ and Yoro $\left(15.13^{\circ} \mathrm{N}, 87.1^{\circ} \mathrm{W}\right)$ departments.

\subsubsection{Theoretical framework}

Motivation is a concept used in behavioural science to explain the "initiation, direction, intensity, persistence, and quality" of behaviour (Brophy 2004). We follow the definition by Brophy (2004), where motives are "hypothetical constructs used to explain why people are doing what they are doing". Participation in research is necessarily participation in collective action, and Batson et al. (2002) proposed four types of motives for participation in activities with collective goals: egoism (the ultimate goal of involvement is increasing one's own welfare), altruism (increasing other persons' welfare), collectivism (increasing the welfare of a group one belongs to), and principlism (to uphold one or more moral principles). In this study, we assess the importance of these types of motives for farmers' engagement in a citizen science project.

We distinguish egoistic motivation driven by intrinsic motives, which involves inherent satisfaction, and extrinsic motives, which are believed to lead to some desirable, separable outcome (Ryan and Deci 2000a). This study applies incentive theory to study motivation, seeing human beings as fundamentally active, proactively pursuing goals, and responsive in their behaviour to external reinforcement, i.e., incentives (Laffont and Martimort 2001). Therefore, we seek to identify the most important incentives that researchers may set to increase farmer participation in citizen science.

\subsubsection{Survey design: Selection of motivational factors}

As starting point for this study, a literature study about the motivation of people to participate in different crowdsourcing and citizen science activities was conducted. Motivational factors identified by previous studies were used as a starting point to develop a questionnaire for semi-structured interviews (Table 3.1). 
What are the prospects for citizen science in agriculture? Evidence from three continents on motivation and mobile telephone use of resource-poor farmers

Table 3.1: Motivational factors identified by previous studies and used in this study. Typology is based on the framework of Batson et al. (2002).

\begin{tabular}{|c|c|c|c|c|}
\hline No. & $\begin{array}{l}\text { Motivational } \\
\text { factors }\end{array}$ & Code & $\begin{array}{l}\text { Type(s) of } \\
\text { motivation }\end{array}$ & References \\
\hline Mot 1 & $\begin{array}{l}\text { Want to } \\
\text { contribute to } \\
\text { scientific } \\
\text { research }\end{array}$ & Contributing & Collectivistic & $\begin{array}{l}\text { (Land-Zandstra et } \\
\text { al. 2016a; Curtis } \\
\text { 2015; Raddick et al. } \\
\text { 2013; Raddick et al. } \\
\text { 2010; Holohan and } \\
\text { Garg 2005). }\end{array}$ \\
\hline Mot 2 & $\begin{array}{l}\text { Wish to pass } \\
\text { free time (fun) }\end{array}$ & Pastime & $\begin{array}{l}\text { Egoistic } \\
\text { (Intrinsic) }\end{array}$ & $\begin{array}{l}\text { (Schunko et al. } \\
\text { 2015; Curtis 2015; } \\
\text { Raddick et al. 2010; } \\
\text { Brabham 2008). }\end{array}$ \\
\hline Mot 3 & $\begin{array}{l}\text { Interest in } \\
\text { sharing } \\
\text { information }\end{array}$ & $\begin{array}{l}\text { Sharing } \\
\text { info }\end{array}$ & $\begin{array}{l}\text { Egoistic } \\
\text { (Intrinsic) }\end{array}$ & $\begin{array}{l}\text { (Land-Zandstra et } \\
\text { al. 2016a). }\end{array}$ \\
\hline Mot 4 & $\begin{array}{c}\text { Expectation of } \\
\text { something in } \\
\text { return }\end{array}$ & Expectation & $\begin{array}{l}\text { Egoistic } \\
\text { (Extrinsic) }\end{array}$ & $\begin{array}{l}\text { (Johnson et al. } \\
2014 ; \text { Holohan and } \\
\text { Garg 2005). }\end{array}$ \\
\hline Mot 5 & $\begin{array}{c}\text { Interest in } \\
\text { networking } \\
\text { with experts }\end{array}$ & $\begin{array}{c}\text { Expert } \\
\text { interaction }\end{array}$ & $\begin{array}{l}\text { Egoistic } \\
\text { (Extrinsic) }\end{array}$ & (Rotman et al. 2012) \\
\hline Mot 6 & $\begin{array}{l}\text { Interest in } \\
\text { networking } \\
\text { with other } \\
\text { community } \\
\text { members }\end{array}$ & $\begin{array}{l}\text { Community } \\
\text { interaction }\end{array}$ & $\begin{array}{l}\text { Egoistic } \\
\text { (Extrinsic) }\end{array}$ & $\begin{array}{l}\text { (Schunko et al. } \\
\text { 2015; Johnson et al. } \\
\text { 2014; Raddick et al. } \\
\text { 2010; Brabham } \\
\text { 2010; Krebs 2010; } \\
\text { Brabham 2008). }\end{array}$ \\
\hline Mot 7 & $\begin{array}{l}\text { Wish to help } \\
\text { the } \\
\text { researcher(s) }\end{array}$ & Helping & Altruistic & $\begin{array}{l}\text { (Curtis 2015; } \\
\text { Rotman et al. 2012; } \\
\text { Raddick et al. 2010; } \\
\text { Krebs 2010; Batson } \\
\text { et al. 2002). }\end{array}$ \\
\hline
\end{tabular}

We interviewed farmers about their motivation to participate in the citizen science project using a semi-structured interview format. We asked farmers whether they were interested in continuing participation in the future, and to elaborate their answer. Then, we presented the seven potential motivational factors for participation (Table 3.1), including intrinsic and extrinsic egoistic, as well as collectivistic and altruistic motivational factors, and asked for the 
level of importance of each motivational factor for their personal motivation to participate in crop variety trials.

In addition, three open questions about motivation were included in the survey. Firstly, respondents were given the opportunity to express additional motivational factors that were not included in the options. Secondly, farmers who had ranked motivational factor 4 (I participate because I expect something in return from the expert) "Important" or "Very important" were asked to specify the incentives they expected from the expert or from the citizen science process.

Lastly, farmers were asked whether they would expect a reward (Yes/No) for sharing farm information in the future. Respondents answering "Yes" were asked to specify the type of preferred reward they would like to receive. The latter question was asked only in India and Ethiopia.

\subsubsection{Data collection}

In 2014 and 2015, we conducted 426 face-to-face structured interviews in three countries; India (300), Ethiopia (94), and Honduras (32). In India, farmers who had participated in more than two growing seasons were selected and data collection was carried out by junior agronomists working for Bioversity International-India. In Ethiopia, researchers and agricultural extension workers of the Ethiopian Biodiversity Institute selected the farmers for interview, giving preference to individuals who had participated in the trials for more than one growing season. The first author conducted the interviews together with project team members of the Ethiopian Biodiversity Institute. In Honduras, farmers were selected by local NGO extension workers, and the second author carried out the interviews. The selection of participants was determined by ongoing activities of the local NGO and no explicit criteria were used to select farmers.

During the structured interview, motivational factors (Table 3.1) were read to each farmer one by one in their local language and each farmer was asked to mark if they apply to his/her personal motivations for participation in the crowdsourcing for crop improvement trials. Farmers were asked to rank the motivational factors using Likert scales with the values 1 ("Not important at all"), 2 ("Not important"), 3 ("Neutral"), 4 ("Important") and 5 ("Very important"). Farmers' characteristics (age, education level, head of household (Yes/No) and gender) and use of mobile phones were also collected during the interview (see S1 Appendix for a complete list of questions). 


\subsubsection{Data analysis}

\subsubsection{Quantitative data analysis}

Data were first analysed by frequencies and percentages. Comparisons of motivational factors within each of the three countries were performed using Friedman's test, a non-parametric model used to test for differences between groups across multiple conditions. This was followed by post-hoc pairwise comparisons using the Wilcoxon signed-rank test. Comparisons of motivational factors between the three countries were performed using the Kruskal-Wallis test followed by post-hoc pairwise comparisons using the Dunn-Bonferroni approach. The Kruskal-Wallis test is a non-parametric statistical test that assesses differences among three or more independently sampled groups on a single, non-normally distributed continuous variable (Kruskal and Wallis 1952). The test can deal with non-normally distributed data (e.g., ordinal or rank data) (McKight and Najab 2010). For both tests, the level of significance was set at 0.05 and Bonferroni adjustment was used to account for multiple comparisons (Rice 1989).

Principal Component Analysis (PCA) was used to group the motivational factors into smaller sets of groups and also to assess the correlation between the motivational factors. We determined how different types of motivation can be explained with farmers' characteristics (gender, age, education level, household head (Y/N) and country) using Generalized Linear Models (GLM). To create the GLMs, we chose the linear model type, included only main effects, and selected Type III analyses, Wald statistics, and a significance level of $p=$ 0.05 for identifying significant relations.

In addition, Redundancy analysis (RDA) was used to identify the most important farmers' characteristics that explain the variation of farmers' motivations in the three countries. RDA can assess how much of the variation in the motivational factors values can be explained by the farmers' characteristics. The suitability of RDA was first identified by a detrended correspondence analysis (DCA) to obtain the gradient length of response variables (Šmilauer and Lepš 2014). The linear ordination method (RDA) was suggested because of the small gradient length $(0.8 \mathrm{SD})$. By using the manual forward selection procedure of Canoco advisor (an expert system built into Canoco 5) (Šmilauer and Lepš 2014), the statistical significance of each of the farmers' characteristics included in the model was calculated by performing Monte Carlo permutation tests (499 unrestricted permutations), testing against the null hypothesis that the factor does not add to the explanation of the motivation data. In this stepwise selection, we chose factors with a threshold of $p<0.05$ for retention in the model. Moreover, the score scaling 
type was set to focus on response variable correlations, and response variable scores were divided by standard deviations (ك̌milauer and Lepš 2014).

The relative relationship between motivational factors (response variables) and farmers' characteristics (explanatory variables) were demonstrated using triplot diagrams. In the RDA triplot, the correlation between motivational factors and farmers' characteristics is given by the cosine of the angle between the two vectors ( ̌́milauer and Lepš 2014). Vectors crossing at right angles indicate a near zero correlation, vectors pointing in the same direction indicate a positive correlation, while vectors pointing in opposite direction show a high negative correlation.

For the last three analyses (i.e., for GLM, PCA and RDA) normalized Likert scale data were used. Missing values were treated as missing listwise in the calculations. All non-parametric tests and GLMs were performed using SPSS version 22 and multivariate analyses (PCA and RDA) were performed using Canoco 5.

\subsubsection{Qualitative data analysis}

To identify the main motives, effective incentives and farmers' expectations from experts, the responses from the open-ended survey questions were subjected to a qualitative content analysis method. The open-ended survey questions about farmers' additional motivations, expectations and types of rewards farmers would like to receive for sharing agronomic information were analysed qualitatively. This analytical approach involves a close examination of textual data, which is explored inductively for emerging themes relating to the same central meaning (Graneheim and Lundman 2004). These themes were grouped into coding units, counted and presented graphically. Responses from open-ended questions were analysed using Atlas.ti 7 (Muhr 1991).

\subsubsection{Mobile phone usage}

Farmers' current and preferred use of mobile phone was analysed using frequency and percentage analysis.

\subsubsection{Ethical Statement}

Prior to beginning of the study, approval was obtained from both the Laboratory of Geo- information Science and Remote Sensing-Wageningen University, The Netherlands and Bioversity international Seeds for Needs initiative scientific project leaders. Our university does not require prior ethical approval from the Social Sciences Ethics Committee for a study like this. The people who are asked to participate are not specifically vulnerable, and the interview questions were not sensitive. Oral informed consent was obtained 
What are the prospects for citizen science in agriculture? Evidence from three continents on motivation and mobile telephone use of resource-poor farmers

from all respondents, who were already participating in the ongoing broader Seeds for Needs project. In Ethiopia, following the ABS proclamation 482-2006 of the Ethiopian government, farmers were interviewed after getting the necessary permission from local agricultural office administrators.

\subsection{Results}

\subsubsection{Quantitative analysis}

\subsubsection{Demography of farmer communities}

The average age of the respondents in the three countries was similar; respondents were 47 years old on average (standard deviation $(\mathrm{SD})=12$, range: 14-80 years) (Table 3.2). The majority of the respondents were male (83\%). Furthermore, $90.8 \%$ of the respondents were head of the household. The respondents had different educational levels. Indian farmers in our sample were more educated than Ethiopian and Honduran farmers.

Table 3.2: Demographic characteristics of the surveyed farmers in the three countries.

\begin{tabular}{lcccccc}
\hline Variable & \multicolumn{2}{c}{$\begin{array}{c}\text { India } \\
(\mathrm{n}=300)\end{array}$} & \multicolumn{2}{c}{$\begin{array}{c}\text { Ethiopia } \\
(\mathrm{n}=94)\end{array}$} & \multicolumn{2}{c}{$\begin{array}{c}\text { Honduras } \\
(\mathrm{n}=32)\end{array}$} \\
\hline Average age \pm SD & \multicolumn{2}{c}{$47 \pm 13$} & \multicolumn{2}{c}{$48 \pm 11$} & \multicolumn{2}{c}{$46 \pm 14$} \\
\hline Gender & Count & $\%$ & Count & $\%$ & Count & $\%$ \\
\cline { 2 - 7 } Male & 238 & 79 & 85 & 90 & 29 & 91 \\
Female & 62 & 21 & 9 & 10 & 3 & 9 \\
\hline Education level & Count & $\%$ & Count & $\%$ & Count & $\%$ \\
\cline { 2 - 7 } Illiterate & 58 & 19.4 & 15 & 16.0 & 3 & 9.4 \\
Can read \& write & 84 & 28.0 & 41 & 43.7 & 5 & 15.6 \\
Primary school & 3 & 1.0 & 24 & 25.5 & 15 & 47.0 \\
Secondary school & 118 & 39.3 & 14 & 14.8 & 0 & 0 \\
Higher education & 34 & 11.3 & 0 & 0 & 0 & 0 \\
Missing & 3 & 1.0 & 0 & 0 & 9 & 28.0 \\
\hline Household head & Count & $\%$ & Count & $\%$ & Count & $\%$ \\
\cline { 2 - 7 } Yes & 263 & 87.7 & 93 & 98.9 & 31 & 96.9 \\
No & 31 & 10.3 & 1 & 1.1 & 1 & 3.1 \\
Missing & 6 & 2.0 & 0 & 0 & 0 & 0 \\
\hline
\end{tabular}




\subsubsection{Comparison of motivational factors within each country}

Among Indian farmers, the average response rates for the motivational factors 'Sharing info, 'Expectation', 'Expert interaction', 'Community interaction' and 'Helping' were similar (average score ranging from 4.38 to 4.52) (Figure 3.2). However, the value of the motivational factor 'Helping' was significantly higher than 'Sharing info' (Table 3.3). The Indian farmers valued their participation to 'Contributing' (4.86) significantly higher and 'Pastime' (3.66) was valued significantly less compared to the other motivational factors (Figure 3.2 and Table 3.3).

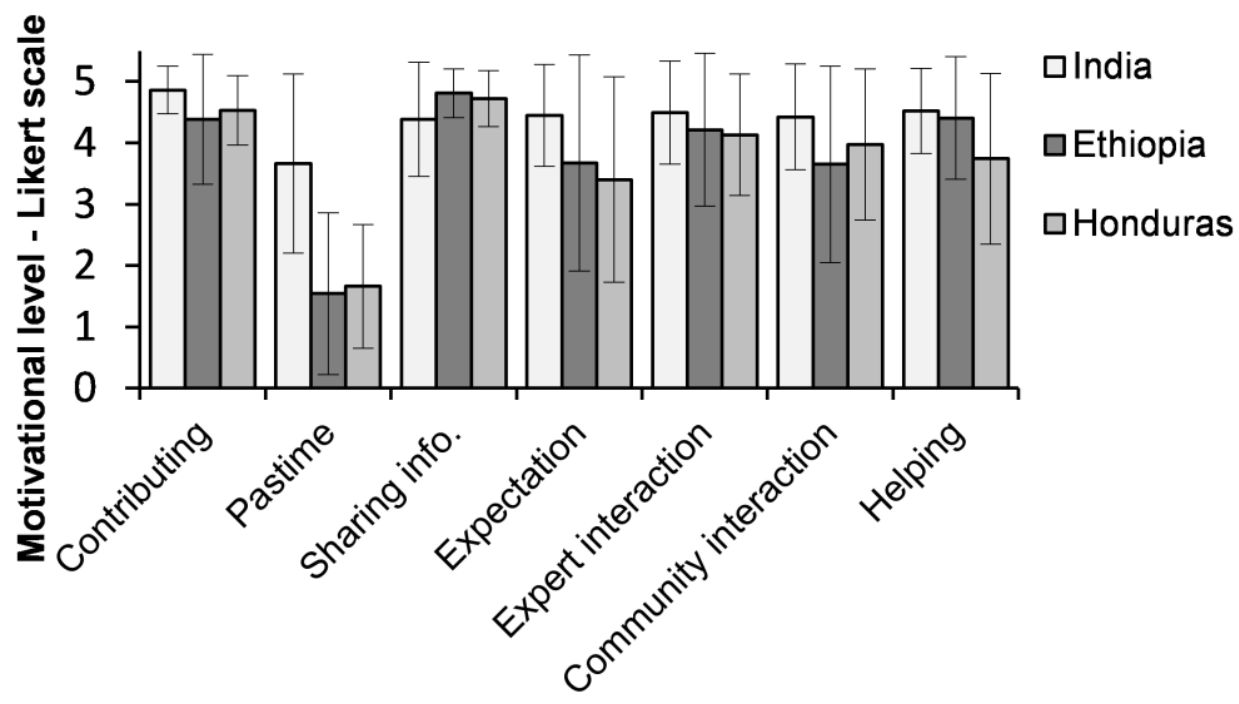

Motivational factors

Figure 3.2: Motivational factors of farmers in the three countries (India, Ethiopia and Honduras) to participate in the crop improvement trials as citizen scientists.

Among Ethiopian farmers, the motivational factor 'Sharing Info' was valued significantly higher and 'Pastime' was valued significantly less compared to the other motivational factors (Figure 3.2 and Table 3.3). After 'Sharing info', the motivations to 'Helping' and 'Contributing' were valued highest but not significantly different from 'Expert interaction' (Table 3.3). In addition to these two, 'Helping' and 'Expert interaction' were valued significantly higher than 'Community interaction'. 'Expectation' was valued lowest after 'Pastime' and 'Community interaction', but the value was not significantly different from 'Expert interaction' and 'Community interaction'. 
Results for Honduras were similar to Ethiopia. Also here, 'Sharing info' was valued highest, 'Contributing' second and, 'Pastime' lowest (Figure 3.2 and Table 3.3). The average rates for the motivational factors 'Expert interaction', 'Community interaction', 'Helping' and 'Expectation' were in between and similar (average score ranging from 3.38 to 4.13) (Figure 3.2). The high value for 'Contributing' and low value for 'Pastime' was also found in India, while 'Sharing info' was valued less in that country.

\subsubsection{Comparison of motivational factors between countries}

The results of the Kruskal-Wallis test show that the importance of different motivations differed between the three countries for all motivational factors (Table 3.4). Post-hoc pairwise comparisons using the Dunn-Bonferroni test revealed a large number of significant differences. For farmers in India 'Contributing' and 'Pastime', were more important than for farmers in Ethiopia and Honduras (Figure 3.2 and Table 3.4). Ethiopian farmers found 'Sharing info' more important for their motivation than Indian farmers, while the difference between Honduras and India was not significant. 'Expectation' was valued higher by farmers in India than farmers in Honduras and the difference with Ethiopia was almost significant. Also 'Expert Interaction' was more motivating for Indian farmers than for Honduran farmers, and 'Community Interaction' was more motivating in India than in Ethiopia. Extrinsic egoistic motivations (Table 3.1) were thus more important in India than in Honduras and Ethiopia. Lastly, 'Helping' was more motivating to Indian and Ethiopian farmers than to Honduran farmers. 
Table 3.3: Differences of the motivational factors of farmers within each of the three countries' using Friedman's test and post-hoc Wilcoxon signed-rank test. For codes of motivational factors see Table 3.1.

\begin{tabular}{|c|c|c|c|c|c|c|c|c|c|c|c|c|}
\hline \multirow[b]{2}{*}{ Comparisons } & \multicolumn{4}{|c|}{ India } & \multicolumn{4}{|c|}{ Ethiopia } & \multicolumn{4}{|c|}{ Honduras } \\
\hline & $\mathrm{N}$ & $\mathrm{T}$ & $\mathbf{r}$ & $\begin{array}{c}p^{-} \\
\text {Value }\end{array}$ & $\mathrm{N}$ & $\mathrm{T}$ & $\mathbf{r}$ & $\begin{array}{l}p- \\
\text { Value }\end{array}$ & $\mathrm{N}$ & $\mathrm{T}$ & $\mathbf{r}$ & $\begin{array}{l}p- \\
\text { Value }\end{array}$ \\
\hline Contributing - Pastime & 282 & 12.23 & 0.45 & $0.000^{\star *}$ & 94 & 3331.5 & 0.57 & $0.000^{* *}$ & 32 & 465 & 0.61 & $0.000^{* *}$ \\
\hline Contributing - Sharing & 281 & 5409 & 0.37 & $0.000^{* *}$ & 94 & 762 & 0.24 & $0.001^{* *}$ & 32 & 58.5 & 0.22 & 0.083 \\
\hline Contributing - Expectation & 276 & 3917.5 & 0.02 & $0.000^{* *}$ & 94 & 1022.5 & 0.22 & $0.002^{* *}$ & 30 & 220.5 & 0.40 & $0.002^{* *}$ \\
\hline Contributing - Expert interaction & 284 & 3424 & 0.31 & $0.000^{* *}$ & 94 & 455 & 0.09 & 0.206 & 31 & 92 & 0.25 & 0.049 \\
\hline $\begin{array}{l}\text { Contributing - Community } \\
\text { interaction }\end{array}$ & 280 & 4471 & 0.35 & $0.000^{* *}$ & 94 & 1205.5 & 0.27 & $0.001^{* *}$ & 32 & 209.5 & 0.29 & 0.021 \\
\hline Contributing - Helping & 282 & 4087.5 & 0.33 & $0.000^{* *}$ & 94 & 414.5 & 0.01 & 0.950 & 31 & 116 & 0.32 & 0.011 \\
\hline Pastime - Sharing & 279 & 5.39 & 0.34 & $0.000^{* *}$ & 94 & 3734 & 0.62 & $0.000^{* *}$ & 32 & 496 & 0.62 & $0.000^{* *}$ \\
\hline - Expectation & 274 & 8.09 & 0.38 & & 94 & 1956 & 0.50 & $0.000^{* *}$ & 30 & 264 & 0.5 & $0.000^{* *}$ \\
\hline Pastime - Expert interaction & 282 & 8.68 & 0.37 & $0.000^{* *}$ & 94 & 3299 & 0.56 & $0.000^{* *}$ & 31 & 435 & 0.61 & $0.000^{* *}$ \\
\hline Pastime - Community interaction & 279 & 8.43 & 0.36 & & 94 & 2365 & 0.47 & & 32 & 431.5 & 0.59 & $0.000^{* *}$ \\
\hline Pastime - Helping & 281 & 8.85 & 0.40 & $0.000^{* *}$ & 94 & 3705.5 & 0.57 & $0.000^{* *}$ & 31 & 322.5 & 0.55 & $0.000^{* *}$ \\
\hline Sharing - Expectation & 273 & 1316.5 & 0.06 & 0.169 & 94 & 1004.5 & 0.38 & $0.000^{* \star}$ & 30 & 149.5 & 0.45 & $0.000^{\star *}$ \\
\hline - Expert ir & 281 & 1807 & 0.09 & 0.038 & 94 & 835 & 0.30 & $0.000^{* *}$ & 31 & 121 & 0.38 & 0.003 \\
\hline Sharing - Community interaction & 278 & 2105.5 & 0.04 & 0.402 & 94 & 1347 & 0.42 & $0.000^{* *}$ & 32 & 167.5 & 0.38 & $0.002^{* *}$ \\
\hline Sharing - Helping & 279 & 1818.5 & 0.14 & $0.000^{* *}$ & 94 & 625 & 0.25 & $0.001^{* *}$ & 31 & 120 & 0.44 & $0.001^{* *}$ \\
\hline Expectation - Exper & 276 & 1147 & 0.03 & 0.461 & 94 & 894 & 0.21 & 0.004 & 30 & 179 & 0.29 & 0.023 \\
\hline tion - Comn & 273 & 1376.5 & 0.04 & & 94 & 721 & 0.02 & 0.766 & 30 & 124 & 0.22 & 0.090 \\
\hline Expectation - Helping & 275 & 903 & 0.07 & & 94 & 1151 & 0.24 & $0.001^{* *}$ & 29 & 132 & 0.2 & 0.125 \\
\hline $\begin{array}{l}\text { Expert interaction - Community } \\
\text { interaction }\end{array}$ & 280 & 993 & 0.08 & 0.054 & 94 & 699.5 & 0.23 & $0.002^{* *}$ & 31 & 76 & 0.12 & 0.341 \\
\hline Expert interaction - Helping & 286 & 967 & 0.02 & 0.689 & 94 & 480.5 & 0.09 & 0.196 & 30 & 68 & 0.21 & 0.109 \\
\hline Community interaction - Helping & 279 & 1205 & 0.10 & 0.027 & 94 & 807 & 0.30 & $0.001^{* *}$ & 31 & 139.5 & 0.11 & 0.392 \\
\hline
\end{tabular}

*: Difference within a country was statistically significant at $(P<0.05)$.

**: Statistically significant difference detected at $P=0.002$ (after Bonferroni adjustment for multiple comparisons)

$\mathrm{N}$ : total number of respondents, $\mathbf{T}$ : test statistics for Wilcoxon signed-rank test, $\mathbf{r}$ : effect size 
What are the prospects for citizen science in agriculture? Evidence from three continents on motivation and mobile telephone use of resource-poor farmers

Table 3.4: Comparisons of motivational factors of farmers between the three countries using the Kruskal-Wallis test followed by pairwise comparisons using the Dunn-Bonferroni test.

\begin{tabular}{|c|c|c|c|c|c|c|c|}
\hline \multirow{2}{*}{$\begin{array}{l}\text { Motivational } \\
\text { factor }\end{array}$} & \multirow{2}{*}{$\mathrm{N}$} & \multicolumn{3}{|c|}{ Kruskal-Wallis test } & \multicolumn{3}{|c|}{$\begin{array}{c}\text { Pairwise comparisons using Dunn- } \\
\text { Bonferroni test }\end{array}$} \\
\hline & & $\mathbf{H}$ & $d f$ & $\begin{array}{c}p \\
\text { Value }\end{array}$ & & $\begin{array}{l}- \\
\text { Value }\end{array}$ & $\mathbf{r}$ \\
\hline \multirow{3}{*}{ Contributing } & \multirow{3}{*}{410} & \multirow{3}{*}{39.15} & \multirow{3}{*}{2} & \multirow{3}{*}{$0.000^{*}$} & India-Ethiopia & $0.000^{* *}$ & -0.28 \\
\hline & & & & & Ethiopia-Honduras & 1.000 & 0.04 \\
\hline & & & & & India-Honduras & $0.000^{* *}$ & -0.22 \\
\hline \multirow{3}{*}{ Pastime } & \multirow{3}{*}{408} & \multirow{3}{*}{152.47} & \multirow{3}{*}{2} & \multirow{3}{*}{$0.000^{*}$} & India- Ethiopia & $0.000^{* *}$ & -0.58 \\
\hline & & & & & Ethiopia-Honduras & 1.000 & -0.03 \\
\hline & & & & & India-Honduras & $0.000^{* *}$ & -0.38 \\
\hline \multirow{3}{*}{ Sharing info } & \multirow{3}{*}{407} & \multirow{3}{*}{18.09} & \multirow{3}{*}{2} & \multirow{3}{*}{$0.000^{*}$} & India-Ethiopia & $0.000^{* *}$ & 0.21 \\
\hline & & & & & Ethiopia-Honduras & 1.000 & 0.07 \\
\hline & & & & & India-Honduras & 0.259 & 0.09 \\
\hline \multirow{3}{*}{ Expectation } & \multirow{3}{*}{400} & \multirow{3}{*}{14.68} & \multirow{3}{*}{2} & \multirow{3}{*}{$0.001^{*}$} & India-Ethiopia & 0.059 & -0.12 \\
\hline & & & & & Ethiopia-Honduras & 0.236 & 0.16 \\
\hline & & & & & India-Honduras & $0.002^{* *}$ & -0.19 \\
\hline \multirow{3}{*}{$\begin{array}{l}\text { Expert } \\
\text { interaction }\end{array}$} & \multirow{3}{*}{409} & \multirow{3}{*}{8.56} & \multirow{3}{*}{2} & \multirow{3}{*}{$0.014^{*}$} & India-Ethiopia & 0.561 & -0.07 \\
\hline & & & & & Ethiopia-Honduras & 0.220 & 0.16 \\
\hline & & & & & India-Honduras & $0.016^{* *}$ & -0.16 \\
\hline \multirow{3}{*}{$\begin{array}{l}\text { Community } \\
\text { interaction }\end{array}$} & \multirow{3}{*}{406} & \multirow{3}{*}{18.303} & \multirow{3}{*}{2} & \multirow{3}{*}{$0.000^{*}$} & India-Ethiopia & $0.000^{* *}$ & -0.21 \\
\hline & & & & & Ethiopia-Honduras & 1.000 & -0.03 \\
\hline & & & & & India-Honduras & 0.081 & -0.13 \\
\hline Helping & 407 & 12.92 & 2 & $0.002^{*}$ & India-Ethiopia & 1.000 & -0.01 \\
\hline & & & & & Ethiopia-Honduras & $0.004^{* *}$ & 0.28 \\
\hline & & & & & India-Honduras & $0.001^{* *}$ & -0.20 \\
\hline
\end{tabular}

*: Difference between the three countries was statistically significant at $(P=0.05)$.

${ }^{* *}$ : Statistically significant difference detected at $p=0.017$ (after Bonferroni adjustment for multiple comparisons)

$\mathrm{N}$ : total number of respondents, $\mathrm{H}$ : test statistics for Kruskal-Wallis test, $\boldsymbol{d} \boldsymbol{f}$. degree of freedom, r: effect size

\subsubsection{Relationships among motivational factors}

The result of the PCA of motivational factors revealed four components. The four components explained $81.7 \%$ of the variance (S2 Appendix A). The first two main components explained most of the variance (56.5\%) in the motivational factors. The first component accounted for $35 \%$ of the variance and comprised of four factors ('Sharing info', 'Helping', 'Contributing' and 'Pastime' (Figure 3.3). While 'Sharing info', 'Helping', and 'Contributing' contribute positively to this component, 'Pastime' was negatively related. The 
second component accounted for $21.5 \%$ of the variance and mainly associated with 'Expectation', 'Expert interaction' and 'Community interaction' and all were negatively related to the second component. The first component also reflects what was observed earlier: the generally high importance of 'Sharing info', 'Helping' and 'Contributing' and lower importance of 'Pastime'.

The vectors of the motivational factors 'Sharing info', 'Helping' and 'Contributing' point in the same direction, indicating a strong positive correlation between these three motivational factors (Figure 3.3). The correlation was specifically strong between 'Sharing info' and 'Helping'. This implies that farmers who were motivated to share information were also motivated to help researchers and contribute to scientific research and vice versa. On the other hand, the negative relation between the factors 'Sharing info', 'Helping' and 'Contributing' and 'Pastime' vectors, suggests that farmers who were motivated either to contribute to scientific research, to help researchers or had an interest in sharing information did not consider their participation as a pastime activity. The vectors of the motivational factors 'Expectation', 'Expert interaction' and 'Community interaction' points in the same direction, suggesting a strong positive correlation among these three motivational factors (Figure 3.3). Some vectors ('Pastime' and 'Expectation'; 'Contributing' and 'Expert interaction') cross nearly at right angle, suggesting a near zero correlation. The centroids of the supplementary variable (country) were closer for Ethiopia and Honduras than for India. This indicates that there was more similarity between Ethiopia and Honduras compared to India. 
What are the prospects for citizen science in agriculture? Evidence from three continents on motivation and mobile telephone use of resource-poor farmers

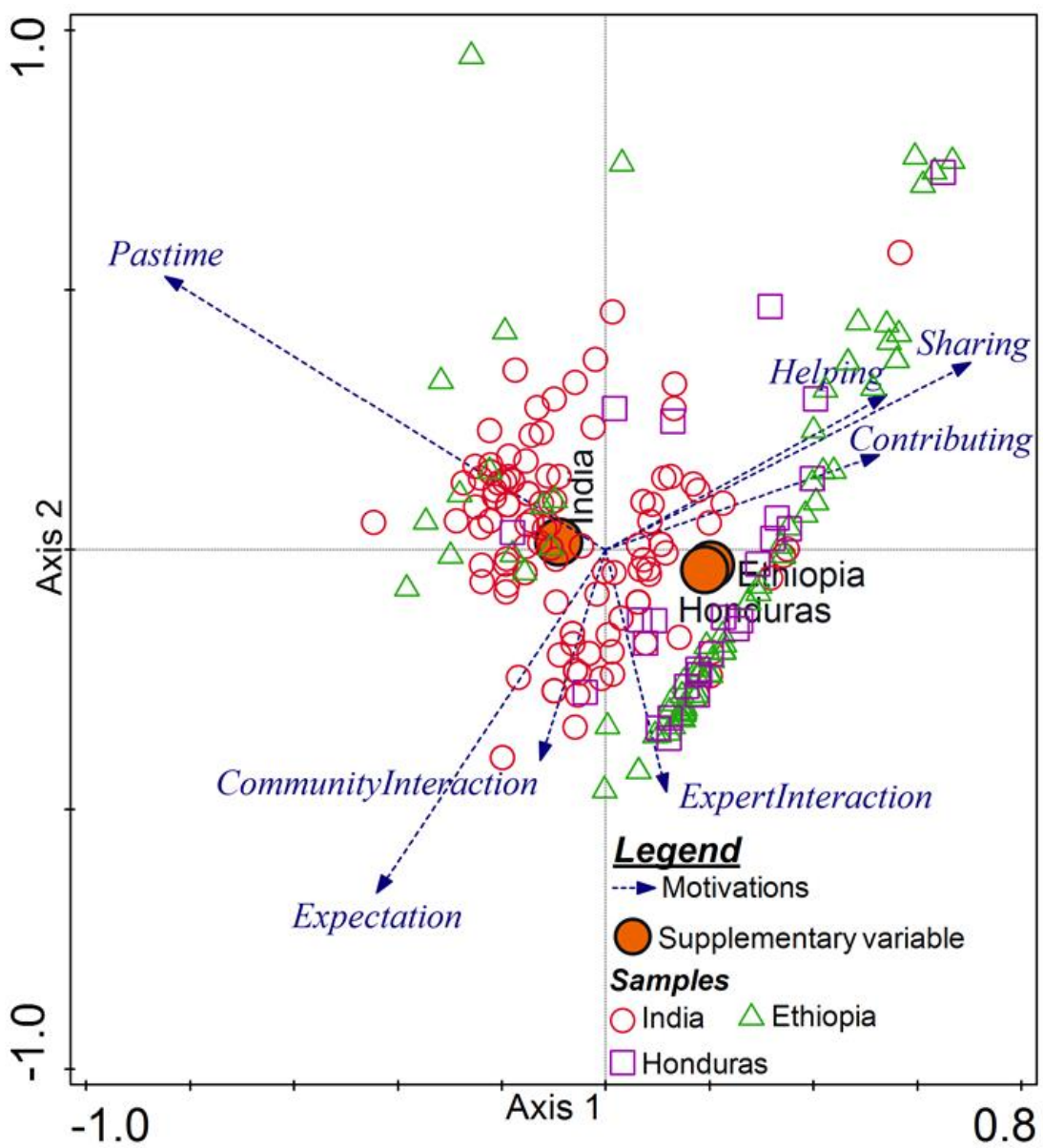

Figure 3.3: Triplot diagram showing the result of the PCA analysis of motivational factors using country as a supplementary variable (filled circle) together with samples from the three countries. The blue (dashed) vectors represent motivational factors. The circles (unfilled), triangles and squares represent samples from India, Ethiopia and Honduras, respectively.

\subsubsection{Relationship between motivational factors and farmers' characteristics}

The relationship between each of the motivational factors and farmers' characteristics was examined using Generalized Linear Models (GLM). For educated farmers (Regr $\mathrm{B}=0.009 ; p=0.000)$, contributing to scientific research was a more important factor to participate as citizen scientists compared to less educated farmers (Table 3.5). Women (Regr B $=0.020 ; p=0.004)$ and less 
educated farmers (Regr $\mathrm{B}=-0.008 ; p=0.000)$ valued their participation as 'Pastime' activity more than men and educated farmers. The relationship between gender and the motivational factor 'Sharing info' was almost significant (Regr $\mathrm{B}=-0.010 ; p=0.068$ ). This suggests that female farmers were less interested in sharing information compared to men farmers.

Redundancy Analysis (RDA) was used to identify the most important farmers' characteristics that explain the variation in the set of motivational factors (Figure 3.4). After stepwise forward selection by RDA, only two farmers' characteristics, country and education level, were retained $(p<0.05$, tested by Monte Carlo permutation). The factors country and education level explained $15 \%$ and $5 \%$ of the variation in the motivational factors respectively. The education level vector points in the same direction as the motivational factor 'Contributing' vector indicating a positive correlation between education level and farmers motivation to contribute to scientific research (Figure 3.4). On the other hand, the vector of education level points roughly in an opposite direction to the motivational factor 'Pastime' vector. This indicates that there was a negative correlation between education level and the motivational factor 'Pastime'. The vectors of the explanatory factor education level and the motivational factor 'Sharing info' cross nearly at right angle, suggesting a near zero correlation. These results also confirm what was observed earlier in the GLM analysis results (Table 3.5).

Table 3.5: Generalized linear model showing relationship between motivational factors and farmers' characteristics using pooled data from the three countries.

\begin{tabular}{|c|c|c|c|c|c|c|c|c|}
\hline \multirow{2}{*}{$\begin{array}{l}\text { Motivational } \\
\text { factors }\end{array}$} & \multicolumn{2}{|c|}{$\begin{array}{c}\text { Gender } \\
\text { (Male, Female) }\end{array}$} & \multicolumn{2}{|c|}{$\begin{array}{c}\text { Age } \\
\text { (in years) }\end{array}$} & \multicolumn{2}{|c|}{$\begin{array}{c}\text { Education } \\
\text { level }\end{array}$} & \multicolumn{2}{|c|}{$\begin{array}{c}\text { Household } \\
\text { Head } \\
\text { (Yes, No) }\end{array}$} \\
\hline & $\begin{array}{c}\text { Regr } \\
B^{a}\end{array}$ & $\begin{array}{c}P- \\
\text { Value }\end{array}$ & $\begin{array}{c}\text { Regr } \\
B\end{array}$ & $\begin{array}{c}P- \\
\text { Value }\end{array}$ & $\begin{array}{c}\text { Regr } \\
B\end{array}$ & $\begin{array}{c}P- \\
\text { Value }\end{array}$ & $\underset{B}{R e g r}$ & $\begin{array}{c}P- \\
\text { Value }\end{array}$ \\
\hline Contributing & 0.006 & 0.135 & 0.000 & 0.172 & 0.009 & $0.000^{*}$ & 0.007 & 0.247 \\
\hline Pastime & 0.020 & $0.004^{*}$ & 0.000 & 0.438 & -0.008 & $0.000^{*}$ & 0.011 & 0.283 \\
\hline Sharing Info & -0.010 & 0.068 & -0.000 & 0.717 & -0.003 & 0.115 & -0.004 & 0.637 \\
\hline Expectation & 0.008 & 0.159 & 0.000 & 0.965 & 0.001 & 0.627 & -0.005 & 0.511 \\
\hline $\begin{array}{l}\text { Expert } \\
\text { Interaction }\end{array}$ & -0.005 & 0.231 & 0.000 & 0.344 & 0.002 & 0.218 & -0.003 & 0.613 \\
\hline $\begin{array}{l}\text { Community } \\
\text { Interaction }\end{array}$ & -0.004 & 0.458 & 0.000 & 0.297 & 0.001 & 0.428 & -0.006 & 0.409 \\
\hline Helping & -0.007 & 0.107 & 0.000 & 0.156 & 0.001 & 0.596 & -0.008 & 0.221 \\
\hline
\end{tabular}


What are the prospects for citizen science in agriculture? Evidence from three continents on motivation and mobile telephone use of resource-poor farmers

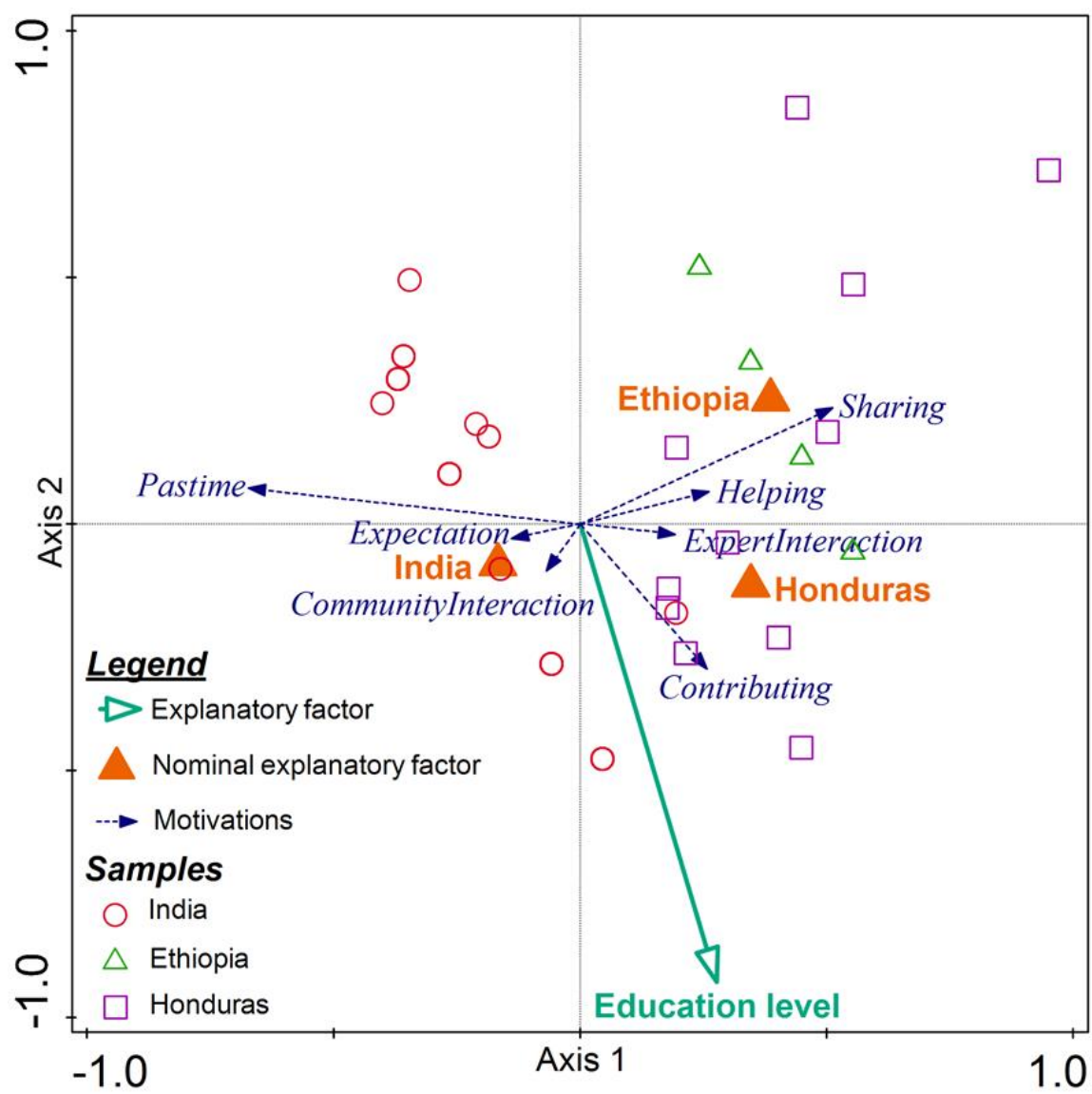

Figure 3.4: Triplot diagram showing the result of the RDA analysis of motivational factors and farmers' characteristics together with samples from the three countries. The blue (dashed) vectors represent motivational factors, green (solid) vector denotes the explanatory factor, education level and triangles (filled) represent the nominal explanatory variable, country.

\subsubsection{Qualitative analysis}

\subsubsection{What do farmers expect in return from the citizen science process (Expectation')?}

We asked farmers who had responded "Important" or "Very important" to the motivational factor 'Expectation' to specify their expectations. The main returns which farmers expect to receive from the citizen science process for participation in the crop improvement trials were: agronomic advice (e.g., weed 
management), capacity building (e.g., training) and seed innovation (e.g., improved seed) (Figure 3.5). In Ethiopia, 33\% of the farmers expected to receive agronomic advice. For farmers in Honduras, capacity building was the most important factor (50\%), while in India, seed innovation was what farmers $(44 \%)$ expected to receive. Production inputs (e.g., fertilizers) were expected by $9.4 \%$ of farmers in Honduras. Only in India, a few farmers mentioned that they would like to receive money (1\%) and weather information (1\%) in return. Around $3 \%$ of the farmers in India and Honduras and around $2 \%$ of the farmers in Ethiopia indicated that they expected to receive research results from the trials they participated in.

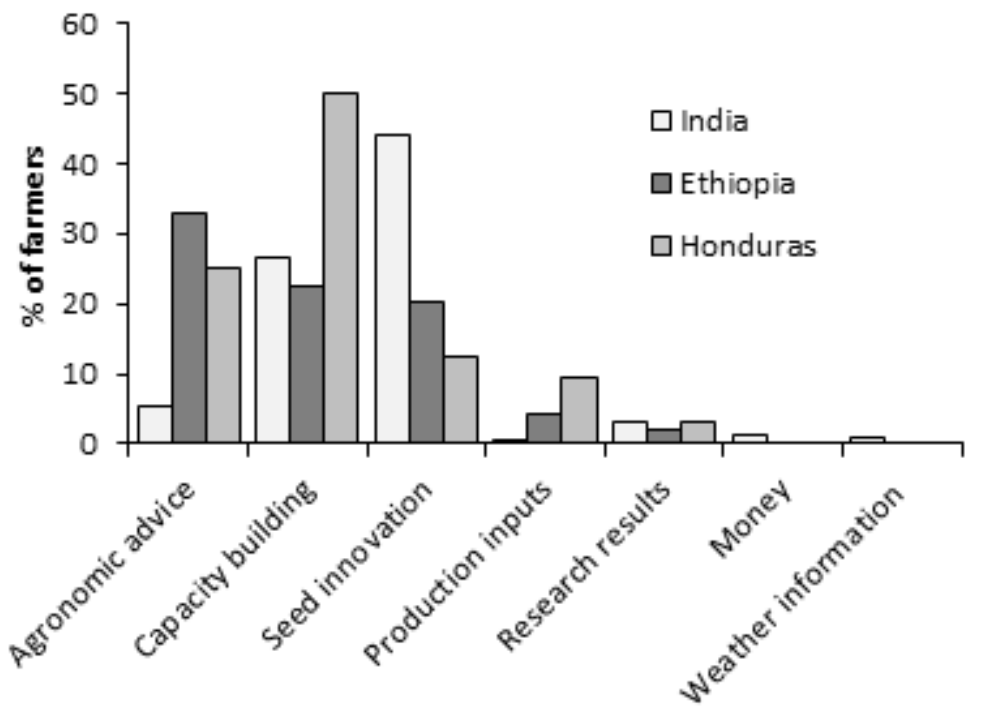

Figure 3.5: Factors which farmers expected from the citizen science process in return for their participation.

\subsubsection{Additional motivations}

Farmers were also asked for any additional motivations than the pre-defined motivations (Table 3.1) using an open-ended question. In Ethiopia, 24.5\% of the farmers mentioned production inputs (e.g., receive pesticides) as one of their motivations to participate in the crop improvement trials (Figure 3.6). Moreover, both expert recommendation and the desire for improved production were mentioned by $16 \%$ of the farmers. Beneficial previous experiences from research and capacity building were mentioned by $12.8 \%$ and $8.5 \%$ of the Ethiopian farmers respectively. The desire for improved production $(21.9 \%)$ and capacity building $(25 \%)$ were the two most mentioned motivations for 
farmers in Honduras. Seed innovation was the most mentioned motivation by Indian farmers (10\%). Around 1\% of Ethiopian and 3\% of Honduran farmers had the desire to help the researcher to accomplish his/her task.

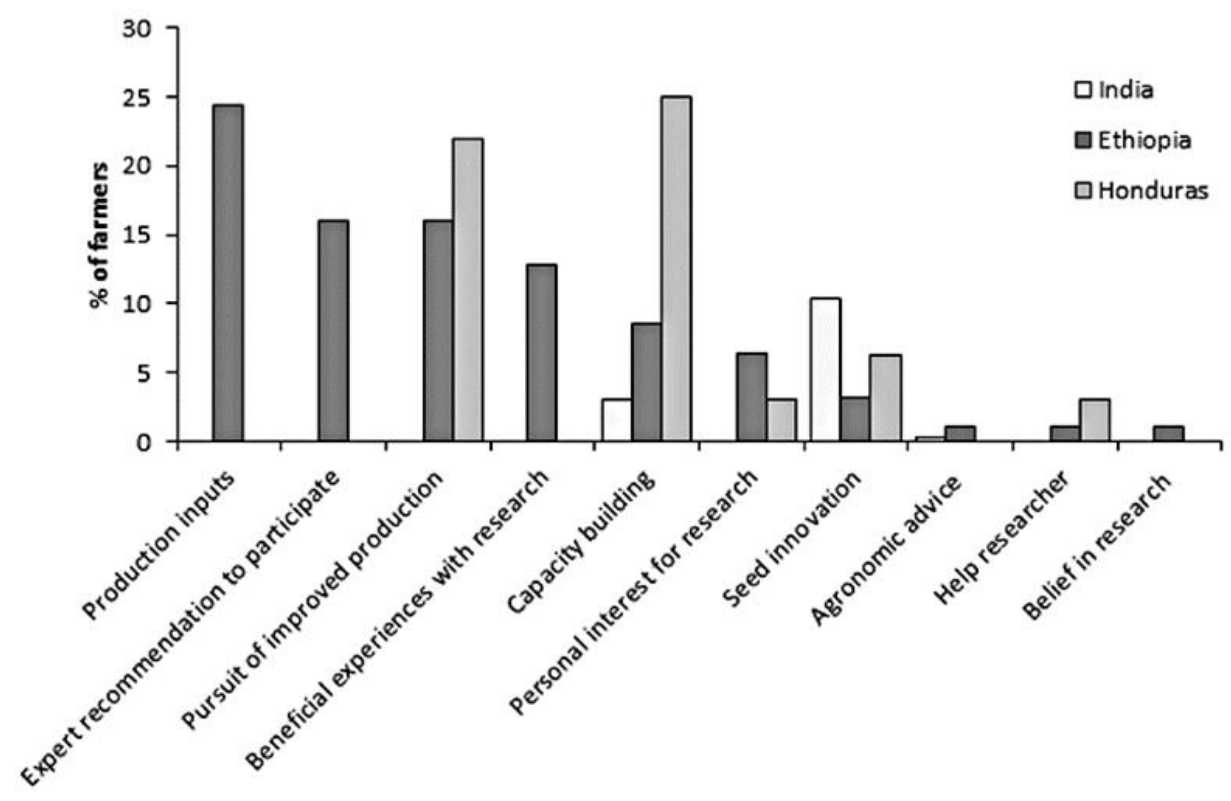

Figure 3.6: Additional motivations to participate in crop improvement trials using the crowdsourcing approach.

\subsubsection{What reward farmers expect for sharing agronomic information?}

The types of reward farmers would like to receive for sharing their agronomic information in the future was also identified using an open-ended question. Around $50 \%$ of the farmers in India and $44 \%$ in Ethiopia indicated that they do not expect any reward for sharing their agronomic information (Figure 3.7). However, around $42 \%$ of the farmers in Ethiopia indicated that they would like to receive agronomic information in return as a kind of reward. In India, the farmers that did indicate they expect reward, expected either seed innovation $(30 \%)$, capacity building $(25 \%)$ or money $(11 \%)$. Information related to market and weather were also mentioned by few farmers in Ethiopia. 


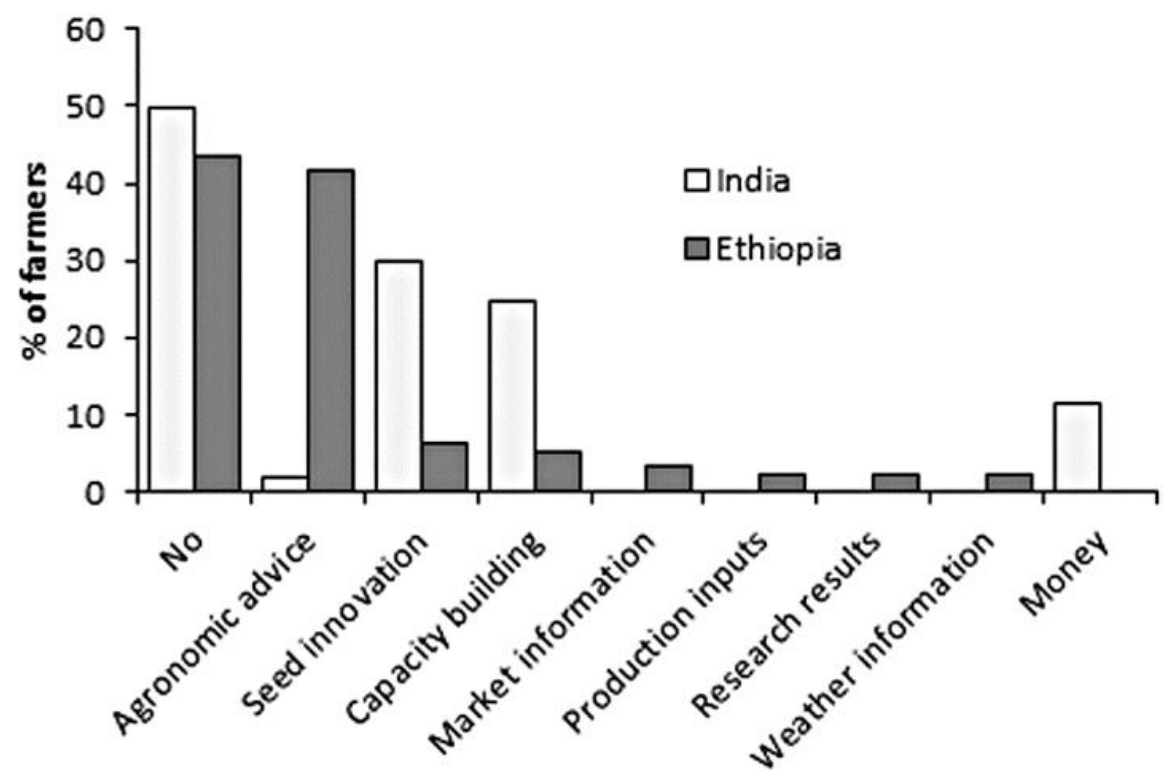

Figure 3.7: Types of rewards farmers would like to receive for sharing agronomic information.

\subsubsection{Current and preferred use of mobile phones by farmers}

More than $90 \%$ of the farmers in the three countries had mobile phones (Table 3.6). Around $59 \%$ in India, $52 \%$ in Ethiopia and $43 \%$ in Honduras "always maintain airtime" on their mobile phones. Making and receiving calls were the two most often used functions of the mobile phone in the three countries. Using the mobile phone to browse the internet was very low in Ethiopia (1\%) and Honduras (4\%), but also low in India (8\%). A majority of the farmers in all the three countries preferred calls over short message service (SMS) as a medium for communication. Farmers in Ethiopia used their mobile phones to access weather and market information more than Honduran and Indian farmers. Ethiopian farmers mainly used the calling feature of the phone to get market information from non-formal information channels (e.g., local traders, brokers and friends). Farmers in Ethiopia (77\%) also mentioned that they used their mobile phones to receive agricultural advice. The mobile phone was mainly used by the Ethiopian farmers to communicate with extension workers and receive information (e.g., availability of inputs) and also to get extension support. Farmers used their mobile phone to receive extension support in different stages of cultivation i.e., from pre-planting (e.g., land preparation advice) until harvesting (e.g., when to harvest the crop based on the weather condition). 
What are the prospects for citizen science in agriculture? Evidence from three continents on motivation and mobile telephone use of resource-poor farmers

Table 3.6: An overview of mobile phone usage variables in the three countries.

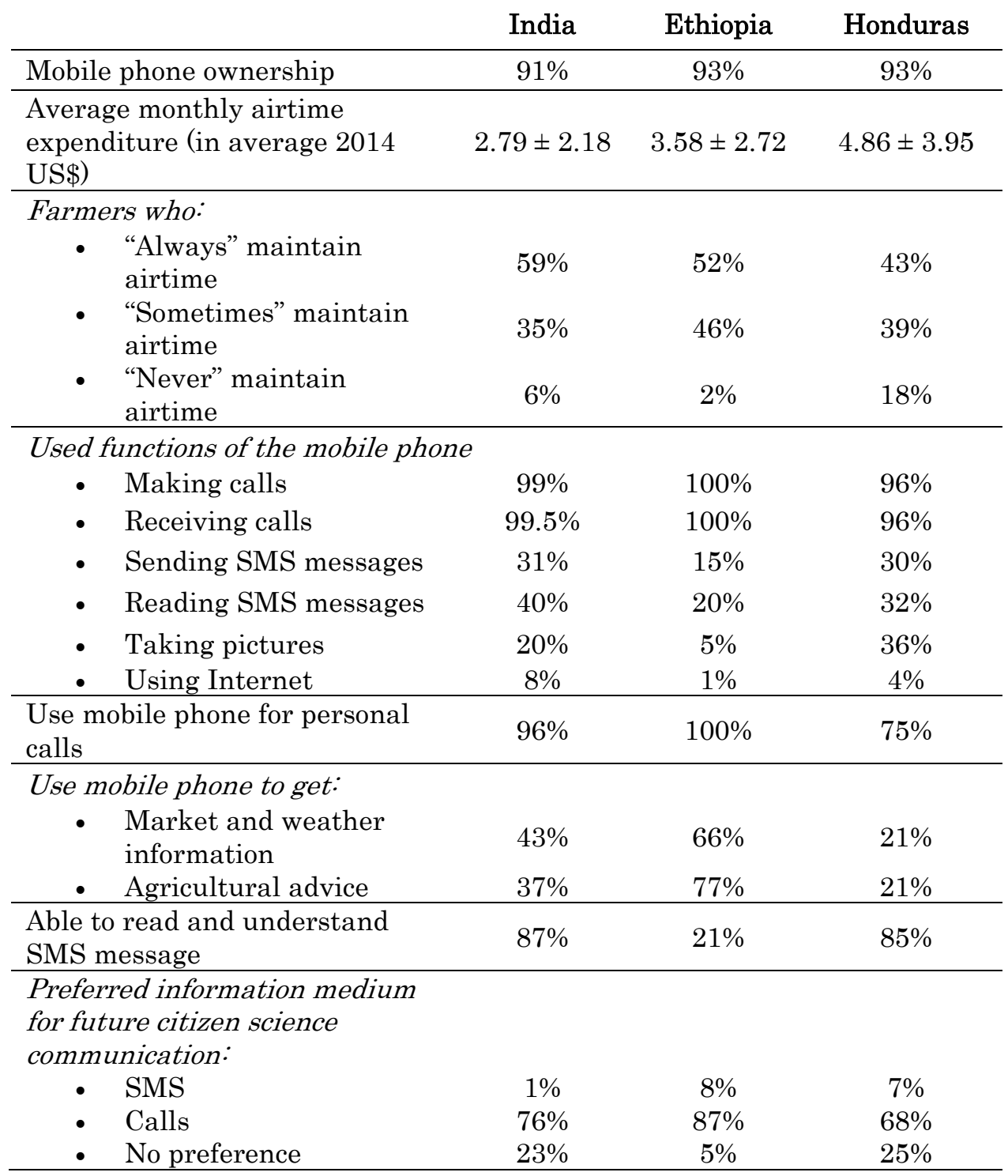

\subsection{Discussion}

To increase the understanding of farmers' motivation to participate in citizen science projects, we have interviewed 426 smallholder farmers in India, Ethiopia and Honduras as part of the "Seeds for Needs" initiative. 


\subsubsection{Country-by-country analysis}

For Indian farmers, the collectivistic (increasing the welfare of a group that one belongs to) type of motivation (i.e., 'Contribute to scientific research') was valued more important than egoistic and altruistic motivation types (Figure 3.2 and Table 3.3). This means that Indian farmers valued their contribution to scientific research more than their participation to receive something in return (egoistic extrinsic) and interest in sharing information (egoistic intrinsic). The altruistic type of motivation 'Helping' and egoistic extrinsic type of motivation 'Expert Interaction' were the second and third important factors for Indian farmers respectively.

For Ethiopian farmers, the egoistic intrinsic type of motivation ('Sharing info') was valued more than collectivistic, altruistic and egoistic extrinsic types of motivations (Figure 3.2 and Table 3.3). The altruistic type of motivation 'Helping' and collectivistic type of motivation 'Contributing' were the second and third important factors for Ethiopian farmers respectively. Like Ethiopian farmers, for Honduran farmers, the egoistic intrinsic type of motivation ('Sharing info') was valued more important than collectivistic, altruistic and egoistic extrinsic types of motivations (Figure 3.2 and Table 3.3). The collectivistic type of motivation 'Contributing' and egoistic extrinsic type of motivation 'Expert Interaction' were the second and third important factors for Honduran farmers respectively. The difference in motivations of farmers between the three countries suggests that future citizen science projects targeting the farming community in developing countries might need to consider different approaches to attract and retain farmer citizen scientists. Factors that motivate farmers in a specific country might not necessarily motivate farmers in another country.

\subsubsection{Comparisons between countries}

Comparison of motivational factors between the three countries revealed that Indian farmers valued their contribution to scientific research ('Contributing') more than Ethiopian and Honduran farmers, making 'Contributing' a more salient motivator for Indian farmers (Figure 3.2 and Table 3.4). This might be because our sampled farmers in India are more educated (Table 3.2) and hence, have better understanding and perception of their participation to contribute to scientific research. Participation to 'Contributing' was still the second and third most important motivational factor for Honduran and Ethiopian farmers, respectively. This indicates that the motivational factor 'Contributing' is in general an important factor for farmers in all the three countries to participate as citizen scientists. 
For Ethiopian and Honduran farmers, 'Interest in Sharing information' was the first ranked motivational factor. By sharing their (mostly agronomic) information, farmers thought that they would receive expert advice on how to improve their crop production. As revealed from the open-ended questions (Figure 3.5), 33\% of Ethiopian and 25\% of Honduran farmers would like to receive agronomic advice for their participation as citizen scientists'. In order to achieve this need of farmers, sharing their agronomic information with experts or researchers is necessary. Besides, for experts to deliver helpful agronomic advice for the farmers, receiving information from farmers about the different agronomic practices performed in the farmers' fields and socioeconomic conditions of the farmers helps to provide a set of site-specific agronomic advices (Car et al. 2012; Antonopoulou et al. 2010; Reddy and Ankaiah 2005; Bernet et al. 2001). In the context of variety selection, receiving information from farmers about their variety preferences can be used by agrodealers and provide preferred seed varieties to farmers in the following cropping season.

For both Ethiopian and Indian farmers, the motivational factor ' Helping' was the second ranked motivational factor. The direct reason or ultimate goal for this can be because farmers in Ethiopia and India have the desire to help researchers or experts to accomplish their tasks. However, these farmers also might have thought, if they help the researchers or experts to get their job done, researchers or experts in return will help them when they have problems (e.g., visiting an agronomic expert when a farmer has an urgent question). According to Batson et al. (2002), a goal can be either ultimate or instrumental. An ultimate goal is the valued state the individual is seeking to reach, while the instrumental goals are sought as they act as stepping stones to one's ultimate goals. In this situation, farmers might use the opportunity of 'Helping' as a stepping stone to their ultimate goals. In this case, the ultimate goal of farmers is to produce better yield and for this they need expert advice for the different problems they might face over the growing season.

\subsubsection{Generalization and reliability of results}

The study was exploratory and, as such does not claim to statistically represent farmers in all the three countries (e.g., in terms of age and gender). However, the findings give insights on motivations that are likely to be common among smallholder farmers in Ethiopia, India and Honduras.

An earlier exploratory study, by Johnson et al. (2014), assessed the motivation of citizen science volunteers in India to participate in wildlife conservation projects, and one of the motivations to participate was 'concern to the environment and wildlife conservation'. This motivation can be categorized 
under the theme "collectivistic motivation" (Batson et al. 2002), which was also important for Indian farmers in our study. The study of Rotman et al. (2014) showed the importance of 'personal interests' for volunteers to participate in citizen science projects in Costa Rica. In our study, Honduran farmers valued their participation to 'share information' mainly with experts and would like to receive feedback in return (egoistic). Getting similar results both from volunteer citizen scientists in Costa Rica and Honduras highlights that there is some sort of similarity for people to participate in citizen science in central America. In general, the more studies that will be performed, in the more regions, the more can be said about generalization of results.

We took several precautions to ensure good data quality and responsiveness of the farmers. These included adhering a similar approach in the three countries where the study was conducted, having the interviewer being assisted by local people to make the farmers comfortable, and using a well-developed methodology used by previous studies (Table 3.1). In order to cross-check the answers provided by the farmers, the use of role-playing games might be used in future studies. Letting the farmers play games, designed to capture the motivation of a farmer to participate in citizen science, might be used to triangulate what has been said during the interview. For example, the study of Villamor et al. (2017) used role-playing games to identify gender-specific preferences for annual crops and tree-based agroforestry systems, and the underlying motivation of those preferences.

\subsubsection{Comparison with other citizen science applications}

The nature of the Seeds for Needs initiative is different from most other citizen science projects in that it works with smallholder farmers in developing countries. Therefore, we discuss if the findings of other studies on the role of motivation in citizen science can be generalized to this type of citizen science.

The finding that citizen scientists in Seeds for Needs have a high motivation to contribute to science ('Contributing') is in line with many other studies of citizen science projects in applications related to astronomy (Raddick et al. 2013; Raddick et al. 2010), in understanding the three-dimensional structures of protein (Foldit, example of citizen science game (Curtis 2015)), in measuring aerosols using smartphones (e.g., iSPEX; Land-Zandstra et al. 2016a), in health (Land-Zandstra et al. 2016b; Grid 2013) and in collaborative distributed computing projects (Holohan and Garg 2005). In ecology-based citizen science projects, Rotman et al. (2012) found that egoism (one's own welfare) was the most important motivational factor during initial participation. We also found the same result (egoistic intrinsic i.e., 'Sharing Info') for both Ethiopian and Honduran farmers. However, Indian farmers had a more collectivistic motivation ('Contributing') at the start of their participation. 
Although reasons such as enjoyment of the activity ('Pastime') can be an important reason to participate in other citizen science projects (Curtis 2015; Schunko et al. 2015), it was not particularly an important motivational factor for farmers in the three countries who participated in the "Seeds for Needs" initiative. Possibly, the close relation of the project with the professional activities of the participants might have created the difference here. Unlike other citizen science projects that include going outdoors to explore and record observational data in nature (e.g., bird watching; Sullivan et al. 2009), for the smallholder farmers, testing the different seed varieties on their farming condition is crucial for their livelihood. Seed is an important production input for farmers and they would like to participate and perform variety selection as part of their main task, not as a 'Pastime' activity. However, there is a variation between the farmers in the three countries on how they perceive the motivational factor 'Pastime'. Indian farmers significantly scored higher than Ethiopian and Honduran farmers on the motivational factor 'Pastime' (Figure 3.2 and Table 3.4). This indicates that there are still some farmers who enjoyed their participation as citizen scientists more than others and these farmers might be important agents to promote citizen science locally in the future. The study of Johnson et al. (2014) discussed that when citizens are interested in one or more environmental issues, they seek out citizen science opportunities to gain expertise through participation and diffuse acquired skills and knowledge to peers through social networks, education of other non-scientist citizens.

The lower scoring of the motivational factor 'Pastime' by the farmers might also be that farmers may have interpreted this as being about "funny fun", and not about "serious fun" (e.g., the difference between card playing and enjoying our job). Even though farmers scored low for 'Pastime' compared to the other motivational factors, this does not mean that enjoyment should not be an important ingredient in designing a future digital citizen science system. It could also be that the citizen science in this project was 'not fun enough'.

In all the three countries, the motivational factor 'Community interaction' was valued less by farmers for their participation (Figure 3.2 and Table 3.3). This might be because farmers mostly test the different varieties in their own fields and farmers did not have much opportunity to interact with other farmers during the variety selection process. However, social interaction was an important motivational factor for other citizen science projects (Raddick et al. 2013; Holohan and Garg 2005). This could also point to the fact that farmers in our study areas conceive their productive activities as centered on the household and not the community, which may explain the difficulty of community-based approaches to participation in agricultural projects (e.g., Misiko 2013). Also, motivational factors may change over time (Rotman et al. 
2012). It remains to be seen if citizen science projects have the potential of strengthening local communities around agricultural experiments.

\subsubsection{Grouping of farmers based on motivations}

The result of the PCA showed that motivational factors in the same category i.e., from egoistic extrinsic type such as 'Expectation', 'Expert interaction' and 'Community interaction' were positively correlated (Figure 3.3). The strong correlation between these extrinsic motivations indicates that there was a group of farmers who were motivated extrinsically. On the other hand, the positive strong correlation among the motivational factors from different motivation types 'Sharing info' (egoistic intrinsic), 'Helping' (altruistic) and 'Contributing' (collectivistic) indicate another group of farmers who participated because they had different types of motivations. This indicates that many farmers did not have only one type of motivation to participate; rather they had different types of motivations. Similar results i.e., people having different types of motivations to participate in citizen science were also found in other studies (Curtis 2015; Raddick et al. 2010). Motivational factors, 'Pastime' and 'Sharing info' both egoistic intrinsic, were oppositely valued by the farmers. This indicates that farmers' motivations need to be assessed as specific as possible rather than generalize it under major motivation types. If the citizen science approach had to tailor to different groups of farmers with different motivations, these two groupings of farmers can be used to divide the farmers into major groups that can be handled differently.

\subsubsection{Effects of farmers' characteristics on farmers' motivations}

The relationship between motivational factors and farmers' characteristics using redundancy analysis revealed that country is a main factor explaining the variation in the motivations of the farmers (Figure 3.4). This might be because of cultural differences between the three countries. An in-depth comparison of cultures is beyond the scope of this paper. However, for example according to the Hofstede's cultural dimensions, Ethiopian and Honduran nationals are on average more collectivistic compared to Indian nationals (Hofstede 2001; Hofstede 1984; https://geert-hofstede.com/countries.html). This might be the reason why farmers in Ethiopia and Honduras valued sharing information more than Indian farmers.

Farmer's characteristics, country and education level explained only $20 \%$ of the total variation in the motivational factors (S2 Appendix C). The large unexplained variation indicates that there were other factors which were not considered in the current study but might had been relevant to explain the variation in the motivations of farmers in the three countries. 


\subsubsection{Prospects of gamification}

The findings about motivational factors in farmers' participation shed light on the prospects of gamification in this type of citizen science and which motivational factors it needs to support. Even though there are important differences between groups of participants with different educational level and gender, at the same time the diversity of motivations within each group imply that gamification should tailor to a number of different motivations at the same time to be inclusive. There is a low emphasis on 'Pastime' as a motivation for participating in tricot citizen science trials and it has a negative correlation with other motivational factors of more weight. This finding suggests that a careful approach is needed to support the enjoyment of tricot trials. Even though game-like elements in a broad sense may play a role, it will be important to determine if each element is appropriate in this context. In any case, gamification through the unreflective adoption of game elements that emphasize extrinsic motivation (scoreboards, badges, etc.) will likely be counterproductive. Intrinsic motivation features highly in the motivation factors that participating farmers score highly in all three study areas. Likewise, Deterding (2011) emphasizes intrinsic motivation for enjoyable game experiences, with references to Self-Determination Theory. According to this theory, intrinsically motivating activities are those that the individual finds interesting and performs without any kind of conditioning, just by the mere pleasure of carrying them out, supported by autonomy (which requires the task to be voluntary), the need to feel competent and efficient and to feel connected to other persons (Ryan and Deci 2000a; Ryan and Deci 2000b). The relatively high scores for intrinsic motivation factors from the current study reinforces this view.

\subsubsection{Future potential of mobile phone as technological interface for citizen science}

Volunteers' participation in digital citizen science activities is grounded on two facilitating pillars: a motivational, and a technological pillar (Nov et al. 2011b). The results of this study show the high initial motivation of smallholder farmers to act as citizen scientist. The next important issue is to assess the technological pillar for digital citizen science. For smallholder citizen scientist farmers, mobile phone is the most accessible technology to use and provide their experimental results. Interestingly, an overwhelming majority of the sampled farmers in the present study have mobile phones (Table 3.6). This result shows a promising potential as most of the farmers have the mobile telephone technology to provide their experimental results. In terms of preferences, farmers preferred calling over SMS because of their illiteracy. This means citizen science projects targeting the farmers' community need to 
consider to include features like Interactive Voice Response (IVR) systems as a data collection mechanism to harness the full potential of mobile phone as a citizen science data collection tool. Recent examples of using IVR to collect food security indicators at the household level shows its huge potential to be used in citizen science projects which target the farming community (Robinson and Obrecht 2016). Furthermore, mobile phones also have the potential to facilitate the interaction between the farmers and experts. In earlier examples, in the Digital Early Warning Network (DEWN) project, an initiative at the International Institute of Tropical Agriculture (IITA), farmers send text messages to researchers about incidence of Cassava Mosaic Disease (CMD) and Cassava Brown Streak Disease (CBSD) and receive disease control options in return (Ogodo 2009). Having detailed agronomic data from farmers participating as citizen scientists can also be used by researchers to identify the key causes of the yield gap, in order to prioritize efforts in research and extension (Beza et al. 2017a). Moreover, participating in citizen science projects and share their information using mobile phones (e.g., land information) can even give farmers the opportunity to get connected across the globe and learn on how to manage their plot of land from other farmers with similar land characteristics (www.landpotential.org/; Herrick et al. 2013).

\subsection{Conclusions}

This study explored the motivations of farmers to participate as citizen scientists in crop improvement trials in three countries: Ethiopia, Honduras and India. The most pronounced motivation for Indian farmers was the desire to contribute to scientific research (i.e., collectivistic). For Ethiopian and Honduran farmers, the motivation 'Interest in sharing information' (i.e., egoistic intrinsic) was more salient than the other types of motivations. 'Pastime' was in general less motivating compared to the other motivational factors. Two major groups of farmers could be distinguished for future design: one motivated by sharing information (egoistic intrinsic), helping (altruism) and contribute to scientific research (collectivistic) and one motivated by egoistic extrinsic factors (expectation, expert interaction and community interaction). Around half of the farmers expected something in return from the citizen science process. Agronomic advice, capacity building and seed innovation were the most needed incentives.

The majority of the farmers have mobile phones and they are already using their mobile phones to access extension advice and market information. Even if the farmers who participated in the present study did not use their mobile phones to provide their experimental results yet, we can conclude that there is a high potential for farmers to use their mobile phones to provide information from their experimental results. However, since there are many farmers who 
are not educated, it is recommended to introduce easy to use mechanisms (e.g., Interactive Voice Response).

We conclude that motivations to participate in citizen science are different for smallholders in agriculture compared to other sectors. Citizen science does have high potential, but easy to use mechanisms are needed. Moreover, gamification may increase the egoistic intrinsic motivation of farmers.

The supporting materials for this chapter are available online:

S1 Appendix: Motivation interview questions :

https://doi.org/10.1371/journal.pone.0175700.s001

S2 Appendix: Summary of PCA and RDA results :

https://doi.org/10.1371/journal.pone.0175700.s002

S3 Appendix: GLM result: https://doi.org/10.1371/journal.pone.0175700.s003

\section{Acknowledgements}

This research was carried out in a $\mathrm{PhD}$ project and it is part of the Wageningen UR strategic program 'Mapping for sustainable intensification', 2012-2016, funded by the Strategic Funds of Wageningen UR. The research is also a contribution to the CGIAR Research Program on Climate Change, Agriculture and Food Security (CCAFS). The views expressed in this document cannot be taken to reflect the official opinions of CGIAR or Future Earth. The authors also would like to thank all the farmers and project team members in the three countries who participated in this research. 



\section{Chapter}

\section{Exploring farmers' intentions to adopt mobile Short Message Service (SMS) for citizen science in agriculture}

Eskender Beza, Pytrik Reidsma, P. Marijn Poortvliet, Melisew Misker Belay, Ben Sjors Bijen, Lammert Kooistra

Under review (Computers and Electronics in Agriculture) 


\section{Abstract}

Understanding the factors that determine the intention of farmers to adopt mobile SMS technology for agricultural data collection is an essential step in the process of developing digital citizen science in agriculture. The main objective of this study was to explore the acceptance of mobile SMS technology by smallholder farmers to provide farm related information. A second objective was to assess the role of farmer's characteristics (i.e., age and experience) in predicting farmer's behavioural intention to adopt mobile SMS. This study extended the unified theory of acceptance and use of technology (UTAUT2) model with constructs from trust, personal innovativeness in information technology and mastery-approach goals, to identify the factors that affect the intention of farmers to adopt mobile SMS for agricultural data collection. The model was applied to a sample of 220 smallholder farmers using structural equation modelling. The sample consisted of group of farmers involved in a mobile SMS experiment and another group which was not involved in a mobile SMS experiment, in three regions of Ethiopia. The results showed that performance expectancy, effort expectancy, price value and trust were all positively and significantly correlated with farmer's intention. The intention of farmers to adopt mobile SMS for agricultural data provision was therefore influenced by the perceived usefulness of the technology, the effort needed to use the technology, the cost of using the technology and the trustworthiness of the organising body (e.g., organisations behind the citizen science initiative). Multi-group analysis using farmer's characteristics age and experience as moderator variables revealed that performance expectancy was important for younger farmers, whereas price value was important for farmers who did not participate in a mobile SMS experiment. This study generates useful information and implications for citizen science practitioners, policy makers and mobile application developers by identifying the determinant factors for smallholder farmers to adopt mobile SMS for agricultural data collection.

Keywords: Mobile phone, citizen science, data collection, unified theory of acceptance and use of technology, smallholder farmers 


\subsection{Introduction}

Closing the yield gap between actual yields currently achieved on farms and those that can be achieved with best practice and current technology in a given environment is a key strategy for increasing crop production on existing cropland (van Ittersum et al. 2013). To conduct yield gap analysis at the farm level, detailed information about soil, management activities, farm(er) characteristics and socio-economic factors for large number of farmers are needed (Beza et al. 2017a). However, collecting this information for a large number of farms is costly and time consuming and therefore not always feasible. Citizen science, the involvement of citizens such as farmers, in the research process (Dehnen-Schmutz et al. 2016), supported by the proliferation of mobile communication technologies such as smartphones allows for collecting a large amount of data (Herrick et al. 2013). Although the use of citizen science in agriculture is in its early stage, recent studies showed the potential of citizen science in agriculture (Rossiter et al. 2015; Rahman et al. 2015; van Etten 2011). A recent special issue on the next generation of agricultural system data, models and knowledge products also emphasized the potential of innovative data collection approaches (Antle et al. In Press; Janssen et al. In Press).

According to Nov et al. (2011b), volunteer's participation in digital citizen science is grounded on two facilitating pillars. The first is motivational: how to attract and retain people who would be willing to contribute their skills, time and effort for citizen science initiatives. Recruiting and sustaining community members to participate in citizen science requires an understanding of the motivations of the community to participate (Beza et al. 2017b). The second pillar - which the current study investigates - is the technological pillar: developing systems to collect, manage, and aggregate large amount of data. The rapid spread and ubiquitous availability of mobile phones, especially in developing countries, has created the opportunity to use mobile phones to support rural development (Qiang et al. 2011).

According to the International Telecommunication Union (ITU), seven billion people ( $95 \%$ of the global population) live in an area that is covered by a mobilecellular network (ITU 2016). Considering its broad coverage, the utilization of mobile Short Message Service (SMS) for agricultural data collection, especially in developing countries, offers a technological platform for agricultural citizen science projects. However, the promising development of the mobile-cellular network alone does not guarantee that mobile phones can be used to collect detailed information for yield gap analysis by a large number of farmers. For this reason, it is necessary to explore the intention of farmers to adopt mobile SMS for agricultural data collection. The study of Newman et al. (2012) 
discussed the importance of assessing technology adoption for managers of future citizen science projects and to be open to experimenting with and exploiting new technologies as they emerge. Although there are a number of studies on the adoption of mobile services (e.g. mobile government) in rural regions (Liu et al. 2014), to the authors' best knowledge, there is no a single study that has studied the adoption of mobile SMS for agricultural citizen science. The current study seeks to fill this gap.

The objectives of the current study are twofold. First, to explore the acceptance of mobile SMS technology by smallholder farmers to provide farm related information. More specifically, we aim to identify the factors that are important for the farmers to adopt mobile SMS technology for agricultural data provision. Second, to assess the role of farmer's characteristics (i.e., age and experience) in predicting farmer's behavioural intention to adopt mobile SMS.

The remainder of the chapter is structured as follows. Section 4.2 presents the theoretical background, followed by a discussion about the research model and its hypotheses in section 4.3. Section 4.4 provides a description on the mobile SMS experiments and technologies used in the experiments to collect agronomic information. Section 4.5 is about the research methodology, followed by the results in section 4.6. The discussion and implications, and limitations of the research and future research directions are presented in section 4.7, followed by conclusion in section 4.8 .

\subsection{Theoretical background}

\subsubsection{Adoption and use of information technology models}

In this section, we provide an overview of the most commonly used theories that have been applied within the context of adoption and use of mobile technology in order to build a foundation for our research model.

\subsubsection{Unified theory of acceptance and use of technology (UTAUT)}

The Technology Acceptance Model (TAM) is one of the most commonly used models to assess the behavioural intention to use information technology (Davis et al. 1989). However, TAM was criticised for its predictive capacity by some researchers and as a result the Unified theory of acceptance and use of technology (UTAUT) was developed by Venkatesh et al. (2003). The UTAUT model was developed after a comprehensive examination of eight prominent user adoption models that earlier research had employed to explain information systems usage behaviour, namely: Theory of reasoned action (TRA), Technology acceptance model (TAM), the motivational model (MM), theory of planned behaviour (TPB), the PC utilization model, Combined TAM 
and TPB (C-TAM-TBP), innovation diffusion theory and social cognitive theory (Venkatesh et al. 2003). The resulted model from the aforementioned theories (UTAUT) postulates that behavioural intentions and behaviour are determined by four key constructs: (i) performance expectancy, (ii) effort expectancy, (iii) social influence, and (iv) facilitating conditions. Moreover, the model posits that the effects of these four constructs on behavioural intention and use behaviour are moderated by different combinations of gender, age, experience and voluntariness to use. Since its inception in 2003, the UTAUT model has attracted the attention of many researchers in different research fields and has been applied to examine a wide range of technologies (Williams et al. 2015; Ovčjak et al. 2015; Williams et al. 2011) in single and multiple countries (Im et al. 2011). Amongst others, the model has been used in studies examining the acceptance of mobile wallet (Shin 2009), mobile health (m-health) (Dwivedi et al. 2016), mobile learning (m-learning) (Sabah 2016) and mobile banking (Oliveira et al. 2014).

Although the UTAUT model provides a very good and detailed model for acceptance and use of technology, it still has some limitations (Negahban and Chung 2014). Therefore, Venkatesh et al. (2012) developed UTAUT2 extending and adapting the theory to the consumer context by adding three more constructs, namely hedonic motivation, price value and habit. Hedonic motivation, which is conceptualized as perceived enjoyment, was added as it was found to be a key predictor in earlier research (Venkatesh et al. 2003). Price value was added because users in a consumer context need to bear the costs associated with the service use (Venkatesh et al. 2012), and habit, which reflects the multiple results of previous experiences (Venkatesh et al. 2012) was added because it was supported in previous studies that showed it to be a critical factor in technology context use (Limayem et al. 2007; Kim and Malhotra 2005). The UTAUT2 model (Figure 4.1) thus comprises seven constructs: (1) performance expectancy, (ii) effort expectancy, (iii) social influence, (iv) facilitating conditions, (v) hedonic motivation, (vi) price value, and (vii) habit. Individual differences- namely age, gender and experience - are hypothesized to moderate the effects of the aforementioned constructs on behavioural intention and technology use (Venkatesh et al. 2012). The moderating variable voluntariness from the previous UTAUT model has been dropped in the latest version of UTAUT2. Some additional changes were made with respect to whether constructs and moderating variables affect both or either behavioural intention and use behaviour ('use behaviour' is not in Figure 4.1, as it is not part of our study). UTAUT2 provides a complete theoretical framework, and has been playing a prominent role in the literature and received strong empirical validation in a variety of disciplines and task environments (e.g., Dwivedi et al. 2016; Baptista and Oliveira 2015). In addition, compared to its predecessor, UTAUT2 yields considerable 
improvement in the variance explained in behavioural intention and technology use (Venkatesh et al. 2012). Therefore, the UTAUT2 model serves as the theoretical basis for the present research.

The conceptual model used in the current research (Figure 4.1) extended the UTAUT2 model with additional antecedents from the concept of diffusion of innovation (i.e., personal innovativeness in information technology (PIIT)), trust (i.e., benevolence), and goal orientation (i.e., mastery-approach goals).

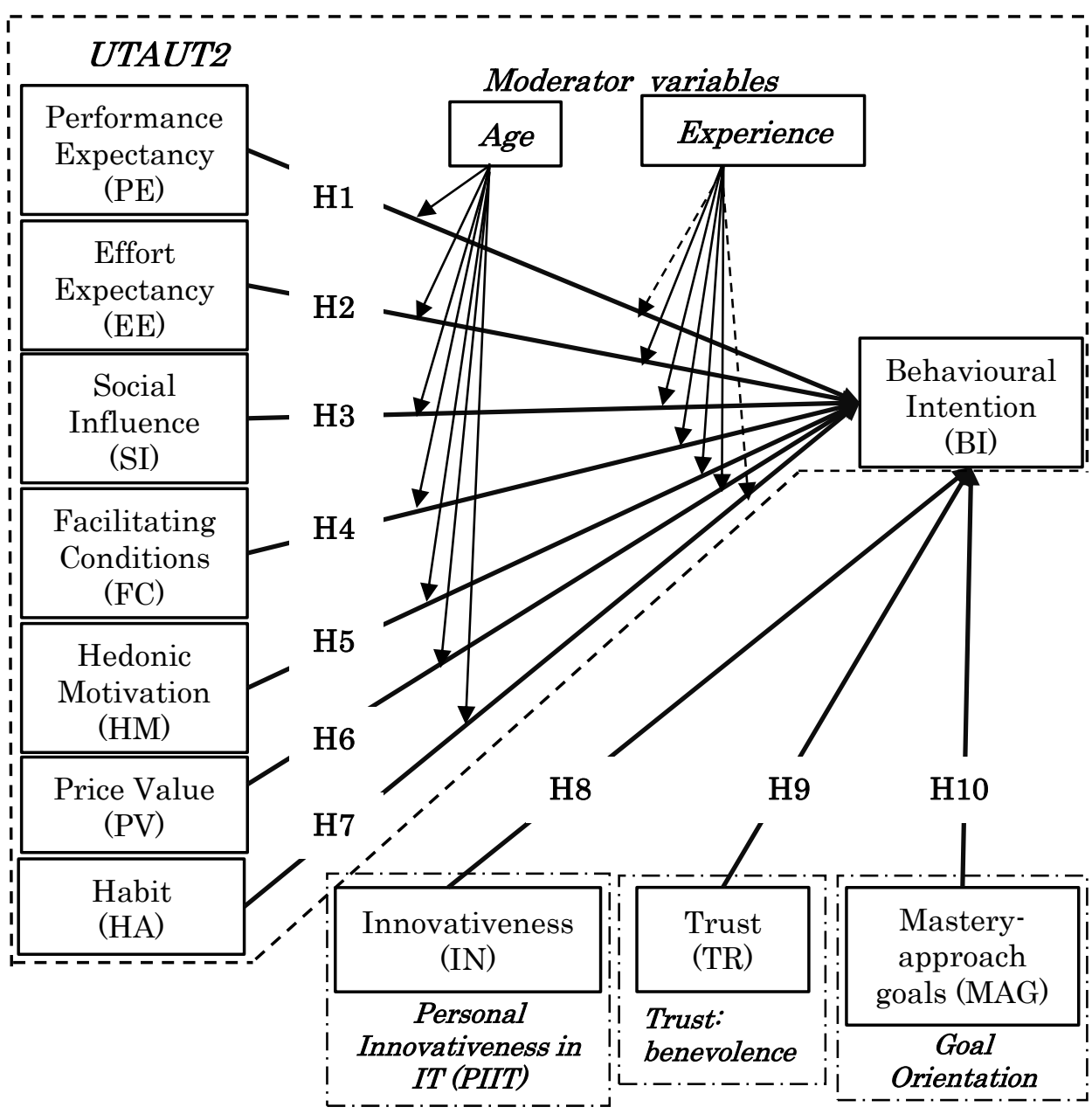

Figure 4.1: Conceptual model for the current research. The dashed line depicts a moderation effect of experience on performance expectancy and price value which was not in the original UTAUT2 model. 


\subsubsection{Diffusion of innovation}

A second theoretical approach that is used in this research is derived from Diffusion of Innovation theory (DOI) (Rogers 2002, 1995). DOI has originated from sociology and it views innovation diffusion as a particular type of communication process in which the message about a new idea is passed from one member to another in a social system. The theory of DOI posits that the rate of adoption is partially determined by the perceived attributes of an innovation, called innovation characteristics, and proposes several attributes potentially important across diverse innovation adoption models (Rogers 2002, 1995). Importantly, and relevant for the conceptual framework we put forward, DOI suggest that one particular individual characteristic is important in the adoption of innovation: personal innovativeness (Yi et al. 2006; Agarwal and Prasad 1998). Agarwal and Prasad (1998) adapted the concept to the domain of Information Technology (IT) and proposed a new instrument to measure personal innovativeness in IT (PIIT) defined as, "the willingness of an individual to try out any new IT". Since farmers participating in the current research did not have experience in using the SMS feature of the mobile phone for agricultural data provision, it is considered as a new technology for the farmers to test. Therefore, we found it relevant to extend the UTAUT2 model by including the PIIT construct and assess the personal innovativeness of farmers to test mobile SMS for agricultural data collection (Figure 4.1).

\subsubsection{Trust}

The framework of Mayer et al. (1995) defines trust as "a willingness to be vulnerable to the actions of another party". According to Mayer et al. (1995) trustworthiness contained three factors: ability, benevolence, and integrity. Ability is described as that group of competencies, skills, and characteristics that allow a party to have influence within some specific domain. Benevolence is the extent to which a trustee (i.e., to-be-trusted; e.g. researcher) is believed to want to do good to the trustor (i.e., trusting party; e.g. farmer) apart from an egocentric motive. If a farmer believes a researcher cares about the farmer's interests, the researcher will be seen as having benevolence for the farmer. The third factor of trustworthiness, integrity is defined as the trustor's perception that the trustee obeys to a set of principles that the trustor finds acceptable.

The importance of the aforementioned factors in defining trustworthiness depends between individuals and between situations (Mayer and Davis 1999). In our study, we seek to investigate how one of the key factors of trust, benevolence, affects the acceptance of mobile SMS for agricultural data collection. For this reason, we extended the UTAUT2 model with one construct to measure trust (i.e., benevolence) (Figure 4.1). 


\subsubsection{Mastery-approach goals}

According to goal orientation theory, there are two main goal types people can hold while performing a task: mastery (learning) goal orientation, and performance goal orientation (Nicholls 1984). The aim of people with a mastery goal orientation while approaching a task is to understand something new or to improve their level of competence (Yi and Hwang 2003). People with a mastery goal orientation consider ability as an incremental skill that can be continually improved by acquiring knowledge and perfecting competencies (Wood and Bandura 1989). In contrast, the aim of people with a performance goal orientation while approaching a task is to demonstrate their competence. Performance goals orient the individual to focus on the self and to demonstrate competence relative to others. People with a performance goal orientation approach see ability as a fixed entity that reveals their intellectual capacity. They prefer tasks that minimize errors at the expense of acquiring new skills, and are concerned about their ability and performance relative to others (Nicholls 1984). Previous technology adoption studies have shown that mastery goal orientation has a significant positive effect on self-efficacy, implying that individuals with a mastery goal orientation are more likely to develop a higher sense of confidence (Yi and Hwang 2003; Hwang and Yi 2002). The study of Janssen and Van Yperen (2004) revealed a positive relationship between mastery goal and innovative behaviour of employees. In the current study, we would like to explore the relationship between mastery goal orientation and the behavioural intention of farmers to adopt mobile SMS for agricultural data collection.

\subsection{Research model and hypotheses}

As mentioned in the previous section, the ten constructs that make up our research framework are expected to positively affect intention to adopt mobile SMS technology (Figure 4.1). In this section, we will detail our hypotheses pertaining the relationships between the proposed drivers for adoption and behavioural intention (BI) to use mobile SMS for agricultural data collection on smallholder farms specifically.

\subsubsection{UTAUT2 constructs}

"Performance expectancy" is the degree to which using a technology will provide benefits to users in performing certain activities (Venkatesh et al. 2012). In our research context, it is the degree to which a farmer believes that providing agronomic information to others (e.g. to agronomic experts) using mobile SMS will benefit the farmer. It indicates that individuals will use computing technology if they believe it will have positive outcomes in their day to day life (Compeau and Higgins 1995). In the original model of UTAUT, 
Venkatesh et al. (2003) found performance expectancy to be the strongest predictor of intention and the effect of performance expectancy on behavioural intention has been supported in the adoption of mobile services such as mobile banking (Baptista and Oliveira 2015), mobile cloud services (Park and Kim 2014), mobile maps (Park and Ohm 2014) and mobile learning (Ho et al. 2010). The reason for this is due to the benefits the technologies provide such as mobility, personalization, flexibility and convenience (Gilbert and Han 2005). One of the attractive features of mobile SMS for farmers to provide agricultural information is the ability to provide the information anywhere, at any time, without wasting much of their productive time to answer long surveys. As mobile SMS offers a convenient method for data provision, with no spatial constraints via a mobile device that has become ubiquitous, it offers practical benefits that are likely to be important drivers of adoption. Therefore, we hypothesised that:

H1: Performance expectancy (PE) positively affects behavioural intention (BI) to use mobile SMS.

"Effort expectancy" is the degree of ease associated with farmers' use of technology (Venkatesh et al. 2012). In the case of mobile SMS data collection, some farmers might be more mobile SMS literate than others and, consequently, would expect to have fewer problems to use their mobile phone to provide agronomic information via SMS. If farmers find data provision using mobile SMS easy to use, then we expect them to be more willing to use it to provide agronomic information. Therefore, we hypothesised that:

H2: Effort expectancy (EF) positively affects behavioural intention (BI) to use mobile SMS

"Social influence" is the extent to which farmers perceive that important others believe they should use a particular technology (Venkatesh et al. 2012). The underlying assumption is that individuals tend to consult their social network, especially friends and family, about new technologies and can be influenced by perceived social pressure of important others. Therefore, we hypothesised that:

H3: Social influence (SI) positively affects behavioural intention (BI) to use mobile SMS.

"Facilitating conditions" refers to how farmers believe that technical infrastructure exists to help them to use the system whenever necessary (Venkatesh et al. 2012). Sending SMS requires some skills, such as being able to operate a mobile phone or tablet, inserting the receivers' mobile number, and writing/inserting the content of the SMS. A farmer who has educated 
household members or has access to a favourable set of facilitating conditions, such as support from extension workers, will have a greater intention to use. Therefore, we hypothesised that:

H4: Facilitating conditions (FC) positively affect behavioural intention (BI) to use mobile SMS.

"Hedonic motivation" is defined as the fun or pleasure derived from using a technology (e.g. mobile SMS) (Venkatesh et al. 2012), and it has been shown to play an important role in determining technology acceptance and use (Brown and Venkatesh 2005). The greater entertainment value the mobile SMS brings, the greater acceptance intention farmers will show to use the mobile SMS. Therefore, we hypothesised that:

H5: Hedonic motivation (HM) positively affects behavioural intention (BI) to use mobile SMS.

"Price value" is the farmers' cognitive trade-off between the perceived benefits of using mobile SMS and the monetary cost of using it (Venkatesh et al. 2012). It includes factors such as data service carrier costs, device cost and service costs. The price value is positive when the benefits of using the mobile SMS are perceived to be greater than the associated monetary cost. Therefore, we hypothesise that:

H6: Price value (PV) positively affects behavioural intention (BI) to use mobile SMS.

"Habit" reflects the multiple results of previous experiences (Venkatesh et al. 2012) and people often consult their past behaviours as anchoring points to inform their future actions (Ajzen 2002). Therefore, we hypothesise that:

H7: Habit (HA) positively affects behavioural intention (BI) to use mobile SMS.

\subsubsection{Additional constructs}

In general innovation diffusion research, it has long been recognized that highly innovative individuals are active information seekers about new ideas. They are able to cope with high levels of uncertainty and develop more positive intentions toward acceptance (Rogers 1995). Therefore, we hypothesise that:

H8: Personal innovativeness in information technology (IN) positively affects behavioural intention (BI) to use mobile SMS. 
The majority of the smallholder farmers' livelihood is dependent on agriculture and the probability of sharing their agronomic information using mobile SMS is highly dependent on the trustworthiness of the party (i.e., trustee) on the other side of the communication channel (e.g., agronomic experts, researchers, and research institutes). Farmers try to avoid using any technology which might bring any uncertainties and risks into their farming activity, such as disclosing confidential agro-business information to an untrusted recipient. Therefore, we hypothesise that:

H9: Trust (TR) positively affects behavioural intention (BI) to use mobile SMS.

The majority of the smallholder farmers' livelihood is dependent on farming. Therefore we believe that farmers will always look for options that help them to improve their agricultural production. To achieve this, farmers will strive for more skills and knowledge that help them to achieve their goals. Thus, in the context of adopting a new technology, farmers with a mastery goal orientation are expected to use the mobile SMS to acquire new skills and knowledge. Therefore, we hypothesise that:

H10: Mastery-approach goal orientation positively affects behavioural intention (BI) to use mobile SMS.

\subsubsection{Moderator effects}

We hypothesise that farmer's characteristics age and experience moderate the effects of UTAUT2 constructs (PE, EE, SI, FC, HM, PV and HA) on behavioural intention (Venkatesh et al. 2012; Venkatesh et al. 2003). In our case, farmers who participated in the mobile SMS experiment are "experienced" and farmers who did not participate are "non-experienced". The effect of effort expectancy (EE), facilitating conditions (FC) and price value (PV) on behavioural intention (BI) are expected to be stronger for older farmers with no experience. The effect of performance expectancy (PE) and hedonic motivation (HM) are expected to be stronger for younger farmers with no experience. Lastly, the effect of social influence (SI) and habit (HA) are expected to be stronger for older and experienced farmers. The added constructs (IN, TR, MAG) could also be influenced by age and experience, but were not included in the analysis as further explained later. 


\subsection{Research context}

\subsubsection{Description of the mobile Short Message Service (SMS) experiment}

During the 2014 and 2015 growing seasons, around 125 farmers from three regions in Ethiopia participated in an experiment where farmers were sending their daily agricultural activities using SMS over the growing season. The experiment was conducted as part of two large ongoing projects, N2Africa (http://www.n2africa.org/) and Sesame Business Network (SBN; http://sbnethiopia.org/). Farmers in N2Africa have been participating in agronomic experiments and have been testing the effect of inoculants (I) and phosphorus (P) on the yield of legume crops (chickpea in our study area). Farmers in the SBN project have been testing the effect of applying the so called " 20 steps" (production/agricultural practices identified \& recommended by experts) in experimental plots in their own fields on sesame yields. The farmers that participated in the SMS experiments were randomly selected from the list of farmers participating in the two projects. However, one of the requirements to be part of the SMS experiment was that farmers needed to have at least a basic mobile phone in the household. In both years, farmers received a short training before the start of the growing season on how to send SMS messages using their mobile phones. During the training, short codes associated with the different agricultural activities (e.g. send "1" for sowing date, " 2 " for emergence) were introduced and farmers received a laminated A4 paper with the list of factors with the associated codes of the activities in their local language for later reference during the season. The list of the factors that needed to be collected using SMS were identified from previous agronomic crop yield gap analysis studies (Beza, Vasco Silva, et al. 2017). The main objective of collecting factors was to demonstrate the potential of innovative bottom-up data collection approaches (e.g. crowdsourcing) and use the collected factors in crop yield gap analysis studies that aim to identify the main causes of the crop yield gap at the farm level.

\subsubsection{Data collection technologies used in the experiment}

In order to receive and manage SMS messages sent by the farmers, FrontlineSMSdesktop (http://www.frontlinesms.com/) \& Ushahidi applications (https://www.ushahidi.com/) were used. We selected FrontlineSMS and Ushahidi as the messaging platforms because they are free and open source software tools and commonly used for data collection. FrontlineSMS enables users to send, receive and manage large numbers of incoming and outgoing SMS messages (Mahmud et al. 2010). FrontlineSMS does not require the internet to work, but does need to be connected to a mobile network. When a computer running FrontlineSMS is connected to a GSM (Global System for 
Mobile communication) modem or mobile phone, it is converted to a two-way text-messaging hub (Figure 4.2) (Mahmud et al. 2010). Farmers with mobile phones can send and receive messages to and from the platform, which is linked to a specific phone number with a SIM (Subscriber Identity Module) card. The software manages contacts, allows for mass-messaging, auto-forwarding and auto-reply.

Ushahidi is a platform for collecting, visualising and mapping information. Using FrontlineSMS and Ushahidi tools together can produce good results, with FrontlineSMS being used as a tool which can manage incoming SMS data which can then be visually represented using Ushahidi (Banks and Hersman 2009). The cloud-based version of Ushahidi (Crowdmap) was used in this pilot study to receive an automatically forwarded SMS message from the FrontlineSMS application. FrontlineSMS application uses a local SIM card; data sent to the application can only be accessed by people who have access to the local computer where the FrontlineSMS application is installed. To overcome this limitation, we linked the FrontlineSMS application with the Crowdmap platform so that SMS data received by FrontlineSMS is automatically forwarded to the Crowdmap platform and project partners (researchers) far from the implementation area and having connection to internet can also access the SMS data received using the Ushahidi Crowdmap platform.

We deployed the data collection platform at the International Livestock Research Institute (ILRI), Addis Ababa campus, where the Ethiopian national office of N2Africa is located, and in the regional offices in Gondar and Humera, Ethiopia, for the data collection campaign for the Sesame Business Network project (Figure 4.2). Agronomists working for both projects received a training on how to manage the application and were managing the FrontlineSMS application over the growing seasons. Technical problems beyond the capacities of the agronomists were solved in consultation with researchers at Wageningen University \& Research in the Netherlands.

During the 2015 growing season around 685 SMS messages were received from the farmers (Figure 4.3). As shown in the top right figure (Figure 4.3), using the Ushahidi Crowdmap application allowed us to sort the SMS messages based on their categories. In addition to its potential to collect detailed information from a large number of farmers, the application can also be used to visualise where there is an outbreak of pest or disease for immediate remedial actions. An overview of the individual factors belonging to each of the groups in Figure 4.3 is provided in Appendix 4.1. 


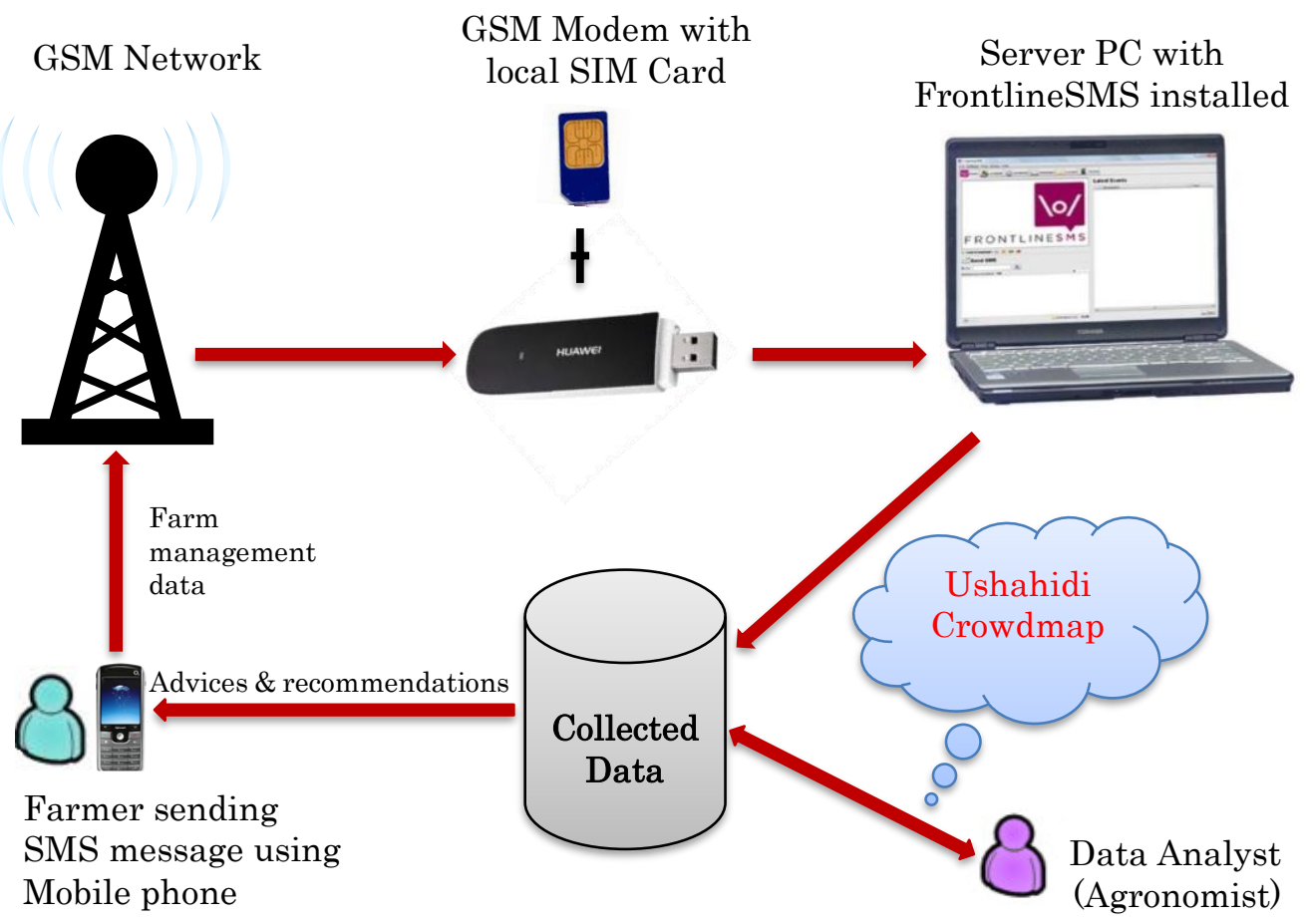

Figure 4.2: Overview of the information flow between the farmer and agronomists within the N2Africa and Sesame Business Network projects.

\subsection{Research methodology}

\subsubsection{Measurement tool}

In order to analyse the behavioural intention of farmers to adopt mobile SMS for agricultural data collection, a study was carried out in November and December 2015 using a standardised questionnaire. The questionnaire was originally written in English and a back translation process was applied (Brislin 1986) for the Ethiopian Amharic version and minor corrections have been done for the items that did not match precisely. The questionnaire consisted of two distinct sections. The first section consisted of general information and demographic characteristics of the farmers. It also included questions on the use of SMS in the context of agronomic data collection for the specific projects. The second section consisted of measurement items for the constructs of UTAUT2, and the added constructs trust, mastery approach goal and personal innovativeness in information technology. 

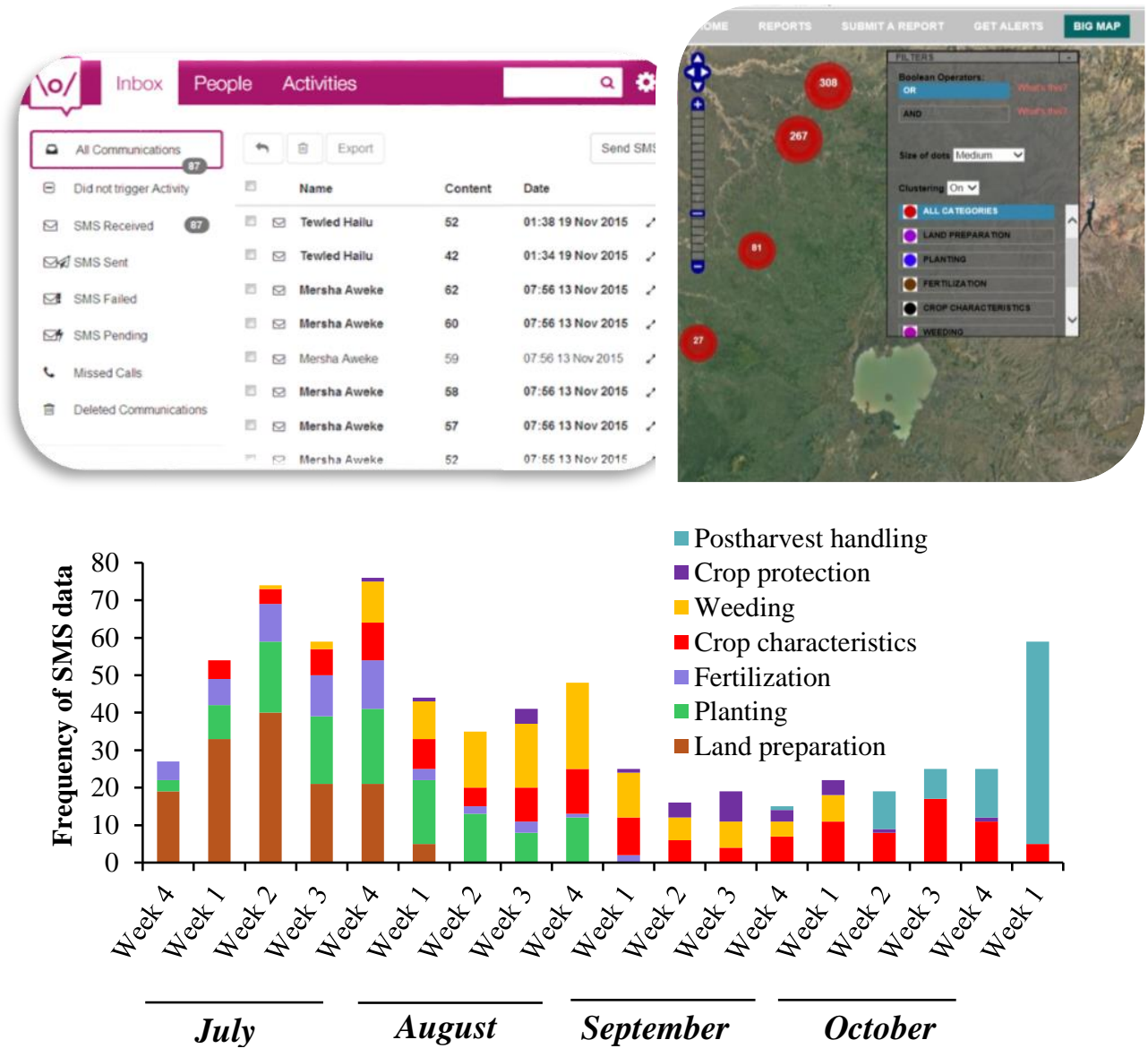

Figure 4.3: Screenshots of FrontlineSMS (top left) and Ushahidi Crowdmap (top right) applications. The bottom figure presents the types of factors and frequency of SMS data collected from sesame fields during the 2015 growing season in North West Ethiopia.

To make the objective of the second section of the questionnaire clear for the farmers, we used a "scripted introduction" which clearly describes that the follow-up questions were related to the use of their mobile SMS for agricultural data collection/provision. The measurement items for the constructs of our research model were derived from previous studies and are included in Appendix 4.2. Each construct was based on three to five items. The items for the UTAUT2 constructs were adapted from Venkatesh et al. (2003) and Venkatesh et al. (2012). The items for measuring trust (benevolence) were 
adapted from Mayer and Davis (1999). The items for measuring mastery approach goals were adapted from Elliot and McGregor (2001) and the items for personal innovativeness in information technology were adapted from Yi et al. (2006). A total of 40 measurement items were adapted from prior studies and each item was carefully rephrased for the agricultural data collection context using mobile SMS (Appendix 4.2). Each item was measured with a fivepoint Likert scale, ranging from "Strongly disagree" (1) to "Strongly agree" (5).

\subsubsection{Respondents, sampling and data collection}

The respondents formed two groups. The first group comprised of farmers who have participated in mobile SMS for agricultural data collection experiment. These farmers were called "SMS farmers". The second group comprised of farmers who have mobile phones but did not participate in the mobile SMS for agricultural data collection experiment. These farmers are called "Non SMS farmers". The survey was conducted in a face-to-face interview with both group of farmers. Both "SMS farmers" and "Non SMS farmers" were randomly selected from the list of farmers participating in the N2Africa and Sesame Business Network projects; multi-group analysis was conducted to control for and explore the possible influence of group membership. During the selection process, an equal number of respondents from each group were selected per Kebele (smallest administrative unit). A total of 220 responses with no missing values were collected and all were used in the analysis. Oral informed consent was obtained from all respondents, who were already participating in the ongoing N2Africa and Sesame Business Network projects.

\subsubsection{Data analysis}

The demographic data was first analysed using descriptive statistics. We conducted Structural Equation Modelling (SEM) to test our research model (Figure 4.1) using AMOS 23. SEM is a set of statistical models that seek to explain the relationships between multiple variables (Hair et al. 2010). SEM was used as a preferable method compared to regression as it allows simultaneous analysis of all relationships, combining multiple regression with factor analysis, while also allowing for both observed and latent variables to be analysed at the same time, and providing overall fit statistics (Tabachnick and Fidell 2007; Gefen et al. 2000). Moreover, SEM takes into account measurement errors within observed variables (Hair et al. 2010; Gefen et al. 2000). It has also been identified that SEM is an appropriate covariance-based approach for studies like ours with a strong basis on 'a priori' theory (e.g., Hung et al. 2013). Following the recommendations of Anderson and Gerbing (1988), the analysis was done in two steps. First, confirmatory factor analysis (CFA) was conducted using Maximum Likelihood Estimation method to examine reliability and validity of our measurement model (Outer model). Second, we 
evaluated the path analysis of the structural model (Inner model) estimates to test the significance of our hypotheses and the predictive power of the proposed model for this study (Figure 4.1).

The overall fit of the measurement and structural models were assessed using a combination of absolute and relative indexes, namely normed chi-square (CMIN/DF), Adjusted Goodness-of-Fit Index (AGFI), Comparative Fit Index (CFI), and Root Mean Square Error of Approximation (RMSEA). For both the measurement and structural models to have sufficiently good fit, these measures needed to be $<3, \geq 0.8, \geq 0.95$, and $\leq 0.7$ respectively (Hair et al. 2010; $\mathrm{Hu}$ and Bentler 1999). For the structural model, the strength and significance of the relationship between each of the constructs and behavioural intention was assessed using standardised regression weights (SRW) and p-value ( $p<$ $0.05)$.

Prior to the path analysis (hypotheses testing), the measurement model was also assessed for (i) construct reliability, (ii) indicator reliability, (iii) convergence validity, and (iv) discriminant validity. Construct reliability is a measure of internal consistency of the measurement items and was assessed using composite reliability (CR) and Cronbach's alpha values (Nunnally and Bernstein 1994; Straub 1989). The indicator reliability was evaluated based on factor loadings (Churchill 1979). Convergence validity measures whether items can effectively reflect their corresponding construct (i.e., converge on the intended construct), whereas discriminant validity measures whether two constructs are statistically and theoretically different (Hair et al. 2010; Hu and Bentler 1999). Average variance extracted (AVE) was used as the criterion to test convergence validity (Fornell and Larcker 1981). To examine discriminant validity, we compared the square root of AVE and factor correlation coefficients (Fornell and Larcker 1981).

Prior to assessing the measurement and structural models, Common Method Variance (CMV) and multicollinearity were tested. The Common Latent Factor (CLF) method was applied to test Common Method Variance (CMV) (Podsakoff et al. 2003). No factor was found to account for the majority of the variance in the variables, confirming that the common method variance is not a concern in the data. Moreover, to test multicollinearity, Variance Inflation Factors (VIFs) and tolerance were computed for different constructs in our model and they were found to be less than the threshold of 3 and greater than 0.1 respectively, suggesting that multicollinearity was not a major issue in our study (O'brien 2007).

Furthermore, multi-group analysis was performed to assess the moderation effect of farmer's characteristics (age and experience) between UTAUT2 
constructs and behavioural intention (Figure 4.1). For the factor age, respondents were divided into two groups based on the mean age: (1) "Younger farmers" who were less than 43 years old $(n=115)$, and (2) "Older farmers" who were 43 years and older $(n=105)$ at the time of the data collection. To examine the moderation effect of experience, the data were divided into two groups. The first group consisted of farmers who participated in the mobile SMS experiment (i.e. "SMS Farmers", $n=110$ ), and the second group consisted of farmers who did not participate in the mobile SMS experiment (i.e. "Non SMS farmers", $n=110$ ). The moderator variable of the UTAU2 model 'gender' was not further considered in the analysis because there were few female farmers who participated in the study.

As part of the multi-group analysis, measurement model invariance, which includes configural and metric invariance, was assessed following a step by step procedure presented in Steenkamp and Baumgartner (1998). Configural invariance checks if the factor structure is invariant across groups, indicating that the participants from the different groups understand the constructs in the same way (Milfont and Fischer 2015). Metric invariance tests if different groups respond to the items in the same way. That is, it checks if the strengths of the relations between specific items and their respective underlying construct (i.e. factor loadings) are the same across groups (Milfont and Fischer 2015).

To assess configural invariance, unconstrained multi-group measurement models which allow factor loadings to vary across the two groups (i.e. between "SMS farmers", farmers who have participated in mobile SMS for agricultural data collection and "Non SMS farmers", farmers who did not participate in mobile SMS for agricultural data collection) and between "Younger farmers" and "Older farmers") were developed. The model fit for the configural invariance between "SMS farmers" and "Non SMS farmers" was satisfactory $(\mathrm{CMIN} / \mathrm{DF}=1.518 ; \mathrm{CFI}=0.910 ; \mathrm{RMSEA}=0.049)$, and between "Younger farmers" and "Older farmers" it was also satisfactory (CMIN/DF = 1.381; CFI $=0.934$; RMSEA $=0.042$ ) (Milfont and Fischer 2015). This implied that the models fit both groups well and configural invariance was met.

To assess metric invariance, fully constrained measurement models that constrain the measurement weights (i.e., factor loadings) for each measured variable to be equal for the two groups (i.e. between "Younger farmers" and "Older farmers" and between "SMS farmers" and "Non SMS farmers") were developed. Fit indices for the fully constrained measurement model between "SMS farmers" and "Non SMS farmers" were satisfactory (CMIN/DF = 1.569; CFI = 0.90; RMSEA = 0.051), and between "Younger farmers" and "Older farmers" they were also satisfactory $\quad(\mathrm{CMIN} / \mathrm{DF}=1.360 ; \quad \mathrm{CFI}=0.934$; 
RMSEA $=0.041$ ). The results of the fully constrained measurement models were compared to those of the unconstrained multi-group measurement models using chi-square difference test. The chi-square difference test for the two groups were not significant, suggesting metric invariance for the two groups was also met (Milfont and Fischer 2015). After meeting the criteria of both configural and metric invariance at the measurement model level, invariance analysis at the structural model level was assessed.

\subsection{Results}

\subsubsection{Descriptive statistics}

The characteristics of the farmers who participated in this study are presented in Table 4.1. The majority of the respondents were male (91.8\%). Respondent's age fell predominantly between $31-50$ years old (56.8\%), and the education level was mainly primary school (70.9\%). The majority of the respondents $(62.7 \%)$ have been using mobile phones for the last $6-10$ years. Furthermore, $87.3 \%$ of the respondents were married.

Table 4.1: Demographic characteristics of the surveyed farmers.

\begin{tabular}{lcc}
\hline Factor & Frequency & Percentage (\%) \\
\hline Gender & 202 & \\
Male & 18 & 91.8 \\
Female & & 8.2 \\
Age (years) & 37 & \\
$21-30$ & 66 & 16.8 \\
$31-40$ & 59 & 30.0 \\
$41-50$ & 42 & 26.8 \\
$51-60$ & 12 & 19.1 \\
$61-70$ & 4 & 5.5 \\
71 or older & & 1.8 \\
Education level & 9 & \\
Illiterate & 13 & 4.1 \\
Can read \& write & 156 & 5.9 \\
Primary school & 24 & 70.9 \\
Secondary school & 18 & 10.9 \\
Higher education & & 8.2 \\
Years of using mobile phone & 56 & \\
- 5 years & 138 & 25.5 \\
6 - 10 years & 26 & 62.7 \\
11 years and more & & 11.8 \\
Marital status & 192 & 87.3 \\
Married & 28 & 12.7 \\
Single & &
\end{tabular}




\subsubsection{Measurement model results}

The first fit of the measurement model including all the items of the constructs was not sufficient. Therefore, following the suggestions from the analysis of the model fit indices, standardised regression weights and covariance modification indices, as it was also done by Slade et al. (2015), it was decided to remove the items SI3 and SI4 (Appendix 4.2). This improved the model fit indices and resulted in a "good measurement model" (Gefen et al. 2000) with the following index values: CMIN/DF: 1.250; AGFI：0.824; CFI：0.969; and RMSEA：0.034 (Table 4.2).

The measurement model was also further adapted based on an assessment of (i) construct reliability, (ii) indicator reliability, (iii) convergence validity, and (iv) discriminant validity. As shown in Table 4.3, all the constructs have composite reliability (CR) and Cronbach's alpha values greater than 0.7, indicating the construct's reliability criterion was achieved (Nunnally and Bernstein 1994; Straub 1989). The indicator reliability was evaluated based on the criteria that item loading should be higher than 0.7 and that every item with loading less than 0.4 should be eliminated (Churchill 1979). Two items, EE2 and HA3 were dropped because of low factor loading. The factor loadings for the remaining items are greater than the threshold value of 0.7 , confirming a good indicator reliability of the instrument (Table 4.3). The convergence validity was tested with the Average Variance Extracted (AVE) value (Fornell and Larcker 1981). As shown on Table 4.3, all the constructs have an AVE greater than the minimum acceptable value of 0.5 confirming the convergence validity criterion was achieved.

Discriminant validity was analysed using Fornell-Larcker criterion. Table 4.4 contains the square root of the AVE in bold along the diagonal, confirming the condition of being greater than the correlation between the constructs (Fornell and Larcker 1981). The overall results of the measurement model indicate that the model has good indicator and construct reliability, and convergence and discriminant validity, confirming that the constructs are statistically distinct and can be used to test the path analysis of the structural model. 
Table 4.2: Summary of fit indices for the measurement and structural models.

\begin{tabular}{|c|c|c|c|}
\hline Model fit indices & $\begin{array}{l}\text { Recommended } \\
\text { value }\end{array}$ & $\begin{array}{l}\text { Model } \\
\text { results }\end{array}$ & Reference \\
\hline $\begin{array}{l}\text { Normed chi-square } \\
\text { (CMIN/DF) }\end{array}$ & $<3$ & 1.250 & $\begin{array}{l}\text { (Hair et al. 2010; } \\
\text { Hu \& Bentler 1999) }\end{array}$ \\
\hline $\begin{array}{l}\text { Adjusted Goodness-of-Fit } \\
\text { Index (AGFI) }\end{array}$ & $\geq 0.8$ & 0.824 & $\begin{array}{l}\text { (Etezadi-Amoli and } \\
\text { Farhoomand 1996) }\end{array}$ \\
\hline $\begin{array}{l}\text { Comparative Fit Index } \\
\text { (CFI) }\end{array}$ & $\geq 0.95$ & 0.969 & $\begin{array}{l}\text { (Hair et al. 2010; } \\
\text { Hu \& Bentler 1999) }\end{array}$ \\
\hline $\begin{array}{l}\text { Root Mean Square Error of } \\
\text { Approximation (RMSEA) }\end{array}$ & $\leq 0.7$ & 0.034 & $\begin{array}{l}\text { (Hair et al. 2010; } \\
\text { Hu \& Bentler 1999) }\end{array}$ \\
\hline TLI (Tucker-Lewis Index) & Approaches 1 & 0.964 & (Byrne 2001) \\
\hline
\end{tabular}

Table 4.3: Summary of reliability and validity measures of the measurement model.

\begin{tabular}{cccccc}
\hline Construct & $\begin{array}{c}\text { Number } \\
\text { of items }\end{array}$ & $\begin{array}{c}\text { Composite } \\
\text { reliability (CR) }\end{array}$ & $\begin{array}{c}\text { Cronbach's } \\
\text { alpha }\end{array}$ & AVE & $\begin{array}{c}\text { Factor } \\
\text { loadings }\end{array}$ \\
\hline BI & 3 & 0.783 & 0.777 & 0.546 & $0.70-0.80$ \\
PE & 4 & 0.892 & 0.891 & 0.676 & $0.79-0.87$ \\
HA & 4 & 0.863 & 0.857 & 0.681 & $0.79-0.84$ \\
TR & 5 & 0.917 & 0.905 & 0.689 & $0.78-0.90$ \\
PV & 3 & 0.812 & 0.797 & 0.591 & $0.78-0.79$ \\
FC & 4 & 0.857 & 0.851 & 0.601 & $0.75-0.84$ \\
SI & 4 & 0.811 & 0.809 & 0.683 & $0.75-0.80$ \\
HM & 3 & 0.885 & 0.869 & 0.722 & $0.82-0.92$ \\
IN & 3 & 0.837 & 0.824 & 0.633 & $0.77-0.87$ \\
MAG & 3 & 0.922 & 0.919 & 0.799 & $0.89-0.94$ \\
EE & 4 & 0.814 & 0.810 & 0.594 & $0.74-0.79$ \\
\hline
\end{tabular}

Note: AVE=Average Variance Extracted, BI=Behavioural intention, $\mathrm{PE}=$ Performance expectancy, HA=Habit, TR=Trust, $\mathrm{PV}=$ Price value, $\mathrm{FC}=$ Facilitating conditions, SI=Social influence, HM=Hedonic motivation, IN= Innovativeness, MAG= Mastery approach goals, and $\mathrm{EE}=\mathrm{Effort}$ expectancy. 
Table 4.4: Square root of Average Variance Extracted (AVE) in bold on diagonal and factor correlation coefficients.

\begin{tabular}{|c|c|c|c|c|c|c|c|c|c|c|c|}
\hline & BI & PE & HA & TR & PV & FC & SI & HM & IN & MAG & $\mathrm{EE}$ \\
\hline BI & 0.739 & & & & & & & & & & \\
\hline $\mathrm{PE}$ & 0.324 & 0.822 & & & & & & & & & \\
\hline $\mathrm{HA}$ & 0.373 & 0.146 & 0.825 & & & & & & & & \\
\hline TR & 0.329 & 0.070 & 0.100 & 0.830 & & & & & & & \\
\hline PV & 0.476 & 0.292 & 0.454 & 0.196 & 0.769 & & & & & & \\
\hline FC & 0.163 & 0.135 & 0.224 & 0.119 & 0.205 & 0.775 & & & & & \\
\hline SI & 0.224 & 0.294 & 0.062 & 0.136 & 0.278 & -0.049 & 0.826 & & & & \\
\hline HM & 0.201 & 0.138 & 0.073 & -0.006 & 0.144 & -0.037 & 0.332 & 0.850 & & & \\
\hline IN & 0.187 & 0.155 & 0.140 & 0.145 & 0.391 & 0.254 & 0.029 & -0.070 & 0.796 & & \\
\hline MAG & 0.079 & -0.083 & 0.080 & 0.159 & 0.014 & 0.001 & -0.174 & -0.024 & 0.202 & 0.894 & \\
\hline EE & 0.350 & 0.076 & 0.477 & -0.078 & 0.367 & 0.442 & 0.072 & 0.119 & 0.342 & -0.035 & 0.771 \\
\hline
\end{tabular}




\subsubsection{Structural model results}

After assessing the measurement model, the structural model (path analysis) was assessed. The overall model fit for the structural model was also good (Table 4.2). Values of the indices CMIN/DF, AGFI, CFI, and RMSEA were the same as the measurement model. The path analysis revealed that four of the ten hypotheses are supported (Table 4.5). Significant positive impacts on behavioural intention (BI) were found for performance expectancy (PE) (confirming H1), effort expectancy (EE) (confirming H2), price value (PV) (confirming H6) and trust (TR) (confirming H9). However, no significant relationships were observed between behavioural intention and the other constructs implying the hypotheses (H3, H4, H5, H7, H8 and H10) could not be supported. The four significant constructs explained $41 \%$ of the variance in behavioural intention to use mobile SMS for agricultural data collection.

Table 4.5: Summary of results of path analysis of the structural model.

\begin{tabular}{cllll}
\hline \multirow{2}{*}{ Hypothesis } & Structural & \multicolumn{2}{c}{ Estimates } & \multirow{2}{*}{ Result } \\
\cline { 2 - 3 } & Path & SRW & $\boldsymbol{p}^{\text {-Value }}$ & \\
\hline H1 & PE $\rightarrow$ BI & 0.211 & $\mathbf{0 . 0 0 7 ^ { * * }}$ & Supported \\
H2 & EE $\rightarrow$ BI & 0.273 & $\mathbf{0 . 0 1 3 ^ { * }}$ & Supported \\
H3 & SI $\rightarrow$ BI & 0.011 & 0.899 & Not supported \\
H4 & FC $\rightarrow$ BI & -0.065 & 0.438 & Not supported \\
H5 & HM $\rightarrow$ BI & 0.090 & 0.230 & Not supported \\
H6 & PV $\rightarrow$ BI & 0.249 & $\mathbf{0 . 0 1 5 ^ { * }}$ & Supported \\
H7 & HA $\rightarrow$ BI & 0.084 & 0.355 & Not supported \\
H8 & IN $\rightarrow$ BI & -0.081 & 0.363 & Not supported \\
H9 & TR $\rightarrow$ BI & 0.286 & $\mathbf{0 . 0 0 0}$ & Supported \\
H10 & MAG $\rightarrow$ BI & 0.071 & 0.329 & Not supported \\
\hline
\end{tabular}

Note: $\mathrm{BI}=$ Behavioural intention, $\mathrm{PE}=$ Performance expectancy, EE=Effort expectancy, SI=Social influence, $\mathrm{FC}=$ Facilitating conditions, $\mathrm{HM}=$ Hedonic motivation, $\mathrm{PV}=$ Price value, $\mathrm{HA}=\mathrm{Habit}, \mathrm{IN}=$ Innovativeness, TR=Trust, $\mathrm{MAG}=$ Mastery approach goals, SRW = Standardized Regression Weight;

*: Significant at $\mathrm{p}<0.05$ and $* *$ : Significant at $\mathrm{p}<0.01$

\subsubsection{Multi-group analysis results}

After establishing configural and metric invariance at the measurement model level, multi-group analyses were conducted at the structural level to determine if participating in the SMS experiment ('experience') and age had a moderation effect. Because the complexity did not allow to include all variables, and no hypotheses were available for the added constructs, the included variables were limited by the ones from UTAUT2. 
Individual path analysis showed that the effect of price value on behavioural intention was significantly higher for "Non SMS farmers" (farmers who did not participate in mobile SMS for agricultural data collection) compared to "SMS farmers" (farmers who have participated in mobile SMS for agricultural data collection) (Table 4.6). The standardised regression weights (SRW) revealed that price value was significant for those farmers who did not participate in the mobile SMS experiment, but not for those who participated in the experiment. The effect of performance expectancy on behavioural intention was significantly higher for younger (and significant) compared to older farmers (not significant) (Table 4.7). The effect of facilitating conditions on behavioural intention narrowly missed significance $(p=0.056)$, but was higher for older farmers.

Table 4.6: Multi-group analysis between "SMS farmers" (farmers who have participated in agricultural data collection) and "Non SMS farmers" (farmers who did not participate in agricultural data collection).

\begin{tabular}{|c|c|c|c|c|c|c|c|}
\hline \multirow{2}{*}{$\begin{array}{c}\text { Structural } \\
\text { path }\end{array}$} & \multicolumn{2}{|c|}{ SMS farmers } & \multicolumn{2}{|c|}{$\begin{array}{c}\text { Non SMS } \\
\text { farmers }\end{array}$} & \multirow{2}{*}{$\triangle X^{2}$} & \multirow{2}{*}{$\triangle \mathrm{df}$} & \multirow{2}{*}{$p^{\text {-Value }}$} \\
\hline & SRW & $p^{- \text {Value }}$ & SRW & $p$-Value & & & \\
\hline $\mathrm{PE} \rightarrow \mathrm{BI}$ & -0.015 & 0.896 & 0.138 & 0.197 & 1.142 & 1 & 0.285 \\
\hline $\mathrm{EE} \rightarrow \mathrm{BI}$ & -0.081 & 0.632 & 0.041 & 0.748 & 0.262 & 1 & 0.608 \\
\hline $\mathrm{SI} \rightarrow \mathrm{BI}$ & 0.072 & 0.520 & 0.034 & 0.770 & 0.004 & 1 & 0.951 \\
\hline $\mathrm{FC} \rightarrow \mathrm{BI}$ & -0.027 & 0.801 & 0.001 & 0.991 & 0.013 & 1 & 0.908 \\
\hline $\mathrm{HM} \rightarrow \mathrm{BI}$ & -0.167 & 0.094 & 0.133 & 0.241 & 3.066 & 1 & 0.080 \\
\hline $\mathrm{PV} \rightarrow \mathrm{BI}$ & 0.221 & 0.099 & 0.532 & $0.000^{*}$ & 10.763 & 1 & $0.001^{*}$ \\
\hline $\mathrm{HA} \rightarrow \mathrm{BI}$ & 0.638 & 0.001 & 0.086 & 0.440 & 0.948 & 1 & 0.330 \\
\hline
\end{tabular}

SRW = Standardized Regression Weight; $\mathrm{X}^{2}=$ chi-square; $\mathrm{df}=$ degree of freedom; $*$ : Significant at $\mathrm{p}<0.01$.

Table 4.7: Multi-group analysis between younger and older farmers.

\begin{tabular}{cccccccc}
\hline \multirow{2}{*}{$\begin{array}{c}\text { Structural } \\
\text { path }\end{array}$} & \multicolumn{2}{c}{ Younger farmers } & \multicolumn{2}{c}{ Older farmers } & $\triangle \mathrm{X}^{2}$ & $\triangle$ df & $p$-Value \\
\cline { 2 - 8 } & SRW & $p^{\text {-Value }}$ & SRW & $p$-Value & & & \\
\hline $\mathrm{PE} \rightarrow$ BI & 0.392 & $\mathbf{0 . 0 0 0 ^ { * }}$ & -0.008 & 0.947 & 4.586 & 1 & $\mathbf{0 . 0 3 2 ^ { * }}$ \\
$\mathrm{EE} \rightarrow$ BI & 0.157 & 0.225 & 0.121 & 0.431 & 0.005 & 1 & 0.943 \\
$\mathrm{SI} \rightarrow$ BI & -0.083 & 0.483 & 0.146 & 0.271 & 1.636 & 1 & 0.201 \\
$\mathrm{FC} \rightarrow$ BI & -0.232 & 0.052 & 0.115 & 0.370 & 3.665 & 1 & 0.056 \\
$\mathrm{HM} \rightarrow$ BI & 0.100 & 0.311 & 0.067 & 0.562 & 0.028 & 1 & 0.868 \\
$\mathrm{PV} \rightarrow$ BI & 0.356 & 0.034 & 0.314 & 0.023 & 0.215 & 1 & 0.643 \\
$\mathrm{HA} \rightarrow$ BI & 0.111 & 0.423 & 0.056 & 0.655 & 0.139 & 1 & 0.709 \\
\hline
\end{tabular}

SRW = Standardized Regression Weight; $\mathrm{X}^{2}=$ chi-square; $\mathrm{df}=$ degree of freedom; $*$ : Significant at $\mathrm{p}<0.05$. 


\subsection{Discussion and implications}

The purpose of this study was firstly to investigate the intention to adopt mobile SMS by smallholder farmers to provide farm related information. Second, to assess the role of farmer's characteristics (i.e., age and experience) in predicting farmer's behavioural intention to adopt mobile SMS. To address these objectives, the current study employed and extended UTAUT2 with additional constructs of trust, mastery-approach goals and personal innovativeness in information technology.

\subsubsection{Constructs affecting behavioural intention}

The factors that positively influence farmer's intention to adopt mobile SMS for agricultural data provision are performance expectancy, effort expectancy, price value and trust (Table 4.5). While the UTAUT2 model of Venkatesh et al. (2012) explained $44 \%$ of variance in consumers behavioural intention to use mobile internet when the interaction terms (i.e. age, gender and experience) were not included, the three significant factors from the UTAUT2 model in this study explained $32 \%$ of the variance in farmer's intention to adopt mobile SMS for agricultural data collection. The extended model with the additional construct of trust explained $41 \%$ of the variance in farmer's intention to adopt mobile SMS. Getting significant results from additional constructs such as trust indicates the importance of tailoring technology adoption models originally developed for the organisational context to other contexts like mobile data services (e.g. SMS) (Baptista and Oliveira 2015).

The finding of the relationship of performance expectancy with behavioural intention (H1) is consistent with earlier studies in consumers SMS adoption (Kim et al. 2008), mobile banking (Baptista and Oliveira 2015; Oliveira et al. 2014; Zhou et al. 2010), SMS advertising (Muk and Chung 2015), mobile egovernment services (Hung et al. 2013) and adoption of mobile devices/services (Carlsson et al. 2006). In the agricultural domain, studies also found the importance of performance expectancy on the intention of farmers to adopt decision support tools (Rose et al. 2016), precision agriculture (D'Antoni et al. 2012; Adrian et al. 2005) and dairy farming technology (Flett et al. 2004).

The significant impact of performance expectancy on farmer's intention to adopt mobile SMS indicates that using mobile SMS needs to provide utilitarian benefits to the farmers. For example, providing location specific agronomic advice or feedback based on the data received by SMS, which can help the farmers in their management decisions to improve agricultural production, can be an option to show the practical benefit of using mobile SMS for data provision (Car et al. 2012; Aker 2011). 
The research model validated the positive relationship between effort expectancy and behavioural intention (H2). This implies that a farmer who perceives operating the mobile phone to send SMS requires low effort, has a high intention to adopt the mobile SMS for data collection. The finding is consistent with other studies in consumers SMS adoption (Kim et al. 2008), and farmers adoption of decision support systems (Rose et al. 2016) and precision agriculture (Aubert et al. 2012). This finding is also relevant with regard to the question which data collection method to use: while more advanced methods such as smartphones and tablets may be available, the selected method should be suitable for the target community.

The other core factor from the UTAUT2 constructs that has a significant impact on mobile SMS adoption is price value. This implies that the lower the costs for using the mobile SMS, the higher the intention for the farmers to adopt mobile SMS for agricultural data collection. Similar results were found by studies in adoption of decision support tools (Rose et al. 2016).

The results (Table 4.5) show that social influence (H3), facilitating conditions (H4), hedonic motivation (H6), habit (H7), personal innovativeness (H8) and mastery-approach goals (H10) are not significant predictors of behavioural intention to adopt mobile SMS. As farmers in the current study have a collectivistic culture, it was anticipated that social influence would positively affect behavioural intention to adopt mobile SMS. However, our study revealed that social influence is not a strong predictor of farmer's behavioural intention to adopt mobile SMS. This implies that farmers will not simply adopt a technology because important others (e.g. friends or neighbours) are using the technology. Facilitating conditions were also found to have no effect on farmers intention to adopt mobile SMS. This is consistent with what was reported in earlier studies (Baptista and Oliveira 2015; Im et al. 2011). When there is a facilitating condition (e.g., resources, getting support from extension workers) to help farmers to use mobile SMS for agricultural data collection, they do not give it much importance (Baptista and Oliveira 2015). The low importance of hedonic motivation shows that farmers do not enjoy using mobile SMS technology. The low importance of habit can be explained by the fact that the farmers did not have previous experience of using mobile SMS for agricultural data collection and hence it is not yet their habit. The low importance of mastery-approach goals indicate that farmers did not believe that using mobile SMS will help them to improve their level of competence in crop production. Farmers are already using mobile phones (e.g., to access market and weather information) in Ethiopia (Beza et al. 2017b). As a result, they did not consider using the SMS feature of the phone as being innovative. 


\subsubsection{Implications for citizen science in agriculture}

Identifying the most important factors that affect the adoption of mobile technology for data collection is essential for citizen science practitioners and also for researchers who would like to use the citizen science approach to collect farm related information.

In this study, it was revealed that performance expectancy, effort expectancy, price value and trust are the most important factors for the farmers to adopt mobile SMS for data collection. Among these factors, trust is the strongest predictor of farmers intention to adopt mobile SMS to provide their farm related information. This clearly indicates that in order to use the citizen science approach in the agricultural domain, establishing a trusted relationship with the smallholder farming community is crucial. Unlike other citizen science participants who can provide observations without caring much about the implementers (e.g. bird watchers), for farmers the trustworthiness of the people or organisation behind the citizen science campaign is important before sharing their farm related information. At the start of agricultural citizen science initiatives, cooperatives and farmers associations would probably be well placed to take the lead to establish relationships between farmers and citizen science initiatives (Aubert et al. 2012). They already have close relationships with the farmers, and are likely to be perceived as more trustable. Working with local institutes (e.g., research centres and NGOs) which have a good reputation is another alternative to establish initial trust between farmers and citizen science initiatives. Both types of stakeholders (research centres and NGOs) participated in the two projects (N2Africa and SBN) in which the citizen science experiments in this study were performed. Overtime when the relationship between citizen science initiatives and farming community develops, trust between farmers and citizen science initiatives will evolve.

Given that performance expectancy significantly predicted farmer's behavioural intention to adopt mobile SMS, managers of agricultural citizen science projects need to ensure that using mobile SMS for agricultural data collection offers utilitarian benefits to the farmers. For example, providing location specific agronomic advice or feedback based on the data received by SMS, which can help the farmers in their management decisions to improve agricultural production, can be an option to show the practical benefit of using mobile SMS for data provision (Beza et al. 2017b; Car et al. 2012; Antonopoulou et al. 2010).

The multi-group analysis between younger and older farmers reveals that performance expectancy is more important for younger farmers compared to older farmers to adopt mobile SMS (Table 4.7). The possible reason for this may 
be younger farmers are less experienced with farming and hence demand more external information (Taragola and Van Lierde 2010; Schnitkey et al. 1992). Therefore, they expect using mobile SMS will create an opportunity to access information related to farming and also enable them to interact with agronomic experts. For agricultural citizen science initiatives, planning to provide agronomic advice based on the data received, the result highlights the importance of tailoring advises for farmers based on farmer's characteristics (e.g. age).

The comparison between experienced (i.e. "SMS farmers", farmers who have participated in mobile SMS for agricultural data collection) and unexperienced farmers (i.e. "Non SMS farmers", farmers who did not participate in mobile SMS for agricultural data collection) shows that the price value is more important for the "Non SMS farmers" compared to the "SMS farmers" to adopt mobile SMS (Table 4.6). The reason that price value was relatively less important for "SMS farmers" is that in the studied setting the costs of sending the SMS were covered by the projects, and not by the farmers who participated in the experiment. The fact that price value was specifically important for "Non SMS farmers" indicates that projects implementing citizen science need to find a mechanism where the SMS data transmission is free of charge (e.g. by providing free airtime).

\subsubsection{Implications for mobile app developers and policy makers}

The importance of effort expectancy on farmers intention to adopt mobile SMS clearly indicates that mobile phone software developers need to develop easy to use SMS apps. Iannone Iii et al. (2012), in a study of citizen science to assess the abundance of earthworms, stated that a data collection method for citizen science must meet three criteria: (1) ease, (2) safety, and (3) reliability. To simplify the data collection process, applications that support Interactive Voice Response (IVR) (e.g., Robinson and Obrecht 2016) and icon-based user interfaces can potentially be developed (e.g., Herrick et al. 2016). The study of Wyche and Steinfield (2016) discovered a mismatch between the design of market information services (MIS) and smallholder farmers' perceptions of their mobile phones' communication capabilities. While designing mobile SMS applications for agricultural data collection, the farming community needs to be considered (Alvarez and Nuthall 2006) and applications need to be developed following the design principles for low-literacy users (Medhi et al. 2011).

In other sectors (e.g. forestry), researchers have shown the high potential of local communities using mobile phones for national forest monitoring (Pratihast et al. 2013a). The lessons learnt from the forestry sector can also be extended to the agricultural domain. To integrate ICT tools like mobile phones 
in the agricultural sector to collect agricultural information or food security indicators in developing countries (e.g. Hammond et al. 2016) directly from the farmers, there needs to be an enabling environment. As most of the farmers in the rural areas are low-literate, the use of mobile phones for data collection need to be supported by the agricultural extension system.

\subsubsection{Limitations and future research}

Despite its contributions regarding factors that are important for smallholder farmers to adopt mobile SMS for agricultural citizen science, this study is not without limitations. These limitations provide fruitful avenues for future research. First, since half of the farmers participated in this study did not experience the use of mobile SMS for agricultural data collection, we did not examine the effect of behavioural intention on use behaviour. Therefore, it is recommended that future research takes a longitudinal approach which would enable the examination of the effect of behavioural intention on farmers use behaviour. Longitudinal research would also allow to assess if the importance of the constructs would change over time. For example, the effect of trust on farmers behavioural intention to use mobile SMS might become unimportant when farmers trust towards the people and/or organisation managing the citizen science initiative develops. Second, the study does not claim to statistically represent farmers in Ethiopia (e.g. in terms of gender), so it would be interesting to test the model with more woman farmers. Finally, the important factors for technology adoption might differ from location to location, so assessing the validity of this model with farmers across different cultures both in developed and developing countries would be theoretically and practically useful.

\subsection{Conclusion}

The main objective of this research was to explore the factors that influence farmers' adoption of mobile SMS for agricultural data collection. A second objective was to assess the role of farmer's characteristics (i.e., age and experience) in predicting farmer's behavioural intention to adopt mobile SMS. Results showed that farmers' behavioural intention to adopt mobile SMS was influenced by performance expectancy, effort expectancy, price value and trust. These four constructs explained $41 \%$ of the variance of farmers' behavioural intention to adopt mobile SMS. Among these factors, trust is the strongest predictor of farmers intention to adopt mobile SMS to provide their farm related information. This clearly highlights the importance of establishing a trusted relationship with the farming community in order to utilize the full potential of citizen science in the agricultural domain. In addition, managers of agricultural citizen science projects need to ensure that using mobile SMS for agricultural data collection offers utilitarian benefits to the farmers. 
Further, the technology that will be used as part of the digital citizen science need to be easy to use by the farmers. Moreover, the cost of using the technology need to be affordable by the farmers and whenever possible, the citizen science projects need to cover the data transmission cost. Multi-group analysis using farmer's characteristics age and experience as moderator variables revealed that performance expectancy was important for younger farmers; whereas price value was important for farmers who did not participate in a mobile SMS experiment.

\section{Acknowledgements}

This research was carried out in a $\mathrm{PhD}$ project and it is part of Wageningen University \& Research strategic program 'Mapping for sustainable intensification', 2012-2016, funded by the Strategic Funds of Wageningen UR. The first author received financial support for his fieldwork from N2Africa (www.N2Africa.org) and Geodata for Agriculture and Water: CommonSense projects of Wageningen University \& Research. The authors would like to thank the agronomic team members of Sesame Business Network and N2Africa and the extension workers for their dedicated and continuous support during the mobile SMS experiments and during the data collection period. Finally, we would like to thank all the farmers who were volunteer to participate both in the mobile SMS experiments and in this research. 
Appendix 4.1. List of factors and associated group names

\begin{tabular}{lc}
\hline \multicolumn{1}{c}{ List of activities } & Group name \\
\hline Start/end of land clearing & \\
Start/end of land cleaning & Land \\
Start/end of first ploughing & preparation \\
Start/end of second ploughing & \\
Start/end of third ploughing & \\
Start/end of row making & Planting \\
\hline Start/end of sowing/planting & \\
Start/end of gap filling & Weeding \\
Start/end of thinning & \\
\hline Start/end of 1st weeding & \\
Start/end of 2nd weeding & \\
Start/end of 3rd weeding & Crop \\
\hline Date of Emergence & characteristics \\
Date of full canopy closure (no bare soil to be seen) & \\
Start/end of flowering & \\
Full flowering & Crop \\
Crop reaching full maturity (yellowed and ready for harvest) & \\
Start/end of harvesting & protection \\
\hline Start/end of fertilizer application & \\
\hline Start/end of pest scouting & \\
Start/end of pest control/chemical application in the field & \\
\hline Start/end of preparing drying spots & \\
Start/end of threshing & \\
Start/end of winnowing and cleaning & \\
Start/end of bagging sesame in the field & \\
Start/end of loading sesame bags for transporting to store & \\
(home) & \\
Start/end of transporting sesame bags to store (home) & \\
Start/end of (un)loading sesame bags in the store (home) & \\
Start/end of chemical application in the store (home) \\
Start/end of loading bags for transporting sesame to market \\
Start/end of transporting bags to market \\
Start/end of unloading bags in the market & \\
\hline & \\
\hline & \\
\hline
\end{tabular}


Appendix 4.2. Questionnaire to assess mobile SMS technology acceptance of farmers

The main purpose of this survey is to assess the SMS technology acceptance of farmers as a data provision tool to provide agricultural information for yield gap analysis.

\section{Background information}

1.1. Date of interview:

1.2. Region:

1.3. District/Woreda: 1.4. Kebele/Village:

\section{Introduction}

Introduce yourself and explain the purpose of the survey as it will mainly be used for research purpose and assure the interviewee of the confidentiality. Please check if the farmer has any questions at this time.

\section{General information of the respondent}

3.1. Name of the respondent:

3.2. Gender: Male[ ] Female[ ]. 3.3. Age (years): ___ 3.4. Marital status:

3.5. Educational level (grade/illiterate):

3.6. Distance to the nearest city (Min)

\section{Mobile phone information}

4.1. Mobile number:

4.2. Number of years of using mobile phone (Years) (Months)

4.3. Did you send SMS in the 2014/2015 growing season about the N2Africa/SBN 20 steps field? Yes[ ] No [ ]

4.4. If yes, how many SMS messages did you send over the growing season?

4.5. Did you use another mobile number to send SMS about the N2Africa/SBN 20 steps field? Yes[ ] No[ ]

4.6. If yes, mobile number(s) used to send SMS about the N2Africa/SBN 20 steps field

4.7. Did you ever send SMS before you participate in N2Africa/SBN SMS pilot data collection campaign? Yes[] No[]

4.8. What do you prefer to provide agronomic information?

Calling[ ] SMS messaging[] Face-to-face[ ] Other: 
Exploring farmers' intentions to adopt mobile Short Message Service (SMS) for citizen science in agriculture

\begin{tabular}{ccccc}
\hline 1 & 2 & 3 & 4 & 5 \\
$\begin{array}{c}\text { Disagree } \\
\text { strongly }\end{array}$ & Disagree & $\begin{array}{c}\text { Neither agree } \\
\text { nor disagree }\end{array}$ & Agree & Agree strongly \\
\hline
\end{tabular}

\begin{tabular}{|l|l|c|c|c|c|c|}
\hline \multicolumn{2}{|c|}{} & $\mathbf{1}$ & $\mathbf{2}$ & $\mathbf{3}$ & $\mathbf{4}$ & $\mathbf{5}$ \\
\hline 4.9. & I have lots of experience of using SMS messaging & $\bigcirc$ & $\bigcirc$ & $\bigcirc$ & $\bigcirc$ & $\bigcirc$ \\
\hline
\end{tabular}

\section{Read [the following scripted introduction].}

Dear [name of farmer] first I would like to thank you once again for participating in this interview. The questions I ask you after this point are related to your mobile phone, mainly the use of your mobile phone to send agronomic information using short message system (SMS). Thank you for your valuable time and we will proceed to the questions. Please indicate the degree to which you agree with each statement by using the following scale.

\begin{tabular}{ccccc}
\hline 1 & 2 & 3 & 4 & 5 \\
$\begin{array}{l}\text { Disagree } \\
\text { strongly }\end{array}$ & Disagree & $\begin{array}{c}\text { Neither agree } \\
\text { nor disagree }\end{array}$ & Agree & Agree strongly \\
\hline
\end{tabular}

\begin{tabular}{|c|c|c|c|c|}
\hline $\begin{array}{l}\text { Item } \\
\text { No. }\end{array}$ & Constructs & Items & No. & Source \\
\hline 1 & $\begin{array}{l}\text { Behavioural } \\
\text { Intention } \\
\text { (BI) }\end{array}$ & $\begin{array}{l}\text { - I intend to use or continue } \\
\text { using mobile SMS messaging } \\
\text { in the future }\end{array}$ & BI1 & $\begin{array}{l}\text { (Venkatesh et al. } \\
\text { 2012; Venkatesh } \\
\text { et al. 2003) }\end{array}$ \\
\hline 2 & & $\begin{array}{l}\text { - I will always try to use mobile } \\
\text { SMS messaging in my daily } \\
\text { life }\end{array}$ & $\mathrm{BI} 2$ & \\
\hline 3 & & $\begin{array}{l}\text { - I plan to use or continue using } \\
\text { mobile SMS messaging } \\
\text { frequently }\end{array}$ & BI3 & \\
\hline 4 & $\begin{array}{l}\text { Performance } \\
\text { Expectancy } \\
\text { (PE) }\end{array}$ & $\begin{array}{l}\text { - I find mobile SMS messaging } \\
\text { useful in my daily life }\end{array}$ & PE1 & $\begin{array}{l}\text { (Venkatesh et al. } \\
\text { 2012; Venkatesh } \\
\text { et al. 2003) }\end{array}$ \\
\hline 5 & & $\begin{array}{l}\text { - Using mobile SMS messaging } \\
\text { increases my productivity }\end{array}$ & PE2 & \\
\hline 6 & & $\begin{array}{l}\text { - Using mobile SMS messaging } \\
\text { helps me accomplish things } \\
\text { more quickly in the farm }\end{array}$ & PE3 & \\
\hline 7 & & $\begin{array}{l}\text { - Using mobile SMS messaging } \\
\text { increases my chances of } \\
\text { achieving high crop } \\
\text { productivity }\end{array}$ & $\mathrm{PE} 4$ & \\
\hline
\end{tabular}




\begin{tabular}{|c|c|c|c|c|}
\hline $\begin{array}{l}\text { Item } \\
\text { No. }\end{array}$ & Constructs & Items & No. & Source \\
\hline 8 & $\begin{array}{l}\text { Effort } \\
\text { Expectancy } \\
\text { (EE) }\end{array}$ & $\begin{array}{l}\text { - Learning how to use mobile } \\
\text { SMS messaging is easy for me }\end{array}$ & EE1 & $\begin{array}{l}\text { (Venkatesh et al. } \\
\text { 2012; Venkatesh } \\
\text { et al. 2003) }\end{array}$ \\
\hline 9 & & $\begin{array}{l}\text { - My interaction with mobile } \\
\text { SMS messaging is clear and } \\
\text { understandable }\end{array}$ & EE2 & \\
\hline 10 & & $\begin{array}{l}\text { - I find mobile SMS messaging } \\
\text { easy to use }\end{array}$ & EE3 & \\
\hline 11 & & $\begin{array}{l}\text { - It is easy for me to become } \\
\text { skilful at using mobile SMS } \\
\text { messaging }\end{array}$ & $\mathrm{EE} 4$ & \\
\hline 12 & $\begin{array}{l}\text { Social } \\
\text { Influence } \\
\quad \text { (SI) }\end{array}$ & $\begin{array}{l}\text { - People who are important to } \\
\text { me think that I should use } \\
\text { mobile SMS messaging }\end{array}$ & SI1 & $\begin{array}{l}\text { (Venkatesh et al. } \\
\text { 2012; Venkatesh } \\
\text { et al. 2003) }\end{array}$ \\
\hline 13 & & $\begin{array}{l}\text { - People who influence my } \\
\text { behaviour think that I should } \\
\text { use mobile SMS messaging }\end{array}$ & $\mathrm{SI} 2$ & \\
\hline 14 & & $\begin{array}{l}\text { - People whose opinions that I } \\
\text { value prefer that I use mobile } \\
\text { SMS messaging }\end{array}$ & SI3 & \\
\hline 15 & & $\begin{array}{l}\text { - People who are important to } \\
\text { me would use mobile SMS } \\
\text { messaging themselves }\end{array}$ & SI4 & \\
\hline 16 & $\begin{array}{l}\text { Facilitating } \\
\text { Conditions } \\
\text { (FC) }\end{array}$ & $\begin{array}{l}\text { - I have the resources } \\
\text { necessary to use mobile SMS } \\
\text { messaging }\end{array}$ & FC1 & $\begin{array}{l}\text { (Venkatesh et al. } \\
\text { 2012; Venkatesh } \\
\text { et al. 2003) }\end{array}$ \\
\hline 17 & & $\begin{array}{l}\text { - I have the knowledge } \\
\text { necessary to use mobile SMS } \\
\text { messaging }\end{array}$ & $\mathrm{FC} 2$ & \\
\hline 18 & & $\begin{array}{l}\text { - Mobile SMS messaging is } \\
\text { compatible with other } \\
\text { technologies I use }\end{array}$ & FC3 & \\
\hline 19 & & $\begin{array}{l}\text { - I can get help from others } \\
\text { (e.g. extension workers or } \\
\text { children ) when I have } \\
\text { difficulties using mobile SMS } \\
\text { messaging }\end{array}$ & FC4 & \\
\hline
\end{tabular}


Exploring farmers' intentions to adopt mobile Short Message Service (SMS) for citizen science in agriculture

\begin{tabular}{|c|c|c|c|c|}
\hline $\begin{array}{l}\text { Item } \\
\text { No. }\end{array}$ & Constructs & Items & No. & Source \\
\hline 20 & $\begin{array}{l}\text { Hedonic } \\
\text { Motivation } \\
\quad(\mathrm{HM})\end{array}$ & $\begin{array}{l}\text { - Using mobile SMS messaging } \\
\text { is fun }\end{array}$ & HM1 & $\begin{array}{l}\text { (Venkatesh et al. } \\
\text { 2012) }\end{array}$ \\
\hline 21 & & $\begin{array}{l}\text { - Using mobile SMS messaging } \\
\text { is enjoyable }\end{array}$ & HM2 & \\
\hline 22 & & $\begin{array}{l}\text { - Using mobile SMS messaging } \\
\text { is very entertaining }\end{array}$ & HM3 & \\
\hline 23 & $\begin{array}{l}\text { Price } \\
\text { Value } \\
\text { (PV) }\end{array}$ & $\begin{array}{l}\text { - Mobile SMS messaging is } \\
\text { reasonably priced }\end{array}$ & PV1 & $\begin{array}{l}\text { (Venkatesh et al. } \\
2012 \text { ) }\end{array}$ \\
\hline 24 & & $\begin{array}{l}\text { - Mobile SMS messaging is a } \\
\text { good value for the money }\end{array}$ & PV2 & \\
\hline 25 & & $\begin{array}{l}\text { - At the current price, mobile } \\
\text { SMS messaging provides a } \\
\text { good value }\end{array}$ & PV3 & \\
\hline 26 & $\begin{array}{l}\text { Habit } \\
\text { (HA) }\end{array}$ & $\begin{array}{l}\text { - The use of mobile SMS } \\
\text { messaging has become a habit } \\
\text { for me }\end{array}$ & HA1 & $\begin{array}{l}\text { (Venkatesh et al. } \\
\text { 2012) }\end{array}$ \\
\hline 27 & & $\begin{array}{l}\text { - I am addicted to using mobile } \\
\text { SMS messaging }\end{array}$ & HA2 & \\
\hline 28 & & $\begin{array}{l}\text { - I must use mobile SMS } \\
\text { messaging }\end{array}$ & HA3 & \\
\hline 29 & & $\begin{array}{l}\text { - Using mobile SMS messaging } \\
\text { has become natural to me }\end{array}$ & HA4 & \\
\hline 30 & $\begin{array}{l}\text { Trust } \\
\text { (TR) }\end{array}$ & $\begin{array}{l}\text { - SBN1/N2Africa is very } \\
\text { concerned about my } \\
\text { sesame/chickpea }{ }^{2} \text { crop } \\
\text { production }\end{array}$ & TR1 & $\begin{array}{l}\text { (Mayer and } \\
\text { Davis 1999) }\end{array}$ \\
\hline 31 & & $\begin{array}{l}\text { - My needs and desires are very } \\
\text { important to SBN/N2Africa }\end{array}$ & TR2 & \\
\hline 32 & & $\begin{array}{l}\text { - SBN/N2Africa would not } \\
\text { knowingly do anything to } \\
\text { hurt me }\end{array}$ & TR3 & \\
\hline 33 & & $\begin{array}{l}\text { - SBN/N2Africa really looks out } \\
\text { for what is important to me }\end{array}$ & TR4 & \\
\hline 34 & & $\begin{array}{l}\text { - SBN/N2Africa will go out of } \\
\text { its way to help me }\end{array}$ & TR5 & \\
\hline
\end{tabular}




\begin{tabular}{|c|c|c|c|c|}
\hline $\begin{array}{c}\text { Item } \\
\text { No. }\end{array}$ & Constructs & Items & No. & Source \\
\hline 35 & $\begin{array}{l}\text { Mastery- }^{-} \\
\text {approach goals } \\
\text { (MAG) }\end{array}$ & $\begin{array}{l}\text { - I want to learn as much as } \\
\text { possible about } \\
\text { sesame/chickpea crop } \\
\text { production }\end{array}$ & MAG1 & $\begin{array}{l}\text { (Elliot and } \\
\text { McGregor 2001) }\end{array}$ \\
\hline 36 & & $\begin{array}{l}\text { - It is important for me to } \\
\text { completely understand the } \\
\text { recommendations provided by } \\
\text { SBN/N2Africa about } \\
\text { sesame/chickpea crop } \\
\text { production }\end{array}$ & MAG2 & \\
\hline 37 & & $\begin{array}{l}\text { - I desire to completely master } \\
\text { sesame/chickpea crop } \\
\text { production }\end{array}$ & MAG3 & \\
\hline 38 & $\begin{array}{l}\text { Innovativeness } \\
\text { (IN) }\end{array}$ & $\begin{array}{l}\text { - If I heard about a new } \\
\text { technology, I would look for } \\
\text { ways to experiment with it }\end{array}$ & IN1 & (Yi et al. 2006) \\
\hline 39 & & $\begin{array}{l}\text { - Among my peers, I am } \\
\text { usually the first to explore } \\
\text { new gadgets \& technologies }\end{array}$ & IN2 & \\
\hline 40 & & $\begin{array}{l}\text { - I like to experiment with new } \\
\text { technologies }\end{array}$ & IN3 & \\
\hline
\end{tabular}

\footnotetext{
${ }^{1}$ Sesame Business Network

2 The word sesame was used while surveying farmers in the Sesame Business Network project and chickpea was used for N2Africa farmers.
} 


\section{Chapter}

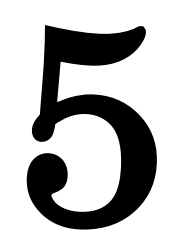

\section{Remote sensing and crowdsourcing for estimating and explaining yields: sesame in Ethiopia}

Eskender Beza, Eliakim Hamunyela, Pytrik Reidsma, Melisew Misker Belay, Lammert Kooistra 


\section{Abstract}

This study aimed to use the synergy of remote sensing and crowdsourcing to estimate and explain yields. Sesame production on medium and large farms in Ethiopia was used as a case study. Firstly, the potential of vegetation indices based on remote sensing images for predicting sesame yield at the field level was explored. A total of 14 Landsat-8 images, representing different growth stages, were used to derive vegetation indices (VIs). Secondly, crowdsourced data on crop phenology was used to improve the prediction of yields based on VIs. Thirdly, farmer reported data using the crowdsourcing approach was compared to the predicted yield from the VIs, in order to explain yield variability among and within fields. Results of the study showed that there is a correlation between sesame actual yield as reported by farmers and predicted yield based on VIs. The highest correlation was observed between sesame actual yield and the predicted yield using average NDVI over the growing season $\left(\mathrm{R}^{2}=0.65\right.$, RMSE $\left.=0.62\right)$. Crowdsourced information related to crop phenology per field used to adjust the VIs, could further improve the performance of the model to predict sesame yield. As yield estimation based on measurements or surveys are not always reliable, the increasing spatial resolution of remote sensing images thus provides increased potential for yield estimation. Crowdsourced information could further identify factors that caused the yield variability within a field, and locations with lower yields in the remote sensing images largely overlapped with locations with reported yield limiting and/or reducing factors. According to the perception of farmers, overall soil fertility is the most important factor explaining the yield variability within a field, followed by high presence of weeds. Identifying the variation within a field based on different types of information will assist the farmers in managing their agricultural practices. While the analysis described in this chapter focused on sesame yield in Ethiopia, the approach of coupling remote sensing with crowdsourcing has the potential to support yield monitoring and forecasting efforts in the other parts of the world.

Keywords: citizen science, yield gap analysis, satellite imagery, actual yield estimation, Sesamum indicum L., vegetation index, Ethiopia, Landsat-8 


\subsection{Introduction}

Closure of the existing yield gap on currently available agricultural lands has been pointed as one of the possible pathways to meet the future food demand (Cassman 1999). Yield gap is estimated as the difference between a benchmarking yield (potential yield (Yp), for irrigated crops or water-limited yield (Yw), for rainfed crops) and actual yield (Ya). This means yield gap estimation requires two quantities: a benchmarking yield and actual yield. The study of (Lobell et al. 2009) provides a detailed explanation about the different approaches used to estimate the benchmarking yield. The second important parameter required and often a bottleneck for yield gap analysis is actual yield (Grassini et al. 2015). For yield gap analysis to have a strong local agronomic relevance (van Ittersum et al. 2013) and to further understand the main factors causing the yield gap, more local studies at the farming system level are needed (Silva et al. 2017; Affholder et al. 2013). However, the main drawback for this type of analysis is that, it requires detailed information including actual yield for each field from a large number of farms (Beza et al. 2017a). The most common traditional methods (e.g., farm surveys and crop cuts) to collect crop yield information are expensive, time-consuming, labour-intensive, and often difficult (Fermont and Benson 2011), and are also limited in spatial and temporal coverage. The study of Fermont and Benson (2011) provides a detailed description about the common traditional approaches to collect crop yield information.

Remote sensing is an alternative to complement/substitute the traditional methods to collect crop yield information. Remote sensing has been successfully used for yield estimation and monitoring over the last few decades due to its ability to acquire spatiotemporal data over a large region (Son et al. 2014; Schulthess et al. 2013). Generally three approaches have been suggested to estimate crop yield using remote sensing data (Lobell 2013). The first approach is based on an empirical relationship that relates ground-based yield measures to vegetation indices (VIs) derived from remotely sensed surface reflectance measured on a single date or integrated over the growing season (Schulthess et al. 2013; Mkhabela et al. 2011). Among the different VIs, the Normalised Difference Vegetation Index (NDVI), the Soil Adjusted Vegetation Index (SAVI), the Modified Soil Adjusted Vegetation Index (MSAVI) and the Enhanced Vegetation Index (EVI) have become popular indicators for studying vegetation health and crop production (Kayad et al. 2016; Johnson 2016).

The second approach to estimate yield is by incorporating VIs or biophysical variables (such as LAI) derived from remote sensing data into crop growth simulation models (Rembold et al. 2013; Dente et al. 2008; Doraiswamy et al. 2005). The simulated yield by the model then provides an estimate of crop yield. 
The third approach is by using the relationship between the fraction of photosynthetically active radiation (fPAR) and crop yield (Monteith and Moss 1977).

Regarding the first approach, previous studies have examined how the relationship between VIs derived from multi-temporal remote sensing and crop yield vary over the growing season (Mkhabela et al. 2011; Wall et al. 2008). The results from these studies have revealed that the correlation between VIs and yield varies through the crop cycle (Mkhabela et al. 2011; Wall et al. 2008). However, crop planting dates and phenology vary by location and change from one year to the next. Thus, using a fixed calendar date to estimate remote sensing-based yield prediction models (e.g., Mkhabela et al. 2011) is not optimal (Bolton and Friedl 2013). Different approaches have been used to capture the spatial variations in planting dates and crop phenology. Some studies have accounted for variations in planting dates and phenology using the onset of the rainy season (e.g., Funk and Budde 2009)) or using the seasonal NDVI curve derived from AVHRR (e.g., Reynolds et al. 2000). Other studies used crop phenology derived from remote sensing data to capture local variation in the timing of optimum periods to use VI for crop yield estimation (e.g., Bolton and Friedl 2013; Funk and Budde 2009). The drawback of using crop phenology information mostly derived from coarse remote sensing data is its limited ability to monitor individual fields (Duncan et al. 2015a). With the advent and ubiquitous availability of mobile phones, crop phenology information can be collected from a large number of individual farmers using the crowdsourcing approach (i.e., farmers send crop phenology dates through SMS) (Beza et al. submitted). The crowdsourced crop phenology information can then be used to improve estimates of crop yields based on remotely sensed VIs at the field level.

While remote sensing may provide improved estimates of actual yields, and information from crowdsourcing may further improve these estimates, crowdsourcing is specifically relevant for explaining yields. It has earlier been argued that farmers' knowledge should be increasingly used in agricultural research (Doré et al. 2011), and crowdsourcing provides new opportunities (Beza et al. 2017a).

The objective of this study was to investigate the capability of remote sensing satellite time-series to estimate and map actual yield at the field level and to explore the potential of bottom-up data collection approaches (e.g., crowdsourcing) to identify the main factors that caused the yield variability within a field. Sesame production on medium and large farms in Ethiopia was used as a case study. The main research question was: how can synergy of remote sensing and crowdsourced data improve the estimation and explanation 
of yield variability? Specific research questions include: (1) which vegetation index is most appropriate to predict sesame yield?, (2) which time of the growing season and number of satellite observations is most suitable to estimate sesame yield using satellite time-series?, (3) can crowdsourced information related to crop phenology be used to improve predictions of sesame yield?, (4) how can farmers crowdsourced data be related to the remote sensing mapped yield variability within a field?, and (5) which factors are important to explain sesame yield variability within a field?

\subsection{Materials and methods}

\subsubsection{Study area}

The study was conducted in three districts in the North-western part of Ethiopia, namely: Mirab Armacho ( $\left.13^{\circ} 13^{\prime} \mathrm{N}, 36^{0} 26^{\prime} \mathrm{E}\right)$, Metemma ( $13^{\circ} 00^{\prime} \mathrm{N}$, $36^{0} 15^{\prime} \mathrm{E}$ ) and Qwara $\left(12^{0} 30^{\prime} \mathrm{N}, 35^{\circ} 45^{\circ} \mathrm{E}\right)$ (Figure 5.1). Agriculture in the region is characterised by a single harvest per year, with a growing season that extends from July to late October. Sesame (Sesamum indicum L.), sorghum (Sorghum vulgare Pers.) and cotton are the main crops produced in the region. Among the crop types, sesame is the focus of this study. For the current study, 45 sesame growing fields from the aforementioned three districts were selected at the start of the 2015 cropping season. The mean area of the studied fields was 34.8 ha and their mean yield was 3.0 quintals/ha.

\subsubsection{Multi-temporal remote sensing data acquisition and processing}

We downloaded Landsat 8 (Level 1 GeoTIFF) data products (vegetation indices) from June to November 2015 covering the study area from the archives of USGS using EarthExplorer (http://earthexplorer.usgs.gov/). Three tiles were needed to cover the study area (Figure 5.1). The downloaded images contained values for the Normalised Difference Vegetation Index (NDVI), Enhanced Vegetation Index (EVI), Soil Adjusted Vegetation Index (SAVI) and Modified Soil Adjusted Vegetation Index (MSAVI). In total, 14 images per vegetation index were available for our study (Table 5.1). Dates of satellite images are presented in Table 5.1.

Each of the vegetation indices images were then processed to mask out pixels which were covered with cloud and cloud shadow using the cloud mask (fmask) distributed with the Landsat surface reflectance data products (Zhu and Woodcock 2012). The cleaned images were then stacked and used to extract temporal and spatial values of each of the vegetation indices over the growing season for each field. We used the extent (boundary) of the fields to clip out pixel values of each of the vegetation indices for each field from the stacked images. For each field two profiles per vegetation index were extracted. The first profile (hereafter optimum growing period VI) is based on the optimum 
growing period (i.e., using all the available images during the growing period) (Figure 5.2). The second profile (hereafter phenologically adjusted VI) is based on crop phenology information crowdsourced by the farmers (i.e., phenologically adjusted vegetation index profile). For the second profile, only images acquired after the sowing date and before the harvest dates for each of the fields were extracted.

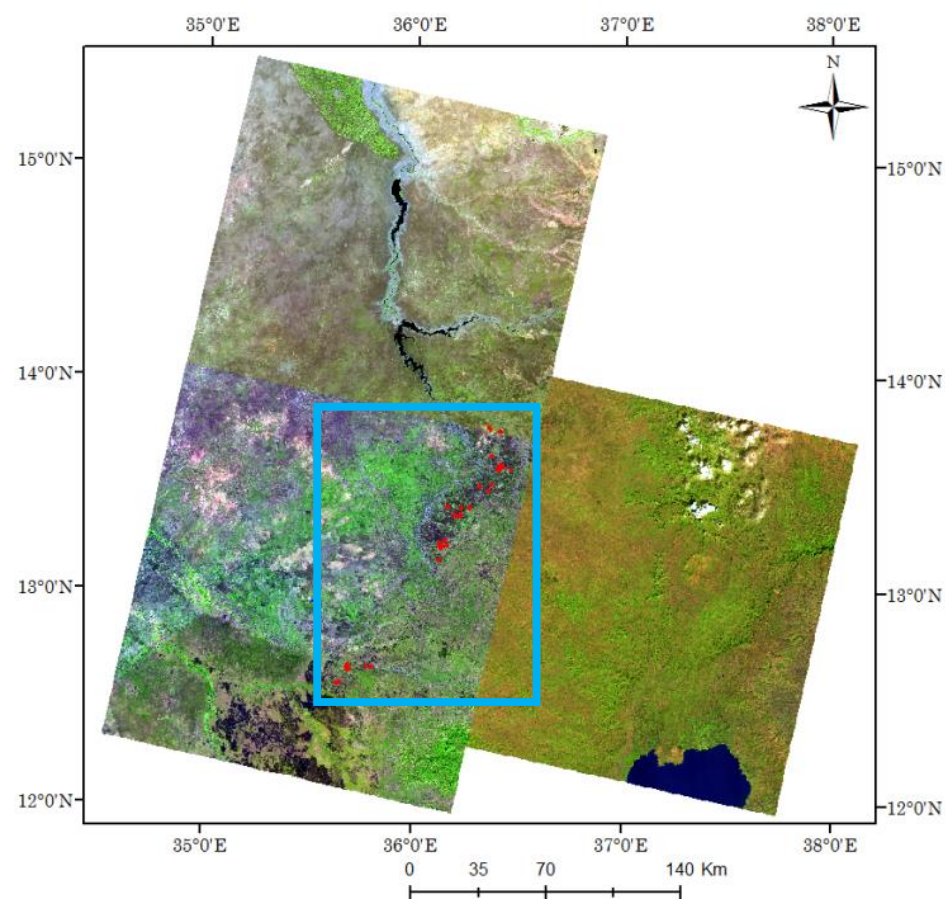

Figure 5.1: Study area represented by three Landsat scenes. The red dots inside the blue box are the farmer's fields.

For both the optimum growing period VI and phenologically adjusted VI profiles several values were extracted for each field and used for the subsequent analysis: original, peak season (maximum values), cumulative and average values of NDVI, EVI, SAVI and MSAVI. The original variables represent the spatial and temporal average (for fields which have values from 2 or 3 Landsat-8 scenes) VI values per date for each field. Peak-season (maximum) variables are spatial average VI values calculated when the crop is in its heading, flowering and grain filling stages. For the sesame crop in our study area, this period mostly extends from the beginning of August until late October. The cumulative and average variables represent sum of the temporal and spatial average, and the temporal and spatial average VI values per field over the cropping season, respectively. 

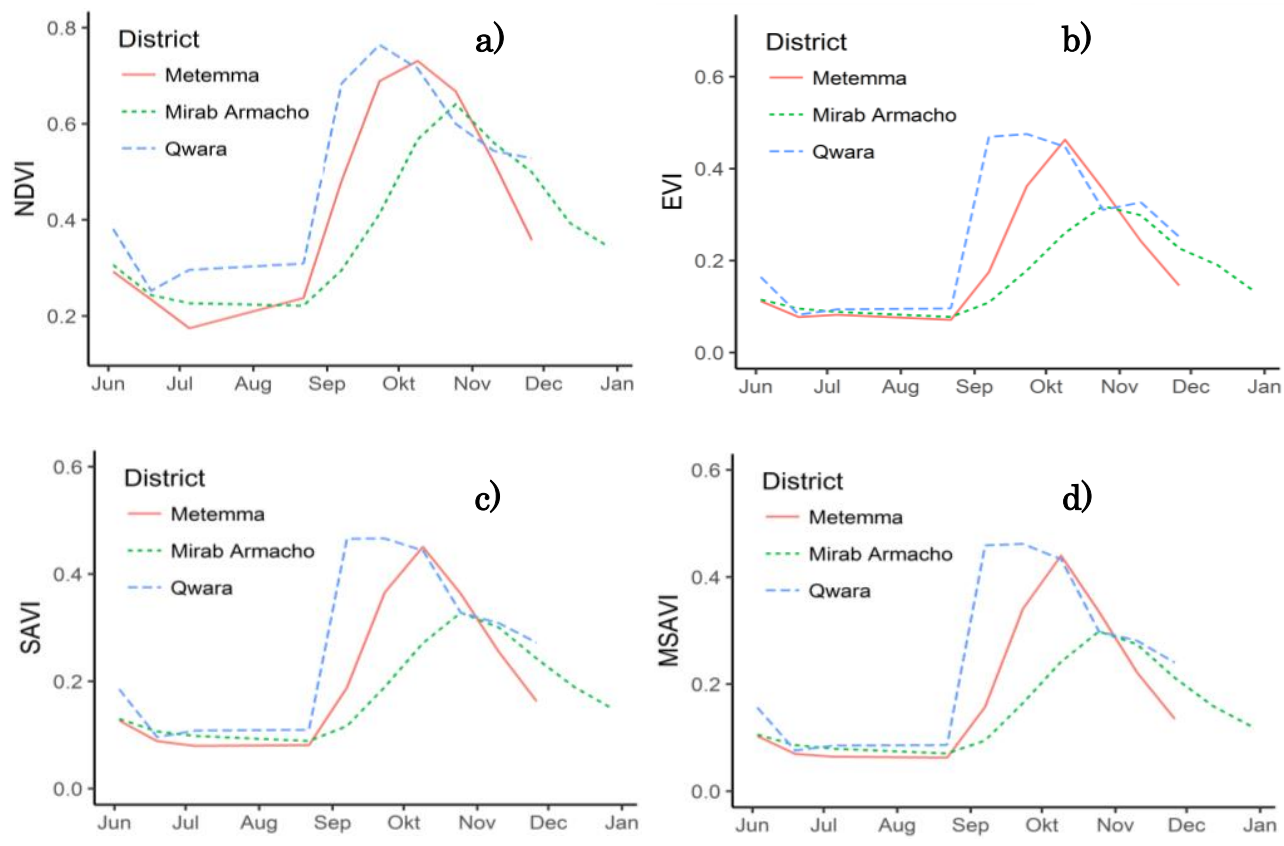

Figure 5.2: Spatial and temporal average profiles of the vegetation indices over the growing season from all the fields per district (a) NDVI, (b) EVI, (c) SAVI and (d) MSAVI.

\subsubsection{Field data collection and processing}

At the beginning of the 2015 growing season, 45 medium and large scale farmers' fields were randomly selected across our study area. We visited these fields twice to gather the necessary information over the growing season. At the start of the growing season in June, farmers were provided a paper note book with the list of management factors and were asked to record the management activities and crop phenology events over the growing season. In addition, by using Garmin handheld GPS, farmers with the help of researchers took the GPS boundary of the fields where sesame was growing in the 2015 cropping season. As suggested by Sibley et al. (2014), taking the GPS tracks of the complete field minimizes the chance of spatial mismatches between the remote sensing and field-based estimates, as this often occurs when only a single reference point is taken for each field. The collected GPS tracks of the field boundaries which were originally in a .gpx format, were converted to a polygon feature class using ESRI ArcMap 10.2. The area for each of the fields (in hectare) was then calculated using the calculate geometry feature of ArcMap. 
Table 5.1: Overview of Landsat 8 imagery dates used in the subsequent analysis.

\begin{tabular}{|c|c|c|c|}
\hline Month & $\begin{array}{c}\text { Number of used } \\
\text { images }\end{array}$ & $\begin{array}{c}\text { DOY } \\
\text { (Day of year) }\end{array}$ & Date \\
\hline June & 1 & 170 & June 19 \\
\hline \multirow{3}{*}{ July } & \multirow{3}{*}{3} & 186 & July 5 \\
\hline & & 195 & July 14 \\
\hline & & 211 & July 30 \\
\hline August & 1 & 234 & August 22 \\
\hline \multirow{3}{*}{ September } & \multirow{3}{*}{3} & 250 & September 7 \\
\hline & & 259 & September 16 \\
\hline & & 266 & September 23 \\
\hline \multirow{4}{*}{ October } & \multirow{4}{*}{4} & 275 & October 2 \\
\hline & & 282 & October 9 \\
\hline & & 291 & October 18 \\
\hline & & 298 & October 25 \\
\hline \multirow{2}{*}{ November } & \multirow{2}{*}{2} & 307 & November 3 \\
\hline & & 314 & November 10 \\
\hline
\end{tabular}

At the end of the growing season (after all the fields were harvested in November-December), we revisited the farmers and all the management and crop phenology information recorded by the farmers over the growing season together with the actual yields were collected and checked for plausibility. The total reported production (in quintals) was divided by the area of the field to obtain the yield per hectare for each field. We used the measurement unit quintal for the total reported production because it is most commonly used by the farmers. As a result of the strong El Niño events in 2015, some parts of Ethiopia including our study area experienced lack of rainfall which led to severe drought (Aaron-Morrison et al. 2016). As a consequence, some fields which were included at the beginning, had to be eliminated from our study. As a result, information from a total of 38 fields was used for further analyses.

To identify the underlying factors that cause the yield variability within a field, during the data collection at the end of the growing season, researchers printed the map of each of the fields under the study in "A4 sheet" with Google Earth image as a background and farmers were asked separately to demarcate their own fields based on differences in yield (Figure 5.3). In addition, farmers were asked to identify the main factors causing the yield variability for the paperdrawn management zones within the fields. 


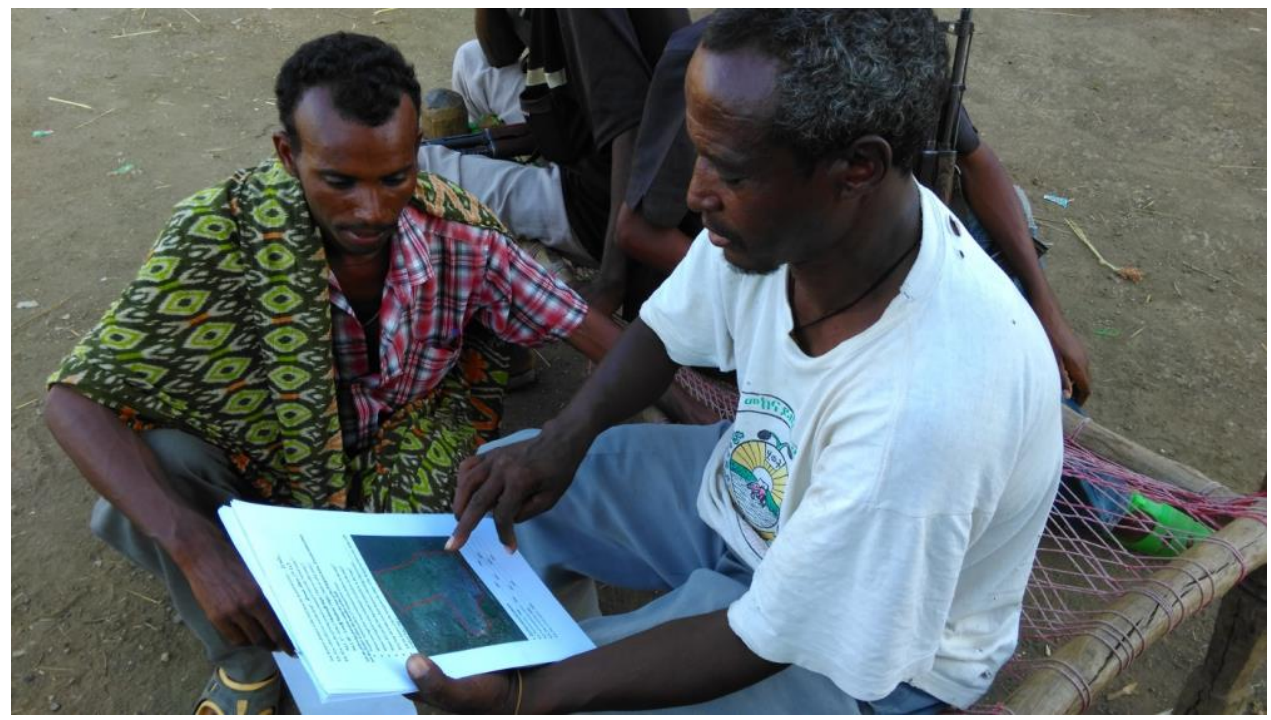

Figure 5.3: A farmer and his assistant using the paper map of a field (red boundary) to delineate zones and provide factors causing yield variability for different zones within a field.

\subsubsection{Vegetation indices}

Vegetation indices (VIs) are mathematical combinations or ratios of spectral bands derived from remote sensing images. They are developed to find functional relationships between crop characteristics and remote sensing observations (Wiegand et al. 1990). In order to identify the vegetation index which gives a better estimation of sesame yield, the most commonly used vegetation indices were selected based on previous studies (Kayad et al. 2016; Johnson 2016). Moreover, the indices were selected to be representative and can be derived from conventional multispectral satellite data (e.g., Landsat-8) (Al-Gaadi et al. 2016; Shang et al. 2015). The selected indices for this study, with their respective mathematical formulas and references are provided in Table 5.2.

The normalised difference vegetation index (NDVI) is one of the first vegetation indices developed and most widely used for monitoring vegetation growth, yield forecasting and estimating (Bolton and Friedl 2013; Funk and Budde 2009). The NDVI is related to the amount of leaf area index and the amount of green biomass in the canopy (Tucker 1979). However, researchers have indicated that NDVI may be inadequate for assessing crop vegetation due to confounding background soil effects and saturation under dense canopy and vulnerability to atmospheric conditions (Huete et al. 2002). To overcome these limitations of 
NDVI, previous studies have proposed the enhanced vegetation index (EVI) which uses the blue band in combination with the red band to reduce atmospheric contamination and also has a background soil adjustment factor $L$ (Huete et al. 2002). The coefficients adopted in the EVI formula are: $C 1=6.0$, $C 2=7.5, L=1$, and $G$ is a gain factor set to 2.5 (Huete et al. 2002). Moreover, to overcome the confounding background soil effect, the use of indices such as soil adjusted vegetation index (SAVI) (Huete 1988) and the modified soil adjusted vegetation index (MSAVI) (Qi et al. 1994) have been suggested.

Table 5.2: An overview of the vegetation indices assessed in the present study with their respective mathematical formulas.

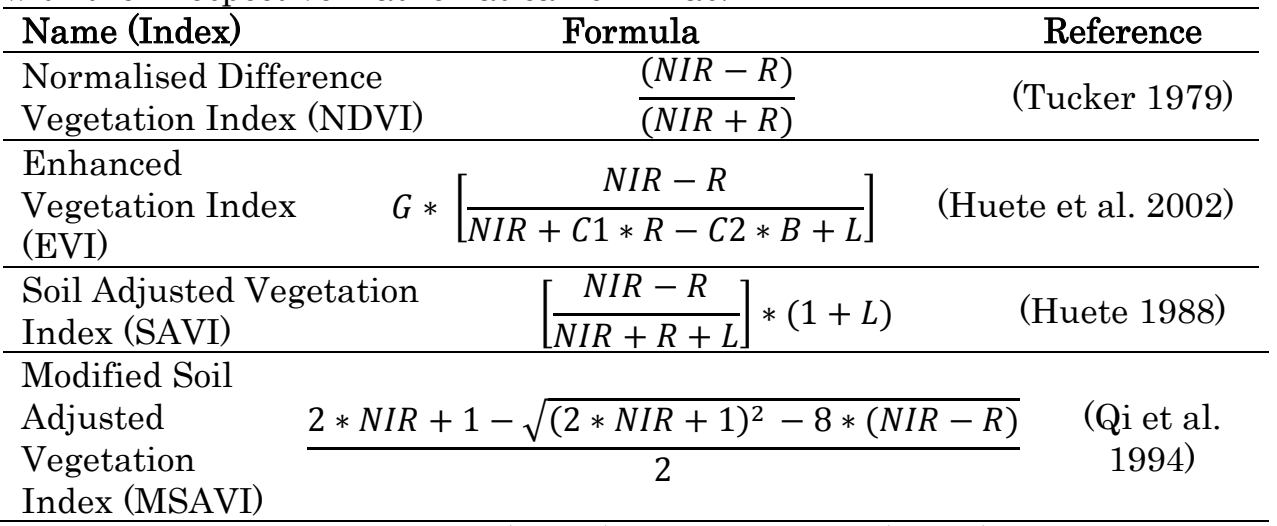

Note:- NIR: Near infrared reflectance (Band 5); $R$ : Red reflectance (Band 4 ); $\boldsymbol{B}$. Blue reflectance (Band 2), $C 1=6.0, C 2=7.5, L=1$ and $G=2.5$.

\subsubsection{Data analysis}

Our analysis includes two main elements. First, we compared the effectiveness of four Landsat- 8 spectral indices for predicting sesame yield at the field level using empirical models. For this, both the optimum growing period and phenologically adjusted VI profiles were assessed. By using the phenologically adjusted VI profile, we investigated the added value of crop phenology information crowdsourced by the farmers to improve the accuracy of the model to predict sesame yield. Second, we explored the potential of crowdsourced data to identify factors causing the yield variability within a field as perceived by the farmers. 


\subsubsection{Establishing relationship between sesame actual yield and vegetation indices}

First, we tested whether sesame yield data for the 38 fields was normally distributed or not using the Shapiro-Wilk test (Shapiro and Wilk 1965). Regression analyses were used to investigate the relationship between each of the vegetation indices and sesame actual yield (Shang et al. 2015). Sesame actual yield was estimated by regressing each of the vegetation indices versus reported yield of the 38 fields. The yield data were regressed using original (NDVI $_{\text {org, }}, \mathrm{EVI}_{\text {org, }}, \mathrm{SAVI}_{\text {org, }}, \mathrm{SAVI}_{\text {org }}$ ), peak-season $\left(\mathrm{NDVI}_{\max }, \mathrm{EVI}_{\max }, \mathrm{SAVI}_{\max }\right.$, MSAVI $\max$ ), average (NDVI $I_{\text {ave }}, \mathrm{EVI}_{\text {ave, }}, \mathrm{SAVI}_{\mathrm{ave}}, \mathrm{MSAVI}_{\text {ave }}$ ), and cumulative $\left(\mathrm{NDVI}_{\text {cum }}, \mathrm{EVI}_{\text {cum }}, \mathrm{SAVI}_{\text {cum }}, \mathrm{MSAVI}_{\text {cum }}\right)$ variables independently for both the optimum growing period and phenologically adjusted VI profiles.

The model with a vegetation index that gave the highest coefficient of determination $\left(\mathrm{R}^{2}\right)$ with sesame actual yield was selected for establishing the prediction model (Wang et al. 2014). If the $\mathrm{R}^{2}$ values of two models were similar, then the model with relatively lower RMSE and RE values would be selected. We tested for normality of the residuals (Poole and O'Farrell 1971) of the regression of the selected vegetation index and sesame yield to test whether the relationship between the vegetation index and sesame yield is linear or nonlinear (Kuri et al. 2014).

\subsubsection{Model validation and accuracy assessment}

Cross validation using Leave-one-out (LOOCV) was applied for the selected model to test its robustness (Kuri et al. 2014; Mkhabela et al. 2011). The model's coefficient of determination $\left(\mathrm{R}^{2}\right)$, the prediction error (root mean square error (RMSE)) and relative error (RE) were computed and used to assess the predictive performance of the model (Wang et al. 2014). The RMSE and RE between the observed and predicted values were computed using the following formulae:

$$
\begin{aligned}
& \boldsymbol{R M S E}=\sqrt{\frac{\sum_{\mathrm{i}=1}^{N}\left(Y_{o b s}-Y_{p r e}\right)^{2}}{N}} \\
& \boldsymbol{R} \boldsymbol{E}=\frac{Y_{o b s}-Y_{\text {pre }}}{Y_{\text {obs }}}
\end{aligned}
$$

Where $\mathrm{Y}_{\text {obs }}$ is measured yield values, $\mathrm{Y}_{\text {pre }}$ is predicted yield values for field $\mathrm{i}$ and $N$ is the total number of fields. 


\subsubsection{Mapping of sesame yield within a field}

The regression equation of the selected model was applied to all the sesame pixels in the remote sensing image within a particular field, to calculate the yield of sesame for each of the fields. The resulting map was used to assess the spatial variability of yield within a field.

\subsubsection{Identification of factors causing yield variability within a field}

Independent of the yield map based on remote sensing, farmers were asked to draw a map of their field delineating management zones related to different yields and/or problems. This map was used to identify factors that caused the yield variability among the delineated zones within a field. Per field, factors were ranked based on the area a farmer perceived a specific factor to explain the yield variability within a field. For example, if a farmer perceived that a large part of the field had low yield because of low soil fertility and small part of the field because of high presence of weeds, then we ranked soil fertility as the $1^{\text {st }}$ important factor followed by weed for that specific field. If a farmer perceived that all the factors were equally important to explain the yield variability within a field, then all the factors were ranked equally. The areas of the zones in which factors were perceived to explain yield variability within a field were estimated (compared) visually. Frequency analysis was then used to determine the number of cases in which factors were perceived important or not important by the farmers to explain yield variability within the fields. Finally, the spatial pattern similarities or differences between the remote sensing yield map of the fields and the maps delineated into zones by the farmers were visually assessed. Here also the number of cases the spatial pattern of the two maps looked very similar (high), moderately similar (medium) and not similar at all (low) were counted and subjected to frequency analysis. A similar approach using crowdsourcing of Google Earth Imagery was used to map and validate cropland in Ethiopia via the Geo-wiki platform (See et al. 2013).

The methodology followed in the present study allowed farmers to participate as a citizen scientist (Van Etten et al. 2016; Aragó Galindo et al. 2012) by involving them in the research process from simple information provision (i.e. contributory; e.g. providing sowing and harvest dates) up to a level which needs their cognitive skills (i.e. collaborative; e.g. reasoning and identifying the factors that cause the yield variability within a field) (Bonney et al. 2009). 


\subsection{Results}

\subsubsection{Estimation of sesame yield using vegetation indices}

Overall, the relationship between sesame yield and vegetation indices was strong when VI values extracted based on crowdsourced crop phenology were used (Table 5.3). Hence, we present results based on VI values extracted using crop phenology. The Shapiro-Wilk test for normality showed that the average yield data for all the sesame fields is not normally distributed. The test for normality of the residuals of the regression also showed that sesame yield and each of the vegetation indices are linearly related. Figure 5.4 depicts significant $(p<0.01)$ linear relationships between sesame yield and the average values of the vegetation indices over the cropping season. The strongest relationship was observed when average NDVI values over the growing season were used to regress sesame yield (Table 5.3). Thus, using average NDVI values over the cropping season is the most appropriate approach to relate satellite time-series and to predict sesame yield. Next to the average values, peak-season values (August-October) for all the four vegetation indices revealed a moderate relationship with sesame yield. For all the four VIs, both the original and cumulative values reveal the weakest relationship with sesame yield.

Table 5.3: Quantitative relationships between sesame actual yield (y) and vegetation indices $(\mathrm{x})$.

\begin{tabular}{|c|c|c|c|c|c|}
\hline \multirow{3}{*}{$\begin{array}{l}\text { Vegetation } \\
\text { index }\end{array}$} & \multicolumn{4}{|c|}{ Using phenologically adjusted VI } & \multirow{3}{*}{$\begin{array}{c}\text { Using optimum } \\
\text { growing period } \\
\text { VI } \\
\begin{array}{c}\text { Model } \\
\text { calibration }\end{array} \\
\mathbf{R}^{2} \\
\end{array}$} \\
\hline & \multicolumn{2}{|l|}{ Model calibration } & \multicolumn{2}{|c|}{$\begin{array}{c}\text { Model } \\
\text { validation } \\
(\mathrm{LOOCV})\end{array}$} & \\
\hline & Fitting model & $\mathrm{R}^{2}$ & RMSE & $\mathrm{R}^{2}$ & \\
\hline $\mathrm{NDVI}_{\text {ave }}$ & $\mathrm{y}=9.56 * \mathrm{x}-1.47$ & 0.654 & 0.623 & 0.612 & 0.114 \\
\hline $\mathrm{EVI}_{\text {ave }}$ & $\mathrm{y}=11.12 * \mathrm{x}+0.48$ & 0.548 & 0.707 & 0.500 & 0.027 \\
\hline $\mathrm{SAVI}_{\mathrm{ave}}$ & $y=12.13 * x+0.18$ & 0.572 & 0.690 & 0.524 & 0.027 \\
\hline MSAVI $_{\text {ave }}$ & $y=11.05 * x+0.69$ & 0.545 & 0.710 & 0.497 & 0.025 \\
\hline
\end{tabular}

Figure 5.2 shows the mean temporal profile characteristics of the four vegetation indices throughout the 2015 growing season. From the temporal profile characteristics there are obvious timing and amplitude differences between the vegetation indices and districts. In general, the cropping calendar of sesame in the study areas varied from Qwara district to Mirab Armacho district. The sowing period of sesame in the Qwara district was earlier than that of the Mirab Armacho district mainly due to the variations in the start of the rainy season (Figure 5.5). Moreover, VI values for the fields in the Qwara 
district reduced earlier in the season which indicates these fields were harvested earlier than fields in the other two districts (Figure 5.6). Qwara and Metemma fields had higher amplitudes for all the four vegetation indices compared to Mirab Armacho fields. This implies that there was more vegetative growth and hence yield in Qwara and Metemma districts compared to Mirab Armacho district (Figure 5.10). The temporal intensity of the vegetation indices from sesame fields generally characterised seasonal changes of sesame crop phenology (Figure 5.2).

District - Metemma * Mirab Armacho " Qwara

District - Metemma * Mirab Armacho = Qwara
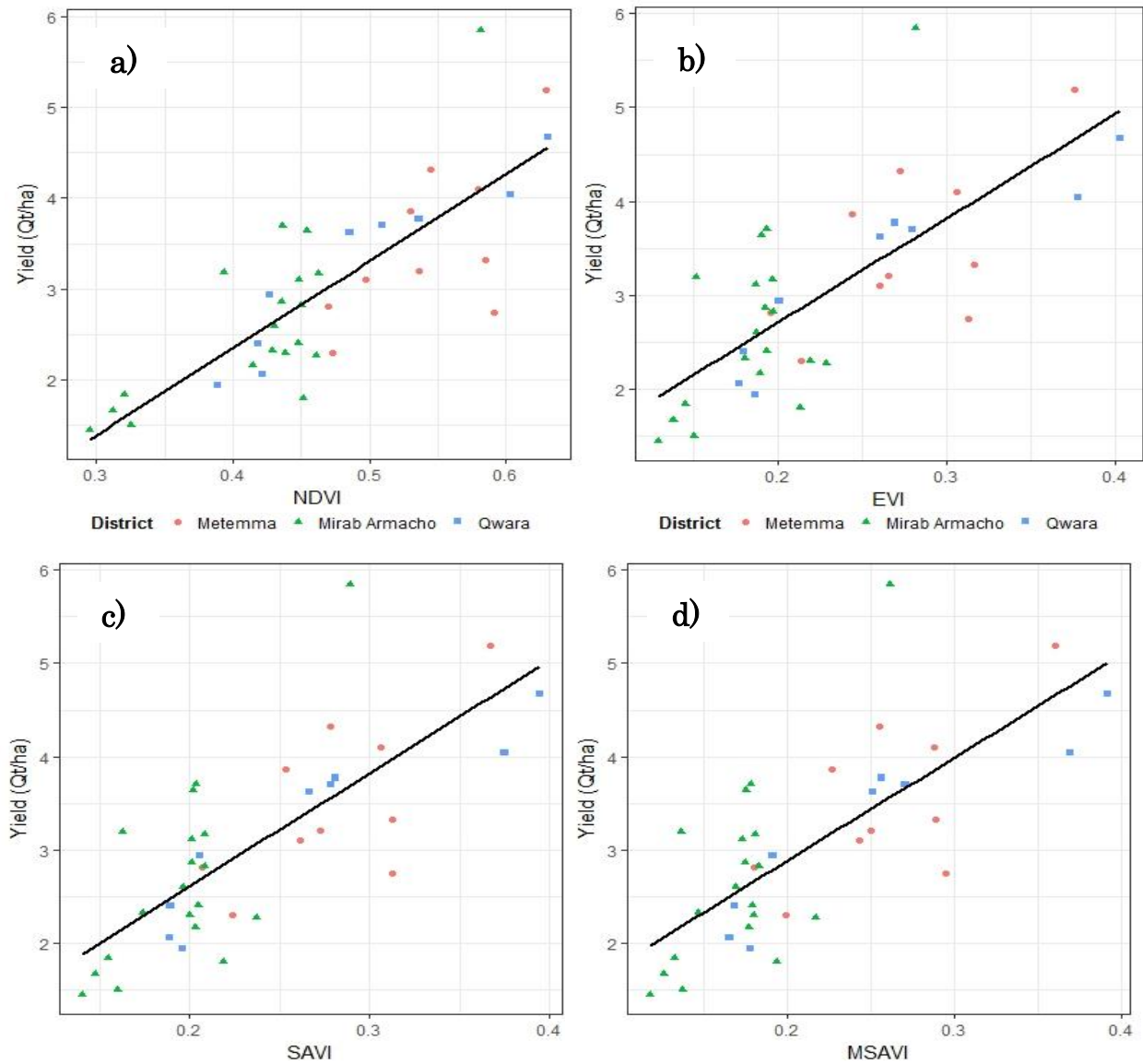

Figure 5.4: Regression per vegetation indices showing the relationships between the selected vegetation indices and sesame actual yield with, a) $\mathrm{NDVI}_{\text {ave }}$ b) $\mathrm{EVI}_{\text {ave }}$ c) SAVI ave and d) MSAVI ${ }_{\text {ave }}$. 


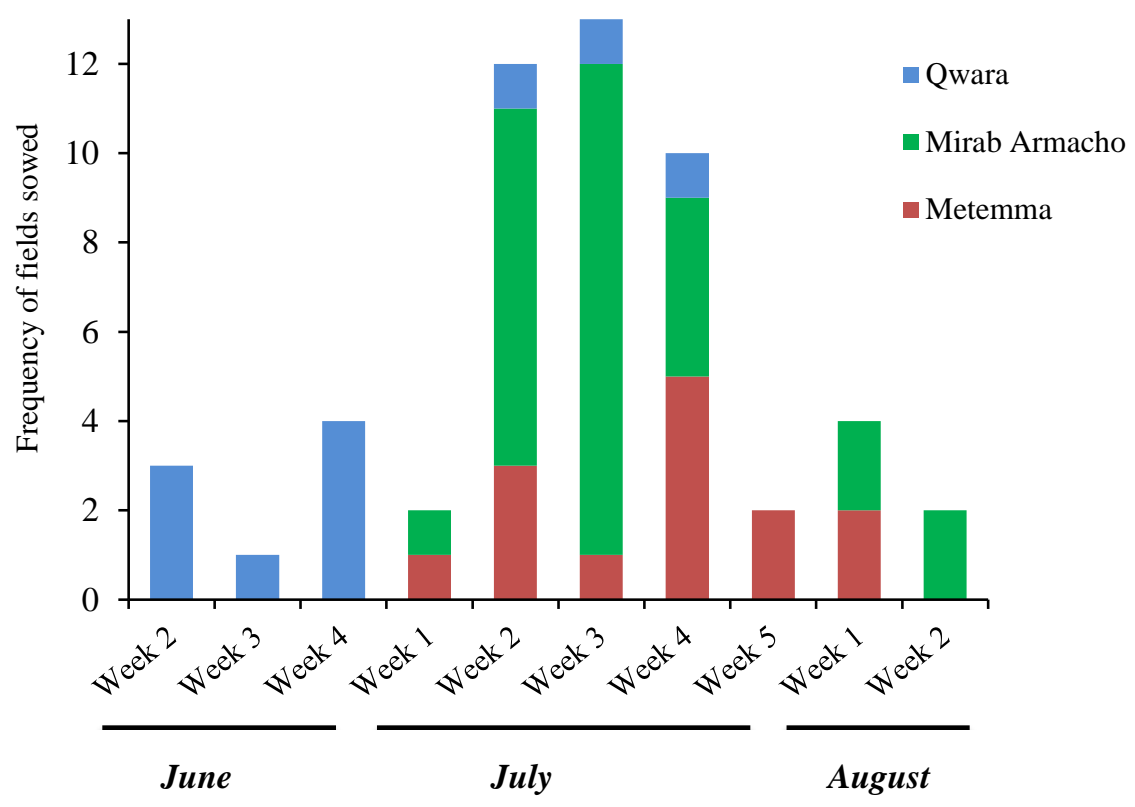

Figure 5.5: Sowing dates of sesame for fields in the three districts.

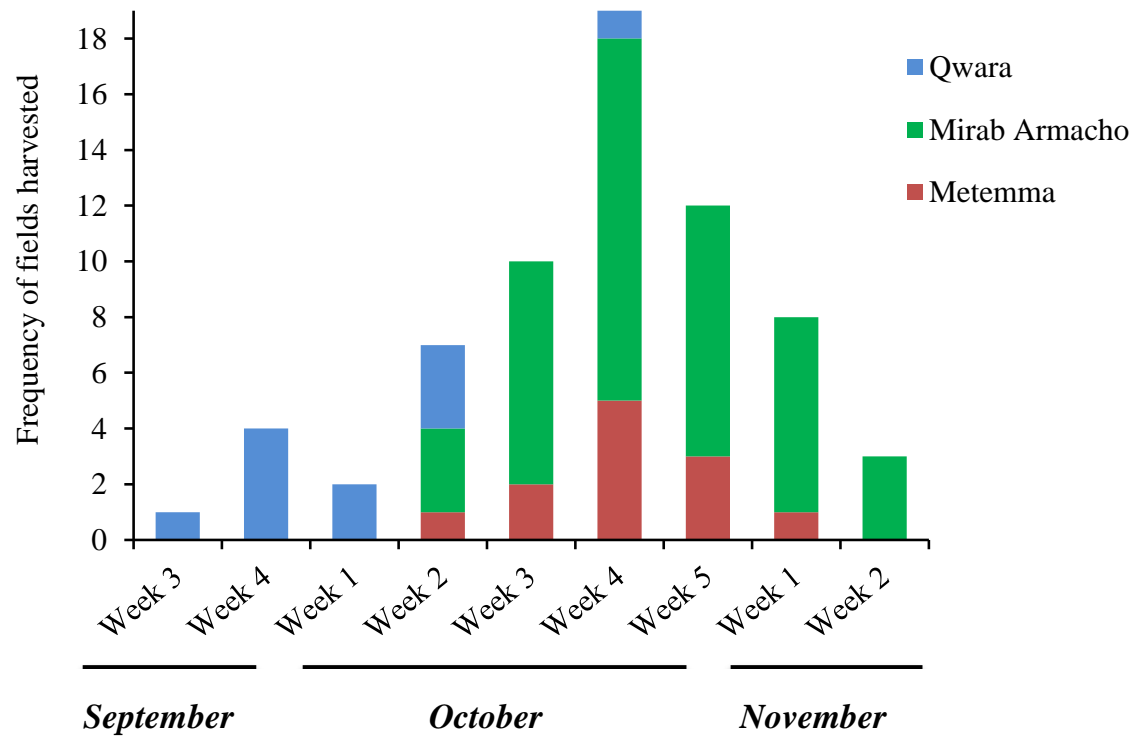

Figure 5.6: Harvest dates of sesame for fields in the three districts. 


\subsubsection{Accuracy of the model used in the prediction of sesame yield}

Figure 5.7 presents the scatter plots of the measured yield against the predicted yield using the models of each of the vegetation indices developed using the leave-one-out cross-validation (LOOCV) approach. The RMSE values range from 0.62 to 0.71 and the model based on average NDVI ( $\left.\mathrm{NDVI}_{\text {ave }}\right)$ had the smallest RMSE (0.62 qtha $\left.^{-1}\right)$ and the highest coefficient of determination $\left(\mathrm{R}^{2}=0.61\right)$ values.
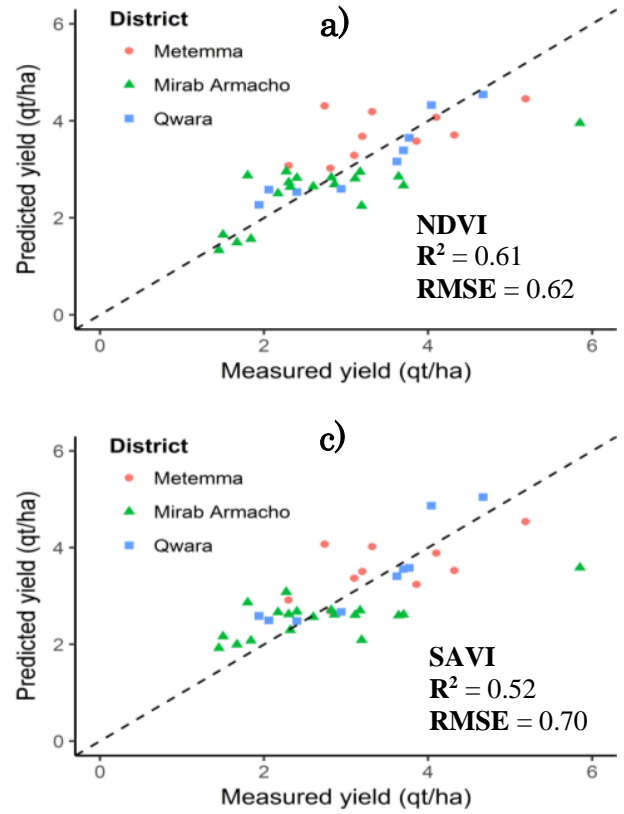
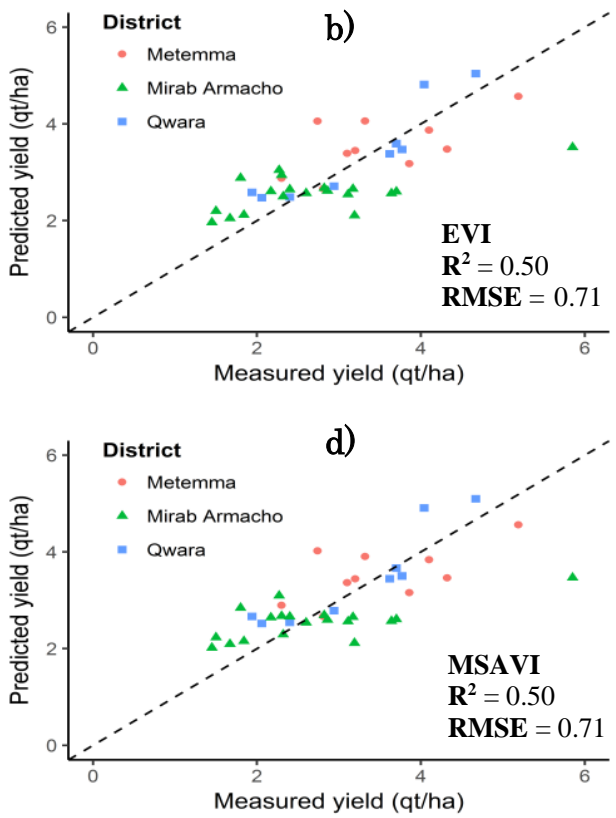

Figure 5.7: Scatter plot of measured yield against predicted yield using a)

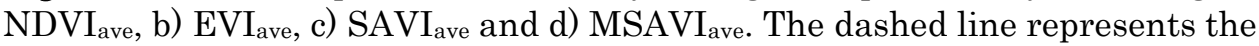
$1: 1$ line $(y=x)$.

\subsubsection{Mapping the spatial variability of sesame yield within a field}

Actual yield of sesame for all the pixels within a field was calculated by using the model based on average NDVI values. Figure 5.8 illustrates the resulting spatial distribution of sesame yield (based on average NDVI) for the low, medium and high yielding fields in the three districts. The maps showed a considerable yield variation within each field (Figure 5.9). For low yielding fields the yield variability within a field was from $2.11 \mathrm{qtha}^{-1}-4.4 \mathrm{qtha}^{-1}$ while for medium fields the variation was from $4.0 \mathrm{qtha}^{-1}-5.2 \mathrm{qtha}^{-1}$. The variation within a field for high yielding fields was relatively smaller compared to the low and medium fields. It ranged from $5.3 \mathrm{qtha}^{-1}-6.2 \mathrm{qtha}^{-1}$ (Figure 5.9). There 
was more variability among the low yielding fields in the three districts compared to the medium and high yielding fields (Figure 5.9). At the district level, there was more variation between fields in Qwara district compared to the Metemma and Mirab Armacho districts (Figure 5.10).

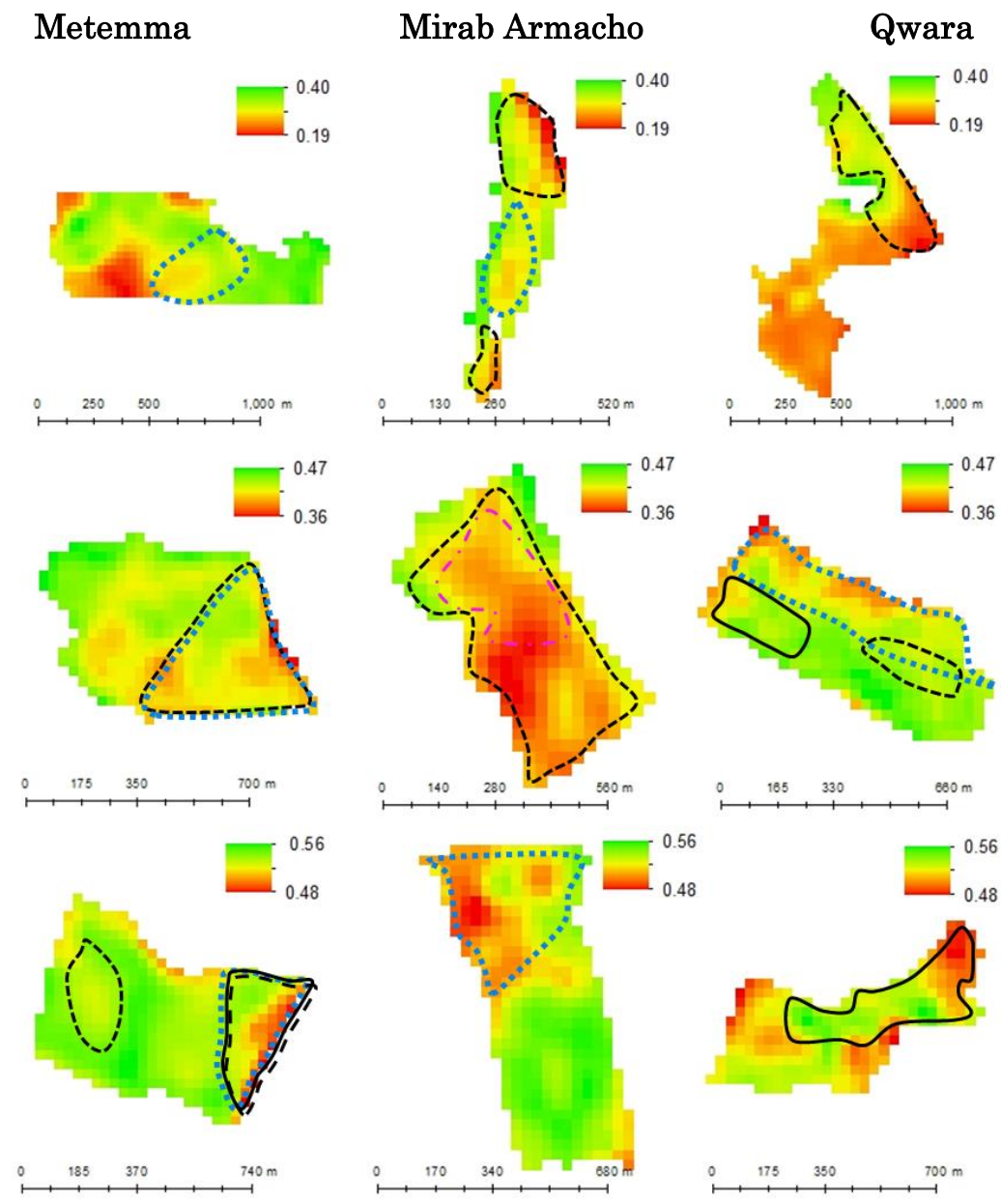

Figure 5.8: Matrix showing the yield variability within a field for some of the fields included in the current study. The rows 1-3 illustrate the low, medium and high yielding fields respectively. The columns 1-3 show fields from Metemma, Mirab Armacho and Qwara districts respectively. Light blue dashed lines represent low soil fertility areas, black dashed lines represent high presence of weeds, solid lines represent an area with high incidence of pests and diseases and purple dashed lines represent presence of water logging as perceived by the farmers. The values are yield in quintal per pixel. 
Metemma
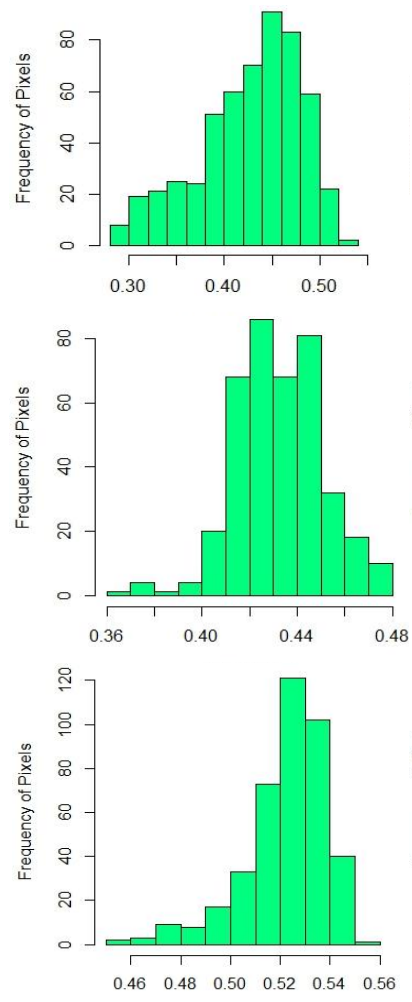

Mirab Armacho
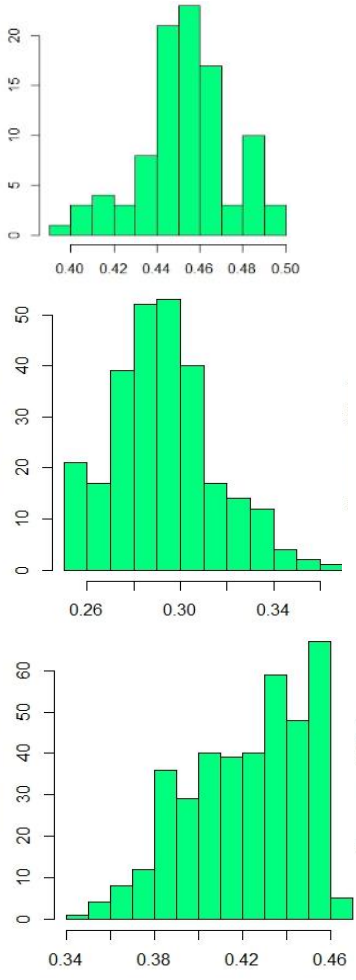

Qwara
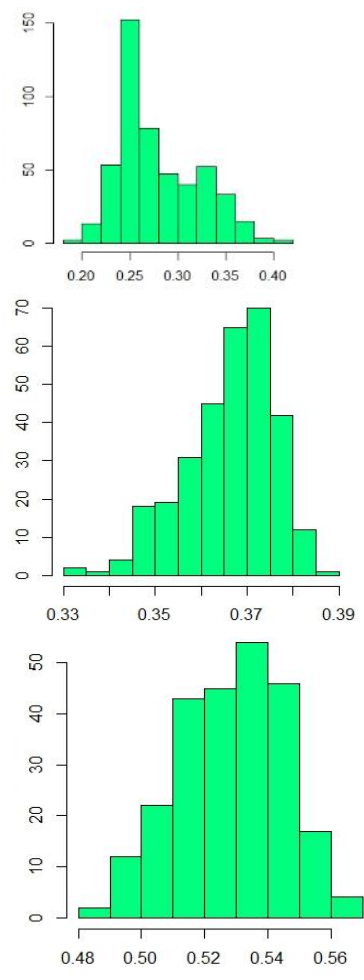

Yield (qt/pixel)

Figure 5.9: Matrix showing the histogram of the low, medium and high yielding fields in the three districts. The $1^{\text {st }}$ row illustrates the low, $2^{\text {nd }}$ row medium and $3^{\text {rd }}$ row high yielding fields. The columns 1-3 show fields from Metemma, Mirab Armacho and Qwara districts respectively.

\subsubsection{Factors causing yield variability within a field}

Farmers perception and their spatial knowledge about their field were used to identify the main factors causing the yield variability within a field. According to the perception of farmers, overall soil fertility is the most important factor explaining the yield variability within a field, followed by high presence of weeds (Figure 5.11). Among the factors, soil fertility and weeds were the main factors causing the yield variability in Mirab Armacho district while incidence of pests and diseases was more important in Qwara district (Figure 5.12). In Metemma district, low soil fertility and presence of weeds were equally important to explain yield variability within a field (Figure 5.12). 


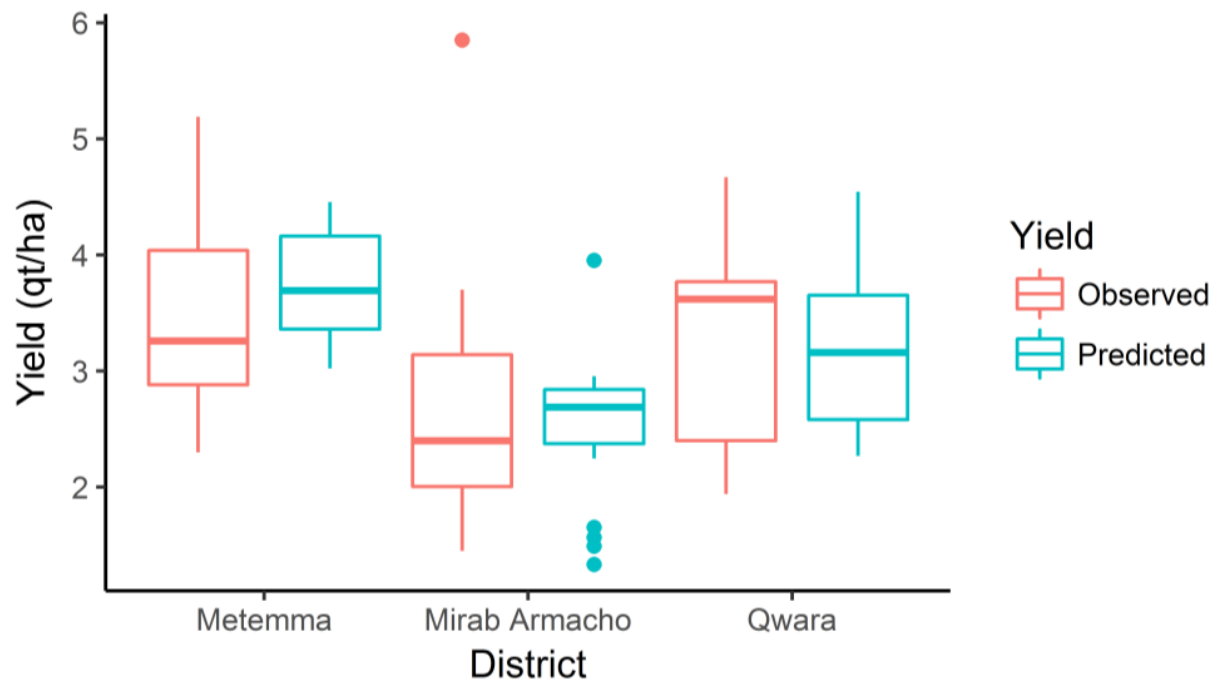

Figure 5.10: Boxplots showing the yield variability of observed and predicted sesame average yield among fields in the three districts.

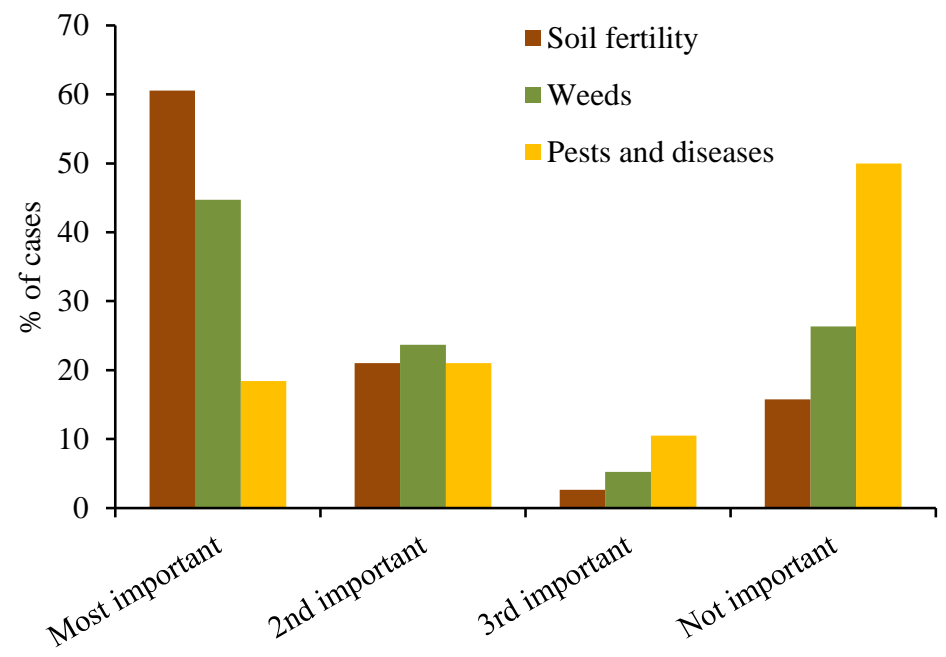

Figure 5.11: Overall rank of the factors causing yield variability within a field as perceived by the farmers. 


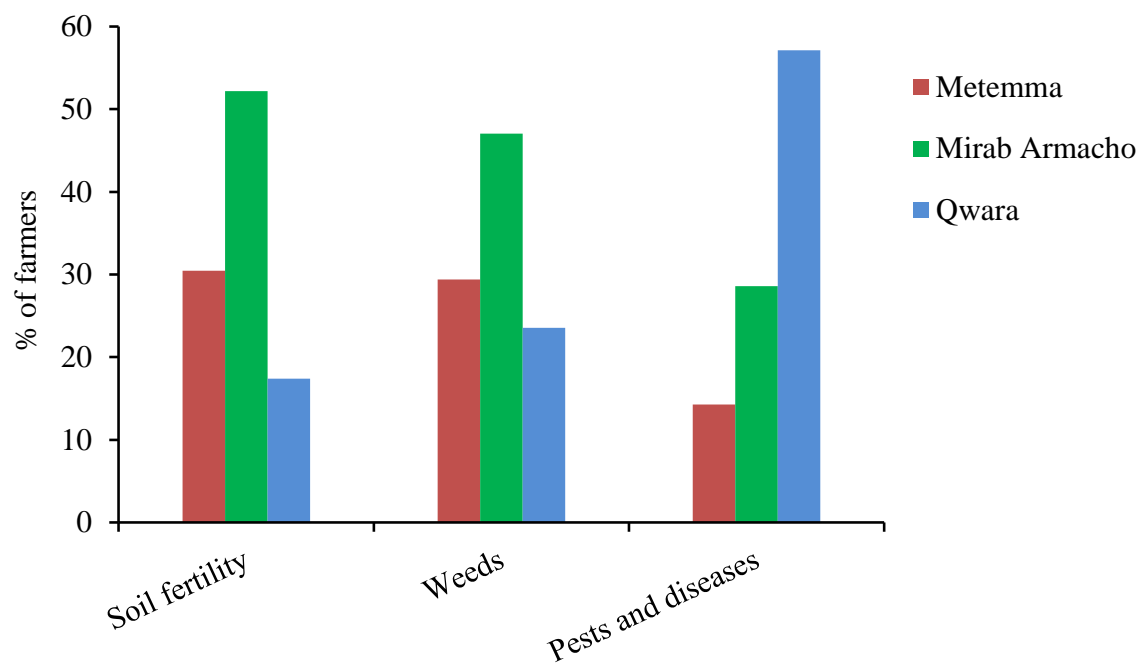

Figure 5.12: Factors causing yield variability within a field in the three districts.

\subsection{Discussion}

The objective of this study was to investigate the capability of remote sensing satellite imagery (i.e., Landsat 8) to estimate and map sesame yield at the field level and to explore the potential of bottom-up data collection approaches (e.g., crowdsourcing) to improve these estimations and to identify the main factors that cause the yield variability within a field. The main research question was: how can synergy of remote sensing and crowdsourced data improve the estimation and explanation of yield variability? During yield estimation, farmers crowdsourced crop phenology information was used to select images acquired after planting and before harvest dates per field. Vegetation indices were then extracted from the selected images and used in the empirical model. This improved the accuracy of the model to predict sesame yield compared to the model based on the VIs extracted from all the images available for the optimal growing period (Table 5.3). Using VIs extracted only from images acquired during the growing season helped to remove pre and post season unnecessary signals and hence resulted in a more accurate model. Moreover, the crowdsourcing approach was used to identify the underlying factors limiting yield at the field level. Coupling the remote sensing approach with crowdsourcing improves the accuracy of the model and also gave the opportunity to acquire yield limiting factors at the field level. Previous studies focusing on land cover, combined remote sensing with crowdsourced data and produced hybrid land cover maps with better overall accuracy compared to the 
existing individual land cover products (Fritz et al. 2015; See et al. 2015). Our results suggest that vegetation indices derived from moderate-resolution satellite imagery (e.g., Landsat-8) can be used to make predictions of sesame crop yield at the field level with acceptable accuracy $\left(\mathrm{R}^{2}=0.65, \mathrm{RMSE}=0.62\right)$.

\subsubsection{Predicting sesame yield using VIs derived from remote sensing time-series data}

In our study, we found a linear relationship between NDVI derived from Landsat-8 time-series and sesame yield (Figure 5.4). Compared to the other vegetation indices, average NDVI over the growing season had the strongest relationship with sesame yield $\left(\mathrm{R}^{2}=0.65, \mathrm{RMSE}=0.62\right)$. The reason for the NDVI to have a better relation with sesame yield compared to the other indices might be because NDVI is sensitive to chlorophyll content while the others (e.g., EVI) are more sensitive to canopy structure and related variables, such as LAI (Huete et al. 2002). Similarly, in the study of Johnson (2016), NDVI outperformed EVI to predict yield of canola, sorghum and sugar beet using MODIS products.

Previous studies have also shown that crop phenology derived from remote sensing data can be used to capture local variation in the timing of optimum periods to use vegetation indices for crop yield estimation (Duncan et al. 2015b; Bolton and Friedl 2013; Funk and Budde 2009). For example, the study of Bolton and Friedl (2013) demonstrated how VI time-series information adjusted using crop phenology derived from remote sensing per pixel increased the accuracy of crop yield estimates. However, remotely derived crop phenology information from coarser spatial resolution data (e.g. MODIS) is limited to monitor individual fields (Duncan et al. 2015a).

In the present study, crowdsourcing was used to collect crop phenology events for all the sesame fields in our study. This information was then used during the data preparation phase. VIs values were extracted and used in the subsequent analysis only from satellite images acquired after planting and before harvest dates for all the fields in our study. Using VIs values extracted based on the crop phenology information improved the accuracy of the model to predict sesame yield (Table 5.3). The study of El Hajj et al. (2009) presented a comparable approach of integrating farmers reported crop phenology information (i.e., maturity dates) and expert knowledge with remote sensing time-series data to improve the accuracy of a decision support system to monitor agricultural practices (sugarcane harvest) at the field level. Similarly, a citizen science project called Season Spotter, engaged volunteer citizen scientists to detect plant phenology events from near-surface remote sensing imagery and use the information to connect landscape-level measures with field-based measures (Kosmala et al. 2016a). 
In our study, we found that average VI values over the growing season gave a stronger relationship with sesame yield compared to peak or single date VI values (Table 5.3). This demonstrates the importance of including multitemporal VI information into crop yield models, and not to isolate time-periods which correspond to the phenological stages of crop development which determine crop yield (Huang et al. 2013; Bolton and Friedl 2013; Sakamoto et al. 2013). Vegetation indices derived from satellite images were earlier used to predict yield levels of corn (Johnson 2016), rice (Son et al. 2014), sugar cane (Morel et al. 2014), winter oilseed rape (Han et al. 2017), among others. As the resolution of satellite images, both in time and space is increasing, yield estimates are becoming increasingly accurate (Burke and Lobell 2017). Remote sensing can thus become important to estimate actual yields, as yield estimates based on surveys or measurements are not always reliable (Fermont and Benson 2011). Measurements depend on samples in the field, and when variability is high as often the case and also shown in this study (Figure 5.8), reliability largely depend on the location and number of samples. Recall of farmers is not always accurate and does not consider within field variability.

\subsubsection{Crowdsourcing to acquire factors explaining yield variability at field level}

The remote sensing based approach was used to estimate sesame crop yield at the field level. The resulting yield map demonstrated clear spatial yield variability within the fields (Figure 5.8). The next step in the workflow is to identify the factors causing the yield variability within the fields. However, the remote sensing approach using moderate-resolution satellite imagery (e.g., Landsat) would not be able to provide detail information. The crowdsourcing approach was used to identify factors that caused yield variability within a field (Figure 5.12). For this specific purpose, the participation of farmers was more of collaboration than the contributory model of citizen science (Bonney et al. 2009). Farmers participated and contributed to the process with their cognitive skills. Figure 5.12 illustrates the main factors explaining the yield variability within a field as perceived by the farmers. In addition to improving the accuracy of the model to predict sesame yield, the crowdsourcing approach has a high potential to collect factors that explain the yield variability with a field.

\subsubsection{Limitations and future recommendations}

A few important limitations are noteworthy for this study. One potential error is in the farmer reported yields because of errors in estimating the weight of a bag. Although we tried to cross-check the average weight of a bag reported by the farmer with the information from the closest ECX (Ethiopian Commodity Exchange) market, it is worth mentioning as it might have affected the accuracy of the prediction model. In most situations, non-negligible errors exist 
in the farmer-reported data, as also mentioned above, suggesting that the true accuracies of remote sensing data can be even higher (Lobell 2013).

Although the model developed in this study was successfully evaluated using one season data, there is a need to continue evaluating the performance of the model using data from other seasons. Improving on the spatial resolution of images used to extract vegetation indices to calibrate the model and using a crop-specific mask may improve the reliability of the model. The open-access Sentinel-2 earth observation system should overcome the spatial limitation because it will provide $10-\mathrm{m}$ resolution satellite images with a 5-day frequency. In addition, in recent studies vegetation indices derived from micro-satellites are used to estimate and map crop yield at the field level even for the small and heterogeneous fields which are typical for the smallholder farming system in the tropics (Burke and Lobell 2017; Jain et al. 2016). The use of Unmanned Aerial Vehicle (UAV) is another possibility to acquire high spatio-temporal data for estimating and mapping crop yield at the field level (Du and Noguchi 2017).

In the current study, farmers delineated zones within a field using paper based maps. However the ubiquitous availability of mobile phones and tablets which are equipped with GPS sensors can potentially be used (e.g. using GeoODK) to collect the information directly from the farmers digitally and send it to a central database (e.g., Land-Potential Knowledge System; Herrick et al. 2016; Herrick et al. 2013) and any error during the data submission can be corrected in a near-real time.

\subsection{Conclusions}

The capability of vegetation indices derived from remote sensing time-series was assessed to estimate sesame yield at the field level. Our results showed that vegetation indices derived based on farmers crowdsourced crop phenology information had strong relationship with sesame yield compared to vegetation indices derived based on the optimal growing period. This made us to conclude that using farmers crowdsourced crop phenology information have improved the accuracy of the model to predict sesame yield at the field level. Furthermore, among the vegetation indices, NDVI was a more effective predictor of sesame yield than the other three VIs (EVI, SAVI, MSAVI). The relationship between NDVI and sesame yield was strong when average values over the growing season were used compared to single date or peak-season NDVI values. This implies using multi-temporal image acquired over the growing season is more suitable to predict sesame yield than using single or few date image(s). 
More generally, the results from this work suggest that remotely sensed information coupled with crowdsourcing is useful for estimating sesame crop yield at the field level with a reasonable accuracy. As a next step, the crowdsourcing approach was used to identify the factors causing the yield variability within a field after the yield was mapped at the field level using the remote sensing approach. According to the perception of farmers participated in the crowdsourcing, overall soil fertility was the most important factor explaining the yield variability within a field followed by high presence of weeds. Our study clearly demonstrated that using the crowdsourcing approach has a huge potential to collect the underlying factors causing yield variability within a field especially in regions where there is scarcity of farm level data. While the analysis described in this chapter focused on sesame yield in Ethiopia, the approach of coupling remote sensing with crowdsourcing has the potential to support yield monitoring and forecasting efforts in the other parts of the world.

\section{Acknowledgements}

This research was carried out in a $\mathrm{PhD}$ project and it is part of Wageningen University \& Research strategic program 'Mapping for sustainable intensification', 2012-2016, funded by the Strategic Funds of Wageningen UR. The first author received financial support for his fieldwork from CommonSense project of Wageningen University \& Research. The authors would like to thank the agronomic team members of Sesame Business Network (SBN), Sjors Bijen and the extension workers for their support during the data collection period. Finally, we would like to thank all the farmers who were volunteer to participate in this research. 
Chapter

Synthesis 


\subsection{Main results}

The main objective of this $\mathrm{PhD}$ thesis was to investigate the applicability of innovative data collection approaches like crowdsourcing and remote sensing to support the assessment and monitoring of crop yield gaps. In the first part of this chapter a synthesis will be given for the main research questions addressed in the thesis. In section 6.2, the necessary additional factors that need to be considered to utilize the full potential of innovative data collection approaches are discussed.

\section{Research question 1: What are the main factors causing the yield gaps at the global, regional and crop level?}

In order to identify the most commonly considered and explaining factors of the yield gap at the global, regional and crop level, a review of yield gap studies (50 agronomic-based peer-reviewed articles) was performed in Chapter 2. The results of the aggregated analysis at the global level show that factors from the management category are most often considered to explain the yield gap compared to the edaphic, farm characteristics and socio-economic categories (Figure 2.2). Among the management groups, the fertilization group is most often considered and often explains the yield gap. However, less often considered factors from the irrigation, land preparation and crop characteristics groups also explain the yield gap in more than $80 \%$ of the cases, when considered (Figure 2.2a). Planting, crop protection and weeding are the other groups which explain the yield gap in more than $60 \%$ of the cases when considered. Overall, this highlights the importance of crop management for existing yield gaps.

Like management factors, edaphic factors also explain the yield gap (Figure $2.2 \mathrm{~b})$. Among edaphic groups, factors related to soil fertility were considered by a relatively large number of records (25\%) compared to the other groups of factors and they explained the yield gap in $69 \%$ of the cases when considered. For $69 \%$ of the records where a factor related to slope was considered in the analysis, this factor could also explain the yield gap. Soil type and soil water explained the yield gap in around $58 \%$ and $38 \%$ of the cases. At the global level, compared to management factors, edaphic factors were in general less often considered to explain the yield gap and when considered, the power of the factors to explain yield gap was less than that of management factors (Figure $2.2 \mathrm{a}$ and $\mathrm{b}$ ). For example, both soil fertility and fertilization were considered by a relatively large number of records, $25 \%$ and $45 \%$ of the cases respectively. However, factors in the fertilization group explained the yield gap more often than factors in the soil fertility group. 
The analysis at the global level shows that in general, few studies considered farm characteristics factors when explaining the yield gap, compared to management and edaphic factors (Figure 2.2c). However, when considered, farm(er) characteristics factors often explain the yield gap. From Figure 2.2c, we see that in $93 \%$ of the records where a factor related to intensity (e.g., resource use intensity) or labour (e.g., cost of labour) was considered in the analysis, this factor could also explain the yield gap. Factors in the size category explained the yield gap in $70 \%$ of the records when a factor related to size (e.g., farm area) was considered in the analysis. Like the farm characteristics factors, socio-economic factors were not often considered to explain the yield gap (Figure 2.2d). However, when socio-economic factors were considered, they were often explaining, especially factors related to population (e.g., rural population density) and institutions (e.g., access to fertilizers and credits), but also technical factors (e.g., technical assistance) were explaining in more than $50 \%$ of the cases.

Results of the detailed analysis for the most often considered and explaining groups showed that, in the fertilization, irrigation and weeding groups, timing of operation (e.g., $\mathrm{N}$ fertilizer timing) was less often considered than amounts used (e.g., N fertilizer quantity) (Figure 2.3a). However, when considered, timing explained the yield gap more often. Also in the planting group, sowing date was more often explaining than sowing density, but it was also more considered. In the soil fertility group of the edaphic category, exchangeable cations and electric conductivity are not often considered, but when considered, they often explained the yield gap (Figure 2.3b). Total $\mathrm{N}$, organic matter, $\mathrm{pH}$ and $\mathrm{P}-\mathrm{Olsen}$ are considered by more records, but have smaller explaining power compared to exchangeable cations and electric conductivity. Detailed analysis on the labour group of the farm characteristics category showed that opportunity cost of labour, availability of machines and mechanisation are the three most often explaining factors despite their low frequency consideration to explain yield gaps (Figure 2.3c). Looking into the institutional group of the socio-economic category, access to fertilizer, credit and markets $(\mathrm{km})$ are the three institutional factors which explain the yield gap the most (Figure 2.3d). Moreover, market access (hrs), market influence and subsidies explain the yield gap in more than $75 \%$ of the cases when considered.

From the results at regional and crop level, it was evident that the relevance of factors depends on the location and crop, and that generalizations should not be made. For example, soil fertility is relevant to explain yield gaps in Africa whereas soil water is more relevant for yield gaps in Asia (Figures 2.4c and d). Fertilization, land preparation and crop protection are the factors that often explain the rice yield gap in Africa while crop characteristics and planting are important factors for the rice yield gap in Europe (Figure 2.5). Therefore, the 
data collection procedure is therefore highly important when performing yield gap analysis, as a focus on few factors may bias the results. Although the data included in yield gap analysis also depends on the objective, knowledge of explaining factors, and methods applied, data availability is a major limiting factor. Bottom-up data collection approaches (e.g., crowdsourcing) involving agricultural communities can provide alternatives to overcome this limitation and improve yield gap analysis.

\section{Research question 2: How could data for yield gap explaining factors be collected with innovative bottom-up approaches?}

In Chapter 2, the results from the first research question were used as a base to discuss the potential of innovative bottom-up data collection approaches to collect the factors causing the yield gap (Table 2.1). Most of the management, farm characteristics and socio-economic factors that explain the yield gap (e.g., timing of management operations, education level/age of the farmer, access to fertilizers) can only be obtained either by asking farmers using traditional farm survey methods or through self-reporting. However, the traditional farm survey methods are often expensive, time-consuming and labour-intensive (Fermont and Benson 2011). With the advent of widespread mobile phone access, crowdsourcing for data collection is an emerging method for data capture (Belden et al. 2013).

With regard to yield gap explaining factors, crowdsourcing can mainly be used to collect information related to the timing of an activity (e.g., timing of fertilization, weeding, irrigation). Moreover, quantity information like amount of fertilizer applied, number of weeding and irrigation operations performed in a specific field can be collected. Cropping calendar (e.g., sowing date, dates of flowering, maturity and harvest) are other potential management factors that can be collected using crowdsourcing (Figure 4.3). The advantage of sending a

message (e.g., SMS) at the moment an activity is performed, a phenological event takes place above traditional methods is that farmers don't need to recall. With the increasing availability of smartphones which are equipped with sensors (e.g., GPS, camera), the geo-location (boundary) of a field can be collected which can be used to calculate field size (Chapter 5). The camera feature of the phone can be used to capture specific incidents in a field (e.g., incidence of pest, disease or weed) which can later be used by experts to assess the infestation level and also to identify the type of pest, disease and/or weed that caused the damage to the crop (Rahman et al. 2015). The crowdsourcing approach can be used to ask farmers to assess the fertility level of their soils using their own local indicators. In addition, an on-farm soil testing kit which allows farmers to diagnose soil constraints in the field and transmit the information quickly through SMS (e.g., SoilDoc) could potentially be used for 
acquiring soil fertility factors. For smartphone or tablet users, apps like MySoil app can be used to provide information about $\mathrm{pH}$ and organic-matter content of the soil (Shelley et al. 2013).

The crowdsourcing approach also has huge potential to collect farm characteristics and socio-economic factors (Table 2.1). Farm(er) characteristics factors like labour (e.g., labour availability), training (e.g., years in school) and income (e.g., farm income) are factors that can be collected using the crowdsourcing approach. Socio-economic factors like access to fertilizer (Y/N), access to credit (Y/N), number of technical assistances received and gender of a farmer are few example factors which can be collected using crowdsourcing.

To receive accurate and timely information, understanding the motivations of the farmers to participate in crowdsourcing and incentivising them to provide the requested information is critical (Beza et al. 2017b). This led us to explore motivations of farmers to participate in citizen science and was addressed in the next research question.

\section{Research question 3: What are motivations of farmers to participate in agricultural citizen science?}

This research question is mainly addressed in Chapter 3. As the sustainability of agricultural citizen science projects depends on volunteer farmers who contribute their time, energy and skills, understanding their motivation is important to attract and retain participants in citizen science projects. Building on motivational factors identified from previous citizen science studies (Table 3.1), a questionnaire based methodology was developed which allowed the analysis of motivational factors and their relation to farmers' characteristics. The questionnaire was applied in three communities of farmers, in countries from different continents (Ethiopia, India and Honduras), participating as citizen scientists (Figure 3.1). For Indian farmers a collectivistic type of motivation (i.e., contribute to scientific research) was more important than egoistic and altruistic motivations (Figure 3.2). For Ethiopian and Honduran farmers an egoistic intrinsic type of motivation (i.e., interest in sharing information) was most important. Grouping of farmers based on their motivations resulted in two major groups of farmers: one motivated by sharing information (egoistic intrinsic), helping (altruism) and contribute to scientific research (collectivistic) and one motivated by egoistic extrinsic factors (expectation, expert interaction and community interaction) (Figure 3.3). Moreover, the majority of the farmers in the three countries indicated that they would like to receive agronomic advice, capacity building and seed innovation as the main returns from the citizen science process (Figure 3.5). Country and education level were the two most important farmers' characteristics that 
explained around $20 \%$ of the variation in farmers' motivations (Figure 3.4). For educated farmers, contributing to scientific research was a more important motivation to participate as citizen scientists compared to less educated farmers. The results show that motivations to participate in citizen science are different for smallholders in agriculture compared to other sectors. In addition to motivation, technology is the other pillar for the success of digital citizen science (Nov et al. 2014). This is addressed in the next research question (Chapter 4).

\section{Research question 4: What determine smallholder farmers to use technologies (e.g., mobile SMS) for agricultural data collection?}

To identify the factors that affect the intention of smallholder farmers to adopt mobile SMS for agricultural data collection, the unified theory of acceptance and use of technology (UTAUT2) model was employed and extended with additional constructs of trust, mastery-approach goals and personal innovativeness in information technology (Figure 4.1). As part of the research, we setup data collection platforms using open source applications (Frontline SMS and Ushahidi, Figure 4.2) and farmers provided their farm related information using SMS for two growing seasons (Figure 4.3). The sample consisted of a group of farmers $(n=220)$ involved in a mobile SMS experiment ("SMS farmers") and another group which was not involved in a mobile SMS experiment ("Non-SMS farmers"), in three regions of Ethiopia.

The results from the structural equation modelling showed (Table 4.5) that performance expectancy, effort expectancy, price value and trust were the factors that influence farmers to adopt mobile SMS technology for agricultural data collection. Among these factors, trust is the strongest predictor of farmer's intention to adopt mobile SMS to provide their farm related information. This clearly indicates that in order to use the citizen science approach in the agricultural domain, establishing a trusted relationship with the smallholder farming community is crucial. Given that performance expectancy significantly predicted farmer's behavioural intention to adopt mobile SMS, managers of agricultural citizen science projects need to ensure that using mobile SMS for agricultural data collection offers utilitarian benefits to the farmers. The importance of effort expectancy on farmer's intention to adopt mobile SMS clearly indicates that mobile phone software developers need to develop easy to use mobile apps. To simplify the data collection process, applications that support Interactive Voice Response (IVR) (e.g., Robinson and Obrecht 2016) and icon-based user interfaces can potentially be developed (e.g., Herrick et al. 2016). The fact that price value was important for farmers to adopt mobile SMS indicates that projects implementing agricultural citizen science especially in developing countries need to find a mechanism where the SMS data 
transmission is free of charge (e.g., by providing free airtime). Moreover, multigroup comparisons using farmer's characteristics age and experience as moderator variables revealed that performance expectancy was important for younger farmers (Table 4.7), whereas price value was important for farmers who did not participate in a mobile SMS experiment ("Non-SMS farmers") (Table 4.6).

\section{Research question 5: How can synergy of crowdsourced data and remote sensing improve the estimation and explanation of yield variability?}

In Chapter 5, the crowdsourcing approach was combined with remote sensing to estimate and explain crop yield at the field level. Sesame production on medium and large farms in Ethiopia was used as a case study. To evaluate the added value of the crowdsourcing approach to improve the prediction of sesame yield using remote sensing, two independent models based on the relationship between vegetation indices (VIs) and farmers reported yield were developed and compared. The first model was based on VI values extracted from all available remote sensing imagery acquired during the optimum growing period (hereafter optimum growing period VI). The second model was based on VI values extracted from remote sensing imagery acquired after sowing and before harvest dates per field (hereafter phenologically adjusted VI). To select the images acquired between sowing and harvesting dates per field, farmers crowdsourced crop phenology information were used (e.g., Figure 4.3).

Results showed that vegetation indices derived based on farmers crowdsourced crop phenology information had a stronger relationship with sesame yield compared to vegetation indices derived based on the optimum growing period (Table 5.3). This implies that using crowdsourced information related to crop phenology per field used to adjust the VIs, improved the performance of the model to predict sesame yield. Among the vegetation indices explored, NDVI was a more effective predictor of sesame yield than EVI, SAVI and MSAVI (Table 5.3). The highest correlation was observed between sesame actual yield and the predicted yield using average NDVI over the growing season $\left(R^{2}=0.65\right.$, RMSE $=0.62$ ). The relationship between NDVI and sesame yield was strong when average values over the growing season were used (Figure 5.4). This implies that using multi-temporal image acquired over the growing season is more suitable to predict sesame yield than using single or few date image(s). Crowdsourced information could further identify factors that caused the yield variability within a field (Figures 5.11 and 5.12), and locations with lower yields in the remote sensing images largely overlapped with locations with reported yield limiting and/or reducing factors. According to the perception of farmers, overall soil fertility was the most important factor explaining the yield variability within a field, followed by high presence of weeds (Figure 5.11). 


\subsection{Reflection and outlook}

Yield gap analysis at the farm and farming system level provides the foundation for identifying the most important crop, soil and management factors limiting current farm yields (e.g., Affholder et al. 2013). The major challenge of this approach is that it needs detailed information about biophysical characteristics and crop and farm management for individual agricultural activities within a farm, as well as farm and farmer's characteristics and socio-economic conditions. Clearly, obtaining this information for a large number of fields from many farms is costly and timeconsuming. However, most of the relevant factors for yield gap analysis can potentially be collected using innovative data collection approaches (e.g., crowdsourcing; Table 2.1). In the next sections, the necessary additional steps that need to be considered to utilize the full potential of innovative data collection approaches for agricultural citizen science are discussed.

\subsubsection{Establishing and sustaining agricultural citizen science initiatives}

In Chapter 2, the potential of alternative data collection approaches (e.g., citizen science) to collect factors relevant for yield gap analysis has been discussed extensively (Table 2.1). However, in order to utilize the full potential of the citizen science approach for yield gap analysis, first the network with the intended community (i.e., farming community) needs to be established (Gharesifard et al. 2017). Network establishment mechanism is described as 'the establishment system of citizen science initiatives' and three main approaches can be distinguished: 'top-down', 'bottom-up' and 'commerce driven' (Gharesifard et al. 2017). In a top-down approach, scientists or authorities at higher-levels of policy making start the citizen science initiative (e.g., eBird; Sullivan et al. 2009 and tricot; Van Etten et al. 2016) while in a bottom-up setup, citizen scientists such as farmers start the citizen science initiative to look for solutions to their local problems (Haklay 2013; Bonney et al. 2009). In the agricultural domain, following the top-down approach, citizen science initiatives can be integrated with the current agricultural data collection system. In other sectors (e.g., forestry), researchers have shown the potential of linking community-based and national forest monitoring (Pratihast et al. 2013b). The lessons learnt from the forestry sector can also be extended to the agricultural domain to link farmers reported data with national or regional data collection efforts (e.g., Dillon 2012).

In the case of a bottom-up approach, farmers can initiate citizen science, for example in order to get a solution when there is an outbreak of a disease and/or pest. In earlier examples, in the Digital Early Warning Network (DEWN) project, an initiative at the International Institute of Tropical Agriculture 
(IITA), farmers send text messages to researchers about incidence of Cassava Mosaic Disease (CMD) and Cassava Brown Streak Disease (CBSD) and received disease control options in return (Ogodo 2009). The third approach (i.e. commerce driven) is a network establishment mechanism developing neither from official administrative bodies nor from grassroots levels, but rather are set up by for-profit organizations (e.g., private companies) (Gharesifard et al. 2017). In the agricultural domain, among others, initiatives like iCow (http://www.icow.co.ke/) and SoilCares (http://www.soilcares.com/en/) are examples where a commerce driven approach is followed to establish networks with the farming community.

As a next step, once the citizen science initiative is established, a mechanism to sustain the initiative is required (Gharesifard et al. 2017; Dickinson et al. 2012). Strategic collaborations and partnerships with potential public, private and NGOs might be necessary to gather the resources and participants required to sustain citizen science projects over the long term. The primary challenges for most projects include maintaining funding for cyberinfrastructure, databases, and project leadership (Dickinson et al. 2012). Gharesifard et al. (2017) identified seven revenue streams to sustain citizen science initiatives. (1) the first revenue stream is 'government sponsorship' that usually exists in a top-down set up. In this case, governments have the plan to use the data and thus allocate resources (e.g., from research budget) to establish and maintain a citizen science network. (2) Platform managers may combine farmers contributed data with other sources such as satellite and UAV data and sell these data products to individuals or organizations (e.g., eLEAF; www.eleaf.com). They may also process the data (e.g. using models) to generate information such as yield forecasts, warnings, maps, etc. and make profit from selling these products. This category of revenue streams is referred to as 'data or information usage fee'. (3) 'Subscription fee' refers to the membership fees that platform users may have to pay in order to gain continuous access to services provided by the platform (e.g., Yield Prophet: http://www.yieldprophet.com.au; (Hochman et al. 2009)). (4) 'Asset sale' refers to selling physical products (e.g.,

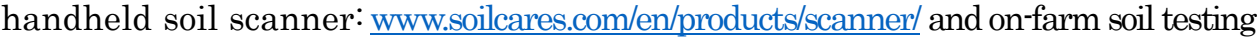
kit (SoilDoc): http://agriculture.columbia.edu/projects/agriculture/soildoc/). (5) 'Advertising': some networks might offer advertisement opportunities on their platform (e.g., for agribusiness companies). (6) 'Licensing' is generated as result of providing intellectual property rights to data sharers or the general public. An example of this classification may be licenses to use a specific software or application that is developed by the network (e.g., ClimMob; Van Etten et al. 2016). (7) 'Donation' indicates the network's full or partial dependence on the contributions of others (donors or the general public) to sustain the initiative (e.g., 'Seeds for Needs' initiative of Bioversity international; www.bioversityinternational.org/seeds-for-needs/). Depending on the situation 
or objectives, one of the aforementioned revenue streams may be used to sustain agricultural citizen science projects.

As part of establishing and sustaining the citizen science initiative, ethical issues such as data ownership, data access policy and privacy need to be addressed (Riesch and Potter 2014). Agricultural data is very much linked with the livelihood of the farmers and protecting and securing the data collected using the citizen science approach is very crucial. The study of Resnik et al. (2015) provides a framework for addressing ethical issues in citizen science. Such a framework can be adopted to ethical issues that should be addressed when agricultural citizen science projects begin and throughout the course of the projects lifetime. Moreover, during the whole establishment and sustainability processes, emphasis need to be given for building a trusted relationship with the farmers (Chapter 4).

\subsubsection{Technological implementation}

Technology is one of the pillars for the success of digital citizen science (Nov et al. 2014). The technological dimension consists of two main components. The first component is to identify the right hardware (e.g., mobile phone) and software (e.g., SMS) to be used by the farmers to collect and send agricultural information to a central database (Figure 4.2). Nowadays, the proliferation of mobile phone technology in developing countries, where there is a large yield gap for most of the crops (http://www.yieldgap.org/), offers a unique opportunity to implement effective and low-cost "bottom-up" data collection approaches (e.g., Herrick et al. 2013). In Chapter 4, effort expectancy (i.e. the effort needed to use a technology) was found as one of the determining factors for farmers to adopt mobile SMS for agricultural data collection (Table 4.5). Therefore, for the typical low-literate smallholder farmers in developing countries (Table 3.2), developing a simple data collection protocol for mobile SMS (e.g., short codes) (Figure 4.3) is needed. In the near future, penetration of smartphones in rural areas is expected to rise (GSMA 2016), hence data collection tools with iconbased user interfaces (e.g., Liebenberg et al. 2017) need to be considered to include all group of farmers in citizen science. This allows to address some of the issues (e.g., skill and usage) discussed under the notion of digital divide (van Dijk 2006). As a next step, a dedicated mobile app to collect relevant factors for yield gap analysis would be developed and make it available in Google Play and Apple App stores (e.g., Herrick et al. 2017).

The second component of the technological dimension constitutes of developing a database to store, manage, analyse and visualise large amounts of farmers crowdsourced data and geospatial datasets from sources such as remote sensing and Unmanned Aerial Vehicle (UAV) (Figure 6.1). Setting up the infrastructure has an initial cost and it might not be affordable for some 
grassroots organisations in developing countries (e.g., farmer unions). The availability of free and open source applications makes the initial set up affordable and can be implemented in a short time with minimum technical skills requirements. In Chapter 4, a data collection platform using FrontlineSMS and Ushahidi (Crowdmap) applications was demonstrated to collect and map farm level data (Figure 4.2) for two growing seasons. The result showed that free and open source applications are promising to collect and map farm level data from geographically distributed farmers in a developing country (Figure 4.3). For the geospatial datasets, the Geoprocessing Web provides a promising framework to facilitate distributed geospatial computation and large networks of collaboration (Zhao et al. 2012). Moreover, applications such as GeoODK (http://geoodk.com) provides a way to collect and store geo-referenced information, along with a suite of tools to visualize, analyse and manipulate ground data for specific needs (Brovelli et al. 2016). Finally, dedicated cyber-infrastructure support system such as CitSci (www.citsci.org) which provides all the tools and resources required for free all in one location on the internet can be used to implement citizen science programs (Newman et al. 2011).

\subsubsection{Mechanisms to assess/improve citizen science data quality}

Data quality is one of the greatest challenges in citizen science projects. While citizen science projects vary widely in their objectives, subject matter, activities, and scale (Wiggins and Crowston 2014), one common goal is the production of reliable data that can be used for scientific purposes. Kosmala et al. (2016b) identified different techniques used by existing citizen science projects to increase the quality of citizen science data. One of the proposed approaches for improving data quality is to train volunteers or to require prequalification via a skills test. For example as part of this research (Chapter 4), farmers received trainings on how to use their mobile phones to send information related to their farm using SMS. During the training, participating farmers received a list of factors with their associated short codes in a laminated A4 paper. By doing this, we put a restriction on the type of factors that need to be send over the growing season (Figure 4.3). This means any code other than the listed codes had to be excluded in the analysis and this had its own contribution for the quality of SMS data collected. To enhance the quality of citizen science data, providing ongoing trainings and feedbacks are beneficial (van der Wal et al. 2016).

The other approach to improve data quality is iterative development of task and tool design (Kosmala et al. 2016b). In this regard, the 'Seeds for Needs' initiative had to improve the data collection formats realising that the first versions did often assume too much about the capacity of farmers to read and to follow procedures that resulted in rather complex data collection formats 
(Van Etten et al. 2016). With subsequent evaluations, more user-friendly formats with graphical representation for each of the aspects to be assessed were developed. This made the format easier to use for farmers with low level of literacy.

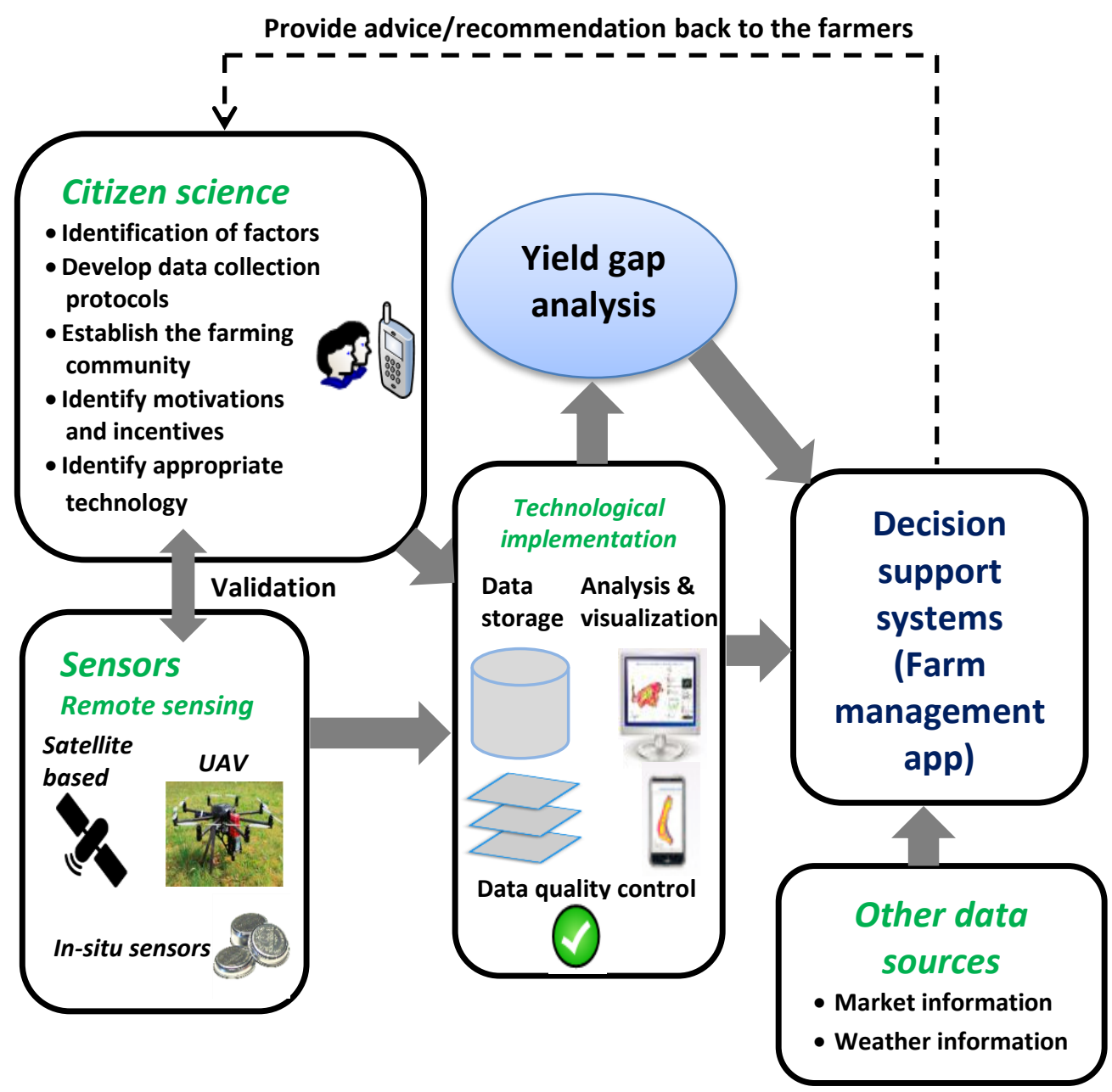

Figure 6.1: Overview of an integrated innovative data collection system for agricultural citizen science. 
Expert validation is the other approach to improve citizen science data quality (Kosmala et al. 2016b; Sullivan et al. 2014). A hierarchical approach for weed identification presented by Rahman et al. (2015) used two crowdsourcing levels. The first level consisted of a non-expert crowd and the second level consisted of a crowd composed of experts such as extension agents for accurate weed identification. Plant clinics of CABI (http://www.plantwise.org/plantclinics/) also use a hierarchical approach where trained farmers known as 'plant doctors' use tablets to submit a photo of the farmer's sample to a central database for validation by experts (Wright et al. 2016). However, expert validation of every data point can be impractical, and for large projects efficiently targeting likely wrong answers is important (Kosmala et al. 2016b). For example, the project FeederWatch uses an automated "smart filter" system that flags observations (Bonter and Cooper 2012). Flagged data are then immediately sent to regional experts who then ask for supporting details from volunteers to validate the observations. Upon receiving a response from the volunteer participant, experts could confirm the report or leave the record flagged if insufficient information was provided. Reports not verified during the review process were permanently flagged as invalid and not used in the subsequent data visualizations or analyses (Bonter and Cooper 2012). The aforementioned techniques to improve citizen science data quality can potentially be incorporated as part of the implementation of agricultural data collection using the citizen science approach (Figure 6.1).

\subsubsection{Linking different data streams}

Given the nature of the factors causing the yield gap (described in detail in Chapter 2), a data collection system that integrates both citizen science and (remote) sensors gives great opportunities to collect information on the biophysical, management, farm(er) characteristics, and socio-economic factors. Since (part of) the data can be digitally collected, it is possible to geolocate the fields within a farm (e.g., field boundary in Chapter 5). This makes it possible to combine the field level crowdsourced data with geospatial data from other sources (e.g., remote sensing). Linking the citizen science approach with remote sensing for example provides the opportunity to use the citizen science data to calibrate remote sensing based models. In Chapter 5, farmer's crowdsourced crop phenology data at the field level was used to select images acquired within the boundaries of the growing season per field and vegetation indices values were extracted only from the selected images. Using these values in the empirical model to estimate sesame yield based on remote sensing improved the accuracy of the model (Table 5.3). In addition, information derived from remote sensing can be used to validate crowdsourced information. For example, field size crowdsourced by a farmer can be compared and validated with field size information extracted from remote sensing (Fritz et al. 2015) or validated using Unmanned Aerial Vehicle (UAV) imagery (Mesas-Carrascosa et al. 
2014). Moreover, edaphic factors like soil fertility information assessed by farmers using local indicators (Desbiez et al. 2004) can be complemented with soil fertility information derived from high resolution remote sensing data (Gomez et al. 2008). Recent studies used vegetation indices derived from microsatellites to estimate and map crop yield at the field level even for the small and heterogeneous fields which are typical for the smallholder farming system in the tropics (Burke and Lobell 2017; Jain et al. 2016). Therefore, as said earlier, there is a potential to integrate data from different sources (Figure 6.1) to acquire the relevant factors for yield gap analysis (Table 2.1). However, some of the sourced data can be unstructured, therefore "Big data" techniques will be needed to synthesise the data from the different sources (Wolfert et al. 2017).

\subsubsection{Linking citizen science with decision support systems}

In Chapter 3, the majority of the farmers indicated that they would like to receive agronomic advice in return as an incentive to actively engage and continue participating in citizen science (Figure 3.5). To attract and retain farmers in citizen science projects, providing the appropriate incentives is very important (Chapter 3). To achieve this, the collected data using the citizen science approach together with data from other sources (e.g., remote sensing or UAV) can potentially be accessed through Application Programming Interface (e.g., Herrick et al. 2017) and used by farm-level decision support tools (e.g., AgBiz Logic; Capalbo et al. 2016 and Rice Crop Manager; Saito et al. 2015). The outputs from the decision support tools can be send to the farmers through SMS and smartphone apps as an advice for their farm-level management decisions (Figure 6.1). Rice Crop Manager (http://cropmanager.irri.org/), previously called Nutrient Manager for Rice (NMR), developed by the International Rice Research Institute (IRRI), provides advice after a farmer answers a series of questions. The recommendations are calculated based on farmer's responses to questions about the agro-ecological or administrative zone of the field, the variety of rice, availability of irrigation water, previous crop and management of its residue, previous rice yield levels, and fertilizer use (Saito et al. 2015). The generated information allows extension officers or lead farmers to give farmers a specific recommendation on nutrient, pest, weed, or water management via SMS. Also, the farmers would have every incentive to provide accurate information because they would be using the recommendations to make their actual management decisions (Capalbo et al. 2016). In order to overcome the low-literacy level of the smallholder farmers in developing countries, where there is a large yield gap for most of the crops (http://www.yieldgap.org), both the data collection and sending feedbacks to the farmers can be facilitated using icon-based or graphical user interfaces (e.g., Liebenberg et al. 2017). 
In the past advisory services were mainly based on general knowledge that once was derived from research experiments. However, currently there is an increasing need for information and knowledge that is generated on-farm in its local-specific context (Wolfert et al. 2017). A system as illustrated in Figure 6.1, allows to collect relevant factors for farm level yield gap analysis and at the same time the collected data can be used by decision support tools to provide advices to the farmers at each stages of the production process (Figure 6.2) based on the local-context of the farm. For example, when a farmer provides information about planting, the system can generate and send an advice in a 'near-real time' about the activities that need to be considered in the next stage of the growth cycle (i.e., growing). The results in Chapter 2 (Figure 2.3) showed that timing of fertilization was one of the factors causing the yield gap. Results from this type of analysis can be coupled with farm level decision support tools (e.g., Nutrient Manager for Rice) to provide appropriate feedback to the farmers as when is the appropriate time to apply fertilization (Saito et al. 2015).

Farmers have different types of information needs during each stage of the process, ranging from weather forecasts, pest attacks, inputs, cultivation practices, pest and disease management, and prices (Figure 6.2) (Aker 2011). Cole and Fernando (2016) demonstrated that delivering timely, relevant, and actionable information and advice to farmers using mobile phones reduced knowledge gaps and increases productivity. The citizen science approach will help not only to collect relevant factors for yield gap analysis (Beza et al. 2017a) but also to provide input data for decision support tools (Janssen et al. In Press). Moreover, as a social networking tool, developing a platform as presented in Figure 6.1, will allow individual farmers to easily connect with other farmers facing similar challenges on similar types of land (Herrick et al. 2013). Finally, the aggregated data across large areas can be used by policy makers for possible interventions at the regional or national level.

In this thesis emphasis was given on the use of citizen science for crop yield gap analysis in developing countries. However, the methods presented and the steps suggested in this thesis are applicable to a broader geographic scope. 


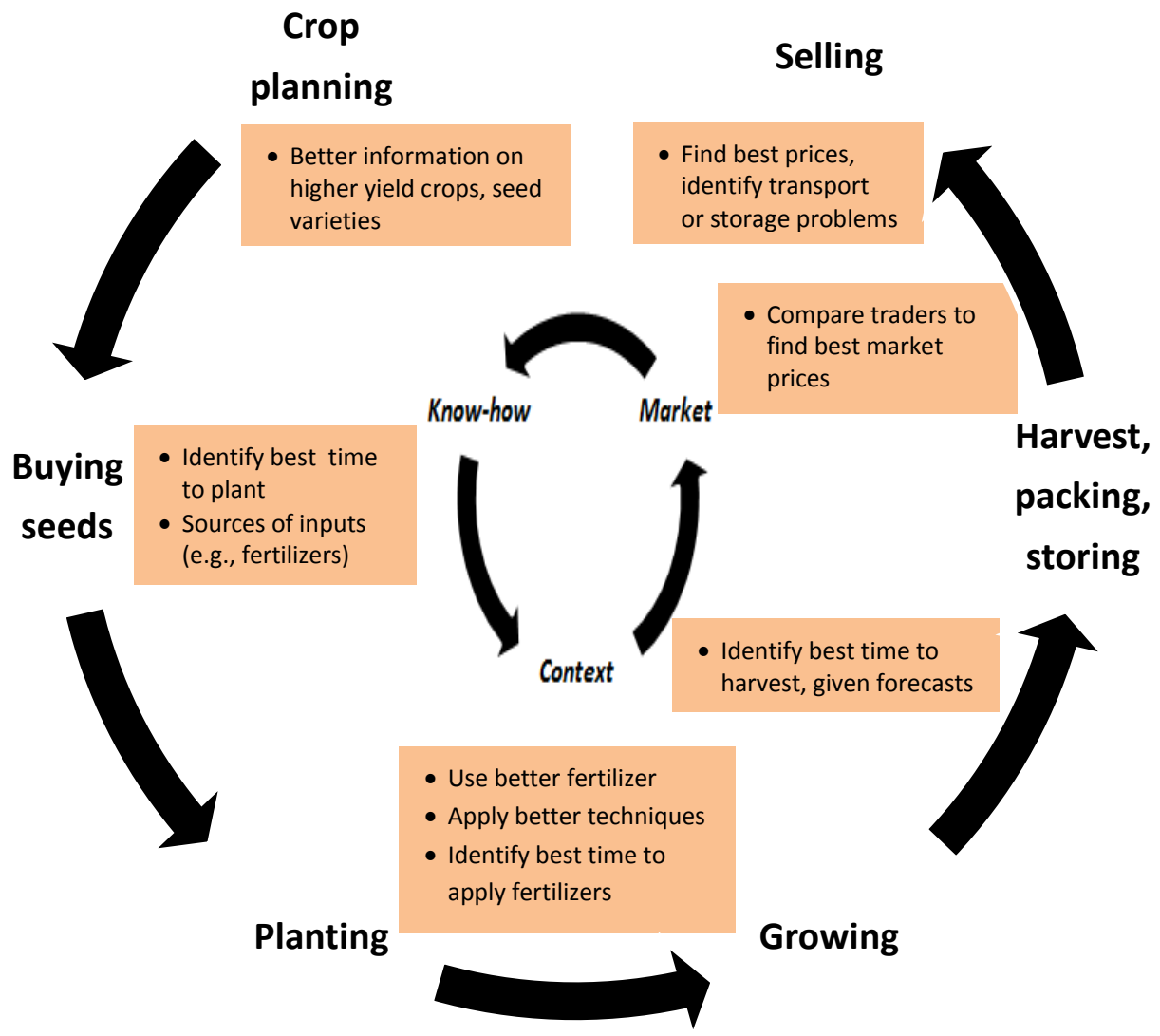

Figure 6.2: Stages of the agricultural production process and information needs of the farmers. Figure reproduced from Aker (2011). 


\section{References}

Aaron-Morrison, A. P., S. A. Ackerman, N. G. Adams, R. F. Adler, A. Albanil, E. J. Alfaro, R. Allan, et al. 2016. State of the climate in 2015. Bulletin of the American Meteorological Society 97 (8): S1-S275.

Abeledo, L. G., R. Savin, and G. A. Slafer. 2008. Wheat productivity in the Mediterranean Ebro Valley: Analyzing the gap between attainable and potential yield with a simulation model. European Journal of Agronomy 28 (4): 541-550.

Adrian, A. M., S. H. Norwood, and P. L. Mask. 2005. Producers' perceptions and attitudes toward precision agriculture technologies. Computers and Electronics in Agriculture 48 (3): 256-271.

Affholder, F., C. Poeydebat, M. Corbeels, E. Scopel, and P. Tittonell. 2013. The yield gap of major food crops in family agriculture in the tropics: Assessment and analysis through field surveys and modelling. Field Crops Research 143: 106-118.

Agarwal, R., and J. Prasad. 1998. A Conceptual and Operational Definition of Personal Innovativeness in the Domain of Information Technology. Information Systems Research 9 (2): 204-215.

Ajzen, I. 2002. Residual Effects of Past on Later Behavior: Habituation and Reasoned Action Perspectives. Personality and Social Psychology Review 6 (2): 107-122.

Aker, J. C. 2011. Dial "A" for agriculture: a review of information and communication technologies for agricultural extension in developing countries. Agricultural Economics 42 (6): 631-647.

Al-Gaadi, K. A., A. A. Hassaballa, E. Tola, A. G. Kayad, R. Madugundu, B. Alblewi, and F. Assiri. 2016. Prediction of Potato Crop Yield Using Precision Agriculture Techniques. PLOS ONE 11 (9): e0162219.

Ali, M. 1995. Institutional and Socioeconomic Constraints on the SecondGeneration Green Revolution: A Case Study of Basmati Rice Production in Pakistan's Punjab. Economic Development and Cultural Change 43 (4): 835-861.

Alvarez, J., and P. Nuthall. 2006. Adoption of computer based information systems: The case of dairy farmers in Canterbury, NZ, and Florida, Uruguay. Computers and Electronics in Agriculture 50 (1): 48-60.

Anderson, J. C., and D. W. Gerbing. 1988. Structural equation modeling in practice: A review and recommended two-step approach. Psychological bulletin 103 (3): 411.

Anderson, W. K., M. A. Hamza, D. L. Sharma, M. F. D’Antuono, F. C. Hoyle, N. Hill, B. J. Shackley, M. Amjad, and C. Zaicou-Kunesch. 2005. The role of management in yield improvement of the wheat crop-a review 
with special emphasis on Western Australia. Australian Journal of Agricultural Research 56 (11): 1137-1149.

Antle, J. M., J. W. Jones, and C. E. Rosenzweig. In Press. Next generation agricultural system data, models and knowledge products: Introduction. Agricultural Systems.

Antonopoulou, E., S. T. Karetsos, M. Maliappis, and A. B. Sideridis. 2010. Web and mobile technologies in a prototype DSS for major field crops. Computers and Electronics in Agriculture 70 (2): 292-301.

Aragó Galindo, P., C. Granell, P. G. Molin, and J. Huerta Guijarro. 2012. Participative site-specific agriculture analysis for smallholders. Precision Agriculture 13 (5): 594-610.

Aubert, B. A., A. Schroeder, and J. Grimaudo. 2012. IT as enabler of sustainable farming: An empirical analysis of farmers' adoption decision of precision agriculture technology. Decision Support Systems 54 (1): $510-520$.

Audebert, A., and M. Fofana. 2009. Rice Yield Gap due to Iron Toxicity in West Africa. Journal of Agronomy and Crop Science 195 (1): 66-76.

Bai, J., J. Li, and S. Li. 2011. Monitoring the Plant Density of Cotton with Remotely Sensed Data. In Computer and Computing Technologies in Agriculture IV, 90-101. Springer Berlin Heidelberg.

Banks, K., and E. Hersman. 2009. FrontlineSMS and ushahidi - a demo. In Proceedings of the 3rd international conference on Information and communication technologies and development. Doha, Qatar: IEEE Press.

Baptista, G., and T. Oliveira. 2015. Understanding mobile banking: The unified theory of acceptance and use of technology combined with cultural moderators. Computers in Human Behavior 50: 418-430.

Batson, C. D., N. Ahmad, and J. A. Tsang. 2002. Four Motives for Community Involvement. Journal of Social Issues 58 (3): 429-445.

Belden, C., C. Bothwell, T. M. Etulain, C. M. D. N. Figueres, A. Goyal, T. J. C. Kelly, K. Pidatala, P. Pruuden, and P. Surya. 2013. ICT for data collection and monitoring and evaluation : opportunities and guidance on mobile applications for forest and agricultural sectors. Washington DC: World Bank Group.

Bellon, M. R. 2001. Participatory research methods for technology evaluation: A manual for scientists working with farmers: CIMMYT.

Bernet, T., O. Ortiz, R. D. Estrada, R. Quiroz, and S. M. Swinton. 2001. Tailoring agricultural extension to different production contexts: a user-friendly farm-household model to improve decision-making for participatory research. Agricultural Systems 69 (3): 183-198.

Beza, E., J. Vasco Silva, L. Kooistra, and P. Reidsma. 2017a. Review of yield gap explaining factors and opportunities for alternative data collection approaches. European Journal of Agronomy 82, Part B: 206-222. 
Beza, E., J. Steinke, J. van Etten, P. Reidsma, C. Fadda, S. Mittra, P. Mathur, and L. Kooistra. 2017b. What are the prospects for citizen science in agriculture? Evidence from three continents on motivation and mobile telephone use of resource-poor farmers. PLOS ONE 12 (5): e0175700.

Beza, E., P. Reidsma, P. M. Poortvliet, M. M. Belay, B. S. Bijen, and L. Kooistra. submitted. Exploring farmers' intentions to adopt mobile Short Message Service (SMS) for citizen science in agriculture.

Bhatia, V. S., P. Singh, S. P. Wani, G. S. Chauhan, A. V. R. K. Rao, A. K. Mishra, and K. Srinivas. 2008. Analysis of potential yields and yield gaps of rainfed soybean in India using CROPGRO-Soybean model. Agricultural and Forest Meteorology 148 (8-9): 1252-1265.

Bolton, D. K., and M. A. Friedl. 2013. Forecasting crop yield using remotely sensed vegetation indices and crop phenology metrics. Agricultural and Forest Meteorology 173: 74-84.

Bonney, R., H. Ballard, R. Jordan, E. McCallie, T. Phillips, J. Shirk, and C. C. Wilderman. 2009. Public Participation in Scientific Research: Defining the Field and Assessing Its Potential for Informal Science Education. A CAISE Inquiry Group Report. Online Submission.

Bonter, D. N., and C. B. Cooper. 2012. Data validation in citizen science: a case study from Project FeederWatch. Frontiers in Ecology and the Environment 10 (6): 305-307.

Boogaard, H., J. Wolf, I. Supit, S. Niemeyer, and M. van Ittersum. 2013. A regional implementation of WOFOST for calculating yield gaps of autumn-sown wheat across the European Union. Field Crops Research 143: $130-142$.

Bouman, B. A. M., and T. P. Tuong. 2001. Field water management to save water and increase its productivity in irrigated lowland rice. Agricultural Water Management 49 (1): 11-30.

Brabham, D. C. 2008. Moving the crowd at iStockphoto: The composition of the crowd and motivations for participation in a crowdsourcing application. First Monday [S.1.].

Brabham, D. C. 2010. Moving the crowd at Threadless: Motivations for participation in a crowdsourcing application. Information, Communication \& Society 13 (8): 1122-1145.

Brislin, R. 1986. The Wording and Translation of Research Instruments. . Field Methods in Cross Cultural Research. Beverly Hills, California: Sage Publications: 159-163.

Brophy, J. 2004. Motivating students to learn. Second Edition ed. Mahwah, New Jersey Lawrence Erlbaum Associates

Brovelli, M. A., M. Minghini, and G. Zamboni. 2016. Public participation in GIS via mobile applications. ISPRS Journal of Photogrammetry and Remote Sensing 114: 306-315. 
Brown, S. A., and V. Venkatesh. 2005. Model of Adoption of Technology in Households: A Baseline Model Test and Extension Incorporating Household Life Cycle. MIS Quarterly 29 (3): 399-426.

Bruinsma, J. 2009. The resource outlook to 2050: by how much do land, water, and crop yields need to increase by 2050 ? In: Expert Meeting on how to feed the world in 2050.

Burke, M., and D. B. Lobell. 2017. Satellite-based assessment of yield variation and its determinants in smallholder African systems. Proceedings of the National Academy of Sciences 114 (9): 2189-2194.

Byrne, B. M. 2001. Structural Equation Modelling With AMOS, EQS, and LISREL: Comparative Approaches to Testing for the Factorial Validity of a Measuring Instrument. International Journal of Testing 1 (1): 5586.

Cao, X., Y. Luo, Y. Zhou, X. Duan, and D. Cheng. 2013. Detection of powdery mildew in two winter wheat cultivars using canopy hyperspectral reflectance. Crop Protection 45 (0): 124-131.

Capalbo, S. M., J. M. Antle, and C. Seavert. 2016. Next generation data systems and knowledge products to support agricultural producers and sciencebased policy decision making. Agricultural Systems.

Car, N. J., E. W. Christen, J. W. Hornbuckle, and G. A. Moore. 2012. Using a mobile phone Short Messaging Service (SMS) for irrigation scheduling in Australia - Farmers' participation and utility evaluation. Computers and Electronics in Agriculture 84: 132-143.

Carballo-Cárdenas, E. C., and H. Tobi. 2016. Citizen science regarding invasive lionfish in Dutch Caribbean MPAs: Drivers and barriers to participation. Ocean \& Coastal Management 133: 114-127.

Carlsson, C., J. Carlsson, K. Hyvonen, J. Puhakainen, and P. Walden. 2006. Adoption of mobile devices/services-searching for answers with the UTAUT. Proceedings of the 39th Annual Hawaii International Conference on System Sciences (HICSS'06).

Cassman, K. G. 1999. Ecological intensification of cereal production systems: Yield potential, soil quality, and precision agriculture. Proceedings of the National Academy of Sciences of the United States of America 96 (11): 5952-5959.

Ceccarelli, S., and S. Grando. 2007. Decentralized-participatory plant breeding: an example of demand driven research. Euphytica 155 (3): 349-360.

Chadwick, D., J. Wei, T. Yan'an, Y. Guanghui, S. Qirong, and C. Qing. 2015. Improving manure nutrient management towards sustainable agricultural intensification in China. Agriculture, Ecosystems \& Environment 209 (0): 34-46.

Churchill, G. A. 1979. A Paradigm for Developing Better Measures of Marketing Constructs. Journal of Marketing Research 16 (1): 64-73. 
Cohn, J. P. 2008. Citizen Science: Can Volunteers Do Real Research? BioScience 58 (3): 192-197.

Cole, S. A., and A. N. Fernando. 2016. 'Mobile'izing Agricultural Advice: Technology Adoption, Diffusion and Sustainability.

Compeau, D. R., and C. A. Higgins. 1995. Computer Self-Efficacy: Development of a Measure and Initial Test. MIS Quarterly 19 (2): 189-211.

Confalonieri, R., M. Foi, R. Casa, S. Aquaro, E. Tona, M. Peterle, A. Boldini, et al. 2013. Development of an app for estimating leaf area index using a smartphone. Trueness and precision determination and comparison with other indirect methods. Computers and Electronics in Agriculture 96 (0): 67-74.

Conrad, C. C., and K. G. Hilchey. 2011. A review of citizen science and community-based environmental monitoring: issues and opportunities. Environmental Monitoring and Assessment 176 (1): 273-291.

Cooper, S., F. Khatib, A. Treuille, J. Barbero, J. Lee, M. Beenen, A. LeaverFay, D. Baker, and Z. Popović. 2010. Predicting protein structures with a multiplayer online game. Nature 466 (7307): 756-760.

Curtis, V. 2015. Motivation to Participate in an Online Citizen Science Game: A Study of Foldit. Science Communication 37 (6): 723-746.

D'Antoni, J. M., A. K. Mishra, and H. Joo. 2012. Farmers' perception of precision technology: The case of autosteer adoption by cotton farmers. Computers and Electronics in Agriculture 87: 121-128.

Davis, F. D., R. P. Bagozzi, and P. R. Warshaw. 1989. User Acceptance of Computer Technology: A Comparison of Two Theoretical Models. Management Science 35 (8): 982-1003.

Dehnen-Schmutz, K., G. L. Foster, L. Owen, and S. Persello. 2016. Exploring the role of smartphone technology for citizen science in agriculture. Agronomy for Sustainable Development 36 (2): 25.

Delmotte, S., P. Tittonell, J. C. Mouret, R. Hammond, and S. Lopez-Ridaura. 2011. On farm assessment of rice yield variability and productivity gaps between organic and conventional cropping systems under Mediterranean climate. European Journal of Agronomy 35 (4): 223236.

Dente, L., G. Satalino, F. Mattia, and M. Rinaldi. 2008. Assimilation of leaf area index derived from ASAR and MERIS data into CERES-Wheat model to map wheat yield. Remote Sensing of Environment 112 (4): 1395-1407.

Desbiez, A., R. Matthews, B. Tripathi, and J. Ellis-Jones. 2004. Perceptions and assessment of soil fertility by farmers in the mid-hills of Nepal. Agriculture, Ecosystems \& Environment 103 (1): 191-206.

DeTar, W. R., and J. V. Penner. 2007. Airborne remote sensing used to estimate percent canopy cover and to extract canopy temperature from scene temperature in cotton. Transactions of the ASABE 50 (2): 495-506. 
Deterding, S. 2011. Situated motivational affordances of game elements: A conceptual model. InGamification: Using Game Design Elements in Non-Gaming Contexts, a workshop at CHI.

Dickinson, J. L., J. Shirk, D. Bonter, R. Bonney, R. L. Crain, J. Martin, T. Phillips, and K. Purcell. 2012. The current state of citizen science as a tool for ecological research and public engagement. Frontiers in Ecology and the Environment 10 (6): 291-297.

Dillon, B. 2012. Using mobile phones to collect panel data in developing countries. Journal of International Development 24 (4): 518-527.

Dobermann, A., C. Witt, D. Dawe, S. Abdulrachman, H. C. Gines, R. Nagarajan, S. Satawathananont, et al. 2002. Site-specific nutrient management for intensive rice cropping systems in Asia. Field Crops Research 74 (1): 37-66.

Doraiswamy, P. C., T. R. Sinclair, S. Hollinger, B. Akhmedov, A. Stern, and J. Prueger. 2005. Application of MODIS derived parameters for regional crop yield assessment. Remote Sensing of Environment 97 (2): 192-202.

Doré, T., D. Makowski, E. Malézieux, N. Munier-Jolain, M. Tchamitchian, and P. Tittonell. 2011. Facing up to the paradigm of ecological intensification in agronomy: Revisiting methods, concepts and knowledge. European Journal of Agronomy 34 (4): 197-210.

Droogers, P., W. W. Immerzeel, and I. J. Lorite. 2010. Estimating actual irrigation application by remotely sensed evapotranspiration observations. Agricultural Water Management 97 (9): 1351-1359.

Du, M., and N. Noguchi. 2017. Monitoring of Wheat Growth Status and Mapping of Wheat Yield's within-Field Spatial Variations Using Color Images Acquired from UAV-camera System. Remote Sensing 9 (3): 289.

Duncan, J., J. Dash, and P. Atkinson. 2015a. The potential of satellite-observed crop phenology to enhance yield gap assessments in smallholder landscapes. Frontiers in Environmental Science 3 (56).

Duncan, J. M. A., J. Dash, and P. M. Atkinson. 2015b. Elucidating the impact of temperature variability and extremes on cereal croplands through remote sensing. Global Change Biology 21 (4): 1541-1551.

Dwivedi, Y. K., M. A. Shareef, A. C. Simintiras, B. Lal, and V. Weerakkody. 2016. A generalised adoption model for services: A cross-country comparison of mobile health (m-health). Government Information Quarterly 33 (1): 174-187.

El Hajj, M., A. Bégué, S. Guillaume, and J.-F. Martiné. 2009. Integrating SPOT-5 time series, crop growth modeling and expert knowledge for monitoring agricultural practices - The case of sugarcane harvest on Reunion Island. Remote Sensing of Environment 113 (10): 2052-2061.

Elliot, A. J., and H. A. McGregor. 2001. A 2 X 2 achievement goal framework. J Pers Soc Psychol 80 (3): 501-519. 
Etezadi-Amoli, J., and A. F. Farhoomand. 1996. A structural model of end user computing satisfaction and user performance. Information \& Management 30 (2): 65-73.

Fermont, A., and T. Benson. 2011. Estimating yield of food crops grown by smallholder farmers. International Food Policy Research Institute, Washington DC: 1-68.

Fermont, A. M., P. J. A. van Asten, P. Tittonell, M. T. van Wijk, and K. E. Giller. 2009. Closing the cassava yield gap: An analysis from smallholder farms in East Africa. Field Crops Research 112 (1): 24-36.

Ferster, C. J., and N. C. Coops. 2013. A review of earth observation using mobile personal communication devices. Computers \& Geosciences 51: 339-349.

Fienen, M. N., and C. S. Lowry. 2012. Social.Water-A crowdsourcing tool for environmental data acquisition. Computers \& Geosciences 49: 164-169.

Fitz-Walter, Z., D. Tjondronegoro, and P. Wyeth. 2011. Orientation passport: using gamification to engage university students. Proceedings of the 23rd Australian Computer-Human Interaction Conference.

Flatla, D. R., C. Gutwin, L. E. Nacke, S. Bateman, and R. L. Mandryk. 2011. Calibration games: making calibration tasks enjoyable by adding motivating game elements. Proceedings of the 24th annual ACM symposium on User interface software and technology.

Flett, R., F. Alpass, S. Humphries, C. Massey, S. Morriss, and N. Long. 2004. The technology acceptance model and use of technology in New Zealand dairy farming. Agricultural Systems 80 (2): 199-211.

Foley, J. A., N. Ramankutty, K. A. Brauman, E. S. Cassidy, J. S. Gerber, M. Johnston, N. D. Mueller, et al. 2011. Solutions for a cultivated planet. Nature 478 (7369): 337-342.

Follett, R., and V. Strezov. 2015. An Analysis of Citizen Science Based Research: Usage and Publication Patterns. PLoS ONE 10 (11): e0143687.

Fornell, C., and D. F. Larcker. 1981. Evaluating Structural Equation Models with Unobservable Variables and Measurement Error. Journal of Marketing Research 18 (1): 39-50.

Fritz, S., L. See, I. McCallum, L. You, A. Bun, E. Moltchanova, M. Duerauer, et al. 2015. Mapping global cropland and field size. Global Change Biology 21 (5): 1980-1992.

Funk, C., and M. E. Budde. 2009. Phenologically-tuned MODIS NDVI-based production anomaly estimates for Zimbabwe. Remote Sensing of Environment 113 (1): 115-125.

Gefen, D., D. Straub, and M.-C. Boudreau. 2000. Structural equation modelling and regression: Guidelines for research practice. Communications of the association for information systems 4 (1): 7. 
Gharesifard, M., U. Wehn, and P. van der Zaag. 2017. Towards benchmarking citizen observatories: Features and functioning of online amateur weather networks. Journal of Environmental Management 193: 381393.

Gianessi, L. P. 2013. The increasing importance of herbicides in worldwide crop production. Pest Manag Sci 69 (10): 1099-105.

Giannakas, K., R. Schoney, and V. Tzouvelekas. 2001. Technical Efficiency, Technological Change and Output Growth of Wheat Farms in Saskatchewan. Canadian Journal of Agricultural Economics/Revue canadienne d'agroeconomie 49 (2): 135-152.

Gilbert, A. L., and H. Han. 2005. Understanding mobile data services adoption: Demography, attitudes or needs? Technological Forecasting and Social Change 72 (3): 327-337.

Giller, K. E., E. C. Rowe, N. de Ridder, and H. van Keulen. 2006. Resource use dynamics and interactions in the tropics: Scaling up in space and time. Agricultural Systems 88 (1): 8-27.

Gittleman, M., K. Jordan, and E. Brelsford. 2012. Using citizen science to quantify community garden crop yields. Cities and the Environment (CATE) 5 (1): 4.

Godfray, H. C. J., J. R. Beddington, I. R. Crute, L. Haddad, D. Lawrence, J. F. Muir, J. Pretty, et al. 2010. Food Security: The Challenge of Feeding 9 Billion People. Science 327 (5967): 812-818.

Goel, P. K., S. O. Prasher, J. A. Landry, R. M. Patel, R. B. Bonnell, A. A. Viau, and J. R. Miller. 2003. Potential of airborne hyperspectral remote sensing to detect nitrogen deficiency and weed infestation in corn. Computers and Electronics in Agriculture 38 (2): 99-124.

Gomez, C., R. A. Viscarra Rossel, and A. B. McBratney. 2008. Soil organic carbon prediction by hyperspectral remote sensing and field vis-NIR spectroscopy: An Australian case study. Geoderma 146 (3-4): 403-411.

Graneheim, U. H., and B. Lundman. 2004. Qualitative content analysis in nursing research: concepts, procedures and measures to achieve trustworthiness. Nurse education today 24 (2): 105-112.

Grassini, P., L. G. J. van Bussel, J. Van Wart, J. Wolf, L. Claessens, H. Yang, H. Boogaard, et al. 2015. How good is good enough? Data requirements for reliable crop yield simulations and yield-gap analysis. Field Crops Research 177: 49-63.

Grey, F. 2009. The age of citizen cyberscience. CERN Courier. Available at: http://cerncourier.com/cws/article/cern/38718, Accessed March 5, 2017.

Grid, W. C. Member Study: Findings and Next Steps 2013. Available from http://www.worldcommunitygrid.org/about_us/viewNewsArticle.do?ar ticleId $=323$.

GSMA. 2016. Agricultural Value-added Services (Agri VAS) Toolkit 2.0 How to design, develop and market next generation VAS for the rural market. 
Haefele, S. M., M. C. S. Wopereis, C. Donovan, and J. Maubuisson. 2001. Improving the productivity and profitability of irrigated rice production in Mauritania. European Journal of Agronomy 14 (3): 181-196.

Hair, J. F., W. C. Black, B. J. Babin, and R. E. Anderson. 2010. Multivariate data analysis: A global perspective. Upper Saddle River.

Haklay, M. 2013. "Citizen science and volunteered geographic information: Overview and typology of participation." In Crowdsourcing Geographic Knowledge: Volunteered Geographic Information (VGI) in Theory and Practice, edited by Daniel Sui, Sarah Elwood and Michael Goodchild, 105-122. Dordrecht: Springer Netherlands.

Hall, A. J., and R. A. Richards. 2013. Prognosis for genetic improvement of yield potential and water-limited yield of major grain crops. Field Crops Research 143: 18-33.

Hammond, J., S. Fraval, J. van Etten, J. G. Suchini, L. Mercado, T. Pagella, R. Frelat, et al. 2016. The Rural Household Multi-Indicator Survey (RHoMIS) for rapid characterisation of households to inform climate smart agriculture interventions: Description and applications in East Africa and Central America. Agricultural Systems.

Han, J., C. Wei, Y. Chen, W. Liu, P. Song, D. Zhang, A. Wang, et al. 2017. Mapping Above-Ground Biomass of Winter Oilseed Rape Using High Spatial Resolution Satellite Data at Parcel Scale under Waterlogging Conditions. Remote Sensing 9 (3): 238.

Hand, E. 2010. Citizen science: People power. Nature 466 (7307): 685-7.

Helfand, S. M., and E. S. Levine. 2004. Farm size and the determinants of productive efficiency in the Brazilian Center-West. Agricultural Economics 31 (2-3): 241-249.

Hellin, J., M. Bellon, L. Badstue, J. Dixon, and R. La Rovere. 2008. Increasing the impacts of participatory research. Experimental Agriculture 44 (01): 81-95.

Herrick, J. E., A. Beh, E. Barrios, I. Bouvier, M. Coetzee, D. Dent, E. Elias, et al. 2016. The Land-Potential Knowledge System (LandPKS): mobile apps and collaboration for optimizing climate change investments. Ecosystem Health and Sustainability 2 (3).

Herrick, J. E., J. W. Karl, S. E. McCord, M. Buenemann, C. Riginos, E. Courtright, J. Van Zee, et al. 2017. Two New Mobile Apps for Rangeland Inventory and Monitoring by Landowners and Land Managers. Rangelands.

Herrick, J. E., K. C. Urama, J. W. Karl, J. Boos, M.-V. V. Johnson, K. D. Shepherd, J. Hempel, et al. 2013. The global Land-Potential Knowledge System (LandPKS): Supporting evidence-based, site-specific land use and management through cloud computing, mobile applications, and crowdsourcing. Journal of Soil and Water Conservation 68 (1): 5A-12A. 
Ho, C.-T. B., Y.-T. Chou, and P. O'Neill. 2010. Technology adoption of mobile learning: a study of podcasting. International Journal of Mobile Communications 8 (4): 468-485.

Hochman, Z., D. Gobbett, D. Holzworth, T. McClelland, H. van Rees, O. Marinoni, J. N. Garcia, and H. Horan. 2012. Quantifying yield gaps in rainfed cropping systems: A case study of wheat in Australia. Field Crops Research 136 (0): 85-96.

Hochman, Z., D. Gobbett, H. Horan, and J. Navarro Garcia. 2016. Data rich yield gap analysis of wheat in Australia. Field Crops Research 197: 97106.

Hochman, Z., H. Van Rees, P. S. Carberry, J. R. Hunt, R. L. McCown, A. Gartmann, D. Holzworth, et al. 2009. Re-inventing model-based decision support with Australian dryland farmers. 4. Yield Prophet ${ }^{\circledR}$ helps farmers monitor and manage crops in a variable climate. Crop and Pasture Science 60 (11): 1057-1070.

Hofstede, G. 1984. Culture's consequences: International differences in workrelated values. Vol. 5: SAGE Publications, Inc.

Hofstede, G. H. 2001. Culture's consequences: Comparing values, behaviours, institutions and organizations across nations: SAGE Publications, Inc.

Holohan, A., and A. Garg. 2005. Collaboration Online: The Example of Distributed Computing. Journal of Computer-Mediated Communication 10 (4).

Howe, J. 2006. Crowdsourcing: A Definition.

Hu, L. t., and P. M. Bentler. 1999. Cutoff criteria for fit indexes in covariance structure analysis: Conventional criteria versus new alternatives. Structural Equation Modelling: A Multidisciplinary Journal 6 (1): 1-55.

Huang, J., X. Wang, X. Li, H. Tian, and Z. Pan. 2013. Remotely Sensed Rice Yield Prediction Using Multi-Temporal NDVI Data Derived from NOAA's-AVHRR. PLOS ONE 8 (8): e70816.

Huete, A., K. Didan, T. Miura, E. P. Rodriguez, X. Gao, and L. G. Ferreira. 2002. Overview of the radiometric and biophysical performance of the MODIS vegetation indices. Remote Sensing of Environment 83 (1-2): 195-213.

Huete, A. R. 1988. A soil-adjusted vegetation index (SAVI). Remote Sensing of Environment 25 (3): 295-309.

Hung, S.-Y., C.-M. Chang, and S.-R. Kuo. 2013. User acceptance of mobile egovernment services: An empirical study. Government Information Quarterly 30 (1): 33-44.

Hwang, Y., and M. Yi. 2002. Predicting the use of web-based information systems: intrinsic motivation and self-efficacy. AMCIS 2002 Proceedings: 149.

Iannone Iii, B. V., L. G. Umek, D. H. Wise, and L. Heneghan. 2012. A Simple, safe, and effective sampling technique for investigating earthworm 
communities in woodland soils: Implications for citizen science. Natural Areas Journal 32 (3): 283-292.

Im, I., S. Hong, and M. S. Kang. 2011. An international comparison of technology adoption: Testing the UTAUT model. Information \& Management 48 (1): 1-8.

ITU. 2016. ICT facts and figures.

Jain, M., P. Mondal, R. S. DeFries, C. Small, and G. L. Galford. 2013. Mapping cropping intensity of smallholder farms: A comparison of methods using multiple sensors. Remote Sensing of Environment 134 (0): 210223.

Jain, M., A. Srivastava, Balwinder-Singh, R. Joon, A. McDonald, K. Royal, M. Lisaius, and D. Lobell. 2016. Mapping Smallholder Wheat Yields and Sowing Dates Using Micro-Satellite Data. Remote Sensing 8 (10): 860.

Janssen, O., and N. W. Van Yperen. 2004. Employees' Goal Orientations, the Quality of Leader-Member Exchange, and the Outcomes of Job Performance and Job Satisfaction. Academy of Management Journal 47 (3): 368-384.

Janssen, S. J. C., C. H. Porter, A. D. Moore, I. N. Athanasiadis, I. Foster, J. W. Jones, and J. M. Antle. In Press. Towards a new generation of agricultural system data, models and knowledge products: Information and communication technology. Agricultural Systems.

Jiji, G. W., and P. Nadar. 2015. Soil Type Identification Using Remotely Sensed Data for Agricultural Purpose. Journal of The Institution of Engineers (India): Series B: 1-7.

Johnson, D. M. 2016. A comprehensive assessment of the correlations between field crop yields and commonly used MODIS products. International Journal of Applied Earth Observation and Geoinformation 52: 65-81.

Johnson, M. F., C. Hannah, L. Acton, R. Popovici, K. K. Karanth, and E. Weinthal. 2014. Network environmentalism: Citizen scientists as agents for environmental advocacy. Global Environmental Change 29: 235-245.

Kassie, B. T., M. K. Van Ittersum, H. Hengsdijk, S. Asseng, J. Wolf, and R. P. Rötter. 2014. Climate-induced yield variability and yield gaps of maize (Zea mays L.) in the Central Rift Valley of Ethiopia. Field Crops Research 160 (0): 41-53.

Kayad, A. G., K. A. Al-Gaadi, E. Tola, R. Madugundu, A. M. Zeyada, and C. Kalaitzidis. 2016. Assessing the Spatial Variability of Alfalfa Yield Using Satellite Imagery and Ground-Based Data. PLOS ONE 11 (6): e0157166.

Keating, B. A., M. Herrero, P. S. Carberry, J. Gardner, and M. B. Cole. 2014. Food wedges: Framing the global food demand and supply challenge towards 2050. Global Food Security 3 (3-4): 125-132. 
Kim, G. S., S.-B. Park, and J. Oh. 2008. An examination of factors influencing consumer adoption of short message service (SMS). Psychology and Marketing 25 (8): 769-786.

Kim, S. S., and N. K. Malhotra. 2005. A Longitudinal Model of Continued IS Use: An Integrative View of Four Mechanisms Underlying Postadoption Phenomena. Management Science 51 (5): 741-755.

Knipling, E. B. 1970. Physical and physiological basis for the reflectance of visible and near-infrared radiation from vegetation. Remote Sensing of Environment 1 (3): 155-159.

Koning, N., and M. K. van Ittersum. 2009. Will the world have enough to eat? Current Opinion in Environmental Sustainability 1 (1): 77-82.

Kosmala, M., A. Crall, R. Cheng, K. Hufkens, S. Henderson, and A. Richardson. 2016a. Season Spotter: Using Citizen Science to Validate and Scale Plant Phenology from Near-Surface Remote Sensing. Remote Sensing 8 (9): 726.

Kosmala, M., A. Wiggins, A. Swanson, and B. Simmons. 2016b. Assessing data quality in citizen science. Frontiers in Ecology and the Environment 14 (10): 551-560.

Krebs, V. 2010. Motivations of cybervolunteers in an applied distributed computing environment: MalariaControl.net as an example. First Monday [S.l.].

Kruskal, W. H., and W. A. Wallis. 1952. Use of Ranks in One-Criterion Variance Analysis. Journal of the American Statistical Association 47 (260): 583-621.

Kuri, F., A. Murwira, K. S. Murwira, and M. Masocha. 2014. Predicting maize yield in Zimbabwe using dry dekads derived from remotely sensed Vegetation Condition Index. International Journal of Applied Earth Observation and Geoinformation 33: 39-46.

Laborte, A. G., K. de Bie, E. M. A. Smaling, P. F. Moya, A. A. Boling, and M. K. Van Ittersum. 2012. Rice yields and yield gaps in Southeast Asia: Past trends and future outlook. European Journal of Agronomy 36 (1): 9-20.

Laffont, J.-J., and D. Martimort. 2001. The Theory of Incentives I: The principal-Agent Model: Princeton University Press.

Land-Zandstra, A. M., J. L. Devilee, F. Snik, F. Buurmeijer, and J. M. van den Broek. 2016a. Citizen science on a smartphone: Participants' motivations and learning. Public Understanding of Science 25 (1): 4560.

Land-Zandstra, A. M., M. M. van Beusekom, C. E. Koppeschaar, and J. M. van den Broek. 2016b. Motivation and learning impact of Dutch flutrackers. Journal of Science Communication 15 (1).

Licker, R., M. Johnston, J. A. Foley, C. Barford, C. J. Kucharik, C. Monfreda, and N. Ramankutty. 2010. Mind the gap: how do climate and 
agricultural management explain the 'yield gap' of croplands around the world? Global Ecology and Biogeography 19 (6): 769-782.

Liebenberg, L., J. Steventon, N. Brahman, K. Benadie, J. Minye, H. Langwane, and Q. Xhukwe. 2017. Smartphone Icon User Interface design for nonliterate trackers and its implications for an inclusive citizen science. Biological Conservation 208: 155-162.

Lillesand, T., R. W. Kiefer, and J. Chipman. 2014. Remote sensing and image interpretation: John Wiley \& Sons.

Limayem, M., S. G. Hirt, and C. M. K. Cheung. 2007. How habit limits the predictive power of intention: The case of information systems continuance. MIS Quarterly: Management Information Systems 31 (4): 705-737.

Liu, Y., H. Li, V. Kostakos, J. Goncalves, S. Hosio, and F. Hu. 2014. An empirical investigation of mobile government adoption in rural China: A case study in Zhejiang province. Government Information Quarterly 31 (3): $432-442$.

Lobell, D. B. 2013. The use of satellite data for crop yield gap analysis. Field Crops Research 143: 56-64.

Lobell, D. B., G. P. Asner, J. I. Ortiz-Monasterio, and T. L. Benning. 2003. Remote sensing of regional crop production in the Yaqui Valley, Mexico: estimates and uncertainties. Agriculture, Ecosystems \& Environment 94 (2): 205-220.

Lobell, D. B., K. G. Cassman, and C. B. Field. 2009. Crop yield gaps: their importance, magnitudes, and causes. Annual review of environment and resources 34: 179-204.

Lobell, D. B., J. I. Ortiz-Monasterio, G. P. Asner, R. L. Naylor, and W. P. Falcon. 2005. Combining field surveys, remote sensing, and regression trees to understand yield variations in an irrigated wheat landscape. Agronomy Journal 97 (1): 241-249.

Lobell, D. B., J. I. Ortiz-Monasterio, C. Lee Addams, and G. P. Asner. 2002. Soil, climate, and management impacts on regional wheat productivity in Mexico from remote sensing. Agricultural and Forest Meteorology 114 (1-2): 31-43.

Lu, C., and L. Fan. 2013. Winter wheat yield potentials and yield gaps in the North China Plain. Field Crops Research 143 (0): 98-105.

Mahmud, N., J. Rodriguez, and J. Nesbit. 2010. A text message-based intervention to bridge the healthcare communication gap in the rural developing world. Technology and Health Care 18 (2): 137-144.

Mayer, R. C., and J. H. Davis. 1999. The effect of the performance appraisal system on trust for management: A field quasi-experiment. Journal of applied psychology 84 (1): 123.

Mayer, R. C., J. H. Davis, and F. D. Schoorman. 1995. An integrative model of organizational trust. Academy of management review 20 (3): 709-734. 
McKight, P. E., and J. Najab. 2010. "Kruskal-Wallis Test." In The Corsini Encyclopedia of Psychology. John Wiley \& Sons, Inc.

Medhi, I., S. Patnaik, E. Brunskill, S. Gautama, W. Thies, and K. Toyama. 2011. Designing mobile interfaces for novice and low-literacy users. ACM Transactions on Computer-Human Interaction (TOCHI) 18 (1): 2.

Mesas-Carrascosa, F. J., M. D. Notario-García, J. E. Meroño de Larriva, M. Sánchez de la Orden, and A. García-Ferrer Porras. 2014. Validation of measurements of land plot area using UAV imagery. International Journal of Applied Earth Observation and Geoinformation 33: 270-279.

Milfont, T. L., and R. Fischer. 2015. Testing measurement invariance across groups: Applications in cross-cultural research. International Journal of psychological research 3 (1): 111-130.

Misiko, M. 2013. Dilemma in participatory selection of varieties. Agricultural Systems 119: 35-42.

Mittra, S., P. Mathur, M. Dadlani, and A. Gupta. 2015. Seeds for Needs-India: Broadening the genetic base of crops to empower farmers for climate change adaptation through crowdsourcing.

Mkhabela, M. S., P. Bullock, S. Raj, S. Wang, and Y. Yang. 2011. Crop yield forecasting on the Canadian Prairies using MODIS NDVI data. Agricultural and Forest Meteorology 151 (3): 385-393.

Monchuk, D. C., Z. Chen, and Y. Bonaparte. 2010. Explaining production inefficiency in China's agriculture using data envelopment analysis and semi-parametric bootstrapping. China Economic Review 21 (2): 346-354.

Monfreda, C., N. Ramankutty, and J. A. C. G. B. Foley. 2008. Farming the planet: 2. Geographic distribution of crop areas, yields, physiological types, and net primary production in the year 2000. Global Biogeochemical Cycles 22 (1): n/a-n/a.

Monteith, J. L., and C. Moss. 1977. Climate and the efficiency of crop production in Britain [and discussion]. Philosophical Transactions of the Royal Society of London B: Biological Sciences 281 (980): 277-294.

Morel, J., P. Todoroff, A. Bégué, A. Bury, J.-F. Martiné, and M. Petit. 2014. Toward a Satellite-Based System of Sugarcane Yield Estimation and Forecasting in Smallholder Farming Conditions: A Case Study on Reunion Island. Remote Sensing 6 (7): 6620.

Mueller, N. D., J. S. Gerber, M. Johnston, D. K. Ray, N. Ramankutty, and J. A. Foley. 2012. Closing yield gaps through nutrient and water management. 490 (7419): 254-257.

Muhr, T. 1991. ATLAS/ti - A prototype for the support of text interpretation. Qualitative Sociology 14 (4): 349-371.

Muk, A., and C. Chung. 2015. Applying the technology acceptance model in a two-country study of SMS advertising. Journal of Business Research $68(1): 1-6$. 
Muller, C. L., L. Chapman, S. Johnston, C. Kidd, S. Illingworth, G. Foody, A. Overeem, and R. R. Leigh. 2015. Crowdsourcing for climate and atmospheric sciences: current status and future potential. International Journal of Climatology 35 (11): 3185-3203.

Murgante, B., O. Gervasi, S. Misra, N. Nedjah, A. C. Rocha, D. Taniar, B. Apduhan, et al. 2012. "DEM Accuracy of High Resolution Satellite Images." In Computational Science and Its Applications - ICCSA 2012, 471-480. Springer Berlin Heidelberg.

Muto, M., and T. Yamano. 2009. The Impact of Mobile Phone Coverage Expansion on Market Participation: Panel Data Evidence from Uganda. World Development 37 (12): 1887-1896.

Neef, A., and D. Neubert. 2011. Stakeholder participation in agricultural research projects: a conceptual framework for reflection and decisionmaking. Agriculture and Human Values 28 (2): 179-194.

Negahban, A., and C.-H. Chung. 2014. Discovering determinants of users perception of mobile device functionality fit. Computers in Human Behavior 35: 75-84.

Neumann, K., P. H. Verburg, E. Stehfest, and C. Müller. 2010. The yield gap of global grain production: A spatial analysis. Agricultural Systems 103 (5): 316-326.

Newman, G., J. Graham, A. Crall, and M. Laituri. 2011. The art and science of multi-scale citizen science support. Ecological Informatics 6 (3-4): 217227.

Newman, G., A. Wiggins, A. Crall, E. Graham, S. Newman, and K. Crowston. 2012. The future of citizen science: emerging technologies and shifting paradigms. Frontiers in Ecology and the Environment 10 (6): 298-304.

Nicholls, J. G. 1984. Achievement motivation: Conceptions of ability, subjective experience, task choice, and performance. Psychological review 91 (3): 328.

Nov, O., O. Arazy, and D. Anderson. 2011a. Technology-Mediated Citizen Science Participation: A Motivational Model. Proceedings of the AAAI International Conference on Weblogs and Social Media (ICWSM), at Barcelona, Spain.

Nov, O., O. Arazy, and D. Anderson. 2011b. Dusting for science: motivation and participation of digital citizen science volunteers. Proceedings of the 2011 iConference.

Nov, O., O. Arazy, and D. Anderson. 2014. Scientists@Home: What Drives the Quantity and Quality of Online Citizen Science Participation? PLoS ONE 9 (4): e90375.

Nunnally, J. C., and I. H. Bernstein. 1994. Psychometric theory. New York: McGraw-Hill.

O'brien, R. M. 2007. A Caution Regarding Rules of Thumb for Variance Inflation Factors. Quality \& Quantity 41 (5): 673-690. 
Ogodo, O. Cassava disease monitoring goes mobile, 04-04-2016 2009.

Okali, C., J. Sumberg, and J. Farrington. 1994. Farmer participatory research: rhetoric and reality: Intermediate Technology Publications Ltd.

Okumu, M., P. Van Asten, E. Kahangi, S. Okech, J. Jefwa, and B. Vanlauwe. 2011. Production gradients in smallholder banana (cv. Giant Cavendish) farms in Central Kenya. Scientia Horticulturae 127 (4): 475-481.

Oliveira, T., M. Faria, M. A. Thomas, and A. Popovič. 2014. Extending the understanding of mobile banking adoption: When UTAUT meets TTF and ITM. International Journal of Information Management 34 (5): 689-703.

Oliver, Y. M., and M. J. Robertson. 2013. Quantifying the spatial pattern of the yield gap within a farm in a low rainfall Mediterranean climate. Field Crops Research 150 (0): 29-41.

Ortiz-Monasterio, J. I., and D. B. Lobell. 2007. Remote sensing assessment of regional yield losses due to sub-optimal planting dates and fallow period weed management. Field Crops Research 101 (1): 80-87.

Ovčjak, B., M. Heričko, and G. Polančič. 2015. Factors impacting the acceptance of mobile data services - A systematic literature review. Computers in Human Behavior 53: 24-47.

Pacheco, A., A. Bannari, K. Staenz, and H. McNairn. 2008. Deriving percent crop cower over agriculture canopies using hyperspectral remote sensing. Canadian Journal of Remote Sensing 34 (SUPPL. 1): S110S123.

Park, E., and K. J. Kim. 2014. An Integrated Adoption Model of Mobile Cloud Services: Exploration of Key Determinants and Extension of Technology Acceptance Model. Telematics and Informatics 31 (3): 376385.

Park, E., and J. Ohm. 2014. Factors influencing users' employment of mobile map services. Telematics and Informatics 31 (2): 253-265.

Paustian, K. 2013. Bridging the data gap: engaging developing country farmers in greenhouse gas accounting. Environmental Research Letters 8 (2): 021001.

Petropoulos, G. P., G. Ireland, and B. Barrett. 2015. Surface soil moisture retrievals from remote sensing: Current status, products \&amp; future trends. Physics and Chemistry of the Earth, Parts A/B/C (0).

Podsakoff, P. M., S. B. MacKenzie, J. Y. Lee, and N. P. Podsakoff. 2003. Common method biases in behavioral research: a critical review of the literature and recommended remedies. J Appl Psychol 88 (5): 879-903.

Poole, M. A., and P. N. O'Farrell. 1971. The Assumptions of the Linear Regression Model. Transactions of the Institute of British Geographers (52): 145-158. 
Pratihast, A., M. Herold, V. Avitabile, S. de Bruin, H. Bartholomeus, C. Jr., and L. Ribbe. 2013a. Mobile Devices for Community-Based REDD+ Monitoring: A Case Study for Central Vietnam. Sensors 13 (1): 21.

Pratihast, A. K., M. Herold, V. De Sy, D. Murdiyarso, and M. Skutsch. 2013b. Linking community-based and national REDD+ monitoring: a review of the potential. Carbon Management 4 (1): 91-104.

Pratihast, A. K., B. DeVries, V. Avitabile, S. de Bruin, M. Herold, and A. Bergsma. 2016. Design and Implementation of an Interactive WebBased Near Real-Time Forest Monitoring System. PLOS ONE 11 (3): $\mathrm{e} 0150935$.

Qi, J., A. Chehbouni, A. R. Huete, Y. H. Kerr, and S. Sorooshian. 1994. A modified soil adjusted vegetation index. Remote Sensing of Environment 48 (2): 119-126.

Qiang, C. Z., S. C. Kuek, A. Dymond, S. Esselaar, and I. Unit. 2011. Mobile applications for agriculture and rural development. World Bank, Washington, DC.

Raddick, M. J., G. Bracey, P. L. Gay, C. J. Lintott, C. Cardamone, P. Murray, K. Schawinski, A. S. Szalay, and J. Vandenberg. 2013. Galaxy Zoo: Motivations of citizen scientists. arXiv preprint arXiv:1303.6886.

Raddick, M. J., G. Bracey, P. L. Gay, C. J. Lintott, P. Murray, K. Schawinski, A. S. Szalay, and J. Vandenberg. 2010. Galaxy zoo: Exploring the motivations of citizen science volunteers. Astronomy Education Review 9 (1): 010103.

Rahman, M., B. Blackwell, N. Banerjee, and D. Saraswat. 2015. Smartphonebased hierarchical crowdsourcing for weed identification. Computers and Electronics in Agriculture 113 (0): 14-23.

Ramankutty, N., A. T. Evan, C. Monfreda, and J. A. C. G. B. Foley. 2008. Farming the planet: 1. Geographic distribution of global agricultural lands in the year 2000. Global Biogeochemical Cycles 22 (1): n/a-n/a.

Reddy, P. K., and R. Ankaiah. 2005. A framework of information technologybased agriculture information dissemination system to improve crop productivity. Current Science 88 (12): 1905-1913.

Reidsma, P., F. Ewert, H. Boogaard, and K. v. Diepen. 2009. Regional crop modelling in Europe: The impact of climatic conditions and farm characteristics on maize yields. Agricultural Systems 100 (1-3): 51-60.

Reidsma, P., F. Ewert, A. O. Lansink, and R. Leemans. 2010. Adaptation to climate change and climate variability in European agriculture: The importance of farm level responses. European Journal of Agronomy 32 (1): $91-102$.

Rembold, F., C. Atzberger, I. Savin, and O. Rojas. 2013. Using Low Resolution Satellite Imagery for Yield Prediction and Yield Anomaly Detection. Remote Sensing 5 (4): 1704. 
Resnik, D. B., K. C. Elliott, and A. K. Miller. 2015. A framework for addressing ethical issues in citizen science. Environmental Science \& Policy 54: 475-481.

Reynolds, C. A., M. Yitayew, D. C. Slack, C. F. Hutchinson, A. Huete, and M. S. Petersen. 2000. Estimating crop yields and production by integrating the FAO Crop Specific Water Balance model with real-time satellite data and ground-based ancillary data. International Journal of Remote Sensing 21 (18): 3487-3508.

Rice, W. R. 1989. Analyzing tables of statistical tests. Evolution 43 (1): 223225.

Riesch, H., and C. Potter. 2014. Citizen science as seen by scientists: Methodological, epistemological and ethical dimensions. Public Understanding of Science 23 (1): 107-120.

Robinson, A., and A. Obrecht. 2016. Using mobile voice technology to improve the collection of food security data: WFP's mobile Vulnerability Analysis and Mapping' HIF/ALNAP Case Study. . London: ODI/ALNAP.

Rogers, E. M. 1995. Diffusion of innovations. New York: 12.

Rogers, E. M. 2002. Diffusion of preventive innovations. Addictive Behaviours 27 (6): 989-993.

Rose, D. C., W. J. Sutherland, C. Parker, M. Lobley, M. Winter, C. Morris, S. Twining, et al. 2016. Decision support tools for agriculture: Towards effective design and delivery. Agricultural Systems 149: 165-174.

Rossiter, D. G., J. Liu, S. Carlisle, and A. X. Zhu. 2015. Can citizen science assist digital soil mapping? Geoderma 259-260: 71-80.

Rotman, D., J. Hammock, J. Preece, D. Hansen, C. Boston, A. Bowser, and Y. He. 2014. Motivations affecting initial and long-term participation in citizen science projects in three countries. iConference 2014 Proceedings.

Rotman, D., J. Preece, J. Hammock, K. Procita, D. Hansen, C. Parr, D. Lewis, and D. Jacobs. 2012. Dynamic changes in motivation in collaborative citizen-science projects. In Proceedings of the ACM 2012 conference on Computer Supported Cooperative Work. Seattle, Washington, USA: ACM.

Roy, H., M. Pocock, C. Preston, D. Roy, J. Savage, J. Tweddle, and L. Robinson. 2012. Understanding citizen science and environmental monitoring: final report on behalf of UK Environmental Observation Framework.

Ryan, R. M., and E. L. Deci. 2000a. Intrinsic and Extrinsic Motivations: Classic Definitions and New Directions. Contemporary Educational Psychology 25 (1): 54-67.

Ryan, R. M., and E. L. Deci. 2000b. Self-determination theory and the facilitation of intrinsic motivation, social development, and well-being. American psychologist 55 (1): 68 . 
Ryu, Y., J. Verfaillie, C. Macfarlane, H. Kobayashi, O. Sonnentag, R. Vargas, S. Ma, and D. D. Baldocchi. 2012. Continuous observation of tree leaf area index at ecosystem scale using upward-pointing digital cameras. Remote Sensing of Environment 126: 116-125.

Sabah, N. M. 2016. Exploring students' awareness and perceptions: Influencing factors and individual differences driving m-learning adoption. Computers in Human Behaviour 65: 522-533.

Saito, K., S. Diack, I. Dieng, and M. K. N'Diaye. 2015. On-farm testing of a nutrient management decision-support tool for rice in the Senegal River valley. Computers and Electronics in Agriculture 116: 36-44.

Sakamoto, T., A. A. Gitelson, and T. J. Arkebauer. 2013. MODIS-based corn grain yield estimation model incorporating crop phenology information. Remote Sensing of Environment 131: 215-231.

Schnitkey, G., M. Batte, E. Jones, and J. Botomogno. 1992. Information preferences of Ohio commercial farmers: implications for extension. American Journal of Agricultural Economics 74 (2): 486-496.

Schulthess, U., J. Timsina, J. M. Herrera, and A. McDonald. 2013. Mapping field-scale yield gaps for maize: An example from Bangladesh. Field Crops Research 143 (0): 151-156.

Schunko, C., S. Grasser, and C. R. Vogl. 2015. Explaining the resurgent popularity of the wild: motivations for wild plant gathering in the Biosphere Reserve Grosses Walsertal, Austria. J Ethnobiol Ethnomed 11: 55 .

Scott, A. B., and P. C. Frost. 2017. Monitoring water quality in Toronto's urban stormwater ponds: Assessing participation rates and data quality of water sampling by citizen scientists in the FreshWater Watch. Science of The Total Environment 592: 738-744.

See, L., I. McCallum, S. Fritz, C. Perger, F. Kraxner, M. Obersteiner, U. D. Baruah, N. Mili, and N. R. Kalita. 2013. Mapping cropland in Ethiopia using crowdsourcing. International Journal of Geosciences 4 (06): 6.

See, L., D. Schepaschenko, M. Lesiv, I. McCallum, S. Fritz, A. Comber, C. Perger, et al. 2015. Building a hybrid land cover map with crowdsourcing and geographically weighted regression. ISPRS Journal of Photogrammetry and Remote Sensing 103: 48-56.

Shang, J., J. Liu, B. Ma, T. Zhao, X. Jiao, X. Geng, T. Huffman, J. M. Kovacs, and D. Walters. 2015. Mapping spatial variability of crop growth conditions using RapidEye data in Northern Ontario, Canada. Remote Sensing of Environment 168: 113-125.

Shapiro, S. S., and M. B. Wilk. 1965. An analysis of variance test for normality (complete samples) $\dagger$. Biometrika 52 (3-4): 591-611.

Shelley, W., R. Lawley, and D. A. Robinson. 2013. Technology: Crowd-sourced soil data for Europe. Nature 496 (7445): 300-300. 
Shin, D.-H. 2009. Towards an understanding of the consumer acceptance of mobile wallet. Computers in Human Behaviour 25 (6): 1343-1354.

Sibley, A. M., P. Grassini, N. E. Thomas, and K. G. Cassman. 2014. Testing remote sensing approaches for assessing yield variability among maize fields. Agronomy Journal 106 (1): 24-32.

Silva, J. V., P. Reidsma, A. G. Laborte, and M. K. van Ittersum. 2017. Explaining rice yields and yield gaps in Central Luzon, Philippines: An application of stochastic frontier analysis and crop modelling. European Journal of Agronomy 82, Part B: 223-241.

Silvertown, J. 2009. A new dawn for citizen science. Trends in Ecology \& Evolution 24 (9): 467-471.

Singh, N. J., K. Danell, L. Edenius, and G. Ericsson. 2014. Tackling the motivation to monitor: success and sustainability of a participatory monitoring program. Ecology and Society 19 (4).

Slade, E. L., Y. K. Dwivedi, N. C. Piercy, and M. D. Williams. 2015. Modeling Consumers' Adoption Intentions of Remote Mobile Payments in the United Kingdom: Extending UTAUT with Innovativeness, Risk, and Trust. Psychology \& Marketing 32 (8): 860-873.

Šmilauer, P., and J. Lepš. 2014. Multivariate analysis of ecological data using CANOCO 5: Cambridge university press.

Son, N. T., C. F. Chen, C. R. Chen, V. Q. Minh, and N. H. Trung. 2014. A comparative analysis of multitemporal MODIS EVI and NDVI data for large-scale rice yield estimation. Agricultural and Forest Meteorology 197: 52-64.

Sopheap, U., A. Patanothai, and T. M. Aye. 2012. Unveiling constraints to cassava production in Cambodia: An analysis from farmers' yield variations. International Journal of Plant Production 6 (4): 409-428.

Steenkamp, J.-B., E. M., and H. Baumgartner. 1998. Assessing Measurement Invariance in Cross-National Consumer Research. Journal of Consumer Research 25 (1): 78-107.

Straub, D. W. 1989. Validating instruments in MIS research. MIS quarterly: 147-169.

Sui, R., J. A. Thomasson, J. Hanks, and J. Wooten. 2008. Ground-based sensing system for weed mapping in cotton. Computers and Electronics in Agriculture 60 (1): 31-38.

Sullivan, B. L., J. L. Aycrigg, J. H. Barry, R. E. Bonney, N. Bruns, C. B. Cooper, T. Damoulas, et al. 2014. The eBird enterprise: An integrated approach to development and application of citizen science. Biological Conservation 169: 31-40.

Sullivan, B. L., C. L. Wood, M. J. Iliff, R. E. Bonney, D. Fink, and S. Kelling. 2009. eBird: A citizen-based bird observation network in the biological sciences. Biological Conservation 142 (10): 2282-2292. 
Sumberg, J., C. Okali, and D. Reece. 2003. Agricultural research in the face of diversity, local knowledge and the participation imperative: theoretical considerations. Agricultural systems 76 (2): 739-753.

Tabachnick, B. G., and L. S. Fidell. 2007. Using multivariate statistics, 5th. Needham Height, MA: Allyn \& Bacon.

Tanaka, A., K. Saito, K. Azoma, and K. Kobayashi. 2013. Factors affecting variation in farm yields of irrigated lowland rice in southern-central Benin. European Journal of Agronomy 44 (0): 46-53.

Taragola, N. M., and D. F. Van Lierde. 2010. Factors affecting the Internet behaviour of horticultural growers in Flanders, Belgium. Computers and Electronics in Agriculture 70 (2): 369-379.

Thom, J., D. Millen, and J. DiMicco. 2012. Removing gamification from an enterprise SNS. Proceedings of the ACM 2012 conference on Computer Supported Cooperative Work.

Thorp, K. R., B. L. Steward, A. L. Kaleita, and W. D. Batchelor. 2008. Using aerial hyperspectral remote sensing imagery to estimate corn plant stand density. Transactions of the ASABE 51 (1): 311-320.

Tittonell, P., and K. E. Giller. 2013. When yield gaps are poverty traps: The paradigm of ecological intensification in African smallholder agriculture. Field Crops Research 143: 76-90.

Tittonell, P., K. D. Shepherd, B. Vanlauwe, and K. E. Giller. 2008. Unravelling the effects of soil and crop management on maize productivity in smallholder agricultural systems of western Kenya-An application of classification and regression tree analysis. Agriculture, Ecosystems and Environment 123 (1-3): 137-150.

Tucker, C. J. 1979. Red and photographic infrared linear combinations for monitoring vegetation. Remote Sensing of Environment 8 (2): 127-150.

Tucker, C. J., B. N. Holben, J. H. Elgin, and J. E. McMurtrey. 1981. Remote sensing of total dry-matter accumulation in winter wheat. Remote Sensing of Environment 11: 171-189.

USAID. 2013. Crowdsourcing Applications for Agricultural Development in Africa.

Vachelard, J., T. Gambarra-Soares, G. Augustini, P. Riul, and V. MaracajaCoutinho. 2016. A Guide to Scientific Crowdfunding. PLOS Biology 14 (2): e1002373.

Van Asten, P. J. A., M. C. S. Wopereis, S. Haefele, M. O. Isselmou, and M. J. Kropff. 2003. Explaining yield gaps on farmer-identified degraded and non-degraded soils in a Sahelian irrigated rice scheme. NJAS Wageningen Journal of Life Sciences 50 (3-4): 277-296.

van der Wal, R., N. Sharma, C. Mellish, A. Robinson, and A. Siddharthan. 2016. The role of automated feedback in training and retaining biological recorders for citizen science. Conservation Biology 30 (3): 550-561. 
van Dijk, J. A. G. M. 2006. Digital divide research, achievements and shortcomings. Poetics 34 (4): 221-235.

van Etten, J. 2011. Crowdsourcing Crop Improvement in Sub-Saharan Africa: A Proposal for a Scalable and Inclusive Approach to Food Security. IDS Bulletin 42 (4): 102-110.

Van Etten, J., E. Beza, L. Calderer, K. Van Duijvendijk, C. Fadda, B. Fantahun, Y. G. Kidane, et al. 2016. First experience with a novel farmer citizen science approach: crowdsourcing participatory variety selection through on-farm triadic comparisons of technologies (tricot). Experimental Agriculture: 1-22.

van Ittersum, M. K., and K. G. Cassman. 2013. Yield gap analysis-Rationale, methods and applications-Introduction to the Special Issue. Field Crops Research 143 (0): 1-3.

van Ittersum, M. K., K. G. Cassman, P. Grassini, J. Wolf, P. Tittonell, and Z. Hochman. 2013. Yield gap analysis with local to global relevance-A review. Field Crops Research 143 (0): 4-17.

van Ittersum, M. K., and R. Rabbinge. 1997. Concepts in production ecology for analysis and quantification of agricultural input-output combinations. Field Crops Research 52 (3): 197-208.

van Ittersum, M. K., L. G. J. van Bussel, J. Wolf, P. Grassini, J. van Wart, N. Guilpart, L. Claessens, et al. 2016. Can sub-Saharan Africa feed itself? Proceedings of the National Academy of Sciences 113 (52): 1496414969.

van Oort, P. A. J., K. Saito, I. Dieng, P. Grassini, K. G. Cassman, and M. K. van Ittersum. 2017. Can yield gap analysis be used to inform $R \& D$ prioritisation? Global Food Security 12: 109-118.

Venkatesh, V., M. G. Morris, G. B. Davis, and F. D. Davis. 2003. User Acceptance of Information Technology: Toward a Unified View. MIS Quarterly 27 (3): 425-478.

Venkatesh, V., J. Y. Thong, and X. Xu. 2012. Consumer acceptance and use of information technology: extending the unified theory of acceptance and use of technology. MIS quarterly 36 (1): 157-178.

Villamor, G. B., D. C. Catacutan, V. A. T. Truong, and L. D. Thi. 2017. Treecover transition in Northern Vietnam from a gender-specific land-use preferences perspective. Land Use Policy 61: 53-62.

Viscarra Rossel, R. A., and J. Bouma. 2016. Soil sensing: A new paradigm for agriculture. Agricultural Systems 148: 71-74.

Waha, K., L. G. J. Van Bussel, C. Müller, and A. Bondeau. 2012. Climate-driven simulation of global crop sowing dates. Global Ecology and Biogeography 21 (2): 247-259.

Wairegi, L. W. I., P. J. A. van Asten, M. M. Tenywa, and M. A. Bekunda. 2010. Abiotic constraints override biotic constraints in East African highland banana systems. Field Crops Research 117 (1): 146-153. 
Wakie, T. T., S. Kumar, G. B. Senay, A. Takele, and A. Lencho. 2016. Spatial prediction of wheat septoria leaf blotch (Septoria tritici) disease severity in Central Ethiopia. Ecological Informatics 36: 15-30.

Wall, L., D. Larocque, and P. M. Léger. 2008. The early explanatory power of NDVI in crop yield modelling. International Journal of Remote Sensing 29 (8): 2211-2225.

Wang, L., Y. Tian, X. Yao, Y. Zhu, and W. Cao. 2014. Predicting grain yield and protein content in wheat by fusing multi-sensor and multi-temporal remote-sensing images. Field Crops Research 164: 178-188.

Westphal, A., J. Von Korff, D. Anderson, A. Alexander, B. Betts, D. Brownlee, A. Butterworth, et al. 2006. Stardust@ home: virtual microscope validation and first results. 37th Annual Lunar and Planetary Science Conference, March 13-17, 2006, at League City, Texas.

Wiegand, C. L., A. H. Gerbermann, K. P. Gallo, B. L. Blad, and D. Dusek. 1990. Multisite analyses of spectral-biophysical data for corn. Remote Sensing of Environment 33 (1): 1-16.

Wiggins, A., and K. Crowston. 2014. Surveying the citizen science landscape. 2014.

Williams, M. D., N. P. Rana, and Y. K. Dwivedi. 2015. The unified theory of acceptance and use of technology (UTAUT): A literature review. Journal of Enterprise Information Management 28 (3): 443-488.

Williams, M. D., N. P. Rana, Y. K. Dwivedi, and B. Lal. 2011. Is UTAUT really used or just cited for the sake of it? a systematic review of citations of UTAUT's originating article. European Conference Information Systems.

Wolfert, S., L. Ge, C. Verdouw, and M.-J. Bogaardt. 2017. Big Data in Smart Farming - A review. Agricultural Systems 153: 69-80.

Wood, C., B. Sullivan, M. Iliff, D. Fink, and S. Kelling. 2011. eBird: Engaging Birders in Science and Conservation. PLoS Biol 9 (12): e1001220.

Wood, R., and A. Bandura. 1989. Impact of Conceptions of Ability on SelfRegulatory Mechanisms and Complex Decision Making. Journal of Personality and Social Psychology 56 (3): 407-415.

Wopereis, M. C. S., C. Donovan, B. Nebié, D. Guindo, and M. K. N'Diaye. 1999. Soil fertility management in irrigated rice systems in the Sahel and Savanna regions of West Africa: Part I. Agronomic analysis. Field Crops Research 61 (2): 125-145.

Wright, H. J., W. Ochilo, A. Pearson, C. Finegold, M. Oronje, J. Wanjohi, R. Kamau, T. Holmes, and A. Rumsey. 2016. Using ICT to Strengthen Agricultural Extension Systems for Plant Health. Journal of Agricultural \& Food Information 17 (1): 23-36.

Wyche, S., and C. Steinfield. 2016. Why Don't Farmers Use Cell Phones to Access Market Prices? Technology Affordances and Barriers to Market 
Information Services Adoption in Rural Kenya. Information Technology for Development 22 (2): 320-333.

Xiao, D., J. Feng, N. Wang, X. Luo, and Y. Hu. 2013. Integrated soil moisture and water depth sensor for paddy fields. Computers and Electronics in Agriculture 98: 214-221.

Yan, L., and D. P. Roy. 2014. Automated crop field extraction from multitemporal Web Enabled Landsat Data. Remote Sensing of Environment $144(0): 42-64$.

Yi, M. Y., and Y. Hwang. 2003. Predicting the use of web-based information systems: Self-efficacy, enjoyment, learning goal orientation, and the technology acceptance model. International Journal of Human Computer Studies 59 (4): 431-449.

Yi, M. Y., J. D. Jackson, J. S. Park, and J. C. Probst. 2006. Understanding information technology acceptance by individual professionals: Toward an integrative view. Information \& Management 43 (3): 350-363.

Zhang, C., D. Walters, and J. M. Kovacs. 2014. Applications of Low Altitude Remote Sensing in Agriculture upon Farmers' Requests- A Case Study in Northeastern Ontario, Canada. PLoS ONE 9 (11): e112894.

Zhao, P., T. Foerster, and P. Yue. 2012. The Geoprocessing Web. Computers \& Geosciences 47: 3-12.

Zheng, B., J. B. Campbell, G. Serbin, and J. M. Galbraith. 2014. Remote sensing of crop residue and tillage practices: Present capabilities and future prospects. Soil and Tillage Research 138 (0): 26-34.

Zhou, T., Y. Lu, and B. Wang. 2010. Integrating TTF and UTAUT to explain mobile banking user adoption. Computers in Human Behaviour 26 (4): 760-767.

Zhu, Z., and C. E. Woodcock. 2012. Object-based cloud and cloud shadow detection in Landsat imagery. Remote Sensing of Environment 118: 8394 . 


\section{Summary}

The world population is anticipated to be around 9.1 billion in 2050 and the challenge is how to feed this huge number of people without affecting natural ecosystems. Different approaches have been proposed and closing the 'yield gap' on currently available agricultural lands is one of them. The concept of 'yield gap' is based on production ecological principles and can be estimated as the difference between a benchmark (e.g. climatic potential or water-limited yield) and the actual yield. Yield gap analysis can be performed at different scales: from field to global level. Of particular importance is estimating the yield gap and revealing the underlying explanatory factors contributing to it. As decisions are made by farmers, farm level yield gap analysis specifically contributes to better understanding, and provides entry points to increased production levels in specific farming systems. A major challenge for this type of analysis is the high data standards required which typically refer to (a) large sample size, (b) fine resolution and (c) great level of detail. Clearly, obtaining information about biophysical characteristics and crop and farm management for individual agricultural activities within a farm, as well as farm and farmer's characteristics and socio-economic conditions for a large number of farms is costly and time-consuming. Nowadays, the proliferation of different types of mobile phones (e.g., smartphones) equipped with sensors (e.g., GPS, camera) makes it possible to implement effective and low-cost "bottom-up" data collection approaches such as citizen science. Using these innovative methodologies facilitate the collection of relatively large amounts of information directly from local communities. Moreover, other data collection methods such as remote sensing can provide data (e.g., on actual crop yield) for yield gap analysis.

The main objective of this thesis, therefore, was to investigate the applicability of innovative data collection approaches such as crowdsourcing and remote sensing to support the assessment and monitoring of crop yield gaps. To address the main objective, the following research questions were formulated: 1) What are the main factors causing the yield gaps at the global, regional and crop level? 2) How could data for yield gap explaining factors be collected with innovative "bottom-up" approaches? 3) What are motivations of farmers to participate in agricultural citizen science? 4) What determines smallholder farmers to use technologies (e.g., mobile SMS) for agricultural data collection? 5) How can synergy of crowdsourced data and remote sensing improve the estimation and explanation of yield variability? 
Chapter 2 assesses data availability and data collection approaches for yield gap analysis and provides a summary of yield gap explaining factors at the global, regional and crop level, identified by previous studies. For this purpose, a review of yield gap studies (50 agronomic-based peer-reviewed articles) was performed to identify the most commonly considered and explaining factors of the yield gap. Using the review, we show that management and edaphic factors are more often considered to explain the yield gap compared to farm(er) characteristics and socio-economic factors. However, when considered, both farm(er) characteristics and socio-economic factors often explain the yield gap. Furthermore, within group comparison shows that fertilization and soil fertility factors are the most often considered management and edaphic groups. In the fertilization group, factors related to quantity (e.g., $\mathrm{N}$ fertilizer quantity) are more often considered compared to factors related to timing (e.g., $\mathrm{N}$ fertilizer timing). However, when considered, timing explained the yield gap more often. Finally, from the results at regional and crop level, it was evident that the relevance of factors depends on the location and crop, and that generalizations should not be made. Although the data included in yield gap analysis also depends on the objective, knowledge of explaining factors, and methods applied, data availability is a major limiting factor. Therefore, bottomup data collection approaches (e.g., crowdsourcing) involving agricultural communities can provide alternatives to overcome this limitation and improve yield gap analysis.

Chapter 3 explores the motivations of farmers to participate in citizen science. Building on motivational factors identified from previous citizen science studies, a questionnaire based methodology was developed which allowed the analysis of motivational factors and their relation to farmers' characteristics. Using the developed questionnaire, semi-structured interviews were conducted with smallholder farmers in three countries (Ethiopia, Honduras and India). The results show that for Indian farmers a collectivistic type of motivation (i.e., contribute to scientific research) was more important than egoistic and altruistic motivations. For Ethiopian and Honduran farmers an egoistic intrinsic type of motivation (i.e., interest in sharing information) was most important. Moreover, the majority of the farmers in the three countries indicated that they would like to receive agronomic advice, capacity building and seed innovation as the main returns from the citizen science process. Country and education level were the two most important farmers' characteristics that explained around $20 \%$ of the variation in farmers' motivations. The results also show that motivations to participate in citizen science are different for smallholders in agriculture compared to other sectors. For example fun has appeared to be an important egoistic intrinsic factor to participate in other citizen science projects, the smallholder farmers involved in this research valued 'passing free time' the lowest. 
Chapter 4 investigates the factors that determine farmers to adopt mobile technology for agricultural data collection. To identify the factors, the unified theory of acceptance and use of technology (UTAUT2) model was employed and extended with additional constructs of trust, mastery-approach goals and personal innovativeness in information technology. As part of the research, we setup data collection platforms using open source applications (Frontline SMS and Ushahidi) and farmers provided their farm related information using SMS for two growing seasons. The sample for this research consisted of group of farmers involved in a mobile SMS experiment $(n=110)$ and another group of farmers which was not involved in a mobile SMS experiment $(n=110)$, in three regions of Ethiopia. The results from the structural equation modelling showed that performance expectancy, effort expectancy, price value and trust were the main factors that influence farmers to adopt mobile SMS technology for agricultural data collection. Among these factors, trust is the strongest predictor of farmer's intention to adopt mobile SMS. This clearly indicates that in order to use the citizen science approach in the agricultural domain, establishing a trusted relationship with the smallholder farming community is crucial. Given that performance expectancy significantly predicted farmer's behavioural intention to adopt mobile SMS, managers of agricultural citizen science projects need to ensure that using mobile SMS for agricultural data collection offers utilitarian benefits to the farmers. The importance of effort expectancy on farmer's intention to adopt mobile SMS clearly indicates that mobile phone software developers need to develop easy to use mobile applications.

Chapter 5 demonstrates the results of synergetic use of remote sensing and crowdsourcing for estimating and explaining crop yields at the field level. Sesame production on medium and large farms in Ethiopia was used as a case study. To evaluate the added value of the crowdsourcing approach to improve the prediction of sesame yield using remote sensing, two independent models based on the relationship between vegetation indices (VIs) and farmers reported yield were developed and compared. The first model was based on VI values extracted from all available remote sensing imagery acquired during the optimum growing period (hereafter optimum growing period VI). The second model was based on VI values extracted from remote sensing imagery acquired after sowing and before harvest dates per field (hereafter phenologically adjusted VI). To select the images acquired between sowing and harvesting dates per field, farmers crowdsourced crop phenology information was used. Results showed that vegetation indices derived based on farmers crowdsourced crop phenology information had a stronger relationship with sesame yield compared to vegetation indices derived based on the optimum growing period. This implies that using crowdsourced information related to crop phenology per field used to adjust the VIs, improved the performance of the model to 
predict sesame yield. Crowdsourcing was further used to identify the factors causing the yield variability within a field. According to the perception of farmers, overall soil fertility was the most important factor explaining the yield variability within a field, followed by high presence of weeds.

Chapter 6 discusses the main findings of this thesis. It draws conclusions about the main research findings in each of the research questions addressed in the four main chapters. Finally, it discusses the necessary additional steps (e.g., data quality, sustainability) in a broader context that need to be considered to utilize the full potential of innovative data collection approaches for agricultural citizen science. 


\section{Samenvatting}

De wereldbevolking zal in 2050 ongeveer 9,1 miljard bedragen en het is een grote uitdaging om dit enorme aantal mensen te voeden zonder dat natuurlijke ecosystemen worden beïnvloed. Verschillende benaderingen zijn voorgesteld en het sluiten van de 'yield gap' op momenteel beschikbare landbouwgrond is daar een van. Het concept 'yield gap' is gebaseerd op productie-ecologische principes en kan worden geschat als het verschil tussen een referentie oogst (bijvoorbeeld klimaatpotentieel of water beperkte opbrengst) en de werkelijke opbrengst voor een gewas. Yield gap analyse kan op verschillende schalen worden uitgevoerd: van veld naar globaal niveau. Het schatten van de yield gap en het identificeren van de onderliggende verklarende factoren is van bijzonder belang Aangezien beslissingen door boeren worden genomen, levert de analyse van de yield gap op boerderij-niveau tot beter begrip en geeft uitgangspunten voor de verhoging van productieniveaus in specifieke landbouwsystemen. Een belangrijke uitdaging voor dit soort analyses is het vereiste hoge detail van inputgegevens die betrekking hebben op (a) de grootte van de steekproef, (b) hoge resolutie en (c) groot detailniveau. Het is kostbaar en tijdrovend om informatie over biofysische eigenschappen van gewas en management voor individuele landbouwactiviteiten binnen een boerderij te verkrijgen. Ook de sociaal-economische gegevens over boerenbedrijven en de agrariërs zijn beperkt beschikbaar voor een groot aantal bedrijven. Tegenwoordig maakt de grootschalige beschikbaarheid van verschillende typen mobiele telefoons (bijvoorbeeld smartphones) uitgerust met sensoren (zoals GPS, camera) het mogelijk om effectieve en goedkope bottom-up-gegevensverzamelingsbenaderingen zoals 'crowdsourcing' te implementeren. Door deze innovatieve methodologieën te gebruiken, wordt het verzamelen van relatief grote hoeveelheden informatie rechtstreeks van de lokale gemeenschappen vereenvoudigd. Bovendien kunnen andere data-verzamelingsmethoden, zoals remote sensing, gegevens verschaffen (bijvoorbeeld werkelijke gewasopbrengst) voor de yield gap analyse.

Het hoofddoel van dit proefschrift was dus om de toepasbaarheid van innovatieve gegevensverzamelingsbenaderingen te onderzoeken, zoals crowdsourcing en remote sensing, ter ondersteuning van de beoordeling en monitoring van de yield gap analyse. Op basis van het hoofddoel zijn de volgende onderzoeksvragen geformuleerd: 1) Wat zijn de belangrijkste factoren die de yield gap veroorzaken op wereldwijde, regionale en gewasniveau schaal? 2) Hoe kunnen gegevens voor yield gap factoren worden verzameld met innovatieve "bottom-up" benaderingen? 3) Wat zijn motivaties van boeren om 
deel te nemen aan de crowdsourcing voor landbouw toepassingen? 4) Wat bepaalt of kleinere boeren mobiele technologieën gebruiken (bijvoorbeeld mobiel SMS) voor de agrarische dataverzameling? 5) Hoe kan synergie van crowdsourced data en remote sensing de schatting van opbrengstvariabiliteit verbeteren?

Hoofdstuk 2 evalueert de beschikbaarheid van gegevens en methoden voor gegevensverzameling voor de analyse van yield gap verklarende factoren op wereldwijde, regionale en gewasniveau schaal zoals die worden beschreven in eerdere studies. Hiervoor is een review uitgevoerd van yield gap studies (50 agronomische artikelen) om de meest algemeen gekozen en geëvalueerde factoren van de yield gap analyse te identificeren. De resultaten van de review laten zien dat management- en bodem factoren vaker worden meegenomen om de yield gap te verklaren in vergelijking met de eigenschappen van het agrarische bedrijf en sociaal-economische factoren. Echter, wanneer ze worden meegenomen in de analyse, dan zijn zowel de eigenschappen van het agrarische bedrijf als de sociaal-economische factoren vaak belangrijke verklarende variabelen. Bovendien blijkt als factoren binnen groepen vergeleken worden, factoren gerelateerd aan bodemvruchtbaarheid het meest worden toegepast binnen de management en bodem groepen. Binnen de bodemvruchtbaarheidsgroep worden factoren die verband houden met kwantiteit (bijvoorbeeld $\mathrm{N}$ meststofhoeveelheid) vaker meegenomen in vergelijking met factoren die verband houden met timing (bijvoorbeeld N-bemestingstiming). Echter, wanneer ze worden meegenomen in de analyse, dan is timing vaker een verklarende voor de yield gap. Ten slotte bleek uit de resultaten op regionaal en gewasniveau dat de relevantie van factoren afhankelijk is van de locatie en het gewas en dat generalisaties niet direct kunnen worden gemaakt. Hoewel de gegevens die in de analyse van de yield gap zijn opgenomen, ook afhankelijk zijn van de doelstelling, de kennis van factoren en de toegepaste methoden, is de beschikbaarheid van gegevens een belangrijke beperkende factor. Daarom kunnen bottom-up-gegevensverzamelingsmethoden (bijvoorbeeld crowdsourcing) waarbij agrariërs betrokken zijn bij gegevens inwinning een alternatief bieden om de analyse van de yield gap te verbeteren.

Hoofdstuk 3 onderzoekt de motivatie van boeren om deel te nemen aan de crowdsourcing. Gebaseerd op motivatie factoren die zijn geïdentificeerd uit eerdere crowdsourcing studies, is een vragenlijst methodologie ontwikkeld die de analyse van motivatie factoren en hun relatie tot de kenmerken van de boeren toonde. Met behulp van de ontwikkelde vragenlijst werden semigestructureerde interviews uitgevoerd met kleine boeren in drie landen (Ethiopië, Honduras en India). Uit de resultaten blijkt dat voor Indiase boeren een collectivistisch type motivatie (dat wil zeggen: bijdragen aan wetenschappelijk onderzoek) belangrijker was dan egoïstische en altruïstische 
motivatie. Voor Ethiopische en Hondurese boeren was een egoïstisch intrinsiek type motivatie (dat wil zeggen: belangstelling voor het delen van informatie) het belangrijkst. Bovendien gaf de meerderheid van de boeren in de drie landen aan dat zij agronomisch advies, capaciteitsopbouw en zaadinnovatie zouden willen ontvangen als tegenprestatie voor hun deelname aan het crowdsourcing proces. Afkomst en onderwijsniveau waren de twee belangrijkste kenmerken van de boeren die ongeveer $20 \%$ van de variatie in de motivatie van boeren hebben verklaard. Uit de resultaten blijkt ook dat de motivatie om deel te nemen aan crowdsourcing verschilt voor kleine telers in vergelijking met andere sectoren. $\mathrm{Zo}$ is vaker aangetoond dat plezier een belangrijke egoïstische intrinsieke factor is om deel te nemen aan andere crowdsourcing projecten. De boeren die bij dit onderzoek betrokken zijn, hebben de factor 'vrije tijd' als laagste beoordeeld.

Hoofdstuk 4 onderzoekt de factoren die bepalen of boeren mobiele technologie willen gebruiken voor de inwinning van agrarische data. Om de factoren te identificeren, werd het model voor uniforme theorie van acceptatie en gebruik van technologie (UTAUT2) ingezet en uitgebreid met aanvullende aannames voor vertrouwen, nieuwsgierigheid naar nieuwe kennis, en persoonlijke innovatie in informatietechnologie. Als onderdeel van het onderzoek hebben we gebruik gemaakt van open source applicaties voor data inwinning (Frontline SMS en Ushahidi) waarbij boeren hun teelt informatie verstrekten via SMS voor twee groeiseizoenen. De populatie voor dit onderzoek bestond uit een groep boeren die betrokken waren bij een mobiel SMS-experiment $(n=110)$ en een andere groep boeren die niet betrokken waren bij een mobiel SMSexperiment $(n=110)$, in drie regio's van Ethiopië. Uit de vergelijkingsmodellering blijkt dat resultaat verwachting, inspanningsverwachting, prijs en vertrouwen de belangrijkste factoren zijn die boeren beïnvloeden om mobiele sms-technologie voor de agrarische dataverzameling te gebruiken. Onder deze factoren is vertrouwen de sterkste voorspeller van het voornemen van de boer om mobiel SMS te gaan te gebruiken. Dit geeft duidelijk aan dat om de crowdsourcing benadering binnen het landbouw domein te gebruiken, een vertrouwde relatie met de telers van cruciaal belang is. Aangezien de factor 'resultaat verwachting' een goede voorspeller bleek om mobiel sms te gebruiken, moeten managers van crowdsourcing projecten ervoor zorgen dat het gebruik van mobiel sms voor gegevensinwinning voor telers voordelen bied in de gebruikspraktijk Het belang van de inspanningsverwachting voor de boer om mobiel SMS te gebruiken, geeft duidelijk aan dat mobiele ontwikkelaars van mobiele telefoons eenvoudige mobiele applicaties moeten ontwikkelen.

Hoofdstuk 5 toont de resultaten van het synergistische gebruik van remote sensing en crowdsourcing voor het schatten en analyseren van opbrengsten op het veldniveau. In een case studie werd deze methode toegepast voor het 
bepalen van sesamproductie op middelgrote en grote boerderijen in Ethiopië. Om de toegevoegde waarde van de crowdsourcing aanpak voor een verbeterde voorspelling van sesamopbrengst op basis van remote sensing te evalueren, werden twee onafhankelijke modellen op basis van de relatie tussen vegetatieindices (VIs) en de door de boeren vermelde opbrengst ontwikkeld en vergeleken. Het eerste model was gebaseerd op VI-waarden die werden geëxtraheerd uit alle beschikbare Landsat beelden die tijdens de optimale groeiperiode werden verkregen (hierna de optimale groeiperiode VI). Het tweede model was gebaseerd op VI-waarden die werden verkregen uit de Landsat beelden die werden verkregen na het zaaien en vóór de oogstdatum per veld (hierna fenologisch aangepast VI). Om de beelden te verkrijgen die werden verkregen tussen het zaaien en oogsten van data per veld, werd gebruik gemaakt van crowdsourcing data over gewasfenologie. Resultaten toonden aan dat de vegetatie-indices afgeleid op basis van de boeren die de gewasfenologieinformatie hadden verzameld, een veel sterkere relatie had met de sesamopbrengst in vergelijking met vegetatie-indices die zijn afgeleid op basis van de optimale groeiperiode. Dit impliceert dat het gebruik van lokale informatie over gewasfenologie per veld, de prestaties van het model verbeterde om de sesamopbrengst te voorspellen. Daarnaast werd crowdsourcing gebruikt om de factoren te identificeren die de opbrengstvariabiliteit binnen een veld veroorzaken. Volgens de perceptie van boeren was de algemene bodemvruchtbaarheid de belangrijkste factor die de opbrengstvariabiliteit binnen een veld verklaart, gevolgd door een hoge aanwezigheid van onkruiden.

Hoofdstuk 6 bespreekt de belangrijkste uitkomsten van dit proefschrift. Er worden conclusies besproken over de belangrijkste onderzoeksresultaten voor elk van de onderzoeksvragen die in de vier hoofdstukken worden behandeld. Ten slotte bespreekt het de noodzakelijke aanvullende stappen (bijv. datakwaliteit, duurzaamheid) in een bredere context die moet worden meegenomen om het volledige potentieel van innovatieve methoden voor gegevensinzameling voor de agrarische crowdsourcing te benutten. 


\section{Acknowledgements}

The PhD journey has come to an end! I would like to take this opportunity to convey my heartfelt gratefulness and sincere appreciation to all the people who have inspired and supported me during the PhD journey. First and foremost, I would like to express my deepest gratitude to my promotor and co-promotors Martin, Lammert and Pytrik. Thank you Martin for your guidance and inputs during the $\mathrm{PhD}$ journey. Lammert, it was a privilege for me to be your $\mathrm{PhD}$ student for the last four years. Our scientific collaboration started while I was doing my MSc major thesis under your main supervision and later it continued as a PhD student. Thank you so much for believing in me and offering me the $\mathrm{PhD}$ position. Your office was always open for me and I felt very comfortable to pop up whenever I had a new idea or issues to discuss! Pytrik, I am very glad to have you as my co-promotor. Thank you so much for your valuable insights in the field of agronomy specially in yield gap analysis and for your eye for detail. I am grateful for all the co-authors for your inputs and insightful comments. A heartfelt thanks to Truus, Antoinette, Patty, Charlotte and AlexJan for your administrative support!

I take this opportunity to thank Ken (N2Africa), Jacob (Seeds for Needs) and Andre, Tomaso, Allard (CommonSense) for your support to conduct the field works in Ethiopia (N2Africa and CommonSense) and, Honduras and India (Seeds for Needs). Jacob, thank you so much for having me in your team and hosting me in Costa Rica! I was fortunate to spend few weeks with you having interesting discussions in the field of citizen science. I am very thankful for N2Africa and Sesame Business Network (SBN) team members for their great support during my field works. My sincere thanks go to the farmers and extension workers who actively participated in the mobile SMS experiments and during the surveys. I am also grateful to the members of the $\mathrm{PhD}$ thesis committee for the thorough and critical assessments of this thesis.

Thanks to my colleagues both at the Laboratory of Geo-information Science and Remote Sensing and Plant Production Systems for sharing the PhD experiences. Jalal, Marston, Qijun, Konstantin, Erika, Giulia, Sarah, Astrid, Alvaro, Jose, Mathieu, Simon, Eliakim, Patric, Sabina, Peter, Nandika, Benjamin Brede, Corne, Alessandra, Yang, Richard, Niki, Arun, Johannes, Maria, Michael, Roberto, Benjamin Devries, Loic, Joao, Aart, Joost, Renske, Esther, Beyene, Banchayehu and Tesfaye: it was my pleasure to meet you all during the PhD journey. Special thanks to my officemates Jalal and Marston for the nice working environment (with the sofa)! Thank you Jalal for the many lunch breaks and the interesting discussions we had. I would like to thank my 
friend and paranymph Kalkidan for her friendship. Special thanks for my MSc classmate Eliakim for your friendship, motivation and support.

Our Ethiopian friends in Wageningen- Tigi, Tade, Mahdi, Abeyo, Edna, Banchi, Dessu, Netsi, Beshir, Mequanint, Engu, Mohammed, Aziza, Hiyam, Mahi, Betty, Josey, Mikinay, Tsion, Mehiret, Zenu and others: I owe you special thanks for your friendship and the very good times we spent together. I also would like to thank our neighbours Rob and Carmelita for their kindness and giving a helping hand whenever needed. I would like to thank my previous student flat mates Ai, Natalie, Maren, Han, Stella and Jacob for the nice times and delicious dinners we had together during the last couple of years. I am very grateful to Diana for your time to draft the first version of the $\mathrm{PhD}$ thesis cover.

My sincere thanks to my father Andualem Beza (Abeye) and to my mother Alemtsehay Demelew (Tabaye) for your endless love, support \& encouragement throughout my academic journey. Abeye and Tabaye, you are amazing parents! From day one of the $\mathrm{PhD}$ journey, my plan was to see you sitting in the front while defending my $\mathrm{PhD}$ thesis in the Aula. However, because of Abeye's health condition you could not make it. Abeye, it is my everyday prayer to hear your well-being and we all are praying for you to get well soon and comeback home. I also would like to thank my siblings Selamawit (Selex), Fisseha (Fish), Degesew (Degesh), Abiy (Abex), Rahel (Richye) and Emiru (Gech) for your encouragement and care during my $\mathrm{PhD}$ journey. I love you all!

I am very grateful for my mother-in-law W/o Asefu Woldu (Eteye) for being with us for the first three months in Wageningen when our son Nolan was born. Your support during those months was very helpful. I sincerely thank all my relatives for their encouragement and kindness.

Last but not least, special words are reserved for the very special persons in my life, for my beloved wife Saba and our son Nolan. Mariewa thank you so much for the great support, love, encouragement and more importantly, for the precious gift of sweet Nolan! His addition to our life during the PhD journey makes our stay in Wageningen very much memorable. He is more than anything! Mariewa you have been doing great taking care of Noli, and me. Your dedicated support, commitment and love is precious. Thank you for always being by my side. I love you very much! Noliye I am very glad and proud to be your baba. Being your father is the best thing that ever happen to me. Your usual smile and charming face especially when I come back home from the long day work has always been my energiser and refresher. You always melt my heart when you call me baba...baba...baba. I love you so much my son and wish you all the very best for the many more years to come. 


\section{List of publications}

\section{Peer reviewed publications}

Eskender Beza, João Vasco Silva, Lammert Kooistra, Pytrik Reidsma, 2017. Review of yield gap explaining factors and opportunities for alternative data collection approaches. European Journal of Agronomy, 82 (2017) 206-222. doi: https://doi.org/10.1016/j.eja.2016.06.016.

Eskender Beza, Jonathan Steinke, Jacob van Etten, Pytrik Reidsma, Carlo Fadda, Sarika Mittra, Prem Mathur, Lammert Kooistra, 2017. What are the prospects for citizen science in agriculture? Evidence from three continents on motivation and mobile telephone use of resource-poor farmers. PLoS ONE 12(5): e0175700. doi: https://doi.org/10.1371/journal.pone.0175700.

Van Etten, J., E. Beza, L. Calderer, K. Van Duijvendijk, C. Fadda, B. Fantahun, Y. G. Kidane, et al. 2016. First experience with a novel farmer citizen science approach: crowdsourcing participatory variety selection through on-farm triadic comparisons of technologies (tricot). Experimental Agriculture: 1-22. doi: https://doi.org/10.1017/S0014479716000739.

\section{Other publications}

Beza, E.A. ; Silva, J.; Reidsma, P.; Herold, M.; Kooistra, L. (2013). Yield gap monitoring: Opportunities for crowdsourcing approaches to collect farm level data for yield gap analysis.

Kooistra, L.; Beza, E.A.; Verbesselt, J.; Borne, J. van den; Velde, W. van der (2012). Integrating remote-, close range- and in-situ sensing for high-frequency observation of crop status to support precision agriculture.

Kooistra, L.; Clevers, J.G.P.W.; Beza, E.A.; Vliet, P. van; Borne, J.; Velde, W. van der (2012). Opportunities for Sentinel-2 in an integrated sensor approach to support decision making in precision agriculture. 


\section{About the author}

Eskender Andualem Beza was born in Bahir Dar, Ethiopia on December 31, 1981. Eskender spent his childhood, elementary and high school education in Bahir Dar. In 1999, Eskender took the Ethiopian School Leaving Certificate Examination (ESLCE) and in the following year he joined Jimma University, College of Agriculture (JUCA) for a two years program and obtained his diploma in plant science in 2001. After graduation, he opted to work in a flower farm as a greenhouse supervisor and later as a production manager for three years. In 2005, Eskender joined HiLCoE School of Computer Science \& Technology, which is one of the most reputed computer science institutes in Ethiopia, to fulfil

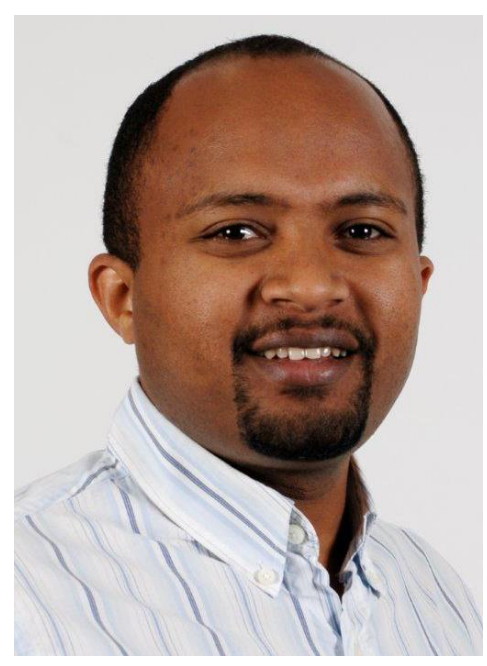
his ambition to become a computer science professional and obtained his BSc degree in computer science in 2007. Since then he worked in Deutsche Gesellschaft für Internationale Zusammenarbeit (GIZ) - engineering capacity building program (ecbp) as a junior ICT4D expert and later promoted to a senior program officer.

In 2010, Eskender was awarded a scholarship from the Netherlands Fellowship Program (NFP) to study his MSc degree in Geo-information Science at Wageningen University, The Netherlands. As part of the MSc degree, his major thesis was about the application of time series methods for analysing multi-temporal sensor data to support precision agriculture. Late 2012 he started a PhD at the Laboratory of Geo-information Science and Remote sensing, and Plant Production Systems (PPS) at Wageningen University. His $\mathrm{PhD}$ was part of the Wageningen UR strategic programme 'Mapping for sustainable intensification', 2012-2016, funded by the Strategic Funds of Wageningen UR. His $\mathrm{PhD}$ research focused on the application of "bottom-up" data collection methods (e.g. crowdsourcing/citizen science) and remote sensing for crop yield gap analysis. As part of his $\mathrm{PhD}$ research, Eskender collaborated with N2Africa, Seeds for Needs and CommonSense projects and carried out (coordinated) his field works in Ethiopia, Honduras and India. His $\mathrm{PhD}$ research resulted in four scientific articles, two of which have already been published and the other two are under review. 


\section{PE\&RC Training and Education Statement}

With the training and education activities listed below the $\mathrm{PhD}$ candidate has complied with the requirements set by the C.T. de Wit Graduate School for Production Ecology and Resource Conservation (PE\&RC) which comprises of a minimum total of 32 ECTS (= 22 weeks of activities)

Review of literature (6 ECTS)

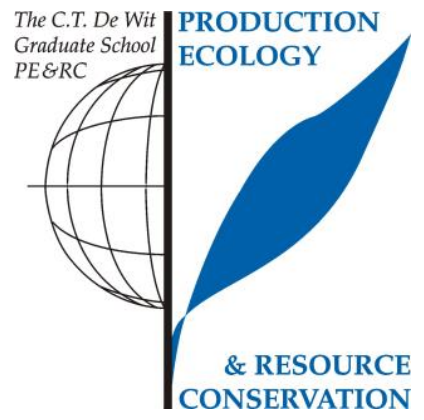

- Yield gap explaining factors and opportunities for alternative data collection approaches

\section{Post-graduate courses (6.9 ECTS)}

- The art of crop modelling; PE\&RC (2013)

- Multivariate analysis; PE\&RC and SENSE (2015)

- Structural Equation Modelling (SEM); PE\&RC and WIAS (2015)

- Companion modelling; PE\&RC and WASS (2016)

- Spatial sampling for mapping; PE\&RC (2015)

Laboratory training and working visits (4.5 ECTS)

- Motivations of farmers to participate in agricultural citizen science; Bioversity International, Costa Rica (2014)

Competence strengthening / skills courses (5.8 ECTS)

- $\quad$ Scientific writing skills; WGS (2013)

- Project and time management; WGS (2013)

- Improve your writing; WGS (2013)

- Techniques for scientific writing and presenting; WGS (2015)

- Reviewing a scientific paper; WGS (2015)

PE\&RC Annual meetings, seminars and the PE\&RC weekend (2.1 ECTS)

- PE\&RC First year weekend (2013)

- PE\&RC Midterm weekend (2014)

- PE\&RC Day (2014, 2016) 
Discussion groups / local seminars / other scientific meetings (7.8 ECTS)

- Food security surveys and interpretation (2013)

- Sustainable Intensification of Agricultural Systems (SIAS) (20132016)

- Seminar on mobile technology for nutrition (2014)

- Modelling and Statistical Networking (MSN) (2014-2015)

- $\quad$ R Users meeting (2015-2016)

- The strength of citizen science in helping society to adapt to environmental change (2016)

International symposia, workshops and conferences (11.2 ECTS)

- First International Conference on Global Food Security (2013)

- ICT4Ag: the digital springboard for inclusive agriculture (2013)

- Healthy Food and Living Environment: benchmarking agricultural systems around the globe for sustainable intensification of food production (2013)

- $\quad$ Smart ICT conference: shaping ideas for a smarter future (2014)

- Citizen Science workshop (2014)

- The $5^{\text {th }}$ International Symposium for Farming Systems Design (2015)

- Spatial data analysis and modelling for agricultural development with R (2016)

- Netherlands Centrum for Geodesy and Geo-informatics (NCG) symposium (2016) 

The research leading to this thesis received funding from the Strategic Funds of Wageningen UR as part of the Wageningen UR strategic program 'Mapping for sustainable intensification', 2012-2016. The research is also a contribution to the CGIAR Research Program on Climate Change, Agriculture and Food Security (CCAFS). Moreover, this work was partially funded by N2Africa and CommonSense projects.

Financial support from Wageningen University for printing this thesis is gratefully acknowledged.

Cover design: Remco Wetzels |Diana Lukjanska Printing: Proefschriftmaken.nl || Digiforce, Vianen 


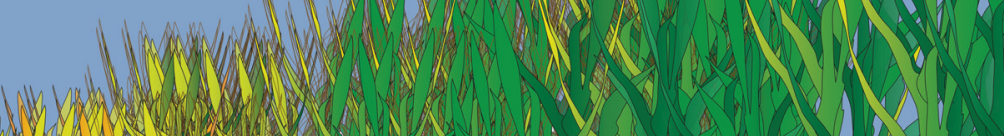

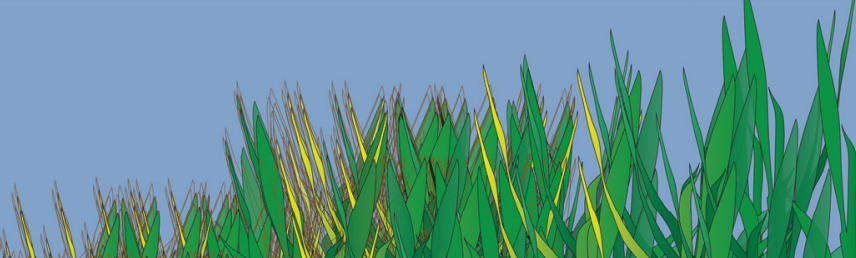

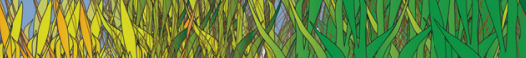

